\title{
DNA-based Population Estimation, Harvest Vulnerability, and Home Range Dynamics of Black Bears in Western Maryland
}

\author{
Michael D. Jones \\ West Virginia University
}

Follow this and additional works at: https://researchrepository.wvu.edu/etd

\section{Recommended Citation \\ Jones, Michael D., "DNA-based Population Estimation, Harvest Vulnerability, and Home Range Dynamics of Black Bears in Western Maryland" (2012). Graduate Theses, Dissertations, and Problem Reports. 304. https://researchrepository.wvu.edu/etd/304}

This Thesis is protected by copyright and/or related rights. It has been brought to you by the The Research Repository @ WVU with permission from the rights-holder(s). You are free to use this Thesis in any way that is permitted by the copyright and related rights legislation that applies to your use. For other uses you must obtain permission from the rights-holder(s) directly, unless additional rights are indicated by a Creative Commons license in the record and/ or on the work itself. This Thesis has been accepted for inclusion in WVU Graduate Theses, Dissertations, and Problem Reports collection by an authorized administrator of The Research Repository @ WVU. For more information, please contact researchrepository@mail.wvu.edu. 
DNA-based Population Estimation, Harvest Vulnerability, and Home Range Dynamics of Black Bears in Western Maryland

Michael D. Jones

Thesis submitted to the

Davis College of Agriculture, Natural Resources and Design

at West Virginia University

in partial fulfillment of the requirements

for the degree of

Master of Science

in

Wildlife and Fisheries Management

John W. Edwards, Ph.D., Chair

Michael P. Strager, Ph.D.

J. Todd Petty, Ph.D.

Harry A. Spiker

Division of Forestry and Natural Resources

Morgantown, West Virginia

2012

Keywords: Black Bear; Ursus americanus; Noninvasive Genetic Sampling; Maryland;

Home Range; Harvest Vulnerability

Copyright 2012 Michael D. Jones 


\section{ABSTRACT \\ DNA-based Population Estimation, Harvest Vulnerability, and Home Range Dynamics of Black Bears in Western Maryland}

\section{Michael D. Jones}

After nearly being extirpated from the state, black bears in Maryland have rebounded to a point where recreational harvest has now become an important management tool. Having a better understanding of bear population parameters, movements, and harvest vulnerability allows managers to implement hunting more effectively and responsibly. To estimate demographics of the Maryland bear population, we implemented noninvasive genetic sampling of bear hair during summer 2011. We used a model-based sampling design that allowed us to collect samples more efficiently. We used presence-only maximum entropy (Maxent) modeling to classify the study area based on predicted probability of bear occurrence, and allocated the majority of our hair snares to areas with high or medium probabilities. Using microsatellite analysis and mark-recapture methods, we estimated the bear population at 701 individuals. This represents a nearly doubling of the population since the previous estimate in 2005. Our density estimate $\left(0.25\right.$ bears $\left./ \mathrm{km}^{2}\right)$ is comparable to other estimates from southeastern and mid-Atlantic states. Our sampling approach did lead to more efficient sample collection, with more hair samples collected at snares located in areas with predicted high or medium probability of bear occurrence than those in low probability areas. However, in the eastern portion of our study area, where bear occurrence is presumed to be much lower, our sampling effort seemed insufficient to collect enough samples for reliable abundance estimation. As a first step toward quantifying harvest vulnerability, we used Global Positioning System (GPS) units to record movements and spatial behaviors of 108 bear hunters during the 2005-2007 Maryland bear hunting seasons. Median values showed that hunters traveled $2.9 \mathrm{~km}$ per hunting event, but only $0.6 \mathrm{~km}$ from their starting point. Hunters did not seem to show any preferential use of areas based on the landscape metrics we examined (e.g., elevation, distance from nearest road) except cover type, where $81 \%$ of locations were in deciduous forests. We found few differences between spatial behaviors of groups of hunters based on harvest success, residency, and previous bear hunting experience, as classified using post-hunt mail surveys. One notable difference is that successful hunters used steeper slopes than unsuccessful hunters. We also found that hunter perceptions of total distance traveled and distance from nearest roads were often highly inaccurate, showing that hunter surveys are not a useful tool for collecting those data. For Garrett County, Maryland, we used the hunter locations to create a Maxent model of the spatial distribution of harvest pressure. We also created a model using fall telemetry locations of female bears and compared the models to identify areas of high (i.e., high hunter and high bear occurrence) and low (i.e., low hunter and high bear occurrence) harvest vulnerability. Both models showed higher probability of occurrence on public lands. Both high and low vulnerability areas comprised small portions of the county. The low vulnerability areas included 9 larger blocks $\left(>1 \mathrm{~km}^{2}\right)$, which were 2.3 times steeper, 2.0 times farther from roads, and 1.5 times farther from streams than the medians for the study area. Those characteristics may limit hunter access to and use of the areas. Our predicted high vulnerability areas did not correspond to most previous bear harvest locations, indicating that our definition of harvest vulnerability often does not translate to actual harvest. Finally, we used GPS collars to track female bear locations in Garrett County and examine home range 
dynamics. Fixed kernel estimates for annual, spring, summer, and fall home ranges were 10.40 $\mathrm{km}^{2}, 8.93 \mathrm{~km}^{2}, 16.08 \mathrm{~km}^{2}$, and $19.35 \mathrm{~km}^{2}$, respectively. Fall and summer home ranges were larger than spring home ranges, but summer and fall ranges were similar. Solitary females had mean spring home ranges 6.9 times larger than females with cubs-of-the-year, but ranges did not differ during other seasons. Bears exhibited high levels of home range fidelity, with home range centroids shifting little among seasons or years. Intraspecific overlap of home ranges occurred during all 3 seasons, but was most common in summer. The results of this study provide Maryland bear biologists and managers with essential information about the state's bear population. Home range estimates represent important baseline information to determine appropriate spatial scales of management. The abundance estimates will be used to set proper harvest quotas with the goal of slowing the bear population growth. The hunter movement analysis and harvest vulnerability modeling may be used by managers to adjust harvest regulations to increase the efficacy of the hunting seasons. 


\section{ACKNOWLEDGMENTS}

I would first like to thank my advisor, Dr. John Edwards, for giving me the opportunity to work on such a great project. I appreciate his guidance, along with all of the experiences he allowed me to have during my time at WVU. His sense of humor and our football talks provided welcomed relief during long days of GIS work. I thank my committee members Dr. Mike Strager for answering my countless GIS questions, and Dr. Todd Petty for his insight into sampling design and mark-recapture. I owe many thanks to my other committee member, Harry Spiker. Aside from his help with the project, his willingness to include me in his other bear work is much appreciated. Whether it was conducting den checks, helping out during the hunting season, or even cutting down cans of rotten sardines, my times at Mt. Nebo gave me some memories I will never forget. I also would like to thank my labmates, Geriann Albers, Andy Tri, Jacob Berl, Milu Karp, and all of the other WVU graduate students for their advice and friendship. They made my time in Morgantown more enjoyable than I ever would have imagined.

I would like to thank the Maryland Department of Natural Resources (MDNR) and West Virginia University Division of Forestry for providing funding and making this project possible. I greatly appreciate all of the MDNR staff, along with staff from the Maryland Conservation Corps, for the time and effort they put into our hair snare survey. I also thank the countless Maryland landowners who allowed us access to their properties. Without them, our hair snare survey never would have been successful. I thank Logan Moon for all of his time and hard work checking hair snares, even when he knew we were paying him nothing. I also would like to specifically thank Georgia Guyton from MDNR for putting together datasets for me and always sending them so quickly. Thank you to Chris Ryan and Roy Martin for their review of our 
MARK analysis and helpful comments. Also, thank you to Dr. Tim King, Barbara Lubinski, and the rest of the staff at the USGS Aquatic Ecology Laboratory for their genetic analysis.

Of course, I have to thank my entire family for their support along the way. My parents, Mike and Lynn, were always great examples for me, and motivated me to be the best I could be in school, work, and life. Finally, I thank my wife, Andrea, for all of her love and unwavering support. Even after having to live apart for a year, then moving halfway across the country, she never complained or questioned my decision. I will always appreciate how her sacrifices allowed me to pursue my dream of working with wildlife. 


\section{TABLE OF CONTENTS}

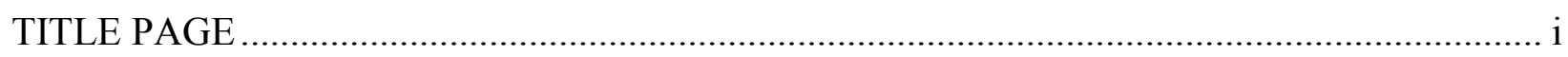

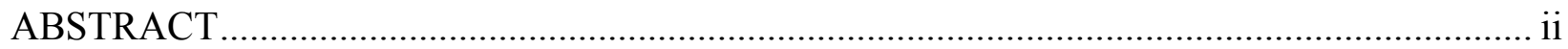

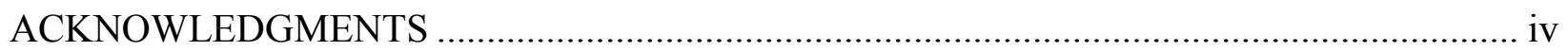

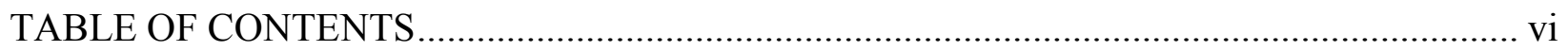

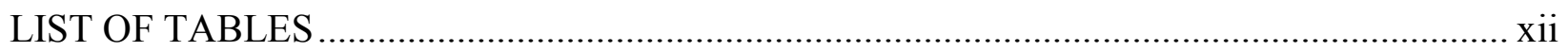

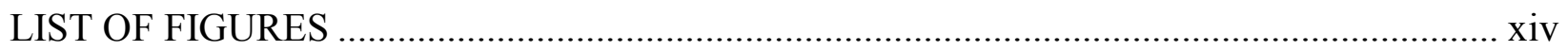

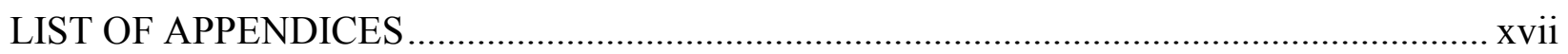

INTRODUCTION, JUSTIFICATION, AND RESEARCH OBJECTIVES ...................................1

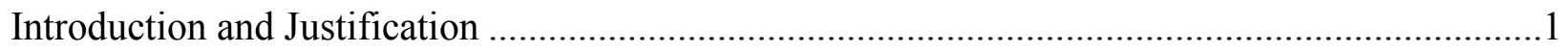

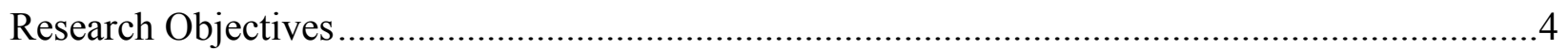

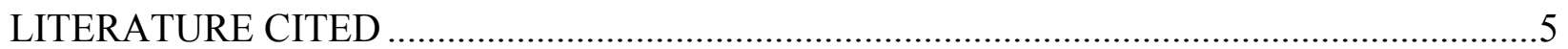

CHAPTER 1: BLACK BEAR LITERATURE REVIEW ..........................................................

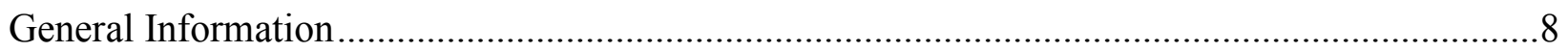

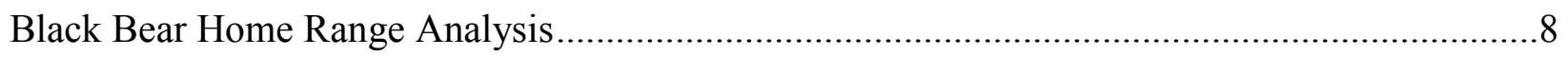

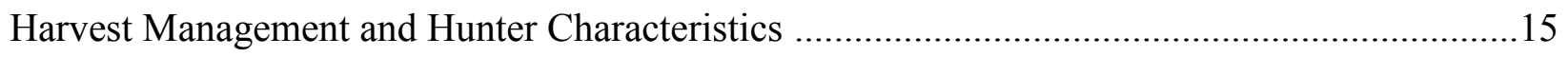

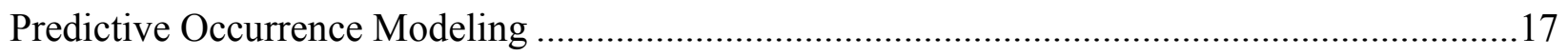

Noninvasive Genetic Surveys for Population Demographic Estimation .......................................20

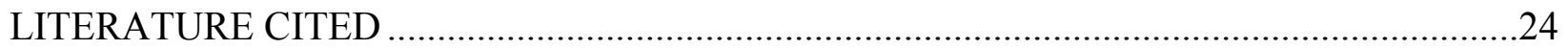


CHAPTER 2: DNA-BASED POPULATION PARAMETERS OF BLACK BEARS IN

WESTERN MARYLAND

ABSTRACT

KEYWORDS.

INTRODUCTION .

METHODS

Study Area .48

Black Bear GPS Data Collection

Predictive Modeling and Site Selection

Maxent modeling .50

Sampling site selection . .52

Hair Snare Survey .53

Genetic Analysis .54

Microsatellite analysis .54

Statistical analysis .56

Abundance and Density Estimation .57

RESULTS .58

Predictive Modeling and Site Selection .58

Maxent modeling .58 
Sampling site selection

Hair Snare Survey

Genetic Analysis

Microsatellite analysis 61

Statistical analysis

Spatial Distribution of Bear Samples

Abundance and Density Estimation. 63

DISCUSSION .65

Predictive Modeling and Hair Snare Survey ....... .65

Genetic Diversity and Population Structure .68

Abundance and Density Estimates. 70

MANAGEMENT IMPLICATIONS

ACKNOWLEDGMENTS

LITERATURE CITED

TABLES .82

FIGURES .90

CHAPTER 3: MOVEMENTS AND SPATIAL BEHAVIORS OF BEAR HUNTERS IN

WESTERN MARYLAND .98

ABSTRACT. .99 


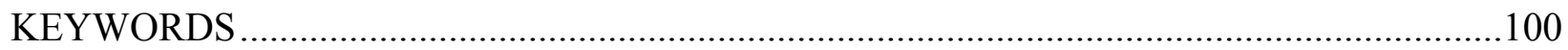

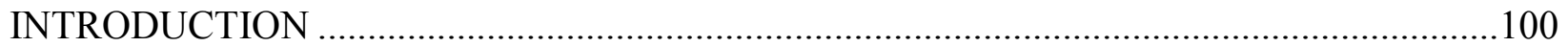

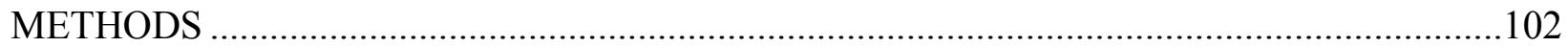

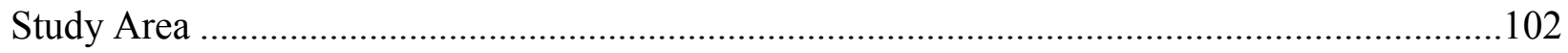

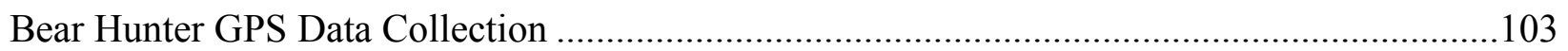

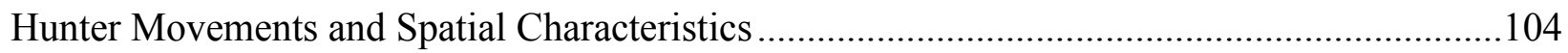

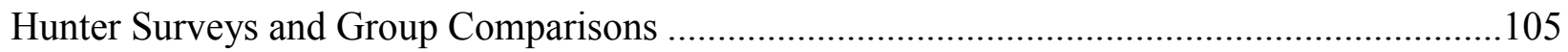

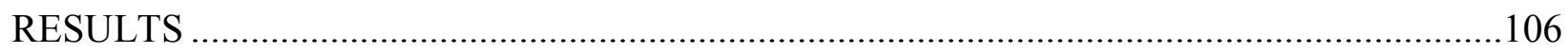

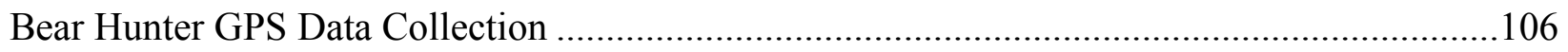

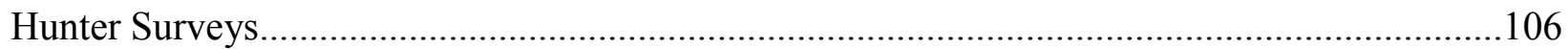

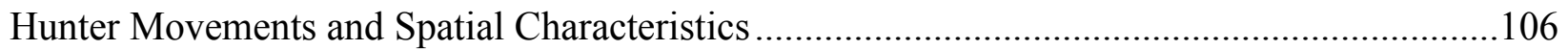

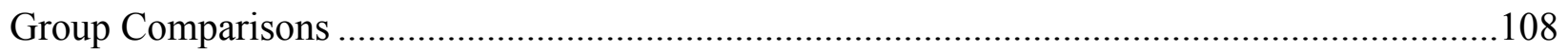

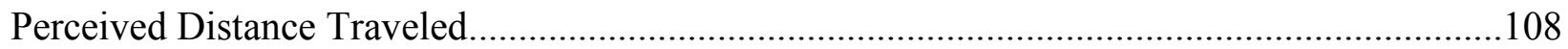

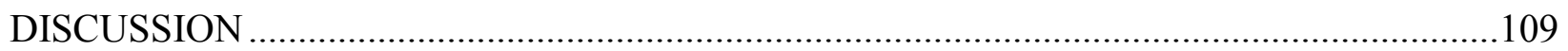

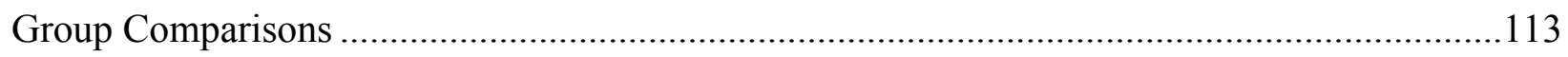

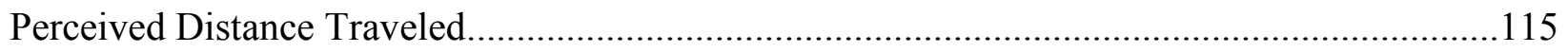

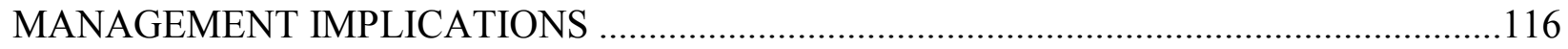

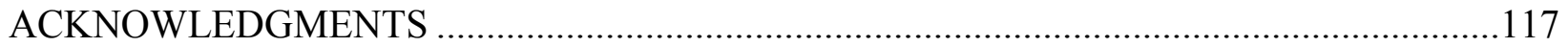

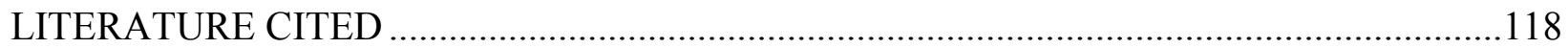


TABLES

FIGURES

CHAPTER 4: HARVEST VULNERABILITY OF FEMALE BLACK BEARS IN WESTERN

MARYLAND .130

ABSTRACT. .131

KEYWORDS.

INTRODUCTION 132

METHODS 135

Study Area 135

Black Bear GPS Data Collection .136

Bear Hunter GPS Data Collection 136

Predictive Occurrence Modeling of Bears and Bear Hunters

RESULTS

DISCUSSION .143

MANAGEMENT IMPLICATIONS 149

ACKNOWLEDGMENTS

LITERATURE CITED .150

TABLES .156

FIGURES .159 
CHAPTER 5: HOME RANGE DYNAMICS OF FEMALE BLACK BEARS IN WESTERN

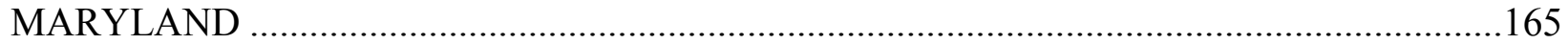

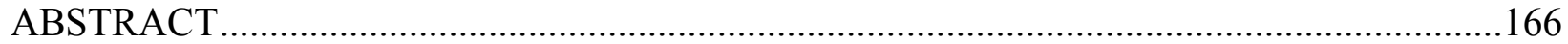

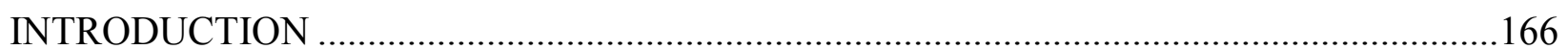

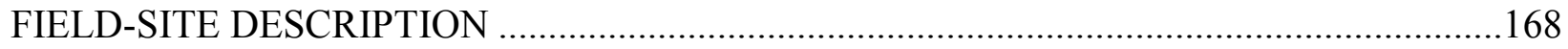

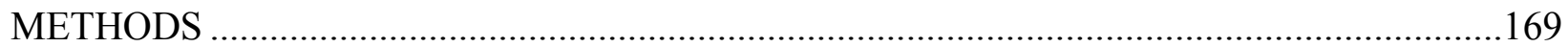

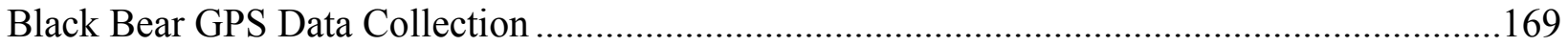

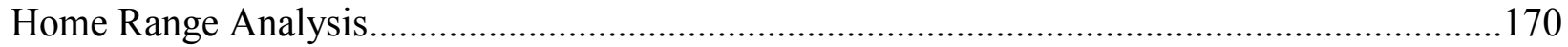

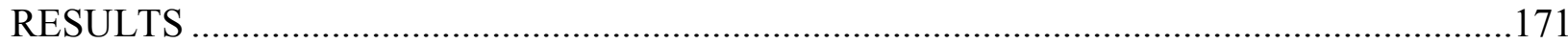

Annual and Seasonal Home Range Size....................................................................... 172

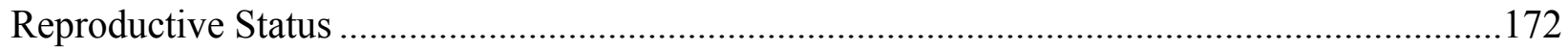

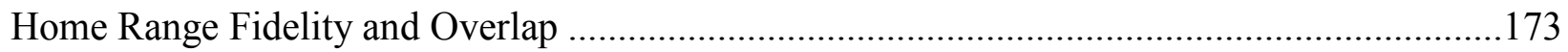

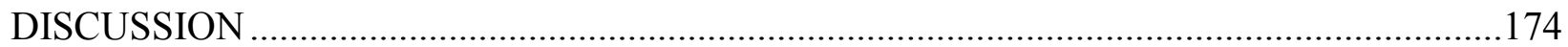

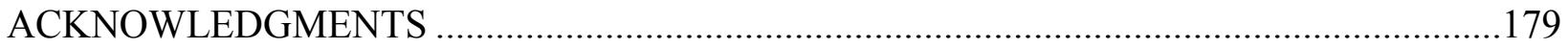

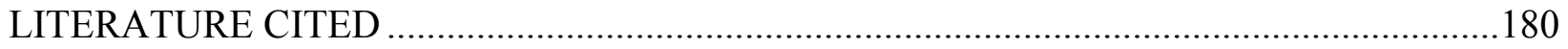

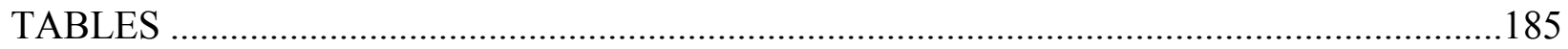

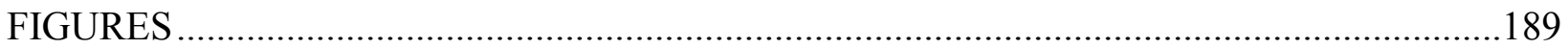

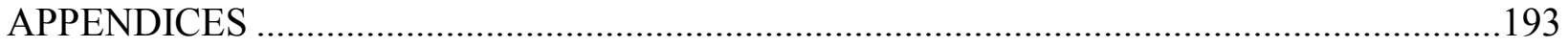




\section{LIST OF TABLES}

Table 2.1. Percent contribution of environmental variables to predictive black bear occurrence models for 4 counties in western Maryland, USA.

Table 2.2. Number of alleles, heterozygosity, and inbreeding coefficients for black bear hair samples collected in western Maryland, USA in summer 2011.

Table 2.3. Black bear hair samples collected during a Maryland, USA hair snare survey in summer 2011, separated by sampling cell classifications as determined from predictive black bear occurrence model.

Table 2.4. MARK results for individuals identified from a hair snare survey in western Maryland, USA in summer 2011.

Table 2.5. Abundance estimates and adjustment factors for black bears in western Maryland, USA in summer 2011.

Table 2.6. Genotype success rates reported from noninvasive genetic studies of black bears.

Table 2.7. Abundance and density estimates derived from black bear hair snare surveys in western Maryland, USA from 2000, 2005, and 2011.

Table 2.8. Black bear densities for mid-Atlantic and southeastern U.S. states since 2005.

Table 3.1. Descriptive statistics for spatial and temporal metrics for black bear hunter locations in Garrett County, Maryland, USA during the 2005-2007 Maryland bear hunting seasons.

Table 3.2. Cover type use vs. availability for black bear hunter in Garrett County, Maryland, USA during the 2005-2007 Maryland bear hunting seasons.

Table 3.3. Spatial and temporal metrics for different groups of black bear hunters from GPS locations recorded in Garrett County, Maryland, USA during the 2005 and 2006 Maryland bear hunting seasons. Values between groups were compared using Mann-Whitney U tests. 
Table 4.1. Environmental variables used to create predictive occurrence models for black bears and bear hunters in western Maryland.

Table 4.2. Percent contribution of environmental variables to predictive occurrence models for female black bears and bear hunters in Garrett County, Maryland.

Table 4.3. Percent overlap (as percent of study area) of probability of occurrence classes for female black bear and bear hunter Maxent models in western Maryland.

Table 5.1. Previously reported mean home range estimates for Ursus americanus (Black Bear) in the Appalachian Region. $\mathrm{MCP}=$ minimum convex polygon.

Table 5.2. Home range estimates for female Ursus americanus (Black Bear) in Garrett County, Maryland, USA from 2005-2007.

Table 5.3. Seasonal $95 \%$ fixed kernel home range estimates by reproductive status for female Ursus americanus (Black Bear) in Garrett County, Maryland, USA from 2005-2007. $*=$ statistically different. COY $=$ female with cubs-of-the-year. Solitary $=$ females without cubs-of-the-year.

Table 5.4. Overlap of seasonal home ranges among female Ursus americanus (Black Bear) in Garrett County, Maryland, USA from 2005-2007. 


\section{LIST OF FIGURES}

Figure 2.1. Study area comprised of the 4 westernmost counties of Maryland, USA.

Figure 2.2. Maxent predictive summer occurrence model for black bears in western Maryland,

USA. This combined model was produced by merging separate Maxent models created for each county, so probability of occurrence is relative within each county.

Figure 2.3. Potential black bear hair snare sampling grid cells $\left(12 \mathrm{~km}^{2}\right)$ in western Maryland, USA for 2011. Each cell is classified based on the mean value, within that cell, of a Maxent predictive summer occurrence model for black bears.

Figure 2.4. Sampling grid cells $\left(12 \mathrm{~km}^{2}\right)$ selected for a 2011 black bear hair snare survey in western Maryland, USA. Cells were selected using a stratified random sampling technique based on their classification of relative probability of bear occurrence.

Figure 2.5. Spatial distribution of total hair samples (including duplicates and samples from non-target species) collected during a black bear hair snare survey conducted in western Maryland, USA in summer 2011.

Figure 2.6. Program Structure output indicating assignment of individual Maryland black bears to genetically differentiated groups. Each vertical line represents a unique individual $(n=108)$ and is broken into 3 different colors representing genetically similar groups (e.g., populations). Lengths of each color in a given line indicate the proportion of membership into each of the 3 genetic groups.

Figure 2.7. Spatial distribution of probable black bear hair samples collected during a hair snare survey conducted in western Maryland, USA in summer 2011.

Figure 2.8. Spatial pattern of genetically differentiated groups of black bears in western Maryland, USA as identified by clustering analysis using program Structure.

Figure 3.1. Garrett County, Maryland, USA, the primary black bear study area. 
Figure 3.2. Distribution of bear hunter locations by year in Garrett County, Maryland, USA during the 2005-2007 Maryland bear hunting seasons.

Figure 3.3. Percentage of hunter locations recorded in the 5 most commonly used cover types by bear hunters in Garrett County, Maryland, USA during the 2005-2007 Maryland bear hunting seasons. The "+" symbol indicates a cover type that was used more than expected based on availability according to chi-square tests. The "-_"symbol indicates a cover type that was used less than expected.

Figure 3.4. Percent difference between perceived distance and actual distance traveled for black bear hunters in Garrett County, Maryland, USA during the 2005-2006 Maryland bear hunting seasons. The largest observed overestimation has been excluded from the plot area to allow greater detail for the remaining data.

Figure 3.5. Percent difference between perceived distance and actual distance to the nearest road for Maryland black bear hunters during the 2005-2006 Maryland bear hunting seasons. Three data points representing the largest observed overestimations have been excluded from the plot area to allow greater detail for the remaining data.

Figure 4.1. Mean output of 50 replications of a Maxent model of female black bear distribution in Garrett County, Maryland. Output has been reclassified as high, medium or low relative probability of bear occurrence.

Figure 4.2. Maxent output of area under the receiver operating characteristic curve (AUC) for 50 replications of a model of female black bear distribution in Garrett County, Maryland.

Figure 4.3. Mean output of 50 replications of a Maxent model of black bear hunter distribution in Garrett County, Maryland. Output has been reclassified as high, medium or low relative probability of hunter occurrence. 
Figure 4.4. Maxent output of area under the receiver operating characteristic curve (AUC) for 50 replications of a model of black bear hunter distribution in Garrett County, Maryland.

Figure 4.5. Areas identified as having high or low harvest vulnerability of female black bears based on Maxent distribution models for female bears and bear hunters in Garrett County, Maryland. High vulnerability locations represent areas where the probability of occurrence of bears and hunters are both high. Low vulnerability locations represent areas where the probability of occurrence is high for bears, but low for hunters.

Figure 5.1. Annual 95\% fixed kernel home ranges of female Ursus americanus (Black Bear) in Garrett County, Maryland, USA from 2006-2007. Each color polygon represents an individual female Black Bear. The year the data was collected is in parentheses following the bear ID.

Figure 5.2. Spring 95\% fixed kernel home ranges of female Ursus americanus (Black Bear) in Garrett County, Maryland, USA from 2006-2007. Each color polygon represents an individual female Black Bear. The year the data was collected is in parentheses following the bear ID.

Figure 5.3. Summer $95 \%$ fixed kernel home ranges of female Ursus americanus (Black Bear) in Garrett County, Maryland, USA from 2005-2007. Each color polygon represents an individual female Black Bear. The year the data was collected is in parentheses following the bear ID.

Figure 5.4. Fall 95\% fixed kernel home ranges of female Ursus americanus (Black Bear) in Garrett County, Maryland, USA from 2005-2007. Each color polygon represents an individual female Black Bear. The year the data was collected is in parentheses following the bear ID. 


\section{LIST OF APPENDICES}

Appendix A. Gender and capture results for each individual black bear indentified from hair samples collected in western Maryland during summer 2011.

Appendix B. Alleles and allele frequencies at 8 loci used to idensitfy black bear hair samples collected in western Maryland during summer 2011.

Appendix C. Maxent output of response curves for models of black bear and bear hunter occurrence in western Maryland. Red lines/bars represent means over 50 replications. Blue lines/bars represent range of values. Turquoise bars represent expected values for a random model.

Appendix D. Annual and seasonal 95\% fixed kernel and 95\% minimum convex polygon (MCP) home range estimates and reproductive statuses of adult female Black Bears monitored in Garrett County, Maryland, USA from 2005-2007. COY = females with cubs-of-the-year. Solitary $=$ females without cubs-of-the-year. $N=$ number of GPS locations used to estimate home range size. 


\section{INTRODUCTION, JUSTIFICATION, AND RESEARCH OBJECTIVES}

\section{Introduction and Justification}

American black bears (Ursus americanus; hereafter black bears or bears) were historically abundant in Maryland and inhabited every county in the state (Mansueti 1950). Following European settlement, the population began to decline primarily due to habitat degradation and unregulated hunting (Paradiso 1969, Spiker and Bittner 2004). Settlers cleared forests to create agricultural land while eradicating bears that were viewed as threats or pests. During the mid 1700 s, a bounty system was established in some counties to promote the killing of bears and unregulated hunting occurred statewide until the early 1900s. From 1937-1951, the population decreased from 150 to 20 individuals (Paradiso 1969). In response to the decline, the bear hunting season was closed in 1953 (Spiker 2011). By that time the bear population was in danger of extirpation and only inhabited remote and mountainous areas of Garrett and Allegany Counties, in the far western portion of the state (Paradiso 1969).

Maryland originally considered the black bear a "forest game species", but that status was changed in 1972 when it was placed on the state's endangered species list (Webster 1994, Dateo 1997, Spiker and Bittner 2004). By the mid 1970s, legal protection and habitat improvements allowed the bear population to rebound (Spiker and Bittner 2004). An increase in bear sightings and nuisance complaints caused the state to change the black bear's status from endangered to "nongame species of special concern" in 1980. In 1985, the bear's status was changed back to "forest game species" (Garner and Matthews 1992). Although hunting remained closed, this classification gave the Maryland Department of Natural Resources (MDNR) the option to implement a hunting season when the population reached a sustainable level. 
In 1991, an MDNR mark-recapture study in Garrett County estimated the bear population at 79 individuals ( 4.6 bears $/ 100 \mathrm{~km}^{2}$ ) (Spiker and Bittner 2004). In 2000, MDNR used noninvasive genetic hair sampling and estimated the bear population in Garrett County and western Allegany County at 227 adult and sub-adult bears $\left(10.5\right.$ bears $\left./ 100 \mathrm{~km}^{2}\right)$, a $128 \%$ increase in density from the previous estimate (Bittner et al. 2002). Scent station visitation rates, road kills, sightings, and damage complaints all increased during that time period, corroborating the results of the genetic study. As the bear population increased, MDNR was challenged with striking a balance between ensuring the long-term viability of the population and keeping bear abundance at a socially tolerable level (Riley et al. 2002). In general, as the bear population expands, human-bear interactions increase and social tolerance decreases (Don Carlos et al. 2009). MDNR considered regulated hunting as an option to reduce the population growth and keep abundance at a socially tolerable level (Spiker and Bittner 2004). A 2004 public opinion survey of Maryland residents showed that $65 \%$ percent of all respondents and $78 \%$ of respondents from western Maryland supported regulated hunting to control the state's bear population (Responsive Management 2004). There was even more support for a bear season (78\% of all respondents) if the respondents knew that hunting would not endanger the population.

In 2004, MDNR decided to reopen a bear hunting season in Garrett and western Allegany counties after 51 years of closed season (Spiker 2011). The hunting season has taken place every year since 2004. In 2006, the hunt area was expanded to include all of Garrett and Allegany counties. MDNR sets a strict harvest quota for each bear hunting season rather than a set season length. The harvest quota for each year is set so that harvest accounts for approximately $8-12 \%$ of the total annual mortality (Spiker 2011). From 2004-2010, the number of bears harvested per 
hunting season has ranged from 20 in 2004 to 67 in 2010 (Spiker 2011). To reduce population growth and prevent overharvest, the objective is to maintain an overall annual mortality rate (i.e., harvest and non-harvest mortality) of approximately 20-25\% (Spiker 2011).

Black bears have a low reproductive capacity relative to other North American mammals, with females typically giving birth to 1 to 5 cubs every other year (Pelton 2000, Eiler et al. 1989, Ryan 1997). In Maryland, average annual litter size ranges from 2.5-3.5 cubs per sow (Spiker 2011). This low reproductive potential makes black bears particularly vulnerable to overharvest (Kolenosky 1986). Therefore, an accurate population estimate is essential for maintaining a viable bear population while still allowing regulated hunting. MDNR's Black Bear Management Plan recommends that a population survey be conducted every 5 years (Spiker and Bittner 2004). The last study to estimate the bear population was conducted in 2005 in Garrett and Allegany Counties (Spiker 2011). MDNR again used noninvasive genetic sampling and obtained an estimate of 362 adults and sub-adults. To compare the results to the 2000 study, MDNR produced a separate estimate for only the area covered by the 2000 study. That estimate was 326 individuals $\left(15.2\right.$ bears $\left./ 100 \mathrm{~km}^{2}\right)$, representing a $45 \%$ increase in density since 2000 . Another important component in preventing overharvest is to predict the vulnerability of bears to hunter harvest. This requires an understanding of how both bears and bear hunters use the landscape. Two previous studies have focused on female bear home ranges in Maryland (Webster 1994, Dateo 1997), but those results are likely no longer applicable due to the increased density of the bear population. MDNR currently mails questionnaires to all bear hunters following the hunting season to obtain information such as hunting techniques and bear observations. Although these surveys provide valuable information, a more comprehensive approach is needed to truly understand how hunters use the landscape and how they may impact Maryland's bear population. 


\section{Research Objectives}

The objectives of my research are:

(1) Develop a GIS-based predictive occurrence model for black bears to increase the efficiency of noninvasive genetic sampling.

(2) Conduct a noninvasive genetic survey and use the results to estimate the sex ratio, abundance, and density of Maryland's black bear population.

(3) Determine home range sizes for female black bears and compare results by season and reproductive status.

$\mathrm{H}_{1}$ : Home range sizes of female bears will differ among seasons

$\mathrm{H}_{2}$ : Seasonal home range sizes will differ between reproductive statuses.

I will test the prediction that fall home ranges will be larger than spring and summer home ranges. I also predict that spring and summer home range size will be smaller for females with cubs than solitary females.

(4) Describe spatial characteristics of black bear hunters and compare results by harvest success, previous hunting experience, and residency.

$\mathrm{H}_{1}$ : Total time spent hunting will differ by hunter success, hunting experience, and residency.

$\mathrm{H}_{2}$ : Total distance traveled will differ by hunter success, hunting experience, and residency.

$\mathrm{H}_{3}$ : Distance to roads will differ by hunting experience and residency. I predict that successful, experienced, and resident hunters will spend more time hunting and will travel farther than other hunters. I will test the prediction that inexperienced and non-resident hunters will hunt closer to roads than other hunters. 
(5) Develop predictive occurrence models for black bears and bear hunters to estimate harvest vulnerability across the study area.

\section{LITERATURE CITED}

Bittner, S. L., T. L. King, and W. F. Harvey. 2002. Estimating Maryland's black bear population. Proceedings Annual Conference of Southeast Association of Fish and Wildlife Agencies.

Dateo, D. M. 1997. Use of home range and influences of habitat selection on crop depredation by black bears (Ursus americanus) in western Maryland. Thesis, Frostburg State University, Frostburg, Maryland, USA.

Don Carlos, A. W., A. D. Bright, T. A. Teel, and J. J. Vaske. 2009. Human-black bear conflict in urban areas: an integrated approach to management response. Human Dimensions of Wildlife 14:174-184.

Eiler, J. H., W. G. Wathen, and M. R. Pelton. 1989. Reproduction in black bears in the southern Appalachian Mountains. Journal of Wildlife Management 53:353-360.

Garner, N. P., and T. P. Matthews. 1992. Maryland's black bear management plan 1992-2001. Maryland Department of Natural Resources.

Kolenosky, G. B. 1986. The effects of hunting on an Ontario black bear population. International Conference on Bear Research and Management 6:45-55.

Mansueti, R. 1950. Extinct and vanishing mammals of Maryland and the District of Columbia. Maryland Naturalist 20:1-48.

Paradiso, J. L. 1969. Mammals of Maryland. North American Fauna. U.S. Fish and Wildlife Service Publication 66, Washington, D. C. 
Pelton, M. R. 2000. Black bear. Pages 547-555 in G. A. Feldhamer, B. C. Thompson, and J. A. Chapman, editors. Wild mammals of North America: biology, management, and conservation. Second edition. The John Hopkins University Press, Baltimore, Maryland, USA.

Responsive Management. 2004. Public attitudes toward black bear management in Maryland. Responsive Management. Harrisonburg, Virginia, USA.

Riley, S. J., D. J. Decker, L. H. Carpenter, J. F. Organ, W. F. Siemer, G. F. Mattfeld, and G. Parsons. 2002. The essence of wildlife management. Wildlife Society Bulletin 30:585-593.

Ryan, C. W. 1997. Reproduction, survival, and denning ecology of black bears in southwestern Virginia, Thesis, Virginia Polytechnic Institute and State University, Blacksburg, USA.

Spiker, H. 2011. Maryland black bear population status report. Maryland Department of Natural Resources, Wildlife and Heritage Service, Oakland, USA.

Spiker Jr., H. A., and S. L. Bittner. 2004. Wildlife and Heritage Service black bear management plan 2004-2013. Maryland Department of Natural Resources Wildlife and Heritage Service.

Webster, T. W. 1994. Movements and use of habitat of female black bears in western Maryland. Thesis, Frostburg State University, Frostburg, Maryland, USA. 
CHAPTER 1

BLACK BEAR LITERATURE REVIEW 


\section{LITERATURE REVIEW}

\section{General Information}

The American black bear (Ursus americanus; hereafter, black bear) is the most widespread and abundant of the 3 bear species found in North America (Pelton 2000). The current estimated population size of black bears in North America is 850,000-950,000, which is greater than the combined abundance of the other 7 bear species of the world (Garshelis et al. 2008). There are 16 recognized subspecies of black bear, with the eastern black bear (U. a. americanus) being the most common (Hall 1981).

The black bear historically inhabited forested areas throughout North America, including all states except Hawaii (Hall 1981). The current range of the species is estimated to be $62 \%$ of the historic range, due mostly to overharvest and large-scale habitat destruction (Pelton and van Manen 1994). Although densities vary throughout their range, black bears are now present in 41 U.S. states, all Canadian provinces and territories except Prince Edward Island, and 8 Mexican states (Garshelis et al. 2008). Besides Hawaii, only states in the Midwest and the Great Plains do not have a bear population. Surveys conducted by Garshelis and Hristienko (2006) showed that $59 \%$ of states and provinces had an increasing trend in bear population size from 1988-2001. The increasing bear populations in many parts of the United States and Canada have allowed the black bear to become an important game species. An estimated 40,000-50,000 bears are harvested recreationally each year (Garshelis et al. 2008).

\section{Black Bear Home Range Analysis}

The home range of an animal is most simply described as "the area, usually around a home site, over which the animal normally travels in search of food" (Burt 1943). Estimating the sizes and spatial distribution of black bear home ranges can be of interest to researchers and wildlife 
managers. Like most wildlife species, bear activities and movements are dictated by the distribution of resources across the landscape (Rogers 1987). Home ranges help identify what locations and resources are important to an individual bear, and can provide insight into how and when bears use those resources. This information aids in developing management objectives and habitat management plans.

Black bears exhibit a promiscuous mating system in which females are responsible for raising cubs (Schenk and Kovacs 1995, Costello 2008). Given this mating system, male home ranges are believed to be heavily influenced by the distribution of females (Rogers 1987).

Female bears, however, are generally territorial and their home ranges are affected mostly by the distribution of food sources (Jonkel and Cowan 1971, Lindzey and Meslow 1977, Garshelis and Pelton 1981, Rudis and Tansey 1995). Therefore, female bear home ranges are often indicative of the overall habitat quality of an area (Beecham 1983, Ford 1983, Koehler and Pierce 2003). If habitat quality is good, females can find all of their required resources (e.g., food, water, denning site) in a relatively small area and their home range sizes tend to be smaller (Lindzey and Meslow 1977, Garshelis and Pelton 1981, Ford 1983). In poor quality habitat, bears have to move farther to find those resources so their home ranges tend to be larger (Beeman and Pelton 1980). The size and spatial distribution of home ranges also can change seasonally as bears shift to the most abundant and nutritional food sources available (Garshelis and Pelton 1981, Rogers 1987). Additionally, home range sizes of female bears are affected by female bear density. Because females are territorial, higher bear density may force the reduction of home range size (Young and Ruff 1982). There is evidence that 2 factors reduce the territoriality of female black bears: family groups and abundant food sources (Reynolds and Beecham 1980, Elowe 1984, Rogers 1987). While most young males disperse relatively long distances, females generally 
exhibit some degree of natal philopatry, often establishing a territory on the periphery of their mother's territory (Reynolds and Beecham 1980, Waser and Jones 1983). In addition, half-siblings or full-siblings may share a portion of their home ranges. Female bears also have been shown to be less territorial around highly abundant food sources (e.g., garbage dumps) because there is less competition for resources (Young and Ruff 1982, Rogers 1987). Females in relatively unproductive boreal forest habitat generally exhibit higher territoriality than females in highly productive Appalachian forests (Jonkel and Cowan 1971, Powell 1987). In both instances, bears may tolerate various degrees of female home range overlap, even to the extent that they can no longer be considered territorial (Elowe 1984, Powell 1987, Horner and Powell 1990).

The advent of global positioning system (GPS) technology for wildlife tracking has greatly improved the ability of researchers to accurately track and estimate the home ranges of black bears. Traditional very high frequency (VHF) telemetry is labor intensive, has more error, and often results in smaller sample sizes compared to GPS-based telemetry (Obbard et al. 1998, Girad et al. 2002, D’Eon 2003). GPS telemetry allows the flexibility of recording data at specified fix intervals so the detail of the movement data can be determined by the researcher. GPS collars are especially useful for bears because the denning period allows for the replacement of collars at regular intervals, unlike other species that require recaptures to replace collar batteries. This reduces the limitations associated with battery life and facilitates the tracking of bears over multiple years. One limitation of GPS transmitters is that signal transmission can be affected by rugged topography or canopy coverage (D'Eon 2003, Cain III et al. 2005, Hansen and Riggs 2008). D'Eon (2003) found that fix-rate success is lower in rough terrain than in more open areas. Rugged topography can also increase location error (Cain III et al. 2005). Hansen 
and Riggs (2008) found that canopy coverage and the amount of available sky had a larger effect on location precision than topographic characteristics. The increase in use of GPS transmitters in bear studies suggests that the benefits of this technology outweigh the possible drawbacks. Overall, GPS technology is beneficial for home range estimation because the greater accuracy and sample sizes associated with GPS data increase the reliability of home range estimates when compared to VHF techniques (Seaman et al. 1999).

Many home range estimation methods have been used in bear studies, each having their own advantages and disadvantages. Currently there is no consensus among wildlife researchers as to which method is best (Laver and Kelly 2008). Mohr and Stumpf (1966) introduced the minimum convex polygon (MCP) method, which is a very simple and intuitive approach that is still commonly used. This method is based on drawing the smallest area convex polygon that encompasses all of the location points. MCP is often used to compare home range sizes to previous studies. Although the simplicity of MCP is appealing, this method has numerous drawbacks. MCP estimates are heavily influenced by sample size and outliers and can include non-use areas such as bodies of water, all of which tend to overestimate the true home range size (Anderson 1982, Bekoff and Mech 1984). As sample size increases, MCP estimates increase up to an asymptote, making it difficult to reliably compare estimates with different sample sizes (Samuel and Fuller 1996). Outliers represent areas that are used by an individual so infrequently that they do not warrant inclusion into the home range of the animal (Burt 1943). Because a standard MCP draws a polygon that includes all locations, outliers can substantially inflate home range sizes. One approach developed to address this issue is to exclude extreme points from the analysis (Michener 1979, White and Garrott 1990). The most commonly used form of this 
technique is the $95 \% \mathrm{MCP}$, which draws the smallest area polygon that includes $95 \%$ of all locations (Schoener 1981).

Fixed kernel density estimation (KDE), which estimates the probability of finding an animal in any one place, is widely viewed as the most reliable home range analysis technique (Powell 2000, Kernohan et al. 2001, Laver and Kelly 2008). This method, introduced by Worton (1989), works by placing a probability density, or kernel, over each point in a set of locations. A grid is then superimposed on the data, and the density at each grid intersection is estimated, creating a utilization distribution. The densities are based on the average of the densities of kernels that overlap a given point. Points closer to grid intersections have a greater influence on the density value than points farther away. Therefore, the density is higher in areas with more location points and lower in areas with few points. Home ranges are obtained from the kernel density estimator by drawing isopleths based on the volume of the curve under the utilization distribution. These isopleths create polygons for which areas can be calculated. Overall home range sizes are generally based on $90 \%$ or $95 \%$ isopleths, while core home ranges are often estimated with $50 \%$ isopleths.

The choice of bandwidth, or smoothing factor, can have a large impact on KDE estimates (Seaman et al. 1999, Gitzen and Millspaugh 2003). The bandwidth is the width of the kernel, and it affects the detail and smoothing of the distribution (Worton 1989). For narrow kernels, nearby points have the largest effect on the density value and the distribution shows more detail (Seaman and Powell 1996). Wider kernels give more weight to distant points, so the distribution is more general and smoothed. Least-squares cross-validation (LSCV) methods are commonly used to select the appropriate bandwidth (Gitzen and Millspaugh 1999). LSCV chooses a bandwidth that minimizes the squared error (i.e., distance between the true density and the fitted 
density) integrated across the surface. Another bandwidth option is to calculate the reference bandwidth $\left(h_{r e f}\right)$ using $h_{r e f}=\sigma n^{-\frac{1}{6}}$, where $\sigma$ is the standard deviation of the $\mathrm{x}$-y coordinates and $\mathrm{n}$ is the number of locations (Worton 1995). The reference bandwidth can account for highly clustered data, but is designed to be the optimal bandwidth for a bivariate normal distribution, which is unlikely for most home ranges and can lead to oversmoothing (Hemson et al. 2005). Although some have argued that LSCV is the best method for choosing the appropriate bandwidth (Worton 1995, Seaman et al. 1999), this method often fails to select a bandwidth when using locations that are identical or are very close together, as is the case with most GPS data (Hemson et al. 2005, Gitzen et al. 2006, Walter et al. 2011). Seaman et al. (1999) concluded that bandwidths chosen using LSCV are more reliable than those chosen using $h_{\text {ref }}$ for simulated data sets containing 20-200 points. Hemson et al. (2005) used actual GPS locations and found that LSCV only successfully calculated a bandwidth value for sample sizes $<100$, and that those values were highly variable. Worton (1995) found that both LSCV and $h_{\text {ref }}$ overestimated home range sizes, and tested various proportions of $h_{\text {ref }}$ to see which best estimated a known home range size. According to those tests, $0.8 h_{\text {ref }}$ corrected for the oversmoothing of $h_{r e f}$ and produced a highly accurate home range result.

More recently, Horne and Garton (2006) recommended using likelihood cross-validation (CVh), which minimizes the Kullback-Leibler distance (KL; Kullback and Leibler 1951), to select the appropriate bandwidth. KL can be described as the information lost when using a specified distribution to estimate the true distribution (Burnham and Anderson 2001). This measure is widely accepted because of its basis in information theory and Burnham and Anderson (2001) advocated its use for model selection in wildlife research. KL tends to be less sensitive to outliers compared to the integrated square error (ISE) measure, which is used in 
LSCV (Horne and Garton 2006). Horne and Garton (2006) compared CVh to LSCV using simulated data and found that CVh produced estimates with better fit and less variability at all sample sizes when using KL. However, when using ISE to measure discrepancy, LSCV performed better at sample sizes $>50$. Moser (2007) found that LSCV produced estimates of northern goshawk (Accipiter gentilis) home ranges that were 55\% smaller than those produced by CVh. Trierweiler (2010) used both methods for locations from the Montagu's harrier (Circus pygargus) and found that LSCV produced more fragmented (i.e., undersmoothed) and inconsistent home range estimates compared to $\mathrm{CVh}$. The variations and contradictions in results of home range studies suggest that bandwidth selection can influence the sizes and shapes of home range estimates, but there is no single best method for selecting a bandwidth.

In addition to differences due to technical aspects, black bear home range size can vary due to biological characteristics such as age and reproductive status (Harested and Bunnell 1979, Alt et al. 1980, Olfenbuttel 2005). Landscapes characteristics such as roads, streams, habitat type, and elevation, also may influence bear movements and home ranges (Brody and Pelton 1989, Unsworth et al. 1989, Schooley 1990, Webster 1994, Dateo 1997). Several studies have found that adult females with cubs-of-the-year exhibit restricted movements compared to barren females, especially during the spring when cubs are not yet self-sufficient (Lindzey and Meslow 1977, Alt et al. 1980, Olfenbuttel 2005). Although Olfenbuttel (2005) found no differences in home range size among adult female age classes, other studies have reported differences between the sizes of adult and subadult home ranges, likely due to the establishment of new territories by subadults (Lindzey and Meslow 1977, Klenner 1987).

Annual home range estimates for female black bears in the Appalachian region range from 5-49 $\mathrm{km}^{2}$ (Table 1). Two female black bear home range studies have been conducted in 
western Maryland (Webster 1994, Dateo 1997). Webster (1994) monitored 5 adult females and estimated a mean annual home range of $40.5 \mathrm{~km}^{2}$. Mean spring-summer home range $\left(28.4 \mathrm{~km}^{2}\right)$ was only slightly smaller than the mean fall home range $\left(31.0 \mathrm{~km}^{2}\right)$. A single barren female and a female with cubs were monitored intensively during each of the 2 years of the study. For the first year, the home range of the barren female $\left(14.9 \mathrm{~km}^{2}\right)$ was more than twice the size of the home range of the female with cubs $\left(7.0 \mathrm{~km}^{2}\right)$. However, reproductive status did not affect home range size the following year. Dateo (1997) estimated the mean annual home range for 8 bears at $35.5 \mathrm{~km}^{2}$. Summer home ranges were larger than fall home ranges for all bears. The study also found that barren females had larger annual and spring-summer home ranges, but smaller fall home ranges, than females with cubs.

\section{Harvest Management and Hunter Characteristics}

Although exact rates are rarely known, it is assumed that natural mortality in black bears is low relative to other mammalian species (Lindzey and Meslow 1977). Food shortages, predation, drowning, cannibalism, parasites, and falls have all been reported as sources of mortality, but their effects are difficult to detect because they mostly influence reproductive success and individuals that are too young to monitor (Rogers 1983, LeCount 1987, Pelton 2000). Human-induced mortality (e.g., vehicle collisions, recreational hunting, poaching) has a larger impact on bear populations than natural mortality in most areas (Cowan 1972, Bunnell and Tait 1985, Pelton 2000). Recreational hunting is the most commonly used management technique where controlling population growth of black bears is an objective (Cowan 1972, Bunnell and Tait 1985). As previously discussed, the low reproductive potential of black bears makes the species susceptible to overharvest (Kolenosky 1986). Bear populations that are overharvested, especially in the female segment of the population, can take years to recover (Miller 1989). 
Miller and Miller (1988) simulated the overharvest of a black bear population and found that, if the population was reduced to $50 \%$ of its original abundance and then hunting ceased, it would take 6 years for the population to recover to the original size. If the harvest rate remained at $75 \%$ of the original rate, it would take the same population 17 years to recover. Although research and harvest data show that males are more vulnerable to hunting, the harvest of females has the greatest potential of impacting the population (Fraser et al. 1982, Bunnell and Tait 1985).

Of the research on harvest vulnerability, most has been focused on the game species, whereas few studies have examined hunter characteristics. Traditional hunter research has relied on hunter surveys to gain information, even though this information can be inaccurate (Stedman et al. 2004, Diefenbach et al. 2005). Much of this research was aimed at determining the attitudes and motivations of hunters (Decker et al. 1980, Hammitt et al. 1990, Frey et al. 2003, Boulanger et al. 2006). With GPS and GIS technology becoming increasingly affordable, researchers are able to use that technology to track hunter movement and habitat use (Lyons and Burcham 1998, Broseth and Pederson 2000, Diefenbach et al. 2005). Lyon and Burcham (1998) issued GPS units to elk (Cervus elaphus) hunters in Montana and were able to record distances and speeds traveled, habitat use, and slope. They found that hunters spent most of their time in less steep areas, areas closer to roads, and open-forest habitat. Broseth and Pederson (2000) tracked willow ptarmigan (Lagopus lagopus) hunters in Norway and determined that willow ptarmigans were most vulnerable when nearby hunter starting locations. Diefenbach et al. (2005) used GPS technology to aerially record the locations and calculate the density of black bear and white-tailed deer (Odocoileus virginianus) hunters in Pennsylvania. They found that hunters generally remained close to roads, although bear hunters were observed farther from 
roads than deer hunters. Keenan (2010) found that the density of Pennsylvania deer hunters on public land was about 2 times greater than on private land in one of his study areas.

One use of location data for bears is to locate potential natural sanctuary areas, which are usually areas that are suitable for bears but relatively inaccessible to hunters and other humans. Powell et al. (1996) examined the population demographics of black bears inside and outside of an established sanctuary in North Carolina. They found that bear density and survivorship were significantly higher inside the sanctuary than outside, and that the sanctuary produced dispersing individuals that traveled into areas where bear harvest was permitted. Beringer et al. (1998) conducted similar research focused on North Carolina sanctuaries and found similar results. They suggest that even small sanctuaries are important for supporting female bears in a heavily hunted population. These sanctuaries also were found to produce surplus bears that would be available for harvest outside of the sanctuaries. Ryan (2009) documented population growth for bears living near active mine sites in West Virginia, which provided protection from hunting, and population decline for bears living on areas more accessible to hunting pressure.

\section{Predictive Occurrence Modeling}

With the availability of detailed environmental data, GIS technology, and new statistical approaches, the use of predictive occurrence modeling in ecology has increased considerably in the past decade (Guisan and Zimmermann 2000). Many modeling approaches incorporate records of presence and absence locations of a species, but absence data is not always available or reliable (Elith et al. 2011). There is some level of uncertainty inherent in absence data because there is a chance that the species occurs in a location but was not detected. To account for that uncertainty, several modeling approaches have been designed that only require presence data (Tsoar et al. 2007). One of those presence-only techniques is a maximum entropy approach. 
For predicting a distribution, maximum entropy is based on estimating the target distribution by finding the distribution with the maximum entropy (i.e., closest to uniform) given environmental constraints (Phillips et al. 2004). By finding the distribution with the maximum entropy, no prior assumptions are made regarding the distribution. Phillips et al. (2004) presented the maximum entropy approach for species distribution modeling and created the program Maxent to carry out the modeling. Maxent requires 2 components: presence location data (i.e., coordinates of a known occurrence of the target species) and raster environmental layers that may help describe factors influencing the suitability of an area for the target species (Phillips et al. 2006). Examples of environmental layers include elevation, precipitation totals, and habitat type. Maxent then generates up to 10,000 random locations across the study area, called pseudoabsences, which help describe the available values of the environmental layers within the study area. By comparing the values of the environmental layers at the presence locations to the available values at the pseudoabsence points, Maxent can define constraints for the range of values of each environmental layer at which the species will occur (Elith et al. 2011). Maxent then generates a distribution that is closest to uniform and still satisfies the constraints (Phillips et al. 2006). The resulting map output is a raster dataset of values that represent the relative probability of occurrence of the target species in each raster cell.

Additional options in Maxent allow the user to partition the occurrence data into test and training data, allowing a measure of the performance of the model, or run a jackknife test to determine the relative contribution of each environmental layer to the final model (Phillips et al. 2006). Maxent has become an increasingly popular program for predictive occurrence modeling as it has consistently outperformed other presence-only modeling approaches (Elith et al. 2006, Peterson et al. 2007, Ortega-Huerta and Peterson 2008). One major benefit of Maxent is its 
ability to accurately predict distributions even with very small sample sizes, making it useful for clustered or sparse data. Kumar and Stohlgren (2009) used Maxent to model the distribution of a threatened and endangered tree in New Caledonia. They used only 11 occurrence locations, yet the model had a $91 \%$ success rate (as measured by the omission rate) and was statistically significant. Similarly, Pearson et al. (2007) used Maxent to model 13 species of geckos (Uroplatus spp.) in Madagascar using 4-23 occurrence locations. The resulting models were statistically significant in the jackknife tests and had high success rates with as few as 5 locations. Another benefit of Maxent is that it is relatively insensitive to the effects of spatial autocorrelation or spatial error in the occurrence locations, which is important for use with telemetry data. Kaliontzopoulou et al. (2008) used highly clustered occurrence data to predict the occurrence of wall lizards (Podarcis spp.) in North Africa. They also ran Maxent with a random subset of the data that was not significantly clustered and found that the model run with the clustered data performed better than the subset data. Graham et al. (2008) ran Maxent on original data and on data with simulated spatial error and determined that it performed well on both datasets. Although occurrence datasets commonly used for Maxent are based on surveys or sightings, the approach also has proven successful when using telemetry data (Monterroso et al. 2009, Edren et al. 2010, Kuemmerle et al. 2010). Monterroso et al. (2009) used Maxent to model European wildcats (Felis silvestris) and used camera-trapping data for field validation of the model, finding that the model performed very well.

The Maxent modeling approach does have some issues and limitations that affect all presence-only modeling techniques. Perhaps the biggest concern is sample selection bias (Phillips et al. 2009). Species distribution models have the underlying assumption that presence data is a random sample representing the population (Araújo and Guisan 2006). However, 
presence data are often biased due to differences in survey effort, with more data occurring in areas with easier access for humans or easier species detection (Dennis and Thomas 2000, Reddy and Dàvalos 2003, Schulman et al. 2007). Issues also can arise when attempting to extrapolate a Maxent model to an unsampled area (Peterson et al. 2007, Baldwin 2009). The transferability of the model to the unsampled area may be reduced due to sample bias or differences in environmental variables compared to the sampled area (Phillips 2008, Ervin and Holly 2011). Additionally, temporal variation inherent in occurrence data collected over a long period of time may reduce the predictive power of the model in the unsampled or sampled areas (Phillips 2008). Another potential weakness of Maxent modeling is the difficulty of model evaluation. The area under the curve (AUC) method compares the model to null expectations and is the most commonly used method (Elith et al. 2006). However, this evaluation technique has drawn some criticism and is not as useful for models of generalist species (Lobo et al. 2007). Models of widespread species that inhabit a large range of environmental variables may accurately predict the species' distributions but still have low AUC values. The lack of a universally accepted method for model evaluation leads to uncertainty in the performance of models without field validation.

\section{Noninvasive Genetics Surveys for Population Demographic Estimation}

Black bear population demographics are often estimated through mark-recapture techniques (Kemp 1976, Hellgren and Vaughan 1989). Although several mark-recapture abundance estimators exist, they are all based on the marking of captured animals and making an inference about the abundance from the proportion of marked individuals in subsequent captures (White et al. 1982). Traditional mark-recapture methods require the physical capture and handling of animals in order to uniquely mark them. However, these methods can prove difficult for black 
bears because they have large home ranges, occur at relatively low densities, and can be difficult to capture using live-trapping techniques. Physical captures also require costly chemicals for immobilization and can cause stress on the animal. In addition, it is possible to lose markers (e.g., ear tags), which violates a basic assumption of mark-recapture estimates and can drastically reduce the reliability of the estimate (Otis et al. 1978).

To circumvent the issues related to traditional mark-recapture techniques, researchers have developed new ways to estimate demographics without physically handling individuals. One such technique is noninvasive genetic sampling, which relies on DNA extracted from hair, scat, feathers, or other similar sources (Waits and Paetkau 2005). Woods et al. (1999) advocated the use of hair samples for genetic tagging of black and brown bears (Ursus arctos). Although bear scat has successfully been used for genetic analysis (Boulanger et al. 2004, Bellemain et al. 2005), hair samples are generally preferred because scat contains chemical inhibitors that can prevent DNA amplification and is more susceptible to contamination from diet items (Schwartz and Monfort 2008). The extraction of DNA from hair was first accomplished on human hair by Higuchi et al. (1988). Soon after, Taberlet and Bouvet (1992) successfully extracted mitochondrial DNA from brown bears. Paetkau and Strobeck (1994) developed the first microsatellites for bears, a technique which is the basis of most non-invasive genetic surveys today.

Woods et al. (1999) tested 4 hair snare designs and found that the barbed wire enclosure design was the most efficient. This design consists of a single strand of barbed wire wrapped around multiple trees at a height of approximately $50 \mathrm{~cm}$, with a suspended scent lure in the center of the enclosure approximately $4 \mathrm{~m}$ off of the ground (Woods et al. 1999). As a bear passes under or over the barbed wire, hairs are plucked and remain attached to the barbs. This 
design, or some variation of it, is the most commonly used hair snare design in black bear studies. Hair snares are set and checked every 5-15 days for 2-11 sampling sessions (Boulanger et al. 2002, Triant et al. 2004, Settlage 2005). To ensure sufficient recaptures and to reduce the chance of closure violations, surveys commonly use 4-5 sampling periods (Dreher et al. 2007, Proctor et al. 2010). For standard closed population analysis, Otis et al. (1978) recommend a trap density of at least 4 traps per individual home range. Although some studies are able to attain that trap density, others achieve approximately 1 hair snare per mean or minimum adult female home range (Bittner et al. 2002, Boulanger et al. 2006, Gardner-Santana 2007). In most cases, researchers sample using a systematic grid with the cell size chosen based on the desired hair snare density (Woods et al. 1999, Bittner et al. 2002, Coster 2008).

From the collected hair samples, species, gender, and individual identity can be determined (Proctor et al. 2010). Microsatellites, which are tandem repeat sequences of DNA, are highly variable, and thus useful for reliably identifying the genetic profile of individuals (Craighead et al. 1998). In order to increase the ability to detect individuals, 6-10 microsatellite loci are generally analyzed (Woods et al. 1999, Bittner et al. 2002, Settlage 2005). Because the microsatellite analysis only takes place at a portion of the genome, it is possible that 2 different individuals can have the same genetic profile at the microsatellite loci being analyzed. Woods et al. (1999) described test statistics to help determine the ability of the chosen microsatellites to differentiate between individuals. A $\mathrm{P}_{\text {sib }}$ value is the probability that 2 full siblings have the same genetic profile at the selected microsatellite loci. This is the most conservative test because full siblings have a similar genetic make-up. A low $\mathrm{P}_{\text {sib }}$ value indicates the microsatellite loci that were chosen do well at differentiating between individuals. Woods et al. (1999) suggests adding or changing loci if $\mathrm{P}_{\text {sib }}>0.05$. Many studies use some degree of subsampling in order to 
reduce costs and duplicate samples (Settlage 2005, Coster 2008). However, subsampling can introduce more error and reduce the chance of identifying all individuals. Tredick et al. (2007) found that the bias and precision of population estimates improves as the proportion of the total samples included in the estimate increases.

Once the hair samples have been analyzed and individuals have been identified, capture histories can be constructed and used in a traditional mark-recapture program, such as MARK (White and Burnham 1999). MARK provides a wide range of potential models for estimating closed population size (Otis et al. 1978). These models can incorporate factors that may affect capture probabilities, such as age, behavioral response, or individual heterogeneity (Cooch and White 2010). The appropriate model can then be chosen using corrected Akaike's Information Criterion values. Population density is most simply estimated by dividing the abundance estimate by the total area that was trapped. However, this may inflate the density somewhat because hair snares on the edge of the sampling grid can detect individuals that have home ranges extending beyond the boundary of the grid (Gardner-Santana 2007). This issue is referred to as "edge effect" (Efford et al. 2005). To correct this problem, Dice (1938) suggested adding a buffer of 0.5 times the home range of the animal to the outer edge of the trapping area, creating an "effective trapping area", but this approach has been relatively unsuccessful (Wilson and Anderson 1985, Soisalo and Cavalcanti 2006). To avoid calculating a buffer, spatially explicit capture-recapture (SECR) density estimation was developed (Efford 2004). SECR fits a probability model using the spatial distribution of the samples and a function for the probability of capture as a function of the distance from a detector (e.g., hair snare) (Efford et al. 2004). The approach takes into account the assumption that the probability of an animal being captured at a 
detector decreases the farther its home range is away from the detector. SECR works for any array of passive detectors, so the technique is applicable to hair-snare surveys (Drewery 2010).

Two hair-snare surveys have been conducted in western Maryland (Bittner et al. 2002, Spiker 2011). In 2000, MDNR used noninvasive genetic hair sampling to estimate the bear population in Garrett County and the portion of Allegany County from Cumberland west (Bittner et al. 2002). A sampling grid with cell size of $19.9 \mathrm{~km}^{2}$ and one hair snare per cell was used. Snares were set for 4 7-day sampling periods. The analysis in program CAPTURE estimated that 227 adult and sub-adult bears $\left(10.5\right.$ bears $/ 100 \mathrm{~km}^{2}$ ) occupied western Maryland, a $128 \%$ increase in density from the 1991 estimate. The sampling design from the 2000 study excluded cubs from the estimate. The last official population estimate was conducted in 2005 in Garrett and Allegany Counties (Spiker 2011). MDNR again used noninvasive genetic sampling but reduced the cell size to $12.0 \mathrm{~km}^{2}$. The abundance estimate from that study was 362 adult and sub-adult bears. To compare the results to the previous study, a separate estimate was calculated for the area from Cumberland west. That estimate was 326 individuals with a density of 15.2 bears $/ 100 \mathrm{~km}^{2}$, a $45 \%$ increase in density compared to the 2000 study. Despite the increase, the bear density in Maryland is still relatively low compared to other parts of the southeast, where densities range from $8-86$ bears $/ 100 \mathrm{~km}^{2}$ (Garshelis 1994).

\section{LITERATURE CITED}

Alt, G. L., G. J. Matula, Jr., F. W. Alt, and J. S. Lindzey. 1980. Dynamics of home range and movements of adult black bears in northeastern Pennsylvania. International Conference on Bear Research and Management 4:131-136.

Anderson, D. J. 1982. The home range: a new nonparametric estimation technique. Ecology 63:103-112. 
Araújo, M. B., and A. Guisan. 2006. Five (or so) challenges for species distribution modeling. Journal of Biogeography 33:1677-1688.

Baldwin, R. A. 2009. Use of maximum entropy modeling in wildlife research. Entropy 11:854-866.

Beecham, J. J. 1983. Population characteristics of black bears in west central Idaho. Journal of Wildlife Management 47:405-412.

Beeman, L. E., and M. R. Pelton. 1980. Seasonal foods and feeding ecology of black bears in the Smoky Mountains. International Conference on Bear Research and Management 4:141-147.

Bekoff, M., and L. D. Mech. 1984. Simulation analyses of space use: home range estimates, variability, and sample size. Behavior Research Methods, Instruments, and Computers $16: 32-37$.

Bellemain, E., J. E. Swenson, D. Tallmon, S. Brunberg, and P. Taberlet. 2005. Estimating population size of elusive animals with DNA from hunter-collected feces: fours methods for brown bears. Conservation Biology 19:150-161.

Beringer, J., S. G. Seibert, S. Reagan, A. J. Brody, M. R. Pelton, and L. D. Vangilder. 1998. The influence of small sanctuary on survival rates of black bears in North Carolina. Journal of Wildlife Management 62:727-734.

Beyer. H. L. 2004. Hawth's analysis tools for ArcGIS. <http://www.spatialecology.com>. Accessed 8 August 2010.

Bittner, S. L., T. L. King, and W. F. Harvey. 2002. Estimating Maryland's black bear population. Proceedings Annual Conference of Southeast Association of Fish and Wildlife Agencies. 
Boulanger, J., G. C. White, B. N. McLellan, J. Woods, M. Proctor, and S. Himmer. 2002. A meta-analysis of grizzly bear DNA mark-recapture projects in British Columbia, Canada. Ursus 13:137-152.

Boulanger, J., S. Himmer, and C. Swan. 2004. Monitoring of grizzly bear population trends and demography using DNA mark-recapture methods in the Owikeno Lake area of British Columbia. Canadian Journal of Zoology 82:1267-1277.

Boulanger, J., M. Proctor, S. Himmer, G. Stenhouse, D. Paetkau, and J. Cranston. 2006. An empirical test of DNA mark-recapture sampling strategies for grizzly bears. Ursus $17: 149-158$.

Boulanger, J. R., D. E. Hubbard, J. A. Jenks, and L. M. Gigliotti. 2006. A typology of South Dakota muzzleloader deer hunters. Wildlife Society Bulletin 34:691-697.

Brody, A. J. 1984. Habitat use by black bears in relation to forest management in Pisgah National Forest, North Carolina. Thesis, University of Tennessee, Knoxville, USA. Brody, A. J., and M. R. Pelton. 1989. Effects of roads on black bear movements in western North Carolina. Wildlife Society Bulletin 17:5-10.

Broseth, H., and H. C. Pederson. 2000. Hunting effort and game vulnerability studies on a small scale: a new technique combining radio-telemetry, GPS, and GIS. Journal of Applied Ecology 37:182-190.

Brown, W. S. 1980. Black bear movements and activities in Pocahontas and Randolph counties, West Virginia. Thesis, West Virginia University, Morgantown, USA.

Bunnell, F. L., and D. E. N. Tait. 1985. Mortality rates of North American bears. Arctic $38: 316-323$. 
Burnham, K. P., and D. R. Anderson. 2001. Kullback-Leibler information as a basis for strong inference in ecological studies. Wildlife Research 111-119.

Burt, W. H. 1943. Territoriality and home range concepts as applied to mammals. Journal of Mammalogy 24:346-352.

Cain III, J. W., P. R. Krausman, B. D. Jansen, and J. R. Morgart. 2005. Influence of topography and GPS fix interval on GPS collar performance. Wildlife Society Bulletin 33:926-934.

Clark, J. D., J. E. Dunn, and K. G. Smith. 1993. A multivariate model of female black bear habitat use for a Geographic Information System. Journal of Wildlife Management $57: 519-526$.

Cooch, E., and G. White, editors. 2010. Program MARK "a gentle introduction". Ninth edition.

Costello, C. M. 2008. The spatial ecology and mating system of black bears (Ursus americanus) in New Mexico. Dissertation, Montana State University, Bozeman, USA.

Coster, S. 2008. Use of genetic tagging to estimate abundance and detect spatial patterns of black bears in New Hampshire. Thesis, University of New Hampshire, Durham, USA.

Cowan, I. McT. 1972. The status and conservation of bears (Ursidae) of the world - 1970. International Conference on Bear Research and Management 2:343-367.

Craighead, F. L., D. Paetkau, H. V. Reynolds, C. Strobeck, and E. R. Vyse. 1998. Use of microsatellite DNA analyses to infer breeding behavior and demographic processes in an Arctic grizzly bear population. Ursus 10:323-327.

Dateo, D. M. 1997. Use of home range and influences of habitat selection on crop depredation by black bears (Ursus americanus) in western Maryland. Thesis, Frostburg State University, Frostburg, Maryland, USA. 
Decker, D. J., T. L. Brown, and R. J. Gutierrez. 1980. Further insights into multiple satisfactions approach for hunter management. Wildlife Society Bulletin 8:323-331.

Dennis, R., and C. Thomas. 2000. Bias in butterfly distribution maps: the influence of hot spots and recorder's home range. Journal of Insect Conservation 4:73-77.

D’Eon, R. G. 2003. Effects of a stationary GPS fix-rate bias on habitat-selection analyses. Journal of Wildlife Management 67:858-863.

Dice, L. 1938. Some census methods for mammals. Journal of Wildlife Management 2:119-130.

Diefenbach, D. R., J. C. Finley, A. E. Luloff, R. Stedman, C. B. Swope, H. C. Zinn, G. J. San Julian. 2005. Bear and deer hunter density and distribution on public land in Pennsylvania. Human Dimensions of Wildlife 10:201-212.

Don Carlos, A. W., A. D. Bright, T. A. Teel, and J. J. Vaske. 2009. Human-black bear conflict in urban areas: an integrated approach to management response. Human Dimensions of Wildlife 14:174-184.

Dreher, B. P., S. R. Winterstein, K. T. Scribner, P. M. Lukacs, D. R. Etter, G. J. M. Rosa, V. A. Lopez, S. Libants, and K. B. Filcek. 2007. Noninvasive estimation of black bear abundance incorporating genotyping errors and harvested bear. Journal of Wildlife Management 71:2684-2693.

Drewery, J. M. 2010. Population abundance and genetic structure of black bears in coastal South Carolina. Thesis, University of Tennessee, Knoxville, USA.

Echols, K. N. 2000. Aspects of reproduction and cub survival in a hunted population of Virginia black bears. Thesis, Virginia Polytechnic Institute and State University, Blacksburg, USA. 
Edren, S. M. C., M. S. Wisz, J. Teilmann, R. Dietz, and J. Söderkvist. 2010. Modelling spatial patterns in harbor porpoise satellite telemetry data using maximum entropy. Ecography 33:698-708.

Efford, M. 2004. Density estimation in live-trapping studies. Oikos 106:598-610.

Efford, M. G., D. K. Dawson, and C. S. Robbins. 2004. DENSITY: software for analyzing capture-recapture data from passive detector arrays. Animal Biodiversity and Conservation 27:217-228.

Efford, M. G., B. Warburton, M. C. Coleman, and R. J. Baker. 2005. A field test of two methods for density estimation. Wildlife Society Bulletin 33:731-738.

Eiler, J. H., W. G. Wathen, and M. R. Pelton. 1989. Reproduction in black bears in the southern Appalachian Mountains. Journal of Wildlife Management 53:353-360.

Elith, J., C. H. Graham, R. P. Anderson, M. Dudik, S. Ferrier, A. Guisan, R. J. Hijmans, F. Huettman, J. R. Leathwick, A. Lehmann, J. Li, L. G. Lohmann, B. A. Loiselle, G. Manion, C. Moritz, M. Nakamura, Y. Nakazama, J. McC. Overton, A. T. Peterson, S. J. Phillips, K. S. Richardson, R. Scachetti-Pereira, R. E. Schapire, J. Sobero'n, S. Williams, M. S. Wisz, and N. E. Zimmermann. 2006. Novel methods improve prediction of species' distributions from occurrence data. Ecography 29:129-151.

Elith, J., S. J. Phillips, T. Hastie, M. Dudik, Y. E. Chee, and C. J. Yates. 2011. A statistical explanation of MaxEnt for ecologists. Diversity and Distributions 17:43-57.

Elowe, K. D. 1984. Home range, movements, and habitat preferences of black bear (Ursus americanus) in western Massachusetts. Thesis, University of Massachusetts, Amherst, USA. 
Ervin, G. N., and D. C. Holly. 2011. Examining local transferability of predictive species distribution models for invasive plants: an example with cogongrass (Imperata cylindrical). Invasive Plant Science and Management 4:390-401

Fecske, D. M., R. E. Barry, F. L. Precht, H. B. Quigley, S. L. Bittner, and T. Webster. 2002. Habitat use by female black bears in western Maryland. Southeastern Naturalist 1:77-92.

Ford, R. G. 1983. Home range in a patchy environment: optimal foraging predictions. American Zoologist 23:315-326.

Fraser, D., J. F. Gardner, G. B. Kolenosky, and S. Strathearn. 1982. Estimation of harvest rate of black bears from age and sex data. Wildlife Society Bulletin 10:53-57.

Frey, S. N., M. R. Conover, J. S. Borgo, and T. A. Messmer. 2003. Factors influencing pheasant hunter harvest and satisfaction. Human Dimensions of Wildlife 8:277-286.

Gardner-Santana, L. C. 2007. Patterns of genetic diversity in black bears (Ursus americanus) during a range expansion into Oklahoma. Thesis, Oklahoma State University, Stillwater, USA.

Garner, N. P. 1986. Seasonal movements, habitat selection, and food habits of black bears (Ursus americanus) in Shenandoah National Park, Virginia. Thesis, Virginia Polytechnic Institute and State University. Blacksburg, USA.

Garner, N. P., and T. P. Matthews. 1992. Maryland's black bear management plan 1992-2001. Maryland Department of Natural Resources.

Garshelis, D. L., and M. R. Pelton. 1981. Movements of black bears in the Great Smoky Mountains National Park. Journal of Wildlife Management 45:912-925. 
Garshelis, D. L. 1994. Density-dependent population regulation of black bears. Pages 3-14 in M. Taylor, editor. Density-dependent population regulation in black, brown, and polar bears. International Conference on Bear Research and Management Monograph 3.

Garshelis, D. L., and H. Hristienko. 2006. State and provincial estimates of American black bear numbers versus assessments of population trend. Ursus 17:1-7.

Garshelis, D. L., D. Crider, F. van Manen. 2008. Ursus americanus in IUCN 2011. IUCN Red List of Threatened Species. Version 2011.2. <www.iucnredlist.org>. Accessed 2 May 2012.

Girard, I., J. Oullet, R. Courtois, C. Dussault, and L. Breton. 2002. Effects of sampling effort based on GPS telemetry on home-range size estimations. Journal of Wildlife Management 66:1290-1300.

Gitzen, R. A., and J. J. Millspaugh. 2003. Comparison of least-squares cross-validation bandwidth options for kernel home-range estimation. Wildlife Society Bulletin $31: 823-831$.

Graham, C. H., J. Elith, R. J. Hijmans, A. Guisan, A. T. Peterson, B. A. Loiselle. 2008. The influence of spatial errors in species occurrence data used in distribution models. Journal of Applied Ecology 45:239-247.

Guisan, A., and N. E. Zimmermann. 2000. Predictive habitat distribution models in ecology. Ecological Modelling 135:147-186

Hall, E. R. 1981. The mammals of North America. Second edition. John Wiley \& Sons, New York City, New York, USA.

Hammitt, W. E., C. D. McDonald, and M. E. Patterson. 1990. Determinants of multiple satisfactions for deer hunting. Wildlife Society Bulletin 18:331-337. 
Hansen, M. C., and R. A. Riggs. 2008. Accuracy, precision, and observation rates of global positioning system telemetry collars. Journal of Wildlife Management 72:518-526.

Harested, A. S., and F. L. Bunnell. 1979. Home range and body weight—a reevaluation. Ecology 60:389-402.

Hellgren, E. C., and M. R. Vaughan. 1989. Demographic analysis of a black bear population in the Great Dismal Swamp. Journal of Wildlife Management 53:969-977.

Hemson, G., P. Johnson, A. South, R. Kenward, R. Ripley, and D. Macdonald. 2005. Are kernels the mustard? Data from global positioning system (GPS) collars suggests problems for kernel home-range analyses with least-squares cross-validation. Journal of Animal Ecology 74:455-463.

Higgens, J. C. 1997. Survival, home range and spatial relationships of Virginia's exploited black bear population. Thesis, Virginia Polytechnic Institute and State University, Blacksburg, USA.

Higuchi, R., C. H. von Beroldingen, G. F. Sensabaugh, and H. A. Erlich. 1988. DNA typing from single hairs. Nature 332:543-546.

Horne, J. S., and E. O. Garton. 2006. Likelihood cross-validation versus least squares crossvalidation for choosing the smoothing parameter in kernel home-range analysis. Journal of Wildlife Management 70:641-648.

Horner, M. A., and R. A. Powell. 1990. Internal structure of home ranges of black bears and analyses of home-range overlap. Journal of Mammalogy 71:402-410.

Jonkel, C. J., and I. M. Cowan. 1971. The black bear in the spruce-fir forest. Wildlife Monographs 27. 
Kaliontzopoulou, A., J. C. Brito, M. A. Carretero, S. Larbes, and D. J. Harris. 2008. Modelling the partially unknown distribution of wall lizards (Podarcis) in North Africa: ecological affinities, potential areas of occurrence, and methodological constraints. Canadian Journal of Zoology 86:992-1001.

Keenan, M. T. 2010. Hunter distribution and harvest of female white-tailed deer in Pennsylvania. Thesis, The Pennsylvania State University, University Park, USA.

Kemp, G. A. 1976. The dynamics and regulation of black bear Ursus americanus populations in northern Alberta. International Conference on Bear Research and Management $3: 191-197$.

Kernohan, B. J., R. A. Gitzen, and J. J. Millspaugh. 2001. Analysis of animal space use and movements. Pages 125-166 in J. J. Milspaugh and J. M. Marzluff, editors. Radio tracking and Animal Populations. Academic Press, San Diego, California, USA.

Klenner, W. 1987. Seasonal movements and home range utilization patterns of the black bear, Ursus americanus, in western Manitoba. Canadian Field Naturalist 101:558-568.

Koehler, G. M., and D. J. Pierce. 2003. Black bear home range sizes in Washington: climatic, vegetative and social influences. Journal of Mammalogy 84:81-91.

Kolenosky, G. B. 1986. The effects of hunting on an Ontario black bear population. International Conference on Bear Research and Management 6:45-55.

Kraus, J. G. 1990. Home ranges and den site characteristics of female black bears and aspects of bear population structure in West Virginia. Thesis, West Virginia University, Morgantown, USA. 
Kuemmerle, T., K. Perzanowski, O. Chaskovskyy, K. Ostapowicz, L. Halada, A. Bashta, I. Kruhlov, P. Hostert, D. M. Waller, and V. C. Radeloff. 2010. European bison habitat in the Carpathian Mountains. Biological Conservation 143:908-916.

Kullback, S., and R. A. Leibler. 1951. On information and sufficiency. The Annals of Mathematical Statistics 22:79-86.

Kumar, S., and T. J. Stohlgren. 2009. Maxent modeling for predicting suitable habitat for threatened and endangered tree Canacomyrica monticola in New Caledonia. Journal of Ecology and Natural Environment 1:94-98.

Laver, P. N., and M. J. Kelly. 2008. A critical review of home range studies. Journal of Wildlife Management 72:290-298.

LeCount, A. L. 1987. Causes of black bear cub mortality. International Conference on Bear Research and Management 7:75-82.

Lindzey, F. G., and E. C. Meslow. 1977. Home range and habitat use by black bears in southwestern Washington. Journal of Wildlife Management 41:413-425.

Lobo, J. M., A. Jiménez-Valverde, and R. Real. 2007. AUC: a misleading measure of the performance of predictive distribution models. Global Ecology and Biogeography $17: 145-151$.

Lotek Wireless Fish and Wildlife Monitoring. 2005. Small and midsize animals GPS location system user's manual GPS_3300.

Lyon, L. J., and M. G. Burcham. 1998. Tracking elk hunters with the global positioning system. U. S. Department of Agriculture, Forest Service, Rocky Mountain Research Station, Fort Collins, Colorado, USA. 
Mansueti, R. 1950. Extinct and vanishing mammals of Maryland and the District of Columbia. Maryland Naturalist 20:1-48.

Michener, G. R. 1979. Spatial relationships and social organization of adult Richardson's ground squirrels. Canadian Journal of Zoology 57:125-139.

Miller, S. D., and S. M. Miller. 1988. Interpretation of bear harvest data. Alaska Department of Fish and Game, Juneau, USA.

Miller, S. D. 1989. Population management of bears in North America. International Conference on Bear Research and Management 8:357-373.

Mohr, C. O., and W. A. Stumpf. 1966. Comparison of methods for calculating areas of animal activity. Journal of Wildlife Management 30:293-304.

Monterroso, P., J. C. Brito, P. Ferreras, and P. C. Alves. 2009. Spatial ecology of the European wildcat in a Mediterranean ecosystem: dealing with small radio-tracking datasets in species conservation. Journal of Zoology 279:27-35.

Moser, B. W. 2007. Space use and ecology of goshawks in northern Idaho. Thesis, University of Idaho, Moscow, USA.

Obbard, M. E., B. A. Pon, and A. Perera. 1998. Preliminary evaluation of GPS collars for analysis of habitat use and activity patterns of black bears. Ursus 10:209-217.

Olfenbuttel, C. 2005. Home range dynamics of black bears in the Alleghany Mountains of western Virginia. Thesis, Virginia Polytechnic Institute and State University, Blacksburg, USA.

Ortega-Huerta, M. A., and A. T. Peterson. 2008. Modeling ecological niches and predicting geographic distributions: a test of six presence-only methods. Revista Mexicana de Biodiversidad 79:205-216. 
Otis, D. L., K. P. Burnham, G. C. White, and D. R. Anderson. 1978. Statistical inference from capture data on closed animal populations. Wildlife Monographs 62.

Paetkau, D., and C. Strobeck. 1994. Microsatellite analysis of genetic variation in black bear populations. Molecular Ecology 3:489-495.

Paradiso, J. L. 1969. Mammals of Maryland. North American Fauna. U.S. Fish and Wildlife Service Publication 66, Washington, D. C.

Pearson, R. G., C. J. Raxworthy, M. Nakamura, and A. T. Peterson. 2007. Predicting species distributions from small numbers of occurrence records: a test case using cryptic geckos in Madagascar. Journal of Biogeography 34:102-117.

Pelton, M. R. 2000. Black bear. Pages 547-555 in G. A. Feldhamer, B. C. Thompson, and J. A. Chapman, editors. Wild mammals of North America: biology, management, and conservation. Second edition. The John Hopkins University Press, Baltimore, Maryland, USA.

Pelton, M. R., and F. T. van Manen. 1994. Distribution of black bears in North America. Proceedings of the Eastern Workshop on Black Bear Research and Management $12: 133-138$.

Peterson, A. T., M. Papes, and M. Eaton. 2007. Transferability and model evaluation in ecological niche modeling: a comparison of GARP and Maxent. Ecography 30:550-560

Phillips, S. J., M. Dudik, and R. E. Schapire. 2004. A maximum entropy approach to species distribution modeling. Proceedings of twenty-first International Conference on Machine Learning.

Phillips, S. J., R. P. Anderson, and R. E. Schapire. 2006. Maximum entropy modeling of species geographic distributions. Ecological Modelling 190:231-259. 
Phillips, S. J. 2008. Transferability, sample selection bias, and background data in presenceonly modelling: a response to Peterson et al. (2007). Ecography 31:272-278.

Phillips, S. J., M. Dudik, J. Elith, C. H. Graham, A. Lehmann, J. Leathwick, and S. Ferrier. 2009. Sample selection bias and presence-only distribution models: implications for background and pseudo-absence data. Ecological Applications 19:181-197.

Powell, R. A. 1987. Black bear home range overlap in North Carolina and the concept of home range applied to black bears. International Conference on Bear Research and Management 7:235-242.

Powell, R. A., J. W. Zimmerman, D. E. Seaman, and J. F. Gilliam. 1996. Demographic analysis of a hunted black bear population with access to a refuge. Conservation Biology $10: 224-234$.

Powell, R. A. 2000. Animal home ranges and territories and home range estimators. Pages 65-110 in L. Boitani and T. K. Fuller, editors. Research techniques in animal ecologycontroversies and consequences. Columbia University Press, New York, New York, USA.

Proctor, M., B. McLellan, J. Boulanger, C. Apps, G. Stenhouse, D. Paetkau, and G. Mowat. 2010. Ecological investigations of grizzly bears in Canada using DNA from hair, 1995-2005: a review of methods and progress. Ursus 21:169-188.

Quigley, H. B. 1982. Activity patterns, movement ecology, and habitat utilization of black bears in the Great Smoky Mountains National Park, Tennessee. Thesis, University of Tennessee, Knoxville, USA.

Reddy, S., and L. M. Dàvalos. 2003. Geographical sampling bias and its implications for conservation priorities in Africa. Journal of Biogeography 30:1719-1727. 
Responsive Management. 2004. Public attitudes toward black bear management in Maryland. Responsive Management. Harrisonburg, Virginia, USA.

Reynolds, D. G., and J. J. Beecham. 1980. Home range activities and reproduction of black bears in west-central Idaho. Bears: Their Biology and Management 4:181-190.

Riley, S. J., D. J. Decker, L. H. Carpenter, J. F. Organ, W. F. Siemer, G. F. Mattfeld, and G. Parsons. 2002. The essence of wildlife management. Wildlife Society Bulletin 30:585-593.

Rogers, L. L. 1983. Effects of food supply, predation, cannibalism, parasites, and other health problems on black bear populations. Pages 194-211 in F. L. Bunnell, D. S. Eastman, and J. M. Peek, editors. Symposium on natural regulation of wildlife populations. Forest, Wildlife, and Range Experiment Station, University of Idaho, Moscow, USA.

Rogers, L. L. 1987. Effects of food supply and kinship on social behavior, movements, and population growth of black bears in northeastern Minnesota. Wildlife Monographs 97:1-72.

Rudis, V. A., and J. B. Tansey. 1995. Regional assessment of remote forests and black bear habitat from forest resource survey. Journal of Wildlife Management 59:170-180.

Ryan, C. W. 1997. Reproduction, survival, and denning ecology of black bears in southwestern Virginia, Thesis, Virginia Polytechnic Institute and State University, Blacksburg, USA.

Ryan, C. W. 2009. Population ecology, residents' attitudes, hunter success, economic impact, modeling management options and retention time of Telazol of West Virginia black bears. Dissertation, West Virginia University, Morgantown, USA. 
Samuel, M. D., and M. R. Fuller. 1996. Wildlife radiotelemetry. Pages 370-418 in T. A. Bookhout, editor. Research and management techniques for wildlife and habitats. Fifth edition. The Wildlife Society, Bethesda, Maryland, USA.

Schenk, A., and K. M. Kovacs. 1995. Multiple mating between black bears revealed by DNA fingerprinting. Animal Behavior 50:1483-1490.

Schoener, T. W. 1981. An empirically based estimate of home range. Theoretical Population Biology 20:281-325.

Schooley, R. L. 1990. Habitat use, fall movements, and denning ecology of female black bears in Maine. Thesis, University of Maine, Orono, USA.

Schulman, L., T. Toivonen, and K. Ruokolainen. 2007. Analysing botanical collecting effort in Amazonia and correcting for it in species range estimation. Journal of Biogeography 34:1388-1399.

Schwartz, M. K., and S. L. Monfort. 2008. Genetic and endocrine tools for carnivore surveys. Pages 238-262 in R. A. Long, P. MacKay, W. J. Zielinski, and J. C. Ray, editors. Noninvasive survey methods for carnivores. Island Press, Washington, D.C., USA.

Seaman, D. E., and R. A. Powell. 1996. An evaluation of the accuracy of kernel density estimators for home range analysis. Ecology 77:2075-2085.

Seaman, D. E., J. J. Millspaugh, B. J. Kernohan, G. C. Brundige, K. J. Raedeke, and R. A. Gitzen. 1999. Effects of sample size on kernel home range estimates. Journal of Wildlife Management 63:739-747.

Settlage, K. E. 2005. Efficacy of DNA sampling to monitor population abundance of black bears in the southern Appalachians. Thesis, University of Tennessee, Knoxville, USA. 
Soisalo, M. K., and S. M. C. Cavalcanti. 2006. Estimating the density of a jaguar population in the Brazilian Pantanal using camera-traps and capture-recapture sampling in combination with GPS radio-telemetry. Biological Conservation 4:487-496.

Spiker, H. 2011. Maryland black bear population status report. Maryland Department of Natural Resources, Wildlife and Heritage Service, Oakland, USA.

Spiker Jr., H. A., and S. L. Bittner. 2004. Wildlife and Heritage Service black bear management plan 2004-2013. Maryland Department of Natural Resources Wildlife and Heritage Service.

Stedman, R., D. R. Diefenbach, C. B. Swope, J. C. Finley, A. E. Luloff, H. C. Zinn, G. J. San Julian, and G. A. Wang. 2004. Integrating wildlife and human-dimensions research methods to study hunters. Journal of Wildlife Management 68:762-773.

Taberlet, P., and J. Bouvet. 1992. Bear conservation genetics. Nature 358:197.

Tredick, C. A., M. R. Vaughan, D. F. Stauffer, S. L. Simek, and T. Eason. 2007. Sub-sampling genetic data to estimate black bear population size: a case study. Ursus 18:179-188.

Triant, D. A., R. M. Pace III, and M. Stine. 2004. Abundance, genetic diversity, and conservation of Louisiana black bears (Ursus americanus luteolus) as detected through noninvasive sampling. Conservation Genetics 5:647-659.

Trierweiler, C. 2010. Travels to feed and food to breed. The annual cycle of a migratory raptor, Montagu's harrier, in a modern world. Dissertation, University of Groningen, Netherlands.

Tsoar, A., O. Allouche, O. Steinitz, D. Rotem, and R. Kadmon. 2007. A comparative evaluation of presence-only methods for modeling species distribution. Diversity and Distributions 13:397-405. 
Unsworth, J. W., J. J. Beecham, and L. R. Irby. 1989. Female black bear habitat use in westcentral Idaho. Journal of Wildlife Management 53:668-673.

U.S. Census Bureau. 2001. 2000 census summary file 1. U.S. Census Bureau, Washington, D.C., USA.

U.S. Department of Agriculture Forest Service [USFS]. 1999. Northeastern forest and inventory analysis. Maryland statewide results. $<$ http://www.fs.fed.us/ne/fia/states/md/ index.html> Accessed 11 Feb 2010.

Waits, L. P., and D. Paetkau. 2005. Noninvasive genetic sampling tools for wildlife biologists: a review of applications and recommendations for accurate data collection. Journal of Wildlife Management 69:1419-1433.

Walter, W. D., J. W. Fischer, S. Baruch-Mordo, and K. C. VerCauteren. 2011. What is the proper method to delineate home range of an animal using today's advanced GPS telemetry systems: the initial step. Pages 249-268 in O. Krejcar, editor. Modern telemetry. Intech, Rijecka, Croatia.

Waser, P. M., and W. T. Jones. 1983. Natal philopatry among solitary mammals. Quarterly Review of Biology 58:355-390.

Webster, T. W. 1994. Movements and use of habitat of female black bears in western Maryland. Thesis, Frostburg State University, Frostburg, Maryland, USA.

White, G. C., D. R. Anderson, K. P. Burnham, and D. L. Otis. 1982. Capture-recapture and removal methods for sampling closed populations. Los Alamos National Laboratory, Los Alamos, New Mexico, USA

White, G. C., and R. A. Garrott. 1990. Analysis of wildlife radio-tracking data. Academic Press, San Diego, California, USA. 
White, G. C., and K. P. Burnham. 1999. Program MARK: survival estimation from populations of marked animals. Bird Study 46:120-139.

Wilson, K. R., and D. R. Anderson. 1985. Evaluation of two density estimators of small mammal population size. Journal of Mammalogy 66:13-21.

Woods, J. G., D. Paetkau, D. Lewis, B. N. McLellan, M. Proctor, and C. Strobeck. 1999. Genetic tagging of free-ranging black and brown bears. Wildlife Society Bulletin $27: 616-627$.

Worton, B. J. 1989. Kernel methods for estimating the utilization distribution in home-range studies. Ecology 70:164-168.

Worton, B. J. 1995. Using Monte Carlo simulation to evaluate kernel-based home range estimators. Journal of Wildlife Management 59:794-800.

Young, B. F., and R. L. Ruff. 1982. Population dynamics and movements of black bears in east central Alberta. Journal of Wildlife Management 46:845-860. 
CHAPTER 2

DNA-BASED POPULATION PARAMETERS OF BLACK BEARS IN WESTERN

MARYLAND 
November 2012

Michael D. Jones

West Virginia University

322 Percival Hall

Morgantown, WV 26506

920/598-0311

mike.jones731@gmail.com

RH: Jones • Maryland Black Bear Population Parameters

\section{DNA-based Population Parameters of Black Bears in Western}

\section{Maryland}

MICHAEL D. JONES, Division of Forestry and Natural Resources, West Virginia University, Morgantown, WV 26506

ABSTRACT Noninvasive genetic sampling (NGS) is a useful technique for studying wildlife populations, and has become increasingly popular as a method of estimating population parameters of bears. Although this approach is generally more cost-effective than traditional mark-recapture techniques, it can expensive and labor-intensive, especially when applied to a large area. We developed a model-based sampling design to efficiently survey black bears in western Maryland while using far less supplies and labor as were previously used when employing the traditional NGS design. The study area included 2 counties that contain the core bear population in Maryland (Garrett and Allegany), and 2 that had a low density, but expanding, bear population (Washington and Frederick). We developed maximum entropy (Maxent) models of black bear occurrence for the 4 counties in our study area, and classified the cells of an overlaid sampling grid based on the probability of bear occurrence (i.e., model value) within each cell. We used stratified random sampling to select 240 cells for inclusion in the survey based on their probability classification. This resulted in a design that focused sampling effort on areas with relatively high likelihood of containing bears. We conducted a hair snare survey in 
the selected cells and collected 342 bear hair samples over 5 1-week sampling sessions. The number of samples collected per high probability cell was approximately 5 times higher than the amount collected per low probability cell. From the hair samples, we identified 108 individual bears (44 M:64 F) and developed capture histories to estimate abundance and density in MARK. Due to low sample size $(n=8)$, we were unable to produce estimates for Washington or Frederick counties. Our estimate of bear abundance in Garrett and Allegany counties, adjusted to account for unsampled cells, was 701 individuals, with a density of 0.25 bears $/ \mathrm{km}^{2}$. This represented a $94 \%$ increase (11.6\% annually) since the previous estimate in 2005. Most (61\%) of the bears were located in Garrett County, whereas Allegany County had a slightly higher bear density ( 0.27 vs. 0.25 bears $\left./ \mathrm{km}^{2}\right)$ and much higher growth (235\%) since the last estimate. We believe similar model-based sampling designs can be used for other NGS studies where funding and manpower limitations prevent intensive sampling. However, this approach likely will yield fewer samples and less precise estimates compared to the traditional continuous grid design, and capture probabilities may be too low to accurately estimate the abundance of low density populations. If budget allows, we recommend opting for the continuous grid sampling design as that has successfully been used on a variety of populations.

KEY WORDS black bear, hair snare, mark-recapture, Maryland, maximum entropy, microsatellite, noninvasive genetic sampling, population estimates, Ursus americanus.

The Journal of Wildlife Management 00(0):000-000, 201X

\section{INTRODUCTION}

Understanding basic population parameters (e.g., abundance, sex ratio) is essential for the proper management of wildlife populations. In recent years, noninvasive genetic sampling (NGS), used in a mark-recapture framework, has become an increasingly popular method for estimating those 
parameters. For black bears (Ursus americanus; hereafter, bears), traditional mark-recapture methods are challenging because bears have large home ranges, occur at relatively low densities, and can be difficult to capture using live-trapping techniques (Garshelis 2006). NGS is appealing as it circumvents many of those issues and can be more cost-effective than livetrapping. Despite these advantages, only 14 states employed NGS to estimate their bear populations as of 2010 (Huffman et al. 2010). One possible explanation for the lack of use is that NGS techniques are usually employed at relatively small scales using high-intensity sampling, whereas most states require population estimates for large areas. Although some NGS research has been conducted on large scales (Kendall et al. 2009), intensive sampling over large areas would likely be financially infeasible for most states.

In Maryland, the bear population permanently inhabits the 4 westernmost counties, with 2 counties (Garrett and Allegany) containing the core population and the other 2 (Washington and Frederick) containing low-density, but expanding, populations (Figure 2.1). The Maryland Department of Natural Resources (MDNR) has used NGS for the last 2 bear population estimates. In 2000, MDNR staff conducted a hair snare survey in Garrett County and western Allegany County to estimate bear abundance (Bittner et al. 2002). In 2004, MDNR decided to reopen a bear hunting season in Garrett and Allegany counties after 51 years of closed season (Spiker 2012). Many states use harvest data to estimate population sizes (Huffman et al. 2010), but that option does not work in Maryland because bear hunting was reestablished so recently. Without sufficient harvest data, MDNR conducted another hair snare survey in 2005 in Garrett and Allegany counties (Spiker 2012). Since that time, bear sightings, nuisance complaints, and road-kills have increased in Washington and Frederick (Spiker 2012), indicating increased abundance in those counties. To account for the increasing population in Washington and 
Frederick counties, MDNR wanted their latest abundance estimate to include all 4 counties in the bear range, which is 2 times larger than the previously sampled area. However, budget constraints, as well as manpower limitations, prevented sampling at the same intensity used in the prior hair snare surveys. We wanted to develop an approach to allow estimates for all 4 counties while keeping costs and sampling effort (e.g., number of hair snares, staff) comparable to the 2005 hair snare survey.

To do this, we proposed creating models of bear occurrence to increase the efficiency of our sampling. This general technique has been used successfully to improve sampling of rare species. Edwards et al. (2005) developed models of topographic and bio-climatic variables to predict the locations of several lichen species. Using these models increased detection rates by 2-5 times. Rachlow and Svancara (2006) used a similar approach to efficiently sample pygmy rabbits (Brachylagus idahoensis) in Idaho. They classified their study area into habitat priority ranks, and found that $84 \%$ of their survey occurrences were located in the top 2 priority ranks, whereas $<0.4 \%$ were found in the lowest 2 priority ranks. Guisan et al. (2006) also had success when using niche-based distribution models to stratify the sampling of an endangered plant species (Eryngium alpinum). Surveys yielded 1.8-4.0 times more samples when using these models.

We are aware of only 1 study that used similar methods for black bear hair snare survey design. In Michigan, Dreher et al. (2007) only placed hair snares on public lands that they identified as high quality bear habitat. They excluded areas with urban, agricultural, or grassland cover types, as well as areas $<500 \mathrm{~m}$ from roads. They also adjusted the number of hair snares placed in each township based on previous bear harvest, with more snares allocated to areas with higher harvest levels. However, this study design did not allow for quantification of sample 
collection efficiency (e.g., samples per hair snare) between the sampled areas and areas considered low quality bear habitat.

We developed bear occurrence models and stratified sampling based on probabilities of bear occurrence to increase bear hair snare survey efficiency in western Maryland. Hair samples underwent genetic analysis to determine bear sex ratios, genetic diversity, and possible population structure. We used individual identification to build capture histories and estimate bear abundance and density using a mark-recapture framework.

\section{METHODS}

\section{Study Area}

We conducted this study in Garrett, Allegany, Washington, and Frederick counties, which are the 4 westernmost counties in Maryland (Fig. 2.1). The study area was bordered by Pennsylvania to the north and West Virginia to the south and west. Frederick County, the easternmost county in the study area, and a small portion of Washington County were bordered by Virginia to the south. The total area of these counties was $5,760 \mathrm{~km}^{2}$. Maryland's black bear population occurred at its highest densities in Garrett and Allegany counties, which is the only area in the state where bear hunting was permitted (Spiker 2012). The population existed at varying densities in other parts of the study area. Elevations ranged from 53-1,028 m, with the highest elevations occurring in Garrett and Allegany counties. The majority of the study area was forested, with approximately $51 \%$ of the total area covered in deciduous forests. Percent forested land decreased from the western portion of the study area to the eastern portion, while percent agricultural and developed land increased. Human population density also increased from west to east, with densities of 18 persons $/ \mathrm{km}^{2}$ in Garrett County and 137 persons $/ \mathrm{km}^{2}$ in Frederick County (U.S. Census Bureau 2010). 
The study area contained 7 different forest-type groups (U.S. Department of Agriculture Forest Service 1999). Oak/hickory (oaks (Quercus spp.) and hickories (Carya spp.)) was by far the most common in each of the counties. Northern hardwood (red maple (Acer rubrum), sugar maple (A. saccharum), American beech (Fagus grandifolia), yellow birch (Betula alleghaniensis), and black cherry (Prunus serotina)) was quite common in Garrett and Allegany counties. The other 5 forest-type groups accounted for a relatively small percentage of the total forested land. The understory vegetation in these forest-type groups included mountain laurel (Kalmia latifolia), rhododendron (Rhododendron spp.), serviceberry (Amelanchier arborea), dogwood (Cornus spp.), and hazelnut (Corylus spp.), which are important sources of food and thick cover for bears.

\section{Black Bear GPS Data Collection}

MDNR captured bears in Garrett County from 2005-2007 using barrel traps, spring-activated foot snares, and running with hounds (H. A. Spiker, MDNR, personal communication). Bears were chemically immobilized and females with neck circumferences of $>48 \mathrm{~cm}$ were fitted with Lotek Model 3300S GPS collars (Lotek Wireless Inc., Newmarket, Ontario, Canada) weighing $285 \mathrm{~g}$ (Lotek 2005). Bears with neck circumferences $<48 \mathrm{~cm}$ do not allow for the proper positioning of the collar antenna, which reduces the accuracy of the GPS coordinates. Morphometric measurements as well as sex and reproductive status were recorded for each captured bear. A premolar was extracted from each bear and used to age the individual using cementum annuli count techniques. The GPS collars were programmed to record a waypoint every 4 hours and the battery life was approximately 1 year. Each waypoint recorded the latitude and longitude at the current position, along with the date and time. Each collar also emitted a VHF signal that could be used to locate the bear in the event of a GPS failure. For bears 
remaining collared into the denning season, den sites were located using the VHF signal and collars were replaced during MDNR's annual den checks. At that point the GPS data were downloaded from the collars. If a collar remained stationary for an extended period of time, the collar would emit a unique VHF "mortality signal." These collars were located to determine the cause of the lack of movement. Any mortalities or slipped collars were recorded and data were recovered from the collar if possible.

\section{Predictive Modeling and Site Selection}

Due to funding and labor limitations, we did not conduct the hair snare survey using the highdensity sampling effort used in most previous non-invasive genetic studies (Triant 2004, Settlage 2005). MDNR had sufficient supplies and manpower to set 240 hair snares, the same amount used in the 2 previous Maryland hair snare surveys, but the current study area is 2.65 times larger than the study area of the 2005 survey. To address this issue, we used predictive occurrence modeling to prioritize the sampling effort and increase the efficiency of sampling.

Maxent modeling.- We used maximum entropy modeling in program Maxent (Phillips et al. 2004) to create a separate model for each of the 4 counties in the study area. Maximum entropy distribution modeling is based on estimating the target distribution by finding the distribution with the maximum entropy (i.e., closest to uniform) given environmental constraints (Phillips et al. 2004). By finding the distribution with the maximum entropy, no prior assumptions are made regarding the distribution. Maxent requires 2 components: presence location data (i.e., coordinates of a known occurrence of the target species) and raster environmental layers that may help describe factors influencing the suitability of an area for the target species (Phillips et al. 2006). The program then generates up to 10,000 random locations across the study area, called pseudoabsences, which help describe the available values of the 
environmental layers within the study area. By comparing the values of the environmental layers at the presence locations to the available values at the pseudoabsence points, Maxent can define constraints for the range of values of each environmental layer at which the species will occur (Elith et al. 2011). Maxent then generates a distribution that is closest to uniform and still satisfies the constraints (Phillips et al. 2006). The resulting map output is a raster dataset of values that represent the relative probability of occurrence of the target species in each raster cell. Maxent has become an increasingly popular program for predictive occurrence modeling as it has consistently outperformed other presence-only modeling approaches (Elith et al. 2006, Peterson et al. 2007, Ortega-Huerta and Peterson 2008).

We used a combination of female bear GPS data, bait station data, and road-kill locations provided by MDNR as the Maxent occurrence input. Although Maxent is generally insensitive to the effects of spatial autocorrelation (Kaliontzopoulou et al. 2008), we reduced those effects more by randomly selecting 25 points per individual bear to use as the occurrence input. Because the survey occurred in the early summer, we only included locations from 1 April-31 July. We set Maxent to randomly select $25 \%$ of the input locations to use as test data. However, we did not set aside test data for the Frederick County due to the low number of occurrences ( $n=$ 12). For the environmental layer inputs, we followed the bear occurrence model created by Clark et al. (1993) and used the following variables: cover type, elevation, slope, aspect, distance to nearest stream, and cover type diversity. Although Clark et al. (1993) also used a distance to nearest road variable, we excluded this due to our use of road-kill data. We defined cover type diversity as the number of unique cover types within the radius of the mean distance traveled by a female black bear in a 4-hr time period. Since the GPS collar fix interval was 4 hrs, we calculated the distance traveled between subsequent locations using Hawth's Analysis Tools 
(Beyer 2004) and used the mean distance. We then used the mean distance traveled as the neighborhood radius in the Focal Statistics tool in ArcGIS to assign a diversity value for each cell. For example, if a given cell was classified as deciduous forest but had wetlands and agricultural land around it within the neighborhood radius, that cell was assigned a cover type diversity value of 3 . We calculated Pearson correlation coefficients for all variables in ENMTools 1.3 (Warren et al. 2010) to test for multicollinearity. If 2 variables were highly correlated $\left(R^{2}>|0.80|\right)$, the least biologically relevant of the 2 would be removed (Lozier et al. 2009). The Maxent output provides a probability of occurrence across the study area, as well as a quantification of the relative importance of each environmental variable in the model. We used the area under the receiver operating characteristic curve (AUC) to evaluate the predictive performance of each model. AUC values, which compare the model to null expectations, are the most commonly used measure of Maxent model performance (Elith et al. 2006). If $\mathrm{AUC}=0.5$, the model does not perform any better than a random model, and model performance gets better as AUC approaches 1.0. Each model produces an AUC for the training data and for the test data. The training data AUC indicates the fit of the model to the training data, whereas the test data AUC is a measure of the predictive power of the model.

Sampling site selection.- For each county's model, we used the Jenks natural breaks to reclassify the output into 3 categories: high (value $=3$ ), medium (value $=2)$, and low (value $=1$ ) relative probability of bear occurrence. We then overlaid a sampling grid with a cell size of 12 $\mathrm{km}^{2}$, consistent with the 2005 hair snare survey and smaller than the mean summer home range size of female bears in Garrett County $\left(16.1 \mathrm{~km}^{2}\right.$; Chapter 5$)$. We then used the Zonal Statistics tool in ArcGIS to calculate an average relative probability value within each cell. We again used Jenks natural breaks to classify each cell as a high (HPC), medium (MPC), or low probability 
cell (LPC). These probabilities served as a proxy for the probability of obtaining a bear hair sample in that cell. The number of hair snares allocated to each county was proportional to the county size, with 75 hair snares set in Garrett County, 45 in Allegany County, 51 in Washington County, and 69 in Frederick County, for a total of 240 hair snares. To increase sampling efficiency, we focused sampling effort in HPCs and MPCs and limited the sampling of LPCs. We did not completely exclude LPCs from sampling because there is always uncertainty in the predictive power of the model without field validation. Of the total hair snares allocated to each county, $25 \%$ were placed in randomly selected LPCs, and the remaining were divided as evenly as possible between randomly selected HPCs and MPCs. The equal sampling of HPCs and MPCs is again due to the uncertainty associated with the model performance.

\section{Hair Snare Survey}

We set one hair snare in each selected cell. Site selection within the cell focused on finding the highest quality bear habitat, taking into account limitations due to property access. If landowner permission or the lack of forested habitat prevented the placement of a hair snare in a cell, another cell was randomly selected from the same probability class. Consistent with Bittner et al. (2002), each hair snare was comprised of a single strand of barbed wire wrapped around several trees at a height of approximately $50 \mathrm{~cm}$, encompassing an area of approximately $25 \mathrm{~m}^{2}$. We used fencing staples to attach the barbed wire to the trees, and we tightened the wire by hand. To ensure a uniform wire height, any dips in the terrain below the wire were filled with woody debris. Where possible, the enclosure surrounded an existing stump. Where existing stumps were not present, a large log was placed in the center of the enclosure. The log placement was such that a bear must cross over or under the barbed wire to reach the log. We baited each log or 
stump with $1.5 \mathrm{~L}$ of molasses. Warning signs or flagging were placed at the discretion of the landowner or worker setting the snare.

We set all hair snares the week of 17 May 2011 and they remained set for 5 7-day sampling periods. All hair snares were disassembled the week of 21 June 2011. During each weekly check, a white envelope was passed behind the barbed wire along the entire length of the hair snare to help detect hair samples. Bear hair samples were collected and placed in \#3 coin envelopes marked with the name of the worker, date, cell ID number, sampling period, and sample number. Additionally, the envelope noted if the sample contained $<5$ hairs or if the species was unknown. Each sample on a unique barb of the barbed wire was considered a unique sample. Upon removal of the hair, the barbs were burnt with a butane lighter to prevent contamination from hair residue. Samples were stored in a large paper envelope with silica packets to control moisture. At the conclusion of the survey period, all samples were placed in a freezer until ready for genetic analysis. We transported samples to the U.S. Geological Survey (USGS) Aquatic Ecology Laboratory, Kearneysville, WV, where each sample underwent analysis to determine species and gender. We did not subsample as that may introduce bias and increases the potential of unique individuals not being included in the samples (Laufenberg 2010).

\section{Genetic Analysis}

Microsatellite analysis. - All hairs were first inspected under a dissecting microscope for the presence of follicles. Ideal samples consisted of at least 5 guard hairs with visible follicles. A 1-2 cm piece of the root end of at least 5 hairs was removed and used in the DNA extraction. For samples consisting of $<5$ hairs, DNA was extracted from all roots. DNA was extracted using the InstaGene Matrix (IGM) system (Bio-Rad Laboratories, Hercules, CA). 
Microsatellite DNA amplification was performed in multiple stages. The initial analysis consisted of the amplification of 8 microsatellite DNA loci using the PCR primers described in Paetkau and Strobeck (1994) and Paetkau et al. (1995). These loci were: G1A, G1D, G10B, G10C, G10L, G10M, G10P, and G10X. Five multiplexed PCRs were created to genotype the 8 microsatellite DNA loci and the sex-determining marker. Amplifications were performed using either a PTC-200 or PTC-225 Thermal Cycler (MJ Research, St. Bruno, Quebec, Canada). Loci were identified using their characteristic molecular mass and attached fluorescent label. An Applied Biosystems's PRISM 3130XL Genetic Analyzer (i.e., automated sequencer; Applied Biosystems, Carlsbad, CA, USA) was used on each sample. GENEMAPPER 4.0 (Applied Biosystems, Carlsbad, CA, USA) DNA fragment analysis software was used to score, bin, and output allelic and genotypic designations for each bear sample.

All samples determined to be potential matches or near matches (i.e., differed by $1-2$ alleles) were subjected to second stage analysis of 3 additional microsatellite loci (UamA107, UamD103, and UamD113; Meredith et al. 2009) to detect and reduce the effect of allelic dropout. Allelic dropout is a source of genotyping error that occurs when only 1 of 2 alleles is amplified in a heterozygous sample, causing the misidentification as a homozygote (McKelvey and Schwartz 2004). This would lead to the sample being considered a unique individual, causing overestimation of any future abundance estimate. If $\geq 2$ samples exhibited the same multilocus genotype after analysis of the 11 loci, the samples were considered to be from the same individual. Sex identification was performed via PCR using male-specific (Y-chromosome) primers described by Taberlet et al. (1993). These primers generated a $\sim 115$ base pair fragment in male bears. 
Statistical analysis. - The multilocus genotype generated for each individual was analysed to determine the uniqueness of each hair sample. Initially, GeneCap v. 1.1 was used to identify unique multilocus genotypes as well as pairs of individuals that differed by 1-2 alleles. It also was used to determine the probability that 2 siblings in the sample, surveyed at all 8 loci, have identical genotypes ( $P I_{s i b}$; Woods et al. 1999). Estimates of individual pair-wise genetic distances based on the proportion of shared alleles algorithm were calculated among all samples using Microsat 1.5d.

Genetic diversity and heterozygosity were estimated by the observed $\left(\mathrm{H}_{\mathrm{o}}\right)$ and expected heterozygosity $\left(\mathrm{H}_{\mathrm{e}}\right)$, the average number of alleles per locus $\left(\mathrm{N}_{\mathrm{a}}\right)$, and the average effective number of alleles $\left(\mathrm{N}_{\mathrm{e}}\right)$ using GenAlEX.41 (Peakall and Smouse 2006). Departures from the expected genotypic frequencies in Hardy-Weinberg equilibrium were tested using the Markov chain method in GENEPOP 4.0. Additionally, linkage disequilibrium was tested for non-random associations between alleles of different loci using GENEPOP.

Program Structure 2.3.3 (Pritchard et al. 2000) was used to identify the genetic relationship of individual bears (i.e., identify populations or clusters of genetically related individuals). Structure probabilistically assigns individuals, without ancestral knowledge, to a specific number of clusters (k), which are presumably populations or subpopulations. In determining the number of clusters, the Structure attempts to minimize deviations from HardyWeinberg equilibrium. Simulations were conducted using the admixture model, which assumes that individuals could have some proportion of membership (q) from each of $\mathrm{k}$ clusters, leading to the potential identification of recent immigrants. Multiple Markov chains can delineate differences within populations; therefore 10 parallel chains were analyzed for $\mathrm{k}=1-10$, with a run-length of 100,000 repetitions of Markov chain Monte Carlo, following the burn-in period of 
10,000 iterations. The optimal number of subsets (i.e., "correct" number of

populations/subpopulations) in the initial phase was identified using $\Delta \mathrm{k}$.

KINALYZER (Ashley et al. 2009) was used to reconstruct full-sibling groups without parental information using data from the 8 microsatellite loci. KINALYZER employs an algorithm, based on Mendelian inheritance rules, that finds the smallest number of sibling groups that contain all individuals in the sample. KINALYZER does not require information about population allele frequencies and makes no assumptions regarding the mating system of the bears.

\section{Abundance and Density Estimation}

We used Huggins closed population models (Huggins 1989, 1991) in program MARK (White and Burnham 1999) to estimate abundance. We chose closed population models based on the timing and duration of the sampling. The sampling occurred just prior to peak breeding season, when males move larger distances, so movement in or out of the study area was limited and assumed to be random. Black bears are a long-lived species so any mortality, especially of adults and sub-adults targeted in the sampling, was likely negligible. The Huggins models accounted for combinations of time and group (i.e., cell probability class) effects on capture probabilities, as well as a null model that assumes equal capture probability. For each model, we calculated the corrected Akaike's Information Criterion $\left(\mathrm{AIC}_{\mathrm{c}}\right)$. Akaike's Information Criterion (AIC) is an index used for selecting the best model based on the goodness-of-fit and the number of parameters. For AIC, if 2 models explain the data equally well, the model with the fewest parameters is preferred because it is more parsimonious. $\mathrm{AIC}_{\mathrm{c}}$ is a similar statistic that is corrected to reduce bias in small samples. Due to uncertainty in the model selection, we calculated a weighted average of all abundance estimates generated by the models. 
To calculate abundance for different portions of our study area, we created separate datasets including only capture histories for individuals captured within the area of interest. We estimated abundance for each county, but also Garrett and Allegany counties combined, and the portion of the study area from Cumberland (in Allegany County) to the west. We included those areas to facilitate comparisons among the previous Maryland hair snare surveys. To account for our sampling design (i.e., sporadic coverage of the study area), we adjusted our estimates for each area. We assumed that the average abundance per cell of a given probability class was equal throughout all cells of that class. Therefore, we determined the percentage of cells that went unsampled for each cell probability class and inflated our abundance estimates by that factor. Because we could not estimate a true confidence interval on our adjusted estimates, we instead calculated a "probable range" of values that we would reasonably expect the true abundance to fall within. This was based on the average standard error (as a percentage of the estimate) of each cell class abundance estimate, which was then transferred to the adjusted estimates.

Our density calculations were consistent with the previous MDNR estimates. We simply divided abundance by the total area of interest. The nature of our study design did not allow us to use more sophisticated approaches for density estimation, such as spatially-explicit methods (Efford et al. 2004). Our hair snare sampling methods excluded cubs, so our abundance and density estimates only applied to sub-adult and adult bears.

\section{RESULTS}

\section{Predictive Modeling and Site Selection}

Maxent modeling.- We used 254, 54, 20, and 12 bear occurrence locations for the Garrett, Allegany, Washington, and Frederick County models, respectively. The Garrett County 
model had a training $\mathrm{AUC}=0.763$ and a test $\mathrm{AUC}=0.700$. The model for Allegany County had a similar training AUC (0.761) but had a much lower test AUC (0.548), which was nearly as poor as a random model $(\mathrm{AUC}=0.5)$. Our Washington County model had the highest training and test AUCs (0.824 and 0.732, respectively) of any county model. We did not calculate a test AUC for the Frederick County model due to small sample size, but that model had a training $\mathrm{AUC}=0.798$. Cover type contributed more than any other variable for all models except Allegany County, where elevation was most important (Table 2.1). Elevation also was important to the Garrett County model, but relatively unimportant for the other 2 models. Although variable contributions were quite different among the 4 models, distance to nearest stream had low percent contributions (0-6.3\%) for all models.

Sampling site selection.- Overlaying our sampling grid on the combined bear distribution model (Fig. 2.2) revealed the study contained 489 potential sampling cells, with 150 (31\%) in Garrett, 92 (19\%) in Allegany, 105 (21\%) in Washington, and 142 (29\%) in Frederick County (Fig. 2.3). The study area had a relatively even distribution of cell classes (32\% LPCs, 38\% MPCs, 30\% HPCs), but distributions within counties varied. HPCs were most common in Garrett County (37\%) and Washington County (37\%), while MPCs were the most common cell class in Allegany (54\%) and LPCs covered the majority (51\%) of Frederick County. Our stratified random sampling resulted in 75 total cells in Garrett County, 45 in Allegany County, 52 in Washington County, and 73 in Frederick County.

\section{Hair Snare Survey}

We set 240 hair snares throughout the selected cells. However, 1 hair snare was excluded due to improper sample collection. We changed 4 snare locations to randomly-selected cells in the same probability class because inadequate habitat (i.e., forested cover) or lack of property access 
prevented the placement of a hair snare. Seven hair snares were set outside the boundary of the designated cells by a distance of 74-748 $\mathrm{m}$. Those hair snares were classified based on the probability class of the cell within which they were actually set. Two hair snares were set within the same cell in 3 instances. For those cases, the hair snare that collected the least amount of hair samples was excluded from analysis. This resulted in the exclusion of only 1 hair sample.

We included 236 hair snares in our analysis after correcting for errors in hair snare placement or sample collection (Fig. 2.4). These cells covered 48.3 percent of the study area. Of the 236 hair snares, 73 (31\%) were set in Garrett County, 45 (19\%) in Allegany County, 51 (22\%) in Washington County, and 67 (28\%) in Frederick County. Forty (17\%) of the 236 hair snares were set in LPCs, 103 (44\%) in MPCs, and 93 (39\%) in HPCs.

We collected 528 total samples (excluding the sample discarded due to improper snare placement) during the 5-week sampling period (Fig. 2.5), which included samples from nontarget species and duplicate samples (i.e., samples from same individual during the same sampling period). Of those, 273 (51.7\%) were collected in HPCs, 231 (43.8\%) in MPCs, and only 24 (4.5\%) in LPCs. Of the 236 hair snares, hair samples were collected in 103 (43.6\%). Fifty-three (58.9\%) HPCs, 44 (42.7\%) MPCs, and 6 (15\%) LPCs provided hair samples. Seventeen hair snares collected $\geq 10$ samples throughout the sampling period, of which 10 were located in HPCs and 7 in MPCs.

Over half $(53.0 \%)$ of the samples came from Garrett County, whereas $29.9 \%$ came from Allegany County, only 2.7\% from Washington County, and 14.4\% from Frederick County. The number of hair samples collected also varied temporally, with 84 samples collected in the first week of sampling, 86 in week 2, 132 in week 3, 143 in week 4, and 84 in the final week. 


\section{Genetic Analysis}

Microsatellite analysis. - Initial inspection of hair samples found that 74 contained hair from an animal other than black bear, based on species-specific structural features of the hairs. Additionally, 75 lacked observable follicles and 38 consisted of very fine non-guard hairs, preventing successful DNA extraction. Another envelope contained no hair, resulting in 342 samples. or $64.8 \%$ of the total samples collected, that were considered to be from bears. Those samples underwent DNA amplification, where 208 (60.8\%) successfully amplified at all 8 loci. The remaining samples $(n=134)$ amplified at few or no loci. Thirty-eight samples were subjected to second stage analysis (i.e., amplification at 3 additional loci) because they differed at only 1-2 alleles and represented possible matches. None of those samples resulted in new genotypes, indicating that the 8 loci examined initially provided sufficient genetic diversity to identify individuals.

The genetic analysis confirmed the presence of 108 unique genotypes (i.e., individual bears; Appendix A). Forty-five of those individuals produced multiple hair samples. However, only 15 of 108 individuals (13.9\%) were detected during $>1$ sampling period, which is required to be considered a recapture when using mark-recapture techniques. Recaptured individuals accounted for 64 of the 342 bear samples (18.7\%). Only 2 individuals (1.9\%) were recaptured more than once. Sex determination was successful for all 108 individuals, which were comprised of 64 females and 44 males (Appendix A). Recaptured bears had a nearly equal sex $\operatorname{ratio}(7 \mathrm{M}: 8 \mathrm{~F})$.

Statistical analysis. - Sixty-six unique alleles were identified from our bear hair samples (Appendix B) . The number of alleles per locus ranged from 5-12 ( $x \square=8.3$; Table 2.2) and the mean observed heterozygosity was $72.1 \%(56.2-88.9 \%)$. The calculated $P I_{s i b}$ was $4.1 \times 10^{-4}$, 
indicating highly diverse loci. This value means that if we compared the genotypes of 10,000 pairs of full-sibling bears at the 8 loci, we would expect to incorrectly identify 4 of those pairs as 2 unique individuals. Inbreeding coefficients were high (>10.8\%) for 3 of the 8 loci (G10B, G1D, and G10M), and significant genetic linkage disequilibrium was detected in 3 pairs of loci. Consistent with those results, the Structure analysis identified 3 distinct groups of genetically similar bears (Fig. 2.6). One group contained 74 individual bears, whereas the other 2 groups each contained 17 bears (Appendix A). The KINALYZER analysis identified 29 distinct sibling groups within our data. Sibling groups ranged from $2-5$ individuals, with the majority $(69.0 \%)$ made up of just 2 individuals. Only 3 of the sibling groups were comprised of $>3$ individuals.

\section{Spatial Distribution of Bear Samples}

After determining which samples came from bears, we reexamined the distribution of those samples across the study area. Garrett County yielded 207 (60.5\%) of the 342 bear samples, whereas 94 (27.5\%) came from Allegany, 8 (2.3\%) from Washington, and 33 (9.6\%) from Frederick County (Fig. 2.7). Over 95\% of the bear samples came from either HPCS or MPCs (Table 2.3). Accounting for our sampling effort, the number of bear samples collected per sampled cell was 5 times higher for HPCs than LPCs, and 3.5 times higher for MPCs than LPCs. The percentage of sampled LPCs that yielded bear samples was 2.6 times lower than that of MPCs, and nearly 3 times lower than HPCs. Of the 108 individual bears identified, 69 (63.9\%) were sampled in Garrett County, 31 (28.7\%) in Allegany, 3 (2.8\%) in Washington, and 5 (4.6\%) in Frederick (Appendix A).

The sex ratio of identified bears was female-biased for all counties. Although Washington (1 M:2 F) and Frederick counties (2 M:3 F) technically exhibited the most skewed 
ratios, the actual ratios likely differ due to low sample size. Garrett County's sex ratio (28 M:41 F) was more heavily in favor of females than in Allegany County (13 M:18 F).

Of the 15 recaptured individuals, 7 (46.7\%) deposited hair samples at 2 different hair snares. No individuals were detected at $>2$ hair snares. Recaptured males were detected at multiple sights more frequently than recaptured females (57.1\% and 37.5\%, respectively). Three of the 7 individuals (all males) left samples at hair snares that were in adjacent sampling cells, all of which were $<5 \mathrm{~km}$ apart. Interestingly, the 3 farthest distances between detections of the same individual (10.9-26.0 km) were all females.

Some general spatial patterns were evident for the groups identified in the Structure analysis (Fig. 2.8). Most of the individuals classified as being part of group 1 were detected in Garrett County, with 34 hair snares in that county collecting hair samples from those individuals. However, group 1 individuals also were detected at 11 hair snares in Allegany County and 1 hair snare in Washington County. Individuals of group 2 were the most widespread, with samples found in all 4 counties. Frederick County had slightly more snares that detected group 2 bears compared to all other counties, and all individuals identified from Frederick County samples belonged to group 2. Group 3 bears were mostly detected at snares in eastern Garrett and western Allegany County, but 1 hair snare in Washington County also collected a sample from a group 3 bear. Eight hair snares detected individuals from 2 different groups, all of which were located in Garrett or Allegany County, but no snares obtained samples from group 2 and group 3 bears.

\section{Abundance and Density Estimation}

Due to the low number of individual bears identified $(n=8)$ and recaptures $(n=3)$ in Washington and Frederick Counties, we were unable to obtain useful abundance and density 
estimates for those counties. All attempts to do so yielded estimates with extremely low precision, making them effectively unusable to MDNR. Therefore, we excluded data from those counties and only calculated estimates for Garrett County, Allegany County, and Cumberland west.

Our sample size prevented us from examining sex or behavioral effects on capture probability. The top model was $M_{t}$ (time effects) for all areas (Table 2.4), and carried $100 \%$ of the $\mathrm{AIC}_{\mathrm{c}}$ weight $\left(w_{i}\right)$ for Cumberland west, and Garrett and Allegany counties combined. No individual bears were identified from samples collected in LPCs in Allegany County, so we had no estimate for that group. The models estimated very low abundance in the LPCs for all areas $\left(\bar{x}_{w}=10.17-14.87\right)$. The raw weighted average abundance (i.e., abundance in sampled cells) was 234 bears in Garrett County, 139 bears in Allegany County, 375 bears in both counties combined, and 317 bears from Cumberland west. Mean capture probabilities ranged from $0.050-0.067$, with a maximum of 0.128 . Capture probabilities were lowest during the first 2 sampling sessions for all areas.

After adjusting for unsampled cells, the final abundance estimate for Garrett and Allegany counties was 701 adult and sub-adult bears, with a probable range of 513-889 bears (Table 2.5). Abundance in Garrett County was $44 \%$ higher than the abundance in Allegany County. The area from Cumberland west had an abundance estimate of 553 bears, representing $78.9 \%$ of the total estimated abundance. The bear density in Garrett and Allegany counties was 0.25 bears $/ \mathrm{km}^{2}$ ( 64.5 bears $/ 100 \mathrm{mi}^{2}$; Table 2.5 ). In Garrett County alone, the bear density was essentially the same, while density was slightly higher in Allegany County $\left(0.27\right.$ bears $\left./ \mathrm{km}^{2}\right)$, and from Cumberland west $\left(0.26\right.$ bears $\left./ \mathrm{km}^{2}\right)$. 


\section{DISCUSSION}

\section{Predictive Modeling and Hair Snare Survey}

The AUCs for our Maxent models were all above the recommended threshold of 0.7, indicating a useful model (Baldwin 2009), except the test AUC for Allegany County. The low test AUC in that county may just be a result of the consistently high probability of bear occurrence throughout most of the county (Fig. 2.2). Several studies report AUC $>0.9$ when using a Maxent modeling approach (Kaliontzopoulou et al. 2008, Monterroso et al. 2009, Gormley et al. 2011). Lozier et al. (2009) used Maxent to model black bear distribution in the western U.S., and achieved an $\mathrm{AUC}=0.983$. However, they used entirely climate-related variables, which likely have a much greater impact on bear distribution in the western U.S. compared to the eastern U.S. We believe the main explanation for the relatively low AUC for our model is the adaptable and generalist nature of black bears. Black bears are a widespread species that occurs throughout much of the U.S. and Canada (Pelton 2000), illustrating their ability to live in a variety of habitats. Because of their adaptability, we would expect them to be relatively insensitive to differences in habitat and environmental variables, such as the ones we used in our model. Research has shown that Maxent and other species distribution modeling approaches often have less predictive power (i.e., lower AUC) when used for generalist species compared to species that are more specialized in their habitat requirements. Evangelista et al. (2008) compared predictive occurrence model performance for a habitat generalist and habitat specialist plant species. They found that AUC values were higher for the generalist species for all 3 modeling approaches they examined. For Maxent, the AUC for the specialist model was $38 \%$ higher than the AUC for the generalist (0.773 vs. 0.559). Lobo et al. (2008) argued that AUC 
can be a misleading measure of model accuracy when used for generalist species, because the AUC will continue to increase as environmental variables are added.

The availability of occurrence data in Washington and Frederick counties was low compared to the other 2 counties. It is expected that bear density in those counties is much lower than in Allegany and Garrett counties (Spiker and Bittner 2004), so road-kill data is less available. In addition, MDNR employs few scent stations in the eastern counties compared to Garrett and Allegany counties. Despite the small occurrence datasets, AUCs for those models were comparable to the other counties, and the Washington County model had the highest training and test AUCs of all counties. Previous research has shown that Maxent can still provide useful models, even with a low number of occurrence locations. Kumar and Stohlgren (2009) used Maxent to model the distribution of a threatened and endangered tree in New Caledonia. They used only 11 occurrence locations, yet the model had a $91 \%$ success rate (as measured by the omission rate) and was statistically significant. Similarly, Pearson et al. (2007) used Maxent to model 13 species of geckos (Uroplatus spp.) in Madagascar using 4-23 occurrence locations. The resulting models were statistically significant in the jackknife tests and had high success rates with as few as 5 locations.

Our total number of samples collected $(n=528)$, prior to species confirmation, was substantially lower than the number collected during the $2000(n=1200)$ and $2005(n=754)$ data. However, both of those surveys were conducted in the core bear habitat (Garrett and Allegany counties), whereas we also sampled areas expected to have very low bear density in order to test our predictive models. During the 2000 survey, all hair samples were collected, even hair obviously not from bears, resulting in a much higher total number of samples (Bittner et al. 2002). The number of samples determined to be from bears $(n=330)$ was similar to our 
study $(n=342)$. The 2005 survey employed the same sample collection protocol as our study, which relied on staff judgment to reduce the amount of non-target samples. During our survey, we experienced several heavy and prolonged rainfall events. Because we relied on scent lure to attract bears to the hair snares, we believe this weather reduced the number of hair samples by washing away or diluting the molasses. This rain also may have affected bear movements (Garshelis and Pelton 1980), reducing activity and the probability of bears encountering a hair snare.

The rate at which we successfully genotyped samples at the 8 loci $(60.8 \%)$ is slightly lower than the 2000 survey (64.2\%; Bittner et al. 2002) and 2005 survey (68.6\%). Similar genotyping success rates have been reported for other black bear hair snare studies (Table 2.6). Other studies have reported much higher success rates ( $>80 \%)$, but many of those use subsampling techniques to remove low quality samples (e.g., $<5$ hairs, fine hairs). The heavy rains during our survey could be a reason for our lower success rate compared to the other Maryland hair snare surveys (Beier et al. 2005). Brinkman et al. (2005) found that rainfall increased the degradation DNA in fecal samples, reported $80 \%$ genotyping success in protected environments and only $22 \%$ success in exposed areas. Although fecal samples are probably more likely to degrade substantially from rainfall, we expect the rain had at least a small affect on the DNA quality of our samples.

The number of individual bears identified in our study $(n=108)$ is higher than in 2000 ( $n=92$; Bittner et al. 2002) but is much lower than in the 2005 study $(n=167)$. Again, this is likely affected by the different sampling design in our study (i.e., sampling low density areas). We had less individuals that were recaptured $(n=15)$ than in the 2000 and 2005 studies $(n=19$ and 32, respectively). This may be due, in part, to our disjointed sampling of the study area 
compared to the continuous coverage used by the previous studies. Certain hair snare locations in our study were relatively isolated, so bears sampled at those locations would be less likely to be recaptured at other sites. As previously mentioned, the heavy rains we experienced may have reduced bear movements and washed away our scent lure, potentially decreasing the number of recaptures. The female-biased sex ratio in our study is consistent with the 2005 Maryland hair

snare survey ( $68 \mathrm{M}: 85 \mathrm{~F}$ ), but contrary to the nearly equal sex ratio found during the 2000 survey (45 M:43 F). Male-biased sex ratios were reported from hair snare surveys in Louisiana (Triant et al. 2004), Oklahoma (Gardner-Santana 2007), New Hampshire (Coster 2008), North Carolina (Tredick and Vaughan 2009), and Virginia (Tredick and Vaughan 2009). In Louisiana, Lowe (2011) documented a female-biased sex ratio (26 M:44 F) when using a single strand of barbed wire, but a nearly equal ratio ( $20 \mathrm{M}: 22 \mathrm{~F}$ ) when using 2 strands. Our use of a single strand may have some effect on our sex ratio results if capture probabilities differ between sexes.

Our use of Maxent models to increase the efficiency of our sampling showed promise (Table 2.3). In terms of the number of bear samples collected per cell, this technique worked well and presumably allowed us to obtain more hair samples than if the cell classes were sampled equally. However, not having continuous coverage of the study area, as in the 2000 and 2005 Maryland hair snare surveys, negatively affected our recapture rates.

\section{Genetic Diversity and Population Structure}

The levels of allelic diversity and heterozygosity in our study were comparable to those of bear populations in Wisconsin (Belant et al. 2005) and South Carolina (Drewry 2010). The Maryland population had more genetic diversity than bears in Louisiana (Boersen et al. 2003, Lowe 2011) and Florida (Dixon et al. 2007), but was slightly less diverse than bears in Idaho (Schwartz et al. 2006) and Oklahoma (Gardner-Santana 2007). The states surrounding our study area 
(Pennsylvania, West Virginia, and Virginia) all have healthy bear populations and bear movement is known to occur among Maryland, Pennsylvania, and West Virginia (Bittner et al. 2002). This mixing of bear populations helps maintain a relatively high level of genetic diversity in Maryland bears. High inbreeding coefficients can indicate the presence of either inbreeding or population structure. We feel that inbreeding in the Maryland bear population is likely negligible based on the relatively abundant bear populations in areas surrounding the study area (i.e., lack of population isolation), and the male-biased dispersal of bears that serves as a means of inbreeding avoidance (Costello et al. 2008).

Our observed inbreeding coefficients, linkage disequilibrium, and Structure analysis suggest there is some level of population structure in western Maryland. Structure analysis identified 3 distinct genetic groups, but none of the groups showed distinct geographic isolation. Although expansion of the bear population likely has occurred from Garrett and Allegany counties into Washington and Frederick counties, there are reports that bears recolonized parts of western Frederick County as early as the 1970s (H. A. Spiker, MDNR, personal communication). Bears belonging to genetic group 2 were detected in all 4 counties, but bears in Frederick County all belonged to that group. This suggests that Frederick County bears may have been relatively isolated from the rest of the Maryland bears. It is possible that the genetic groups classified by our Structure analysis are a result of family groups within the population, as identified by our KINALYZER results, and not true population structure. Higher sample sizes, especially in the eastern counties of the study area, would provide a better understanding of any possible population structure. 


\section{Abundance and Density Estimates}

Our total abundance estimate $(N=701)$ represented a $93.6 \%$ population increase, and $11.6 \%$ annual increase, since the 2005 Maryland hair snare survey (Table 2.7). The Garrett County estimate shows a 52.3\% (7.3\% annual) increase since 2005. Allegany County exhibited dramatic growth, with a $235.2 \%$ overall increase and $22.3 \%$ annual increase. Growth from Cumberland to the west since 2005 was similar to Garrett County, increasing by $9.2 \%$ annually $(69.6 \%$ overall). Our density estimates fall on the lower end of bear densities recently reported in the Southeast and Mid-Atlantic regions (Table 2.8).

Our abundance estimates seem reasonable for the Maryland bear population based on harvest levels and trends monitored by MDNR. MDNR tracks road-kills and other non-seasonal mortality, as well as visitation rates at scent stations placed in the 4 counties in the study area. From 2005-2010, 323 bears (40-68 bears/yr) were harvested in Garrett and Allegany counties. Despite removing those individuals from the population, non-seasonal mortalities during that time still showed a slight increasing trend and scent station visitation rates increased in Garrett and Allegany counties (Spiker 2012). Although non-seasonal mortalities are beginning to stabilize in Garrett and western Allegany counties, they are increasing in the rest of Allegany County. Visitation rates increased much more in Allegany County than Garrett County, which matches our estimates of population growth in those counties.

Harvest distribution in those counties also corroborates our estimates. Of the 323 bear harvests, only $13.0 \%$ of bear harvests occurred in Allegany County, and only $2.2 \%$ occurred east of Cumberland, MD. This low harvest pressure likely played a role in allowing the bear population to increase at a much higher rate than Garrett County. In addition to relatively low harvest pressure, population productivity affects abundance. Female bears in the eastern U.S. 
tend to have larger litter sizes than those in the western U.S. (Bridges et al. 2011), and the longterm mean litter size in Maryland ( $\bar{x}=2.9$ cubs; Spiker 2012) is on the high end of reported reproductive output in the region (Bridges et al. 2011).

We hoped to obtain abundance and density estimates for Washington and Frederick counties, but our low sample size and recapture rate prevented us from doing so. Although bear density is much lower in those counties compared to Garrett and Allegany, we believe bear abundance is sufficient for estimating abundance. Instead, the issues are likely due to detection of those individuals. It seems our sampling design did not allow for adequate coverage of these counties, and resulting capture probabilities were too low to calculate useful estimates. Boulanger et al. (2002) recommended capture probabilities $>0.20$ for population sizes around 100 individuals. White et al. (1982) suggested that a minimum capture probability of 0.10 (preferably $>0.20$ ) was required to reliably estimate (i.e., with high accuracy and precision) populations of 50 to several hundred individuals. They also explain that minimum capture probabilities are high for small populations, and lower for large populations. Our average capture probability for all areas ranged from $0.05-0.07$, below the recommended minimum. This reduced the precision of all our estimates. For Washington and Frederick counties, it is likely there is a minimum sampling effort required to attain adequate capture probability. Our incomplete coverage of those counties apparently did not meet that minimum effort.

\section{MANAGEMENT IMPLICATIONS}

This study provides MDNR with bear abundance and density estimates, which are critical for the proper management of Maryland's bear population. Based on our estimates and MDNRs goal of slowing bear population growth in western Maryland, we recommend increasing harvest quotas for future bear hunting seasons. Our estimates of annual population growth will allow MDNR to 
define specific quotas to meet their goals for overall bear mortality rate. Our description of the spatial distribution of bear abundance gives MDNR more information to make decisions and possible adjustments to the population management and harvest strategies in the state. In response to the dramatic population growth we report in Allegany County and the low harvest levels in that county, attempts should be made to increase harvest there and slow population growth. Options include setting separate quotas for Garrett and Allegany counties, or creating county-specific bear permits. Additionally, informing bear hunters of the high Allegany County bear density, and increasing hunting opportunities through improved hunter access may increase harvest levels.

Our model-based sampling design essentially presents a tradeoff between precision of estimates and sampling effort and cost. To decide if this technique is feasible for a particular study, it is important to first determine the research goals and limitations. In cases where funding and manpower limit the use of NGS, we believe the general technique described in this study can be an efficient and cost-effective alternative to the traditional intensive sampling approach, especially for sampling over large areas. Requirements for this approach (e.g., occurrence data, environmental data) are minimal, and often are readily-available to researchers and managers. If possible, we recommend conducted a small pilot study to determine the minimal trap density required to achieve the desired capture and recapture probabilities.

If the goal is to obtain highly accurate and precise abundance estimates, and budget concerns are not as limiting, we suggest using a traditional NGS design (i.e., continuous grid). We also recommend using those techniques if the population of interest occurs at low densities, as our model-based design was unable to produce useful estimates for counties with presumed 
low bear densities. Traditional grid designs have been successfully used in countless NGS, and represent the best available option if financially feasible.

\section{ACKNOWLEDGMENTS}

Funding for this project was provided by the Maryland Department of Natural Resources and West Virginia University Division of Forestry. Thank you to MDNR personnel, Maryland Conservation Corps, and L. Moon for data collection, and landowners for allowing property access. We thank T. King and the staff at the USGS Aquatic Ecology Laboratory for their genetic analysis. Thank you to C. Ryan and R. Martin for their review of our MARK analysis.

\section{LITERATURE CITED}

Ashley, M. V., I. C. Caballero, W. Chaovalitwongse, B. Dasgupta, P. Govindan, S. I. Sheikh, and T. Y. Berger-Wolf. 2009. KINALYZER, a computer program for reconstructing sibling groups. Molecular Ecology Resources 9:1127-1131.

Beier, L. R., S. B. Lewis, R. W. Flynn, G. Pendleton, and T. V. Schumacher. 2005. A single-catch snare to collect brown bear hair for genetic mark-recapture studies. Wildlife Society Bulletin 33:766-773.

Belant, J. L., J. F. Van Stappen, and D. Paetkau. American black bear population size and genetic diversity at Apostle Islands National Lakeshore. Ursus 16:85-92.

Beyer. H. L. 2004. Hawth's analysis tools for ArcGIS. <http://www.spatialecology.com>. Accessed 8 August 2010.

Bittner, S. L., T. L. King, and W. F. Harvey. 2002. Estimating Maryland's black bear population. Proceedings Annual Conference of Southeast Association of Fish and Wildlife Agencies. 
Boerson, M. R., J. D. Clark, and T. L. King. 2003. Estimating black bear population density and genetic diversity at Tensas River, Louisiana using microsatellite DNA markers. Wildlife Society Bulletin 31:197-207.

Boulanger, J., G. C. White, B. N. McLellan, J. Woods, M. Proctor, and S. Himmer. 2002. A meta-analysis of grizzly bear DNA mark-recapture projects in British Columbia, Canada. Ursus 13:137-152.

Bridges, A. S. 2005. Population ecology of black bears in the Alleghany Mountains of Virginia. Dissertation, Virginia Polytechnic Institute and State University, Blacksburg, USA.

Bridges, A. S., M. R. Vaughan, and J. A. Fox. 2011. American black bear estrus and parturition in the Alleghany Mountains of Virginia. Ursus 22:1-8.

Brinkman, T. J., M. K. Schwartz, D. K. Person, K. L. Pilgrim, and K. J. Hundertmark. 2010. Effects of time and rainfall on PCR success using DNA extracted from deer fecal pellets. Conservation Genetics 11:1547-1552.

Clark, J. D., J. E. Dunn, and K. G. Smith. 1993. A multivariate model of female black bear habitat use for a Geographic Information System. Journal of Wildlife Management 57:519-526.

Costello, C. M. 2008. The spatial ecology and mating system of black bears (Ursus americanus) in New Mexico. Dissertation, Montana State University, Bozeman, USA.

Coster, S. 2008. Use of genetic tagging to estimate abundance and detect spatial patterns of black bears in New Hampshire. Thesis, University of New Hampshire, Durham, USA.

Dixon, J. D., M. K. Oli, M. C. Wooten, T. H. Eason, J. W. McCown, and M. W. Cunningham. 2007. Genetic consequences of habitat fragmentation and loss: the case of the Florida black bear (Ursus americanus floridanus). Conservation Genetics 8:455-464. 
Dreher, B. P., S. R. Winterstein, K. T. Scribner, P. M. Lukacs, D. R. Etter, G. J. M. Rosa, V. A. Lopez, S. Libants, and K. B. Filcek. 2007. Noninvasive estimation of black bear abundance incorporating genotyping errors and harvested bear. Journal of Wildlife Management 71:2684-2693.

Drewry, J. M. 2010. Population abundance and genetic structure of black bears in coastal South Carolina. Thesis, University of Tennessee, Knoxville, USA.

Edwards, Jr., T. C., D. R. Cutler, N. E. Zimmermann, L. Geiser, and J. Alegria. 2005. Modelbased stratifications for enhancing the detection of rare ecological events. Ecology $86: 1081-1090$.

Elith, J., C. H. Graham, R. P. Anderson, M. Dudik, S. Ferrier, A. Guisan, R. J. Hijmans, F. Huettman, J. R. Leathwick, A. Lehmann, J. Li, L. G. Lohmann, B. A. Loiselle, G. Manion, C. Moritz, M. Nakamura, Y. Nakazama, J. McC. Overton, A. T. Peterson, S. J. Phillips, K. S. Richardson, R. Scachetti-Pereira, R. E. Schapire, J. Sobero’n, S. Williams, M. S. Wisz, and N. E. Zimmermann. 2006. Novel methods improve prediction of species' distributions from occurrence data. Ecography 29:129-151.

Elith, J., S. J. Phillips, T. Hastie, M. Dudik, Y. E. Chee, and C. J. Yates. 2011. A statistical explanation of MaxEnt for ecologists. Diversity and Distributions 17:43-57.

Evangelista, P. H., S. Kumar, T. J. Stohlgren, C. S. Jarnevich, A. W. Crall, J. B. Norman III, and D. T. Barnett. 2008. Modelling invasion for a habitat generalist and a specialist plant species. Diversity and Distributions 14:808-817.

Gardner, B., J. A. Royle, M. T. Wegan, R. E. Rainbolt, and P. D. Curtis. 2010. Estimating black bear density using DNA data from hair snares. Journal of Wildlife Management $74: 318-325$. 
Gardner-Santana, L. C. 2007. Patterns of genetic diversity in black bears (Ursus americanus) during a range expansion into Oklahoma. Thesis, Oklahoma State University, Stillwater, USA.

Garshelis, D. L. 2006. On the allure of noninvasive genetic sampling - putting a face to the name. Ursus 17:109-123.

Garshelis, D. L., and M. R. Pelton. 1980. Activity of black bears in the Great Smoky Mountains National Park. Journal of Wildlife Mammalogy 61:8-19.

Gormley, A. M., D. M. Forsyth, P. Griffioen, M. Lindeman, D. S. L. Ramsey, M. P. Scroggie, and L. Woodford. 2011. Using presence-only and presence-absence data to estimate the current and potential distributions of established invasive species. Journal of Applied Ecology 48:25-34.

Guisan, A., O. Broennimann, R. Engler, M. Vust, N. G. Yoccoz, A. Lehmann, and M. E. Zimmermann. 2006. Using niche-based models to improve the sampling of rare species. Conservation Biology 20:501-511.

Huffman, J. E., T. Ombrello and D. Zellner. 2010. Evaluation of genetic structure and population estimate in New Jersey black bears (Ursus americanus). Northeast Wildlife DNA Laboratory, East Stroudsburg University, East Stroudsburg, PA.

Huggins, R. M. 1989. On the statistical analysis of capture-recapture experiments. Biometrika $76: 133-140$.

Huggins, R. M. 1991. Some practical aspects of a conditional likelihood approach to capture experiments. Biometrics 47:725-732.

Kaliontzopoulou, A., J. C. Brito, M. A. Carretero, S. Larbes, and D. J. Harris. 2008. Modelling the partially unknown distribution of wall lizards (Podarcis) in North Africa: ecological 
affinities, potential areas of occurrence, and methodological constraints. Canadian Journal of Zoology 86:992-1001.

Kendall, K. C., J. B. Steltz, J. Boulanger, A. C. Macleod, D. Paetkau, and G. C. White. 2009. Demography and genetic structure of a recovering grizzly bear population. Journal of Wildlife Management 73:3-16.

Kumar, S., and T. J. Stohlgren. 2009. Maxent modeling for predicting suitable habitat for threatened and endangered tree Canacomyrica monticola in New Caledonia. Journal of Ecology and Natural Environment 1:94-98.

Laufenberg, J. S. 2010. Effect of subsampling genotyped hair samples on model averaging to estimate black bear population abundance and density. Thesis, University of Tennessee, Knoxville, USA.

Lobo, J. M., A. Jiménez-Valverde, and R. Real. 2007. AUC: a misleading measure of the performance of predictive distribution models. Global Ecology and Biogeography $17: 145-151$.

Lozier, J. D., P. Aniello, and M. J. Hickerson. 2009. Predicting the distribution of Sasquatch in western North America: anything goes with ecological niche modeling. Journal of Biogeography 36:1623-1627.

Lotek Wireless Fish and Wildlife Monitoring. 2005. Small and midsize animals GPS location system user's manual GPS_3300.

Lowe, C. L. 2011. Estimating population parameters of the Louisiana black bear in the Upper Atchafalaya River Basin. Thesis, University of Tennessee, Knoxville, USA. 
McKelvey, K. S., and M. K. Schwartz. 2004. Genetic errors associated with population estimation using non-invasive molecular tagging: problems and new solutions. Journal of Wildlife Management 68:439-448.

Meredith, E. P., J. A. Rodzen, J. D. Banks, and K. C. Jones. 2009. Characterization of 29 tetranucleotide microsatellite loci in black bear (Ursus americanus) for use in forensic and population applications. Conservation Genetics 10:693-696.

Monterroso, P., J. C. Brito, P. Ferreras, and P. C. Alves. 2009. Spatial ecology of the European wildcat in a Mediterranean ecosystem: dealing with small radio-tracking datasets in species conservation. Journal of Zoology 279:27-35.

Ortega-Huerta, M. A., and A. T. Peterson. 2008. Modeling ecological niches and predicting geographic distributions: a test of six presence-only methods. Revista Mexicana de Biodiversidad 79:205-216.

Paetkau, D., and C. Strobeck. 1994. Microsatellite analysis of genetic variation in black bear populations. Molecular Ecology 3:489-495.

Paetkau, D., W. Calvert, I. Stirling, and C. Strobeck. 1995. Microsatellite analysis of population structure in Canadian polar bears. Molecular Ecology 4:347-354.

Peakall, R., and P. E. Smouse. 2006. GENALEX 6: genetic analysis in Excel. Population genetic software for teaching and research. Molecular Ecology Notes 6:288-295.

Pearson, R. G., C. J. Raxworthy, M. Nakamura, and A. T. Peterson. 2007. Predicting species distributions from small numbers of occurrence records: a test case using cryptic geckos in Madagascar. Journal of Biogeography 34:102-117.

Pelton, M. R. 2000. Black bear. Pages 547-555 in G. A. Feldhamer, B. C. Thompson, and J. A. Chapman, editors. Wild mammals of North America: biology, management, and 
conservation. Second edition. The John Hopkins University Press, Baltimore, Maryland, USA.

Peterson, A. T., M. Papes, and M. Eaton. 2007. Transferability and model evaluation in ecological niche modeling: a comparison of GARP and Maxent. Ecography 30:550-560.

Phillips, S. J., M. Dudik, and R. E. Schapire. 2004. A maximum entropy approach to species distribution modeling. Proceedings of twenty-first International Conference on Machine Learning.

Phillips, S. J., R. P. Anderson, and R. E. Schapire. 2006. Maximum entropy modeling of species geographic distributions. Ecological Modelling 190:231-259.

Pritchard, J. K., M. Stephens, and P. Donnelly. 2000. Inference of population structure using multilocus genotype data. Genetics 155:945-959.

Rachlow, J. L., and L. K. Svancara. 2006. Prioritizing habitat for surveys of an uncommon mammal: a modeling approach applied to pygmy rabbits. Journal of Mammalogy $87: 827-833$.

Robinson, S. J., L. P. Waits, and I. D. Martin. 2009. Estimating abundance of American black bears using DNA-based capture-mark-recapture models. Ursus 20:1-11.

Schwartz, M. K., S. A. Cushman, K. S. McKelvey, J. Hayden, and C. Engkjer. 2006. Detecting genotyping errors and describing American black bear movement in northern Idaho. Ursus 17:138-148.

Settlage, K. E. 2005. Efficacy of DNA sampling to monitor population abundance of black bears in the southern Appalachians. Thesis, University of Tennessee, Knoxville, USA. Spiker, H. 2012. Maryland black bear population status report. Maryland Department of Natural Resources, Wildlife and Heritage Service, Oakland, USA. 
Spiker. Jr., H. A., and S. L. Bittner. 2004. Wildlife and Heritage Service black bear management plan 2004-2013. Maryland Department of Natural Resources Wildlife and Heritage Service.

Taberlet, P., H. Mattock, C. Dubois-Paganon, and J. Bouvet. 1993. Sexing free-ranging brown bears Ursus arctos using hairs found in the field. Molecular Ecology 2:399-403.

Tredick, C. A., and M. R. Vaughan. 2009. DNA-based population demographics of black bears in coastal North Carolina and Virginia. Journal of Wildlife Management 73:1031-1039.

Triant, D. A., R. M. Pace III, and M. Stine. 2004. Abundance, genetic diversity, and conservation of Louisiana black bears (Ursus americanus luteolus) as detected through noninvasive sampling. Conservation Genetics 5:647-659.

U.S. Census Bureau. 2010. Census 2010 summary file 1, geographic header record G001. U.S.

Census Bureau, Washington, D.C., USA.

U.S. Department of Agriculture Forest Service [USFS]. 1999. Northeastern forest and inventory analysis. Maryland statewide results. <http://www.fs.fed.us/ne/fia/states/md/ index.html> Accessed $11 \mathrm{Feb} 2010$.

Warren, D. L., R. E. Glor, and M. Turelli. 2010. ENMTools: a toolbox for comparative studies of environmental niche models. Ecography 33:607-611.

White, G. C., D. R. Anderson, K. P. Burnham, and D. L. Otis. 1982. Capture-recapture and removal methods for sampling closed populations. Los Alamos National Laboratory, Los Alamos, New Mexico, USA.

White, G. C., and K. P. Burnham. 1999. Program MARK: survival estimation from populations of marked animals. Bird Study 46:120-139. 
Woods, J. G., D. Paetkau, D. Lewis, B. N. McLellan, M. Proctor, and C. Strobeck. 1999. Genetic tagging of free-ranging black and brown bears. Wildlife Society Bulletin $27: 616-627$.

Associate Editor: 
Table 2.1. Percent contribution of environmental variables to predictive black bear occurrence models for 4 counties in western Maryland, USA.

\begin{tabular}{lcccc}
\hline & \multicolumn{4}{c}{$\%$ contribution } \\
\cline { 2 - 5 } Variable & $\begin{array}{c}\text { Garrett } \\
\text { County }\end{array}$ & $\begin{array}{c}\text { Allegany } \\
\text { County }\end{array}$ & $\begin{array}{c}\text { Washington } \\
\text { County }\end{array}$ & $\begin{array}{c}\text { Frederick } \\
\text { County }\end{array}$ \\
\hline Aspect & 2.8 & 11.9 & 11.5 & 8.2 \\
Cover type & 32.5 & 23.2 & 52.1 & 67.4 \\
Cover type diversity & 4.1 & 6.3 & 4.3 & 14.5 \\
Distance to nearest stream & 6.2 & 6.1 & 0.0 & 0.0 \\
Elevation & 30.4 & 26.7 & 1.7 & 9.8 \\
Slope & 24.1 & 25.8 & 30.4 & 0.0 \\
\hline
\end{tabular}


Table 2.2. Number of alleles, heterozygosity, and inbreeding coefficients for black bear hair samples collected in western Maryland, USA in summer 2011.

\begin{tabular}{lrrrccr}
\hline Locus & $n^{\mathrm{a}}$ & $\mathrm{N}_{\mathrm{a}}^{\mathrm{b}}$ & $\mathrm{N}_{\mathrm{e}}{ }^{\mathrm{c}}$ & $\mathrm{H}_{\mathrm{o}}{ }^{\mathrm{d}}$ & $\mathrm{H}_{\mathrm{e}}{ }^{\mathrm{e}}$ & \multicolumn{1}{c}{$\mathrm{F}^{\mathrm{f}}$} \\
\hline G1A & 106 & 5 & 3.747 & 0.755 & 0.737 & -0.029 \\
G10B & 105 & 6 & 3.586 & 0.562 & 0.725 & 0.221 \\
G10C & 107 & 8 & 3.289 & 0.738 & 0.699 & -0.061 \\
G1D & 106 & 7 & 3.359 & 0.575 & 0.706 & 0.181 \\
G10L & 107 & 12 & 8.201 & 0.888 & 0.882 & -0.011 \\
G10M & 97 & 8 & 3.533 & 0.639 & 0.721 & 0.108 \\
G10P & 96 & 9 & 4.946 & 0.802 & 0.802 & -0.005 \\
G10X & 98 & 11 & 5.671 & 0.806 & 0.828 & 0.021 \\
\hline
\end{tabular}

${ }^{a}$ Number of individuals identified using the given locus.

${ }^{\mathrm{b}}$ Number of observed alleles.

${ }^{c}$ Effective number of alleles.

${ }^{\mathrm{d}}$ Observed heterozygosity.

${ }^{\mathrm{e}}$ Unbiased expected heterozygosity.

${ }^{\mathrm{f}}$ Inbreeding coefficient, calculated as $\left(\mathrm{H}_{\mathrm{e}}-\mathrm{H}_{\mathrm{o}}\right) / \mathrm{H}_{\mathrm{e}}$. 
Table 2.3. Black bear hair samples collected during a Maryland, USA hair snare survey in summer 2011, separated by sampling cell classifications as determined from predictive black bear occurrence model.

\begin{tabular}{lccccc}
\hline $\begin{array}{c}\text { Probability } \\
\text { class }^{\mathrm{a}}\end{array}$ & $\begin{array}{c}\text { No. } \\
\text { successful } \\
\text { cells }^{\mathrm{b}}\end{array}$ & $\begin{array}{c}\text { \% cells } \\
\text { successful }\end{array}$ & $\begin{array}{c}\text { No. bear } \\
\text { samples }\end{array}$ & $\begin{array}{c}\text { \% total } \\
\text { samples }\end{array}$ & $\begin{array}{c}\text { Bear samples } \\
\text { per cell }\end{array}$ \\
\hline High & 43 & 35.5 & 183 & 53.5 & 2.0 \\
Medium & 33 & 32.0 & 145 & 42.4 & 1.4 \\
Low & 5 & 12.5 & 14 & 4.1 & 0.4 \\
\hline${ }^{\mathrm{a}}$ Represents & 5 & & &
\end{tabular}

${ }^{a}$ Represents high, medium, or low, relative probability of bear occurrence based on Maxent models.

${ }^{\mathrm{b}}$ Sampled cells with hair snares that collected $\geq 1$ bear hair sample. 
Table 2.4. MARK results for individuals identified from a hair snare survey in western Maryland, USA in summer 2011.

\begin{tabular}{lcclrrr}
\hline \multicolumn{1}{c}{ Area } & Model & \multicolumn{1}{c}{$w_{i}^{c}$} & $\begin{array}{c}\text { Probability } \\
\text { class }^{\mathrm{d}}\end{array}$ & \multicolumn{1}{c}{$N$} & \multicolumn{1}{c}{ SE } & Weighted avg. \\
\hline Garrett and Allegany & $M_{t}^{\mathrm{a}}$ & 1.00000 & High & 182.05 & 48.80 & 182.05 \\
counties & $M_{t}$ & 1.00000 & Medium & 178.45 & 47.97 & 178.45 \\
& $M_{t}$ & 1.00000 & Low & 14.87 & 7.28 & 14.87 \\
Garrett County & & & & & & \\
& $M_{t}$ & 0.99997 & High & 111.77 & 34.28 & 111.77 \\
& $M_{o}{ }^{\mathrm{b}}$ & 0.00003 & & 121.63 & 38.03 & \\
& $M_{t}$ & 0.99997 & Medium & 111.84 & 34.31 & 111.84 \\
& $M_{o}$ & 0.00003 & & 122.06 & 38.28 & \\
Allegany County & $M_{t}$ & 0.99997 & Low & 10.17 & 5.64 & 10.17 \\
& $M_{o}$ & 0.00003 & & 11.10 & 6.27 & \\
& & & & & & \\
& $M_{t}$ & 0.80730 & High & 35.21 & 20.55 & 35.74 \\
& $M_{o}$ & 0.19270 & & 37.98 & 22.44 & \\
& $M_{t}$ & 0.80730 & Medium & 101.32 & 53.43 & 102.93 \\
& $M_{o}$ & 0.19270 & & 109.68 & 58.75 & \\
& & & & & & \\
& $M_{t}$ & 1.00000 & High & 145.88 & 40.85 & 145.88 \\
& $M_{t}$ & 1.00000 & Medium & 160.22 & 44.45 & 160.22 \\
& $M_{t}$ & 1.00000 & Low & 10.68 & 5.86 & 10.68 \\
\hline
\end{tabular}

${ }^{a}$ Time effect; capture probability differs between and among sessions.

${ }^{b}$ Null; constant capture probability.

${ }^{\mathrm{c}} \mathrm{AIC}_{\mathrm{c}}$ weight.

${ }^{\mathrm{d}}$ Relative probability of bear occurrence based on Maxent occurrence models. 
Table 2.5. Abundance estimates and adjustment factors for black bears in western Maryland, USA in summer 2011.

\begin{tabular}{|c|c|c|c|c|c|c|}
\hline Area & Probability $^{\mathrm{a}}$ & $N_{\text {MARK }}{ }^{\mathrm{b}}$ & $\begin{array}{l}\text { Adjustment } \\
\text { factor }^{\mathrm{c}}\end{array}$ & $N_{\text {adj }}$ & Total & $\begin{array}{l}\text { Probable } \\
\text { range }\end{array}$ \\
\hline \multirow{3}{*}{$\begin{array}{l}\text { Garrett and Allegany } \\
\text { counties }\end{array}$} & High & 182.05 & 1.63 & 296.20 & \multirow{3}{*}{701} & \multirow{3}{*}{$513-889$} \\
\hline & Medium & 178.45 & 1.94 & 346.73 & & \\
\hline & Low & 14.87 & 3.93 & 58.42 & & \\
\hline \multirow[t]{3}{*}{ Garrett County } & High & 111.77 & 1.77 & 198.28 & \multirow[t]{3}{*}{425} & \multirow[t]{3}{*}{$295-555$} \\
\hline & Medium & 111.84 & 1.66 & 185.21 & & \\
\hline & Low & 10.17 & 4.10 & 41.70 & & \\
\hline \multirow[t]{2}{*}{ Allegany County } & High & 35.74 & 1.40 & 50.04 & \multirow[t]{2}{*}{295} & \multirow[t]{2}{*}{$131-459$} \\
\hline & Medium & 102.93 & 2.38 & 244.97 & & \\
\hline \multirow[t]{3}{*}{ Cumberland west } & High & 145.88 & 1.61 & 234.87 & \multirow[t]{3}{*}{553} & \multirow[t]{3}{*}{$399-707$} \\
\hline & Medium & 160.22 & 1.71 & 273.98 & & \\
\hline & Low & 10.68 & 4.10 & 43.79 & & \\
\hline \multicolumn{7}{|c|}{ models. } \\
\hline \multicolumn{7}{|c|}{${ }^{\mathrm{b}}$ Weighted average abundance estimate from MARK. } \\
\hline \multicolumn{7}{|c|}{${ }^{\mathrm{c} A c c o u n t s}$ for unsampled cells of the same probability class. } \\
\hline${ }^{\mathrm{d}}$ Based on mean SE o & MARK estima & & & & & \\
\hline
\end{tabular}


Table 2.6. Genotype success rates reported from noninvasive genetic studies of black bears.

\begin{tabular}{llcc}
\hline \multicolumn{1}{c}{ Author(s) } & \multicolumn{1}{c}{ State(s) } & $\begin{array}{c}\text { Genotyping } \\
\text { Success (\%) }\end{array}$ & Subsampling \\
\hline Belant et al. (2005) & Wisconsin & 69 & No \\
Drewry (2010) & South Carolina & 84 & Yes \\
Lowe (2011) & Louisiana & 61 & Yes \\
Robinson et al. (2009) & Alaska & 55 & No \\
Settlage (2005) & Tennessee & 82 & Yes \\
Tredick and Vaughan & North Carolina, & 83 & Yes \\
(2009) & Virginia & & \\
\hline
\end{tabular}


Table 2.7. Abundance and density estimates derived from black bear hair snare surveys in western Maryland, USA from 2000, 2005, and 2011.

\begin{tabular}{lccc}
\hline \multicolumn{1}{c}{ Area } & Survey year & $N^{\mathrm{a}}$ & $\begin{array}{c}\text { Density } \\
\left.\text { (bears } / \mathrm{km}^{2}\right)\end{array}$ \\
\hline $\begin{array}{l}\text { Garrett and Allegany } \\
\text { counties }\end{array}$ & 2005 & 362 & 0.13 \\
& 2011 & 701 & 0.25 \\
Garrett County & 2005 & 279 & 0.16 \\
& 2011 & 425 & 0.25 \\
Allegany County & & & \\
& 2005 & 88 & 0.08 \\
Cumberland west & 2011 & 295 & 0.27 \\
& 2000 & 227 & 0.11 \\
& 2005 & 326 & 0.15 \\
& 2011 & 553 & 0.26 \\
\hline
\end{tabular}

\footnotetext{
${ }^{a}$ Abundance estimates from 2011 are extrapolated to account for unsampled areas.
} 
Table 2.8. Black bear densities for Mid-Atlantic and Southeastern U.S. states since 2005.

\begin{tabular}{llc}
\hline \multicolumn{1}{c}{ Author(s) } & \multicolumn{1}{c}{ State } & $\begin{array}{c}\text { Density } \\
\left.\text { (bears } / \mathrm{km}^{2}\right)\end{array}$ \\
\hline Bridges (2005) & Virginia & 0.98 \\
Dobey et al. (2005) & Florida & 0.13 \\
Drewry et al. (2012) & South Carolina & 0.17 \\
Gardner et al. (2010) & New York & 0.20 \\
Tredick and Vaughan (2009) & North Carolina & 0.68 \\
\hline
\end{tabular}




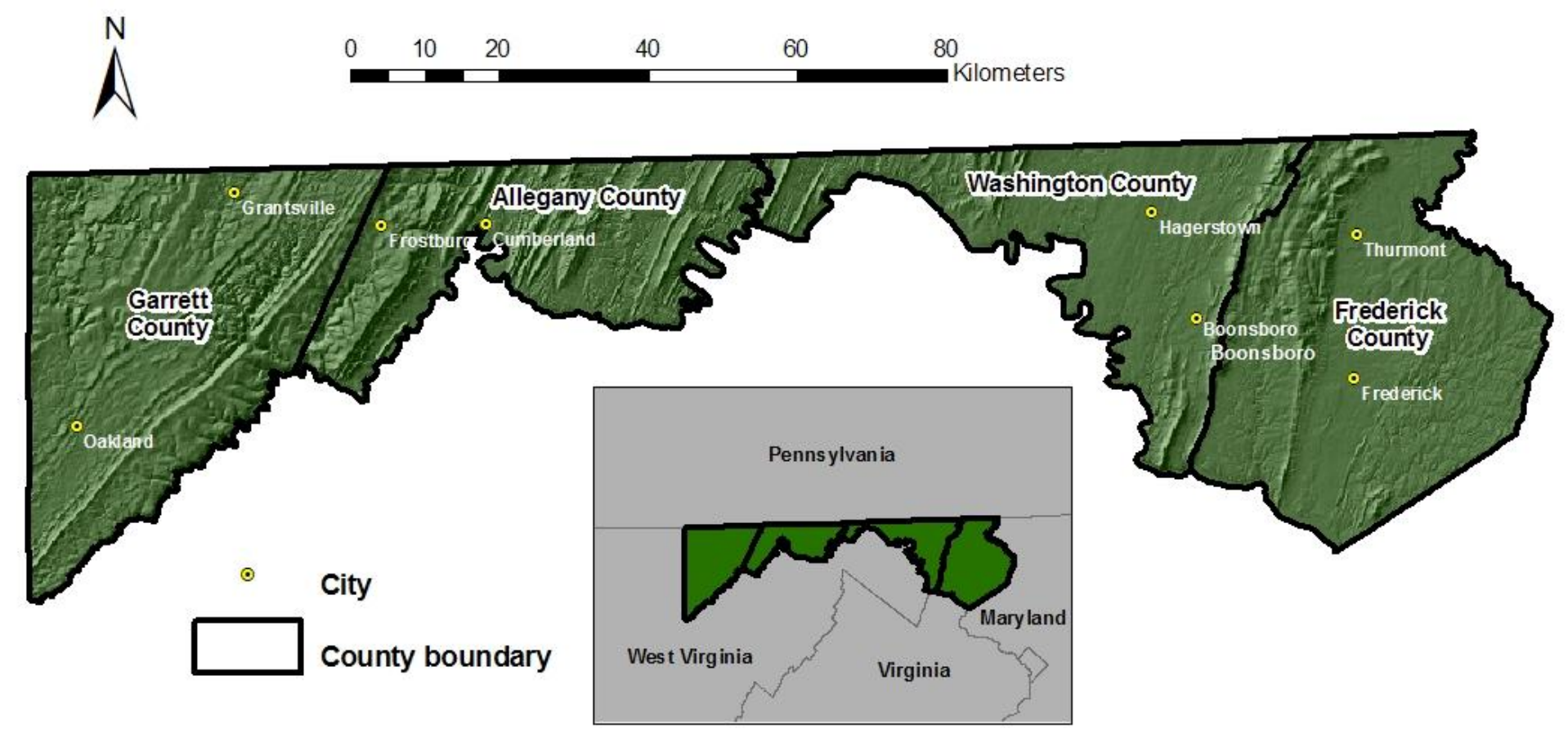

Figure 2.1. Study area comprised of the 4 westernmost counties of Maryland, USA. 


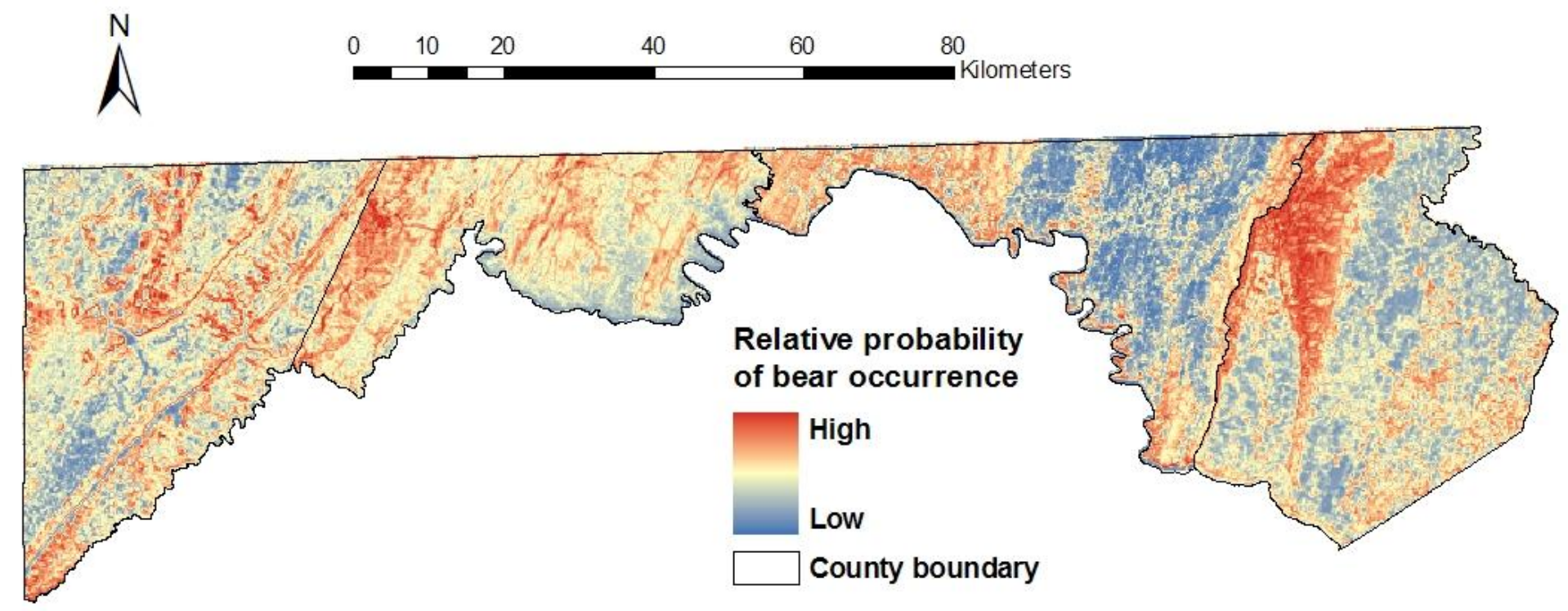

Figure 2.2. Maxent predictive summer occurrence model for black bears in western Maryland, USA. This combined model was produced by merging separate Maxent models created for each county, so probability of occurrence is relative within each county. 


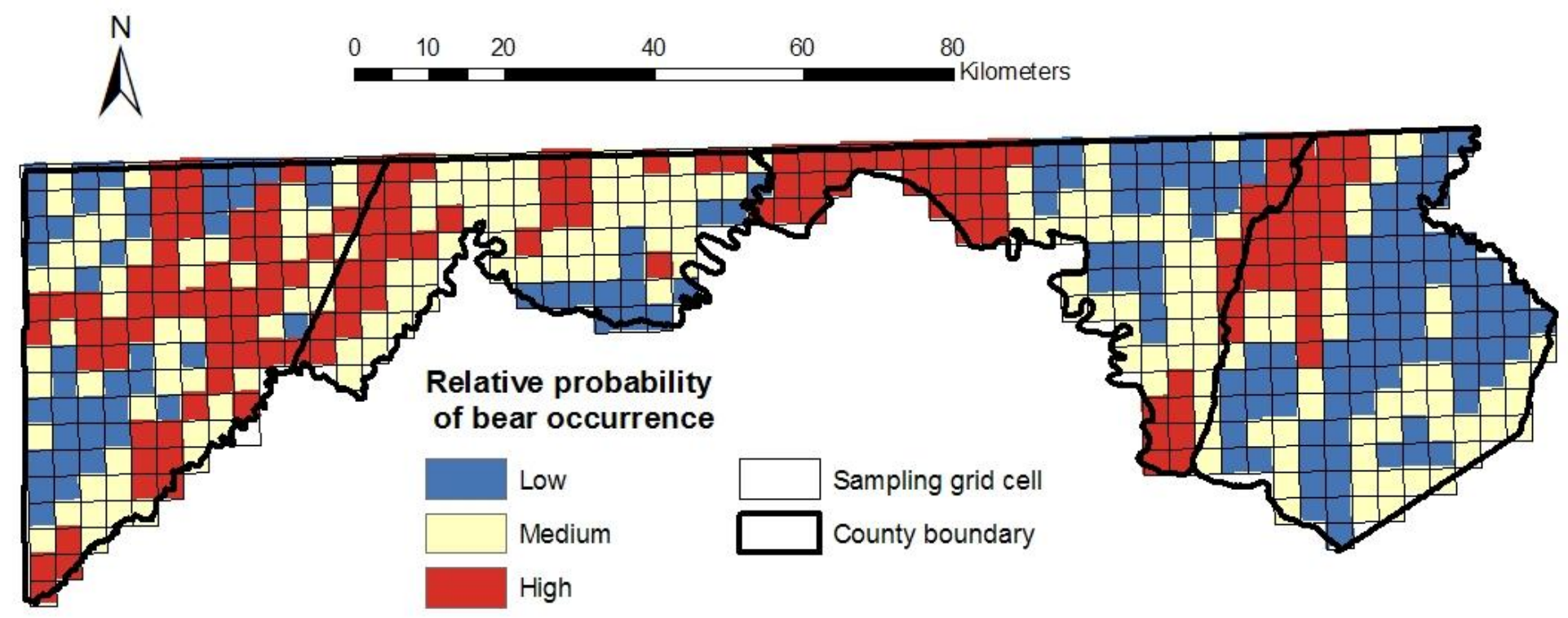

Figure 2.3. Potential black bear hair snare sampling grid cells $\left(12 \mathrm{~km}^{2}\right)$ in western Maryland, USA for 2011. Each cell is classified based on the mean value, within that cell, of a Maxent predictive summer occurrence model for black bears. 


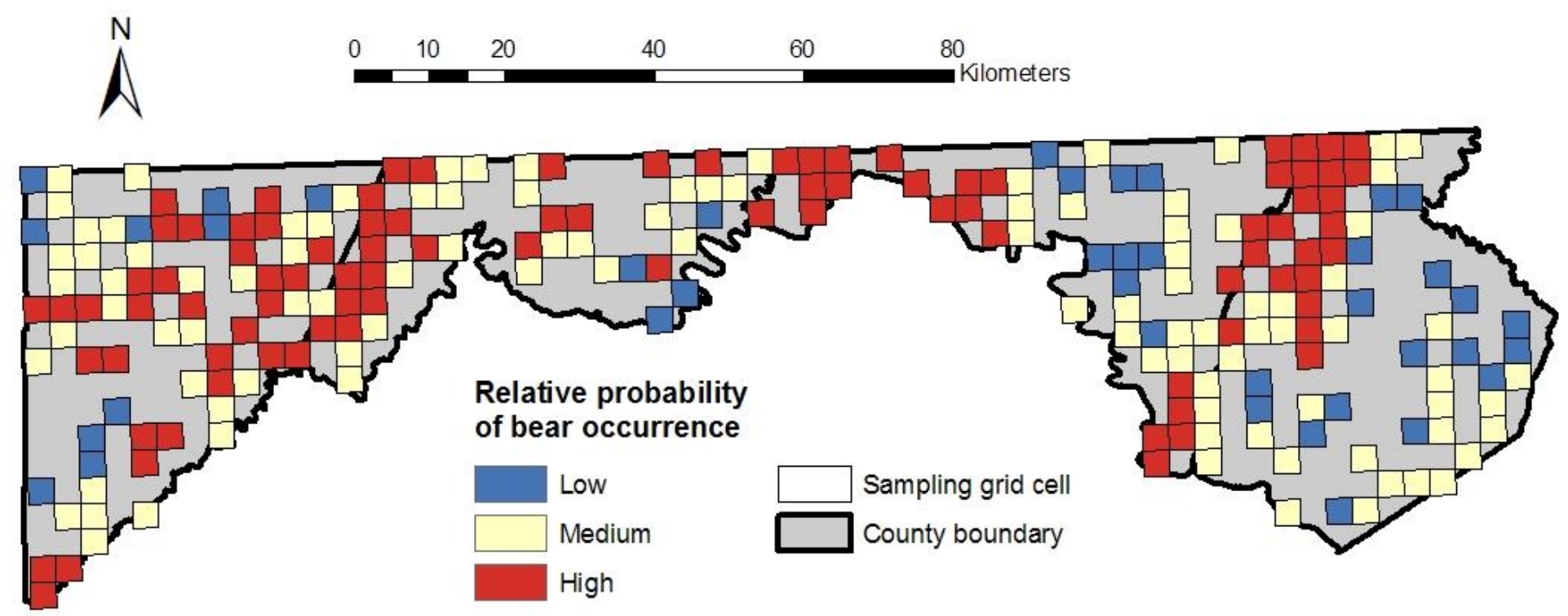

Figure 2.4. Sampling grid cells $\left(12 \mathrm{~km}^{2}\right)$ selected for a 2011 black bear hair snare survey in western Maryland, USA. Cells were selected using a stratified random sampling technique based on their classification of relative probability of bear occurrence. 


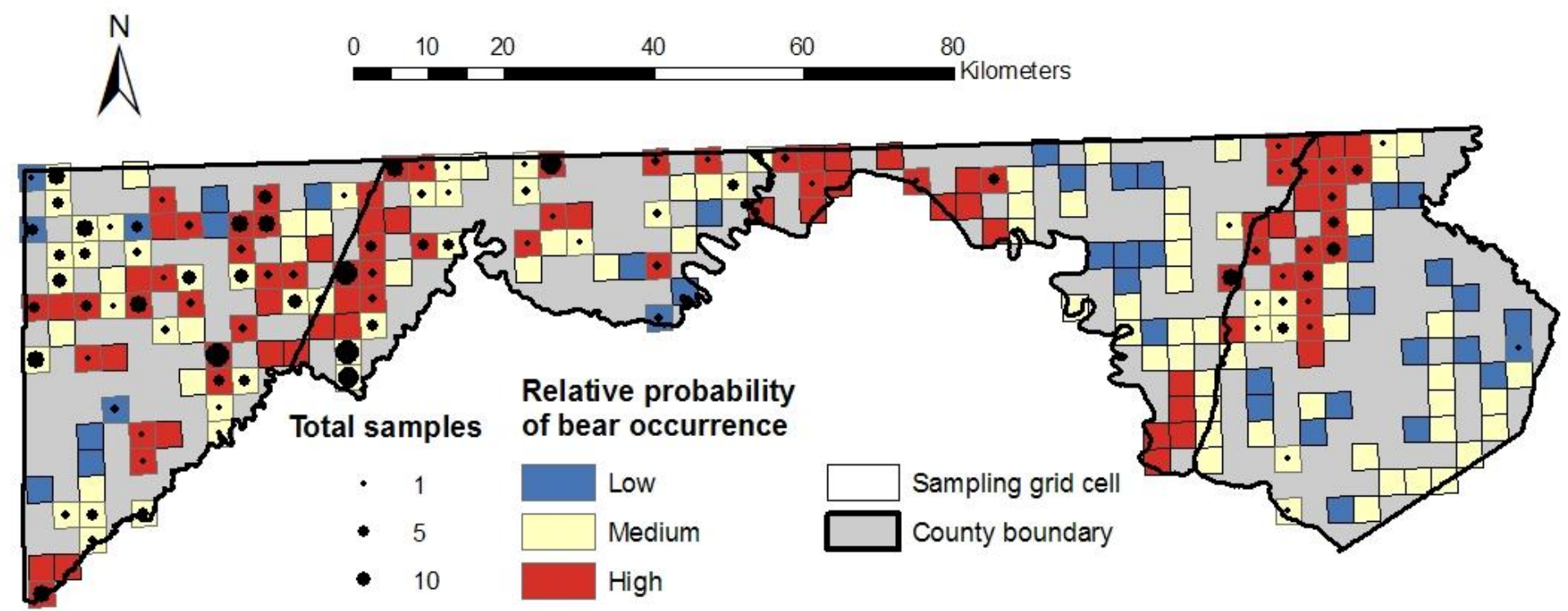

Figure 2.5. Spatial distribution of total hair samples (including duplicates and samples from non-target species) collected during a black bear hair snare survey conducted in western Maryland, USA in summer 2011. 


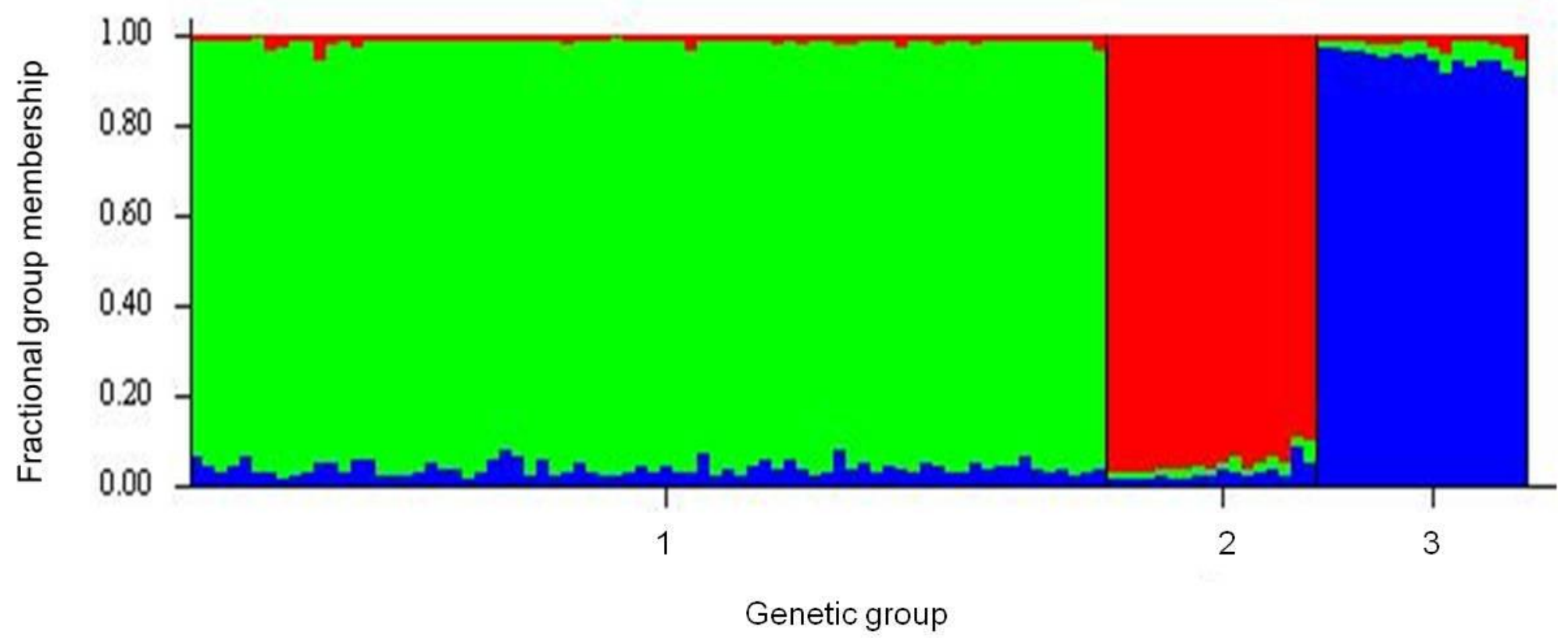

Figure 2.6. Program Structure output indicating assignment of individual Maryland black bears to genetically differentiated groups. Each vertical line represents a unique individual $(n=108)$ and is broken into 3 different colors representing genetically similar groups (e.g., populations). Lengths of each color in a given line indicate the proportion of membership into each of the 3 genetic groups. 


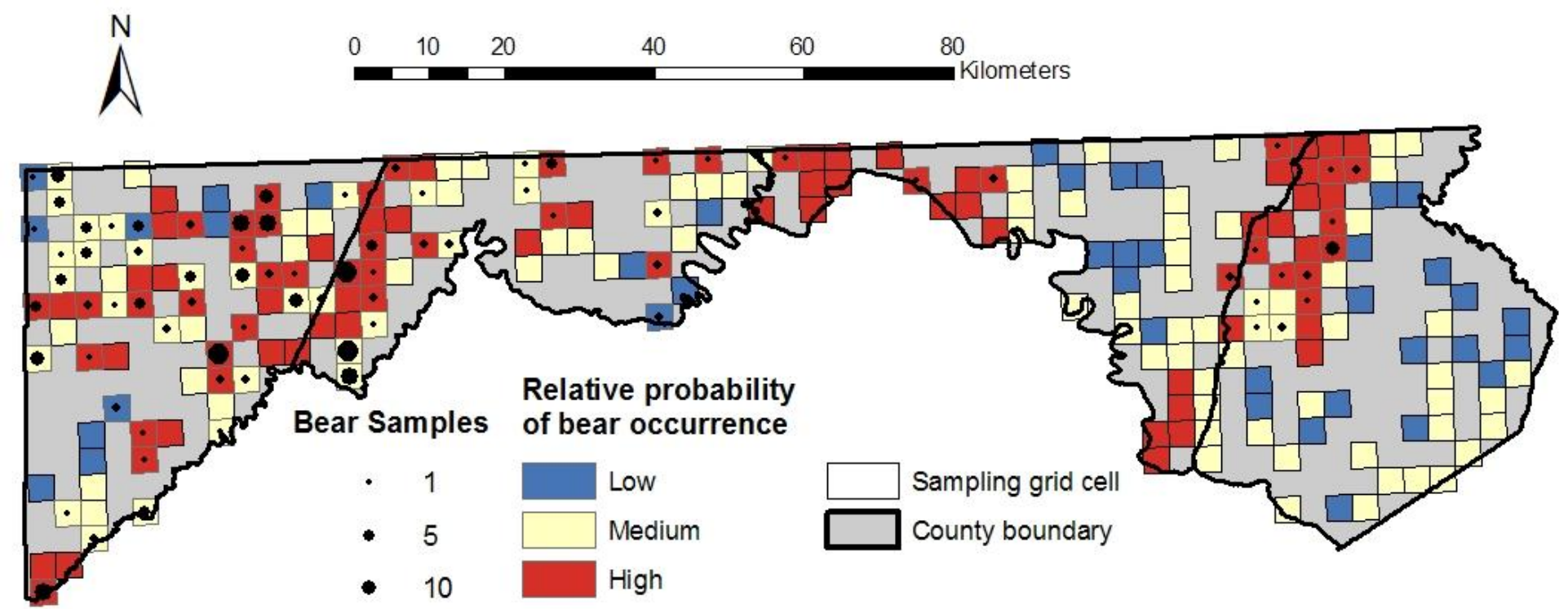

Figure 2.7. Spatial distribution of probable black bear hair samples collected during a hair snare survey conducted in western Maryland, USA in summer 2011. 


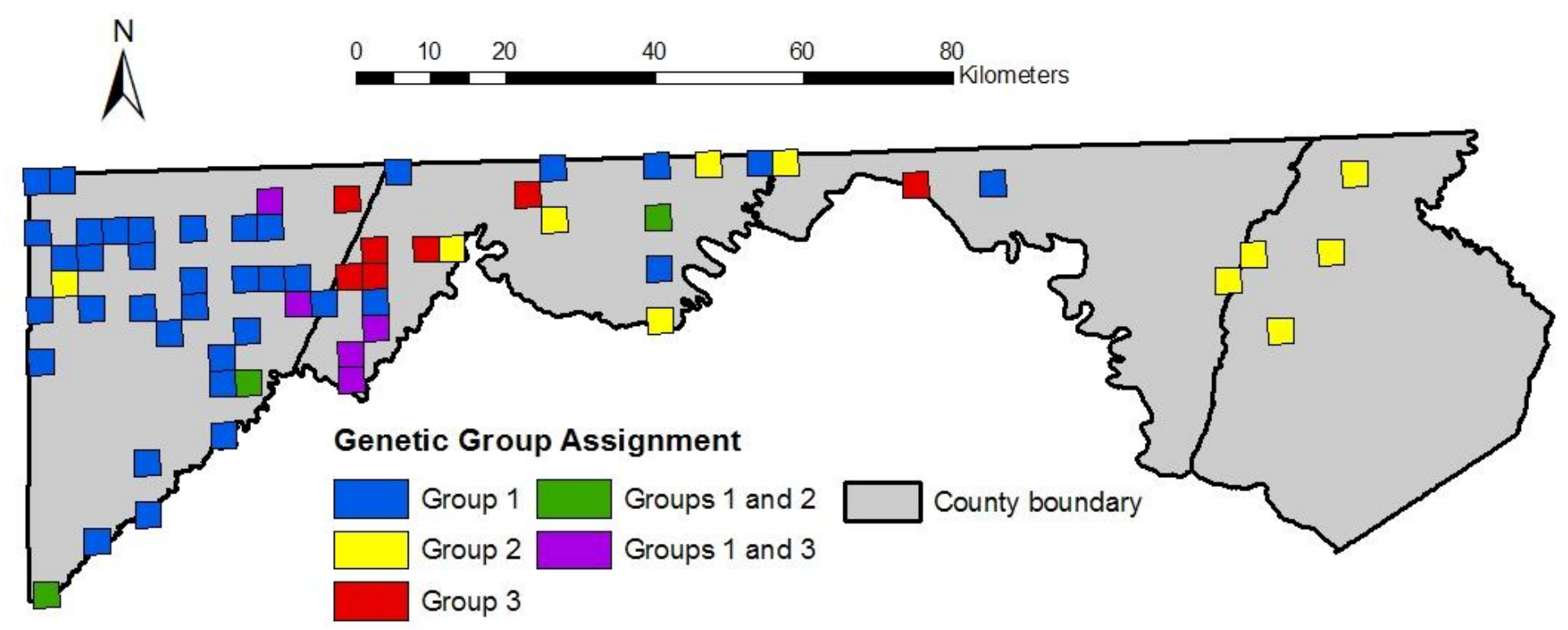

Figure 2.8. Spatial pattern of genetically differentiated groups of black bears in western Maryland, USA as identified by clustering analysis using program Structure. 
CHAPTER 3

MOVEMENTS AND SPATIAL BEHAVIORS OF BEAR HUNTERS IN WESTERN

MARYLAND 
November 2012

Michael D. Jones

West Virginia University

322 Percival Hall

Morgantown, WV 26506

920/598-0311

mike.jones731@gmail.com

RH: Jones • Maryland Bear Hunter Movements

\section{Movements and Spatial Behaviors of Bear Hunters in Western}

\section{Maryland}

MICHAEL D. JONES, Division of Forestry and Natural Resources, West Virginia University, Morgantown, WV 26506

ABSTRACT We analyzed locational data from 108 volunteer black bear hunters fitted with armband Global Positioning System (GPS) units during the 2005-2007 Maryland black bear hunting seasons to describe their movements and spatial behaviors. We also used mail survey responses to classify hunters into groups based on harvest success, residency, and prior bear hunting experience and success, and compared their data using 8 spatial metrics and 2 temporal metrics to see if different types of hunters behaved differently. Hunters spent a median of 5.7 hr/day hunting, but only $8.6 \mathrm{hr} /$ season ( $2-4$ days long). Hunters traveled $2.9 \mathrm{~km}$, on average, during the course of a single hunting event, but only $0.6 \mathrm{~km}$ from their starting point. Median values for all spatial variables were similar to median values across the study area, indicating that hunters likely did not use any areas more or less than expected based on availability. Most hunter locations $(76 \%)$ were $<500 \mathrm{~m}$ from the nearest road, but those areas were common in the study area. The median duration of hunting events was 2.6 times longer for successful hunters than for unsuccessful hunters. Successful hunters also used slopes that were, on average, 53\% steeper than those used by unsuccessful hunters. Hunters incorrectly estimated the distances they 
traveled by a median of $109 \%(3.6 \mathrm{~km})$. Nearly all hunters (96\%) believed they traveled farther from the nearest road than they actually did, by 3.0 times the true distance. These results add to our knowledge of hunter landscape use, and the data will serve as a basis for harvest vulnerability modeling in western Maryland.

KEY WORDS black bear, Global Positioning System, hunter behavior, hunting, Maryland, movements, survey, Ursus americanus.

The Journal of Wildlife Management 00(0):000-000, 201X

\section{INTRODUCTION}

Black bears have long been a species of interest to researchers, and many studies have focused on different aspects of their biology. Countless researchers have investigated bear movements and landscape use alone (Alt et al. 1980, Garshelis and Pelton 1981, Jones and Pelton 2003, Costello 2008). Several studies also have addressed the effect of hunting on bears (Powell et al. 1996, Lee and Vaughan 2005, Obbard and Howe 2006) Recreational hunting is an essential and cost-effective tool for managing large black bear (Ursus americanus; hereafter, bear) populations. With virtually no natural predators, adult bears have natural mortality rates as low as $1 \%$ (Kasworm and Thier 1994), and hunting is often the only feasible option for controlling population growth. Despite the importance of hunting to bear management, most hunting-related studies focus on the bear population and far less is known about the human aspect.

Hunter-based research typically employs survey methods as a relatively simple and inexpensive tool to ascertain hunter demographics (Boulanger et al. 2006), motivations (Bhandari et al. 2006), satisfaction (Peyton 1989), and attitudes (Kennedy 1974). For those uses, surveys have been effective and have yielded useful results. The utility of surveys for collecting accurate spatial and movement data, however, is relatively unknown. With the improved 
accuracy and affordability of Global Positioning System (GPS) technology, researchers now have the ability to examine the behavior of hunters from a spatial perspective. Spatial data from hunters can be invaluable to wildlife managers, who can use them to model hunter distribution and harvest vulnerability, determine factors affecting harvest success, identify areas that require improved hunter access, or increase the efficacy of harvest regulations by adjusting them to fit the behavior of hunters. Recently, more researchers have been using GPS technology for hunter spatial studies. A few studies have been conducted on game bird hunters, including those hunting northern bobwhites (Colinus virginianus; Hardin et al. 2005, Mecozzi and Guthery 2008), ring-necked pheasants (Phasianus colchinus; Frey et al. 2003), and willow ptarmigan (Lagopus lagopus; Broseth and Pederson 2000). Ungulate hunters also have been researched using GPS techniques, included white-tailed deer (Odocoileus virginianus; Stedman et al. 2004, Keenan 2010, Lebel et al. 2012) and elk (Cervus elaphus; Lyon and Burcham 1998) hunters. To our knowledge, no one has ever employed this research technique for bear hunters. Diefenbach et al. (2005) examined spatial behaviors of white-tailed deer and bear hunters in Pennsylvania, but relied on aerial surveys instead of GPS monitoring.

In Maryland, bear hunting has recently been reestablished in response to the rebounding bear population in the state (Spiker 2011). The state wildlife agency closed the bear hunting season in 1953 when populations were extremely low, and the season remained closed for 51 years before being reopened in the western portion of the state in 2004. We initiated this study to help the Maryland Department of Natural Resources (MDNR) develop a basic understanding of the spatial component of bear hunter behavior. Our objectives were to combine tradition human dimensions techniques (mail surveys) with GPS technology to document the profile and behavior of Maryland bear hunters. We also wanted to determine if hunter spatial behavior 
differed based on certain characteristics of the hunters, including harvest success and previous hunting experience.

\section{METHODS}

\section{Study Area}

We conducted this study in Garrett County, Maryland which is the westernmost county in the state (Fig. 3.1). Garrett County is bordered by Pennsylvania to the north and West Virginia to the south and west. The total area of this county is $1,722 \mathrm{~km}^{2}$. Maryland's black bear population occurs at its highest densities in Garrett County and the adjacent Allegany County to the east, which is the only area in the state where bear hunting is currently permitted (Spiker 2011). Elevations on the study area range from $292-1,028 \mathrm{~m}$. The majority of the study area is forested, with approximately $68 \%$ of the total area covered in deciduous forests. The human population density in the area is relatively low at 18 persons $/ \mathrm{km}^{2}$ (U.S. Census Bureau 2010). Approximately $22 \%$ of the area is public land, including several large contiguous public areas. The $221-\mathrm{km}^{2}$ Savage River State Forest is the largest public area in the county and makes up almost $13 \%$ of the study area.

The study area contains 5 different forest-type groups (U.S. Department of Agriculture Forest Service 1999). Oak/hickory (oaks (Quercus spp.) and hickories (Carya spp.)) is the most common, making up 54\% of all forested land in Garrett County. Northern hardwood (red maple (Acer rubrum), sugar maple (A. saccharum), American beech (Fagus grandifolia), yellow birch (Betula alleghaniensis), and black cherry (Prunus serotina)) is also common in the study area, making up 33\% of forests. Elm/ash/red maple (elm (Ulmus spp.), ash (Fraxinus spp.), and red maple), white/red pine (white pine (Pinus strobus) and red pine (Pinus resinosa)), and spruce/fir (spruce (Picea spp.) and fir (Abies spp.)) all account for $\leq 7 \%$ of the total forested land. The 
understory vegetation in these forest-type groups includes mountain laurel (Kalmia latifolia), rhododendron (Rhododendron spp.), serviceberry (Amelanchier arborea), dogwood (Cornus spp.), and hazelnut (Corylus spp.), which are important sources of food and thick cover for bears.

\section{Bear Hunter GPS Data Collection}

During the first years of the reestablished bear hunting seasons in Maryland, each hunter that was awarded a tag was required to attend a pre-hunt meeting the day before the opening of the season. During the pre-hunt meeting from 2005-2007, MDNR asked hunters to voluntarily participate in a GPS study of their movements (H. A. Spiker, MDNR, personal communication). Each volunteer was assigned a uniquely numbered Garmin 12XL GPS unit (Garmin Corporation, Olathe, Kansas) attached to an elastic armband. In order to record detailed movement data, the GPS units were programmed to record a waypoint every 2 minutes. Positional accuracy for these GPS units is $15 \mathrm{~m}$ (Garmin 1997). Hunters were instructed to turn on the GPS when they entered the field during their hunt and turn it off when they left the field. Hunters were given a brief demonstration, written instructions, and additional batteries. They were asked to return the GPS units at an MDNR bear check station. The bear hunts occurred in late October of each year. We downloaded all GPS data and removed extraneous points. Excluded points were locations where the hunter was in a building (e.g., home, business), within a city where hunting is prohibited, outside of Garrett County, or outside of the permitted hunting hours. Additionally, we excluded points where the speed of travel between locations indicating the use of a motorized vehicle. Excluding these locations ensured that we only used data representing times when a hunter was able to encounter and legally harvest a bear. However, additional locations were likely included where hunters were in the field but not actually hunting. 


\section{Hunter Movements and Spatial Characteristics}

We separated GPS data for each hunter into hunting events. Each event represented a period of continuous hunting. We created a new event any time legal hunting hours ended, a hunter moved to a different area by vehicle (assumed based on speed of travel), a hunter left an area and returned, or any other time when continuous hunting was disrupted. We treated each hunting event as independent in the analysis.

We calculated movement parameters for each individual hunter using Hawth's Analysis Tools (Beyer 2004). Specific parameters included total distance traveled, distance traveled per hunting event, and maximum distance from the starting point of the hunt. We also used the following environmental data layers to describe the spatial characteristics of the hunters: elevation, elevation change, percent slope, cover type, distance to nearest road, and distance to nearest stream. We used the National Elevation Dataset (NED) for the elevation layer and to derive the slope layer. Elevation change represented the difference between the highest and lowest elevation of locations in each hunting event. The cover type layer was a reclassified version of the National Land Cover Dataset (NLCD) data layer. This version combined low, medium, and high intensity developed areas into 1 cover type. We created the distance to roads and distance to streams layers using the Euclidean Distance tool in ArcGIS. All data layers were set to a 30-m raster cell size as that was the coarsest resolution of all the data layers. We used ArcGIS to extract values from the data layers to each hunter GPS location and calculated mean values for each variable. To compare hunter values for the spatial variables to what was available within the study area we calculated median values across the study area for each of the spatial variables. We also used chi-square tests to determine if hunters were using cover types more or less than expected based on availability. 


\section{Hunter Surveys and Group Comparisons}

Following the bear hunting seasons, MDNR sends a mail questionnaire to each hunter who was awarded a bear tag. We used the surveys from the 2005 and 2006 bear hunting seasons to classify the hunters based on residency, hunting success in the current season, prior bear hunting success, and hunting experience. Residency is defined as residency of the hunting area (i.e., Garrett and Allegany counties), not residency of the state of Maryland. A hunter was considered successful if they or their designated sub-permittee harvested a bear in the current season. According to MDNR bear hunting regulations, any hunter who is rewarded a bear tag can designate a sub-permittee and a landowner sub-permittee that are allowed to participate in all aspects of the hunt alongside the permittee. Permittees and sub-permittees are required to maintain visual contact during the entire hunt. Therefore, we considered hunters successful if anyone in their hunting party successfully harvested a bear. We used both prior bear hunting success and years bear hunting to measure bear hunting experience because the 2 metrics were not highly correlated. We divided hunters into 3 groups based on years of bear hunting experience: 0 years experience, $1-3$ years experience, and $\geq 4$ years experience. For previous bear hunting success, we divided hunters into 2 groups: 0 bears harvested and $\geq 1$ bears harvested. We used the Mann-Whitney U test (for harvest success, residency, and prior harvest success) and Kruskal-Wallis test (for years of bear hunting experience) to compare the environmental variables and movement parameters among groups for each classification. The post-hunt surveys also asked hunters how far they believed they traveled in total and how far they traveled from roads. We compared those values to the values derived from the GPS data to assess the accuracy of hunter responses. 


\section{RESULTS}

\section{Bear Hunter GPS Data Collection}

GPS units were assigned to 129 bear hunters during the 3 hunting seasons. Of those, 108 hunters returned useable GPS data and were included in our analysis. We excluded 4 hunters that hunted outside of the study area in Allegany County, MD and the other excluded hunters either had GPS failures, usually due to dead batteries, or did not hunt. The number of participating hunters per year was relatively equal, with 36 hunters returning GPS data in 2005, 32 in 2006, and 40 in 2007. We recorded 33,769 hunter locations over 229 distinct hunting events (Fig. 3.2).

\section{Hunter Surveys}

Fifty-nine (87\%) of the participating hunters in 2005 and 2006 returned completed post-hunt surveys. Eight hunters (14\%) successfully harvested a bear or were with a sub-permittee or landowner sub-permittee that harvested a bear, and $18(31 \%)$ were residents of the study area. The average number of years of bear hunting experience was 2.5 years (range $=0-15)$ in 2005, 2.4 years (range $=0-18)$ in 2006, and 2.5 years overall. Seventy-one percent of hunters never harvested a bear, and 54\% had no previous bear hunting experience. Most hunters (88\%) used either a stand or blind to hunt. Sixty percent used a stalking technique at some point during their hunt, and $47 \%$ used a combination of stalking and stand or blind hunting.

\section{Hunter Movements and Spatial Characteristics}

The mean number of locations recorded per hunter was 316 and the mean number of locations recorded per hunting event was 146 . The number of hunting events per hunter ranged from 1-7 $(x=2.1)$. The mean number of hunting events per hunter was similar in 2005 and 2006 (2.3 and 2.4, respectively) but was slightly lower in 2007 (1.85). The maximum number of events for a 
hunter in 2007 was 4, lower than the 6 in 2005 and 7 in 2006. The 2005 and 2007 hunting seasons lasted 4 days, whereas the 2006 season was closed after just 2 days.

Overall, bear hunters spent a median of $3.7 \mathrm{hrs} \mathrm{hunting} \mathrm{per} \mathrm{hunting} \mathrm{event}(5.7 \mathrm{hr} / \mathrm{day})$, and 8.6 hrs hunting during the course of the season (Table 3.1). The median distance traveled per event was $2.9 \mathrm{~km}(\mathrm{range}=0.1-24.8 \mathrm{~km})$, whereas the median maximum distance traveled from a hunter's starting point was only $0.6 \mathrm{~km}($ range $=0.0-3.6 \mathrm{~km})$. Seventy-six percent of hunters traveled $<5 \mathrm{~km}$ during a hunting event, and $75 \%$ stayed within $1 \mathrm{~km}$ of where they started hunting. On average, hunters were $247.4 \mathrm{~m}$ from the nearest road and $300.0 \mathrm{~m}$ from the nearest stream or river, both of which were higher than the medians for the county (192.1 m and $276.6 \mathrm{~m}$, respectively; Table 3.1). Hunters spent most of their time relatively close to roads and streams, with $76 \%$ of locations falling within $0.5 \mathrm{~km}$ of a road ( $48 \%$ within $0.25 \mathrm{~km})$ and $68 \%$ within $0.5 \mathrm{~km}$ of a stream. The median elevation used by hunters was $781.3 \mathrm{~m}$, compared to the median study area elevation of $766.2 \mathrm{~m}$, whereas the median range of elevations covered by a hunter during a hunting event was $58.0 \mathrm{~m}$ (Table 3.1). The median percent slope used by hunters (13.2\%) also was slightly higher than the median slope across the county (11\%).

Hunters overwhelmingly used deciduous forest ( $81 \%$ of locations) and evergreen forests (9\%) were the only other cover type used by hunters for $>5 \%$ of the time (Fig. 3.3). Six cover types were used for $<1 \%$ of the time and probably represent areas where hunters were simply passing through during the course of a hunt. Chi-square tests indicated that deciduous forests, evergreen forests, and mixed forests were used significantly more than expected based on availability (Table 3.2). Pasture and hay fields, cultivated crops, emergent wetlands, and all developed lands were used significantly less than expected. The amount of time hunters spent on public land and private land was almost exactly equal (50.4\% of locations on public land). The 
percentage of locations on public land was lower in 2005 and 2006 (39.7\% and 41.2\%, respectively) than in 2007 (60.3\%).

\section{Group Comparisons}

The results of the Mann-Whitney $U$ tests showed few differences among groups (Tables 3.3) and Kruskal-Wallis tests showed no differences based on bear hunting experience $(P \geq 0.133)$. Hunters who successfully harvested a bear spent significantly more time hunting per event (7.9 hr vs. $3.0 \mathrm{hr}$ ), and hunted on steeper slopes (18.3\% vs. 12.0\%) than unsuccessful hunters. On average, non-resident hunters spent more time hunting per event than resident hunters, and that difference approached significance $(P=0.062)$. The only other significant difference was between hunters who had never harvested a bear and hunters who had harvested at least 1 bear, with hunters who had harvested a bear using higher elevations than the other hunters $(P=0.024)$. No other comparisons came close to showing significant differences $(P \geq 0.143)$.

\section{Perceived Distance Traveled}

For the post-hunt survey question asking hunters how far they traveled during the course of their hunt, $62 \%$ of hunters underestimated the actual distance they traveled (Fig. 3.4). Thirteen percent of hunters provided answers that were within $10 \%$ of the actual distance traveled.

Overall, perceived distance traveled differed from actual distance traveled by a median of $3.56 \mathrm{~km}$, or 109\% (Fig. 3.5). Twenty-two percent of hunters were off from the actual distance by $>300 \%$, and 1 hunter's answer was 39.8 times higher than the actual distance traveled. For the question asking hunters how far they traveled from the nearest road, $96 \%$ of hunters overestimated the actual distance. Six percent of hunters estimated their distance to roads within $10 \%$ of the actual distance. Perceived distances differed from actual distances by a median of $0.98 \mathrm{~km}$, or 3.0 times, and $40 \%$ of hunters overestimated the actual distance by $>300 \%$. 


\section{DISCUSSION}

Although the hunters in our study participated voluntarily, we feel our sample is representative of all Maryland bear hunters. The distribution of hunter locations (Fig. 3.2) closely matches what we expect, with few points near developed and agricultural areas and clusters of points on heavily-forested and public lands. The harvest success rate of hunters in the study (12\%) was close to the average overall bear hunter success rate (10\%) during 2005 and 2006, another indication that we obtained a representative sample.

The values we observed for Maryland bear hunters varied widely for all variables examined, making it difficult to interpret the results and draw useful conclusions. The high variability can be explained by the numerous factors that influence how, when, and where individual bear hunters hunt. Although we may expect hunters to hunt on what is viewed as "prime" bear habitat, this may not always be the best option for an individual hunter. Much of Garrett County is privately-owned, so high quality bear habitat may have restricted access from landowners who do not allow hunting or only allow friends and family to hunt on their land. Hunters may also have access to land that they own, or friends or family own, making it the easiest option for hunting, regardless of the quality of bear hunting in the area. Even areas that allow access for bear hunting opportunities may be off limits due to time or fitness constraints. Bears often use high elevation areas with rough terrain and dense understory cover (Young and Beecham 1986, Pelton 2000), making access to those areas difficult for very young or old hunters, or others who cannot handle strenuous activity. Regulations also were different in 2005 compared to 2006 and 2007, which likely had some affect on the distribution of hunters. In $2005,70 \%$ of the 200 bear permits were for use only on private land, whereas the other $30 \%$ allowed hunting on private or public land. These percentages were chosen to represent the 
approximate percentages of private and public land (H. A. Spiker, MDNR, personal communication). In 2006 and 2007, all permits allowed hunting on either private or public land. All of these factors make it difficult to generalize characteristics and behaviors of hunters and hunter groups. Despite the difficulty associated with this research, our study yielded important information about Maryland bear hunters.

For other game species, studies have reported hunting durations higher and lower than our results. Lyon and Burcham (1998) reported an average hunt duration of $4.7 \mathrm{hr}$ for elk hunters in Montana. Sika deer (Cervus nippon) hunters in New Zealand hunted approximately 6 hr per day, on average (Fraser and Sweetapple 1992). Three studies have reported time spent hunting game birds, which usually incorporates different hunting techniques than large game hunting. Broseth and Pederson (2000) found that willow ptarmigan hunters spent an average of $9 \mathrm{hr}$ hunting per day, nearly $6 \mathrm{hr}$ of which were active hunting. Mecozzi and Guthery (2008) documented much lower hunt durations $(82.0$ and $50.2 \mathrm{~min})$ for northern bobwhite hunters in Oklahoma. Frey et al. (2003) reported a mean hunt duration of $3.7 \mathrm{hr}$ for ring-necked pheasant in Utah. Although our median hunting event duration was lower than most other studies, this is due to differences in measurements of hunting duration. When we calculate hours hunted per day, the median hunting duration $(5.7 \mathrm{hr} /$ day $)$ is comparable to the reported values for other big game hunters.

The total time spent hunting during the season was lower than expected. The median value was especially surprising given the structure of the Maryland bear season. Maryland does not have a set bear season length, so the hunt closes once the harvest quota is reached. Because hunters do not know when the quota will be met, we expected them to spend most of the day hunting, reducing the chance of season closure before harvesting a bear. Instead, the median 
time of $5.7 \mathrm{hr} /$ day represents less than $50 \%$ of the time that hunters are legally allowed to hunt each day. It is important to note, however, that our estimates of time spent hunting are minimum times. Our preliminary filtering of data revealed many extraneous points where it was clear that hunters forgot to turn off their GPS units when they were done hunting. Because of that, we assume that some hunters forgot to turn their GPS units on when they began hunting. Although this probably does not have a large effect on our results, it is likely that our estimates are slightly lower than the true values.

The total distance traveled was lower than values reported in other studies of large game hunters. Stedman et al. (2004) used GPS units to monitor Pennsylvania white-tailed deer hunters and reported average distance traveled of $5.48 \mathrm{~km}, 1.9$ times farther than the hunters in our study. Lyon and Burcham (1998) found that elk hunters on foot averaged $9.5 \mathrm{~km}$ per hunt. Game bird hunters have been documented traveling an average of $2.7 \mathrm{~km}$ (Mecozzi and Guthery 2008) and 16.2 km (Broseth and Pederson 2000). The median maximum distance traveled from the starting point of the hunt for Maryland bear hunters $(0.6 \mathrm{~km})$ was much lower than that reported for elk hunters $(2.6 \mathrm{~km})$ by Lyon and Burcham (1998). Our results are best explained by the high percentage of hunters using either stands or blinds. Hunters that exclusively use stands or blinds would only travel to and from their stands, so total distances traveled would be very low.

Stedman et al. (2004) reported average distance traveled from the nearest road of 0.84 km, 3.4 times farther than Maryland bear hunters. However, that study was conducted on a single tract of public land, which is more remote and has fewer roads than our study area. Thomas et al. (1976), Diefenbach et al. (2005), and Lebel et al. (2012) all found that the number of white-tailed deer hunters decrease with increasing distance from roads. Keenan (2010) found a similar pattern on public land, but reported that hunter use of private land was unaffected by 
distance to roads. In Idaho, Gratson and Whitman (2000) documented significantly lower elk hunter densities in areas managed hunter access or no roads compared to areas with road access. We anticipated similar results because being close to roads allows for easier navigation and removal of harvested bears. Although the median distance from roads was higher than the median for the study area, most hunter locations were still within $0.5 \mathrm{~km}$ of a road. With the high number of roads within the study area, hunters may not be close to roads by choice, but because areas far from roads are relatively rare in Garrett County. Lyon and Burcham (1998) also found that hunters remained close to roads but concluded that it was due to the high number of roads in the study area. We suspect this is the same reason that elevation, slope, and distance to streams are close to the median values across the county. Previous studies have found that hunters tended to use relatively flat slopes (Lyon and Burcham 1998, Keenan 2010), but we found no such preference.

As expected, hunters almost exclusively hunted in forested cover types. The majority of Garrett County is forested, and forests are considered typical bear habitat. It is understandable that hunters avoided developed areas and wetlands, as most people would expect use of those habitats by bears to be low. We expected hunters to spend more time in agricultural areas, especially areas with cultivated crops. Bears are known to rely on agricultural crops in the fall to supplement natural foods (Mattson 1990). MDNR annual hard mast surveys classified mast crops in Garrett County as failures in 2005 and 2007, and average in 2006 (MDNR, unpublished data). With a lack of natural availability, bear use of agricultural areas was probably relatively high during the hunting seasons. The use of public vs. public land in our study differed from the findings of Vieira et al. (2003) and Keenan (2010), who both reported higher hunter densities on public land compared to private land. In our study, hunters only spent more time on public land 
in 2007. However, MDNR's issuance of permits for use on private land only ( $70 \%$ of all permits) in 2005 probably greatly affected our results.

\section{Group Comparisons}

Group comparison showed no significant differences between hunter groups for most variables.

Of interest to black bear managers are the differences between successful and unsuccessful hunters. Successful hunters spent more time hunting per event than unsuccessful hunters. Because successful bear hunting is at least partially reliant on chance encounters between bears and hunters, spending more time hunting should increase the chance of seeing and harvesting a bear, all else being equal. We did not see differences between those groups for total time spent hunting during the season, probably due to the 1 bear limit per hunter. A hunter who successfully harvested a bear would be required to stop hunting, limiting the total time spent hunting. It is possible that hunting durations for successful hunters were overestimated due to time spent recovering the animal. Locations may have been recorded while hunters were tracking a shot bear or field dressing and transporting a carcass. We reported median hunt duration per event of $7.9 \mathrm{hr}$ for successful hunters, whereas times for unsuccessful were 2.6 times lower at $3.0 \mathrm{hr}$. The true values may be closer to each other, but we expect there is still a significant difference. Successful hunters also used slopes that were, on average 1.5 times steeper than slopes used by unsuccessful hunters. Bears have been shown to use steep slopes (Amstrup and Beecham 1976, Powell and Mitchell 1998), so hunter use of those areas should increase the likelihood of hunters encountering bears. In addition, the difficulty in traveling along steep slopes reduces hunter use of those areas (Lyon and Burcham 1998, Stedman et al. 2004, Keenan 2010). We expect bear density to be higher on steep slopes during the hunting season because those areas offer some level of protection from hunters. Therefore, hunters that 
do hunt on steep slopes should have greater chances of seeing and harvesting a bear. However, our sample size for successful hunters was low so it is difficult to attribute harvest success to the hunters spending more time hunting and using steeper slopes.

On average, non-resident hunters spent more time hunting per event than hunters that were residents of the hunting area (although this was only significant at $\alpha=0.10$ ), but there was no difference in total time spent hunting. Because non-resident hunters had to travel to Garrett County, they may have spent more time hunting each day to maximize harvest opportunities during their trip. Overall, resident hunters probably had more flexibility with their hunting time because they lived nearby. Residents might be more likely to end a hunt early due to weather or other factors, knowing they could easily return to the area the next day. We also assume that non-resident hunters are less familiar with the area than residents, so they may be less inclined to move to different areas (beginning a new hunting event). The lack of difference in total time spent hunting between these groups may be due in part to the timing of the hunting season and cost of travel. The Maryland bear season takes place during the week, so work and other obligations likely limit the amount of time available for hunting for some hunters. Non-residents may be limited even more due to the time required for travel to and from Garrett County. Some non-residents may also reduce the duration of their hunts because of the cost of lodging, food, and fuel. We expected resident hunters to perhaps travel longer distances and farther from roads than non-residents because of familiarity with the area, but the results did not support this. As previously mentioned, the prevalence of stand hunting likely impacted these distance variables.

The difference in elevation use based on previous bear harvest success may be explained by landscape characteristics at their prior harvest locations. Black bears often use habitats at relatively high elevation, especially in the fall (Amstrup and Beecham 1976, Raine and Kansas 
1990). If hunters previously had success harvesting bears in higher elevation areas, whether in Maryland or a different state, it makes sense that they would attempt to duplicate that success by focusing hunting efforts on similar areas. It is also possible that their previous hunting success indicates a greater knowledge of bear habitat and biology compared to more inexperienced hunters. If these hunters are knowledgeable about areas with higher likelihood of bear occurrence, they would most likely spend more time in those areas, which include higher elevations.

Other differences between hunting groups may be masked due to the small and unequal sample sizes of some of our groups. For example, there may actually be more differences between successful and unsuccessful hunters, but we do not have sufficient sample size to detect those differences statistically. Similarly, the measures for the variables we examined were highly variable, causing extensive overlap of ranges of values between and among groups and making it difficult to detect significant differences.

\section{Perceived Distance Traveled}

Our result for median percent difference between perceived actual distances traveled from roads (297\%) is comparable to the $265 \%$ difference reported by Stedman et al. (2004). That study also found that hunters generally overestimated that distance, consistent with our results. Although more accurate than those, hunter estimates of total distance traveled also had poor accuracy and varied widely. We expected most hunters to overestimate total distance traveled, as with distance from roads, but the majority (62\%) actually underestimated how far they traveled. We suspect that some hunters used their assigned GPS units to determine their distance traveled, which may explain the few hunter estimates that were very close to the true distances. Without the aid of GPS units, both estimates may have been even more inaccurate. These results show 
that hunters have a difficult time judging distances traveled, bringing into question the reliability of data from movement-related survey questions.

\section{MANAGEMENT IMPLICATIONS}

This study provided much-needed baseline information about the demographics, spatial behavior, and distribution of Maryland bear hunters. Although our study was conducted in Garrett County, neighboring Allegany County also is open to bear hunting, and additional counties may be opened in the future if the Maryland bear population continues to increase (H. A. Spiker, MDNR, personal communication). The behavior of Garrett County hunters can help MDNR develop expectations for how bear hunters in those areas will use the landscape. Having spatial information on bear hunters can help MDNR decide what changes, if any, can be implemented to meet current and future bear hunting goals. For example, if the goal is to increase harvest success, efforts could focus on increasing the time hunters spend in the field, and increasing use of and access to, steeper areas that bears may use to escape hunting pressure. Our data also provide the foundation for modeling hunter distribution across Garrett County, information that can then be used to model spatial patterns of harvest vulnerability for bears. The MDNR post-hunt surveys provided a wealth of information about the hunters in our study, and we advocate their continued use to build a database of hunter characteristics and track any changes over time. However, because our hunters had difficulties assessing how far they traveled, we caution against the use of surveys to obtain movement or similar spatial data.

By combining the results from this study with existing data from the state's bear population, MDNR can ensure they are using all of the scientific information available to make well-informed decisions and continue to implement successful bear hunting seasons. The 
techniques we describe here can serve as a framework for other agencies interested in describing the behavior of hunters.

\section{ACKNOWLEDGMENTS}

Funding for this project was provided by Federal Aid in Wildlife Restoration Act Project

W-61-R, Maryland Department of Natural Resources, and West Virginia University Division of

Forestry. Thank you to MDNR personnel for issuing GPS units and compiling hunter surveys.

We thank all of the Maryland bear hunters who volunteered for the study.

\section{LITERATURE CITED}

Alt, G. L., G. J. Matula, Jr., F. W. Alt, and J. S. Lindzey. 1980. Dynamics of home range and movements of adult black bears in northeastern Pennsylvania. International Conference on Bear Research and Management 4:131-136.

Amstrup, S. C., and J. Beecham. 1976. Activity patterns of radio-collared black bears in Idaho. Journal of Wildlife Management 40:340-348.

Beyer. H. L. 2004. Hawth's analysis tools for ArcGIS. <http://www.spatialecology.com>. Accessed 8 August 2010.

Bhandari, P., R. C. Stedman, A. E. Luloff, J. C. Finley, and D. R. Diefenbach. 2006. Effort versus motivation: factors affecting antlered and antlerless deer harvest success in Pennsylvania. Human Dimensions of Wildlife 11:423-436.

Boulanger, J., G. C. White, B. N. McLellan, J. Woods, M. Proctor, and S. Himmer. 2002. A meta-analysis of grizzly bear DNA mark-recapture projects in British Columbia, Canada. Ursus 13:137-152.

Boulanger, J. R., D. E. Hubbard, J. A. Jenks, and L. M. Gigliotti. 2006. A typology of South Dakota muzzleloader deer hunters. Wildlife Society Bulletin 34:691-697. 
Broseth, H., and H. C. Pederson. 2000. Hunting effort and game vulnerability studies on a small scale: a new technique combining radio-telemetry, GPS, and GIS. Journal of Applied Ecology 37:182-190.

Costello, C. M. 2008. The spatial ecology and mating system of black bears (Ursus americanus) in New Mexico. Dissertation, Montana State University, Bozeman, USA.

Diefenbach, D. R., J. C. Finley, A. E. Luloff, R. Stedman, C. B. Swope, H. C. Zinn, G. J. San Julian. 2005. Bear and deer hunter density and distribution on public land in Pennsylvania. Human Dimensions of Wildlife 10:201-212.

Ervin, G. N., and D. C. Holly. 2011. Examining local transferability of predictive species distribution models for invasive plants: an example with cogongrass (Imperata cylindrical). Invasive Plant Science and Management 4:390-401

Fraser, K. W., and P. J. Sweetapple. 1992. Hunters and hunting patterns in part of the Kaimanawa Recreational Hunting Area. New Zealand Journal of Zoology 19:91-98.

Frey, S. N., M. R. Conover, J. S. Borgo, and T. A. Messmer. 2003. Factors influencing pheasant hunter harvest and satisfaction. Human Dimensions of Wildlife 8:277-286.

Garmin Corporation. 1997. GPS XL personal navigator operator's manual.

Garshelis, D. L., and M. R. Pelton. 1981. Movements of black bears in the Great Smoky Mountains National Park. Journal of Wildlife Management 45:912-925.

Gratson, M. W., and C. L. Whitman. 2000. Road closures and density and success of elk hunters in Idaho. Wildlife Society Bulletin 28:302-310.

Hardin, J. B., L. A. Brennan, F. Hernándex, E. J. Redeker, and W. P. Kuvlesky, Jr. 2005. Empirical tests of hunter-covey interface models. Journal of Wildlife Management 69:498-514. 
Kasworm, W. F., and T. J. Their. 1994. Adult black bear reproduction, survival, and mortality sources in northwest Montana. International Conference on Bear Research and Management 9:223-230.

Kennedy, J. J. 1974. Attitudes and behavior of deer hunters in a Maryland forest. Journal of Wildlife Management 38:1-8.

Keenan, M. T. 2010. Hunter distribution and harvest of female white-tailed deer in Pennsylvania. Thesis, The Pennsylvania State University, State College, USA.

Lebel, F., C. Dussault, A. Massé, and S. D. Côté. 2012. Influence of habitat features and hunter behavior on white-tailed deer harvest. Journal of Wildlife Management 76:1431-1440.

Lee, D. J., and M. R. Vaughan. 2005. Yearling and subadult black bear survival in a hunted Virginia population. Journal of Wildlife Management 69:1641-1651.

Lyon, L. J., and M. G. Burcham. 1998. Tracking elk hunters with the global positioning system. U. S. Department of Agriculture, Forest Service, Rocky Mountain Research Station, Fort Collins, Colorado, USA.

Mattson, D. J. 1990. Human impacts on bear habitat use. International Conference on Bear Research and Management 8:33-56.

Mecozzi, G. E., and F. S. Guthery. 2008. Behavior of walk-hunters and pointing dogs during northern bobwhite hunts. Journal of Wildlife Management 72:1399-1404.

Obbard, M. E., and E. J. Howe. 2006. Demography of black bears in hunted and unhunted areas of boreal forest of Ontario. Journal of Wildlife Management 72:869-880. 
Pelton, M. R. 2000. Black bear. Pages 547-555 in G. A. Feldhamer, B. C. Thompson, and J. A. Chapman, editors. Wild mammals of North America: biology, management, and conservation. Second edition. The John Hopkins University Press, Baltimore, Maryland, USA.

Powell, R. A., and M. S. Mitchell. 1998. Topographic constraints and home range quality. Ecography 21:337-341.

Powell, R. A., J. W. Zimmerman, D. E. Seaman, and J. F. Gilliam. 1996. Demographic analysis of a hunted black bear population with access to a refuge. Conservation Biology $10: 224-234$.

Raine, R. M., and J. L. Kansas. 1990. Black bear seasonal food habits and distribution by elevation in Banff National Park, Alberta. International Conference on Bear Research and Management 8:297-304.

Spiker, H. 2011. Maryland black bear population status report. Maryland Department of Natural Resources, Wildlife and Heritage Service, Oakland, USA.

Stedman, R., D. R. Dieffenbach, C. B. Swope, J. C. Finley, A. E. Luloff, H. C. Zinn, G. J. San Julian, and G. A. Wang. 2004. Integrating wildlife and human-dimensions research methods to study hunters. Journal of Wildlife Management 68:762-773.

Thomas, J. W., J. D. Gill, J. C. Pack, W. M. Healy, and H. R. Sanderson. 1976. Influence of forestland characteristics on spatial distribution of hunters. Journal of Wildlife Management 40:500-506.

U.S. Census Bureau. 2010. Census 2010 summary file 1, geographic header record G001. U.S. Census Bureau, Washington, D.C., USA. 
U.S. Department of Agriculture Forest Service [USFS]. 1999. Northeastern forest and inventory analysis. Maryland statewide results. <http://www.fs.fed.us/ne/fia/states/md/ index.html> Accessed 11 Feb 2010.

Vieira, M. E. P., M. M. Connor, G. C. White, and D. J. Freddy. 2003. Effect of hunter numbers on elk movement. Journal of Wildlife Management 67:717-728.

Webster, T. W. 1994. Movements and use of habitat of female black bears in western Maryland. Thesis, Frostburg State University, Frostburg, Maryland, USA.

Young, D. D., and J. J. Beecham. 1986. Black bear habitat use at Priest Lake, Idaho. International Conference on Bear Research and Management 6:73-80.

Associate Editor: 
Table 3.1. Descriptive statistics for spatial and temporal metrics for black bear hunter locations in Garrett County, Maryland, USA during the 2005-2007 Maryland bear hunting seasons.

\begin{tabular}{|c|c|c|c|c|c|c|c|}
\hline Metric & $\begin{array}{l}\text { Hunter } \\
\text { median }\end{array}$ & Min. & Max. & Q1 & Q3 & IQR & $\begin{array}{c}\text { Study area } \\
\text { median }\end{array}$ \\
\hline Distance from nearest road $(\mathrm{m})$ & 247.4 & 0.0 & 1338.0 & 94.9 & 457.0 & 362.1 & 192 \\
\hline Distance from nearest stream $(\mathrm{m})$ & 300.0 & 0.0 & 891.0 & 150.0 & 488.4 & 338.4 & 277 \\
\hline Elevation (m) & 781.3 & 438.9 & 913.3 & 729.4 & 825.3 & 95.8 & 768 \\
\hline Elevation change (m) & 42.3 & 0.0 & 404.8 & 20.9 & 76.9 & 56.0 & --- \\
\hline Slope $(\%)$ & 13.2 & 1.0 & 43.2 & 8.4 & 21.4 & 12.9 & 11 \\
\hline Total distance traveled per event $(\mathrm{km})$ & 2.9 & 0.1 & 24.8 & 1.3 & 4.9 & 3.5 & --- \\
\hline Max. distance from starting point $(\mathrm{km})$ & 0.6 & 0.0 & 3.6 & 0.3 & 1.0 & 0.7 & --- \\
\hline Time spent hunting per event (hr) & 3.6 & 0.2 & 22.7 & 1.6 & 7.6 & 6.0 & --- \\
\hline Time spent hunting per season (hr) & 8.6 & 0.2 & 35.9 & 4.7 & 14.1 & 9.4 & --- \\
\hline
\end{tabular}


Table 3.2. Cover type use vs. availability for black bear hunter in Garrett County, Maryland, USA during the 2005-2007 Maryland bear hunting seasons.

\begin{tabular}{lcccc}
\hline \multicolumn{1}{c}{ Cover type } & $\begin{array}{c}\text { \% hunter } \\
\text { use }\end{array}$ & \% available & $\chi^{2}$ & $\begin{array}{c}\text { Actual vs. } \\
\text { predicted } \\
\text { use }^{\mathrm{a}}\end{array}$ \\
\hline Deciduous forest & 80.81 & 67.67 & 584.73 & + \\
Evergreen forest & 8.77 & 5.5 & 887.16 & + \\
Pasture/hay & 4.04 & 14.2 & 2096.72 & - \\
Developed, open space & 3.36 & 5.37 & 195.06 & - \\
Mixed forest & 1.38 & 1.35 & 50.24 & + \\
Barren land & 0.93 & 1.28 & 9.61 & $\circ$ \\
Woody wetlands & 0.42 & 142 & 10.32 & $\circ$ \\
Cultivated crops & 0.05 & 1.63 & 465.76 & - \\
Emergent herbaceous wetland & 0.05 & 0.22 & 62.39 & - \\
Developed, low intensity & 0.02 & 0.44 & 113.41 & - \\
\hline a Symbols indicate significantly higher $(+)$ or lower $(-)$ cover type use than expected based on \\
availability, or no significant difference (०) between use and availability.
\end{tabular}


Table 3.3. Spatial and temporal metrics for different groups of black bear hunters from GPS locations recorded in Garrett County, Maryland, USA during the 2005 and 2006 Maryland bear hunting seasons. Values between groups were compared using Mann-Whitney U tests.

\begin{tabular}{|c|c|c|c|}
\hline Hunter group comparison & Variable & $W$ & $P$ \\
\hline \multirow[t]{8}{*}{ Successful vs. unsuccessful ${ }^{\mathrm{a}}$} & Distance to nearest road (m) & 986.5 & 0.898 \\
\hline & Distance to nearest stream (m) & 1183.0 & 0.286 \\
\hline & Elevation $(\mathrm{m})$ & 1015.0 & 0.968 \\
\hline & Slope $(\%)$ & 1448.0 & $0.007 * *$ \\
\hline & Distance traveled per event $(\mathrm{km})$ & 224.0 & 0.782 \\
\hline & Max. distance from starting point $(\mathrm{km})$ & 203.0 & 0.894 \\
\hline & Time spent hunting per event (hr) & 1370.5 & $0.027 * *$ \\
\hline & Time spent hunting per season (hr) & 252.5 & 0.389 \\
\hline \multirow[t]{8}{*}{ Resident vs. non-resident $^{b}$} & Distance to nearest road (m) & 2769.0 & 0.247 \\
\hline & Distance to nearest stream (m) & 2520.0 & 0.854 \\
\hline & Elevation (m) & 2362.0 & 0.667 \\
\hline & Slope $(\%)$ & 2709.0 & 0.357 \\
\hline & Distance traveled per event $(\mathrm{km})$ & 398.0 & 0.551 \\
\hline & Max. distance from starting point $(\mathrm{km})$ & 397.0 & 0.542 \\
\hline & Time spent hunting per event (hr) & 1995.0 & $0.062 *$ \\
\hline & Time spent hunting per season (hr) & 372.5 & 0.336 \\
\hline \multirow[t]{8}{*}{ Prior harvest vs. no harvest ${ }^{\mathrm{c}}$} & Distance to nearest road (m) & 1694.5 & 0.188 \\
\hline & Distance to nearest stream (m) & 1662.5 & 0.143 \\
\hline & Elevation (m) & 1497.0 & $0.025^{* *}$ \\
\hline & Slope $(\%)$ & 2093.5 & 0.575 \\
\hline & Distance traveled per event $(\mathrm{km})$ & 337.0 & 0.881 \\
\hline & Max. distance from starting point $(\mathrm{km})$ & 268.0 & 0.294 \\
\hline & Time spent hunting per event (hr) & 2154.5 & 0.397 \\
\hline & Time spent hunting per season (hr) & 316.5 & 0.845 \\
\hline
\end{tabular}

${ }^{a}$ Successful defined as hunters who harvest a bear during the hunting season in which they were monitored.

${ }^{b}$ Hunters were considered residents only if they lived within the hunting area.

${ }^{c}$ Hunters were classified as either having harvested at least 1 bear in a previous hunting season (not necessarily in Maryland), or having never previously harvested a bear.

*Significantly different at $\alpha=0.10$.

**Significantly different at $\alpha=0.05$. 


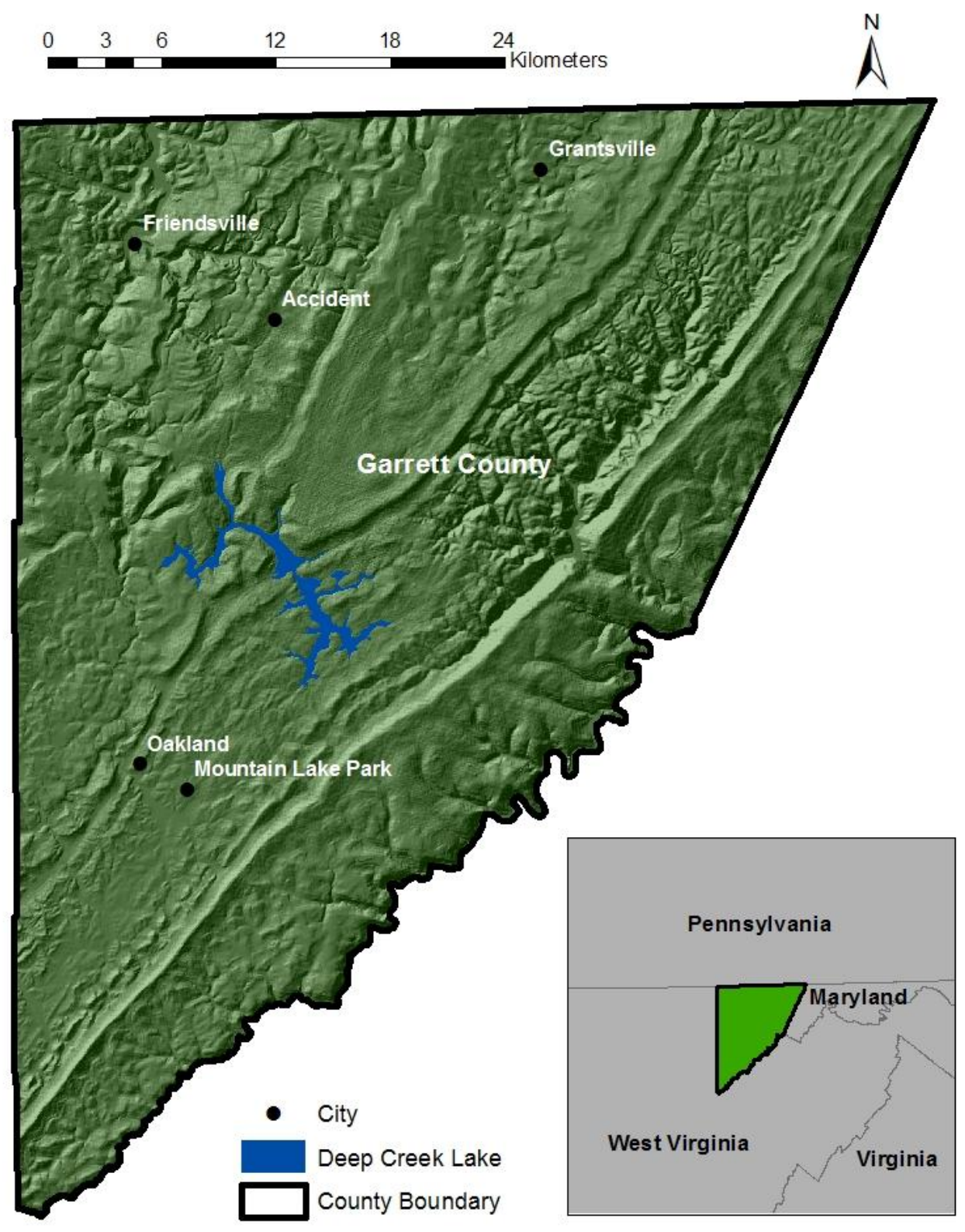

Figure 3.1. Garrett County, Maryland, USA, the primary black bear study area. 


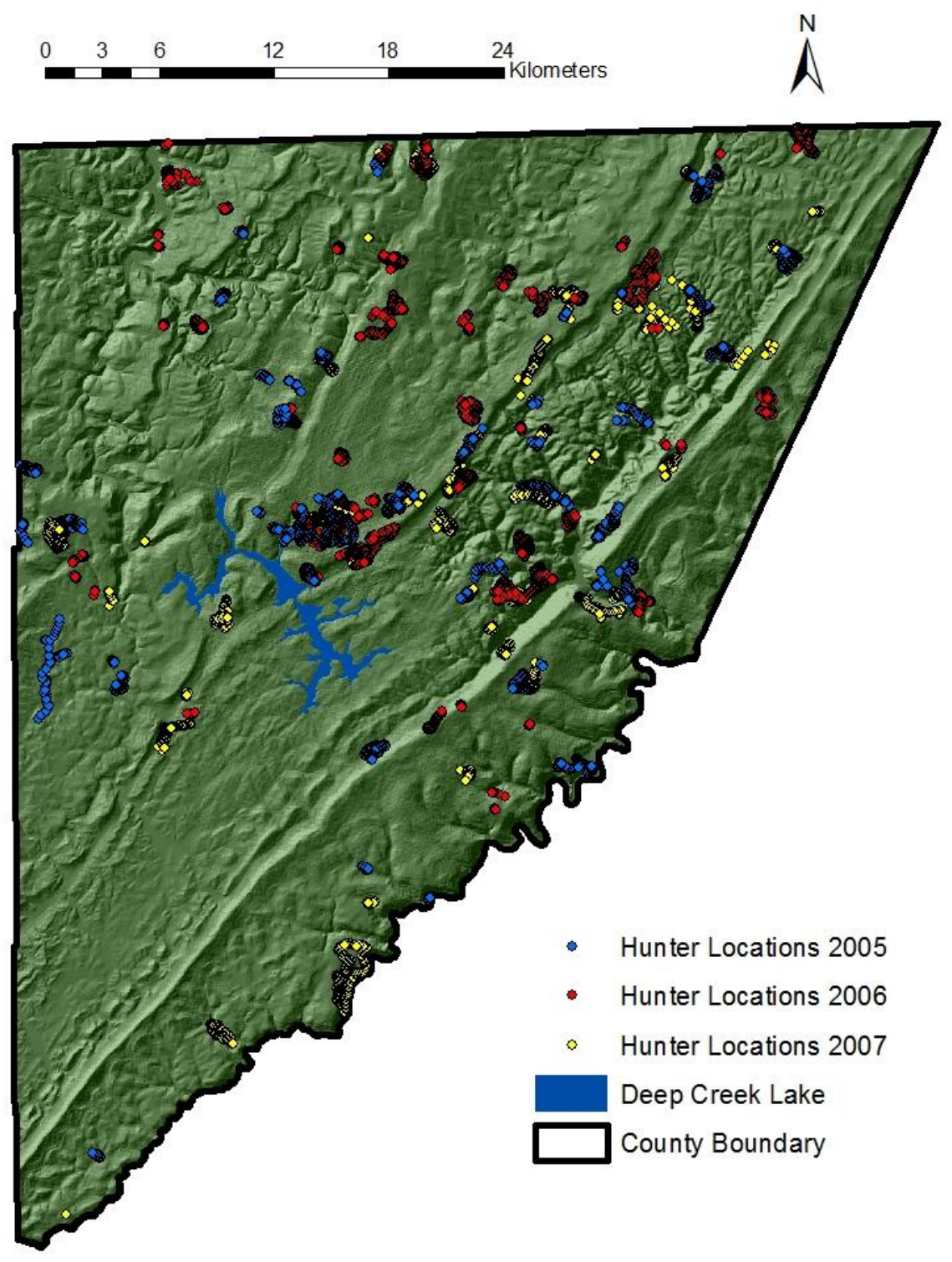

Figure 3.2. Distribution of bear hunter locations by year in Garrett County, Maryland, USA during the 2005-2007 Maryland bear hunting seasons. 


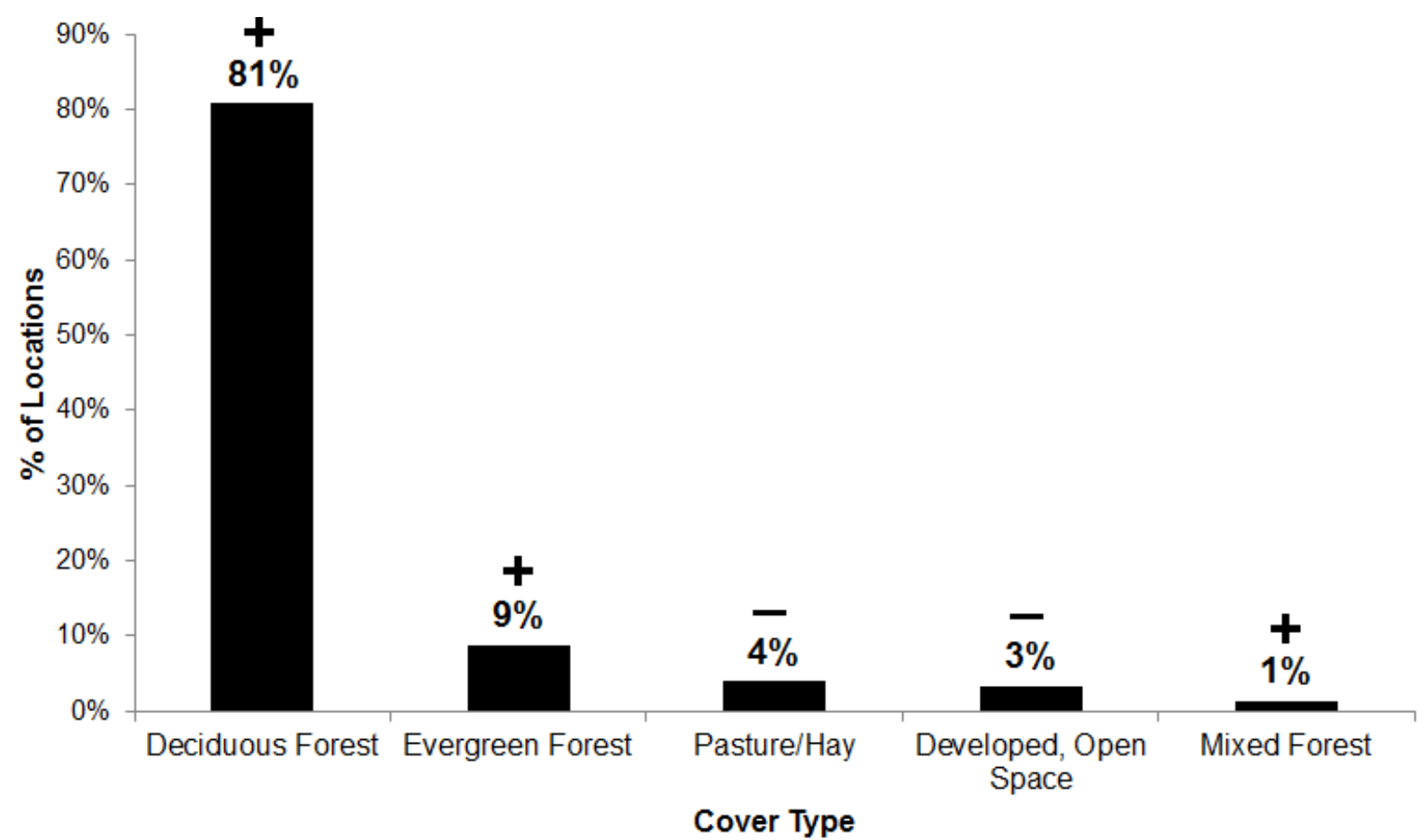

Figure 3.3. Percentage of hunter locations recorded in the 5 most commonly used cover types by bear hunters in Garrett County, Maryland, USA during the 2005-2007 Maryland bear hunting seasons. The "+" symbol indicates a cover type that was used more than expected based on availability according to chi-square tests. The "-“" symbol indicates a cover type that was used less than expected. 


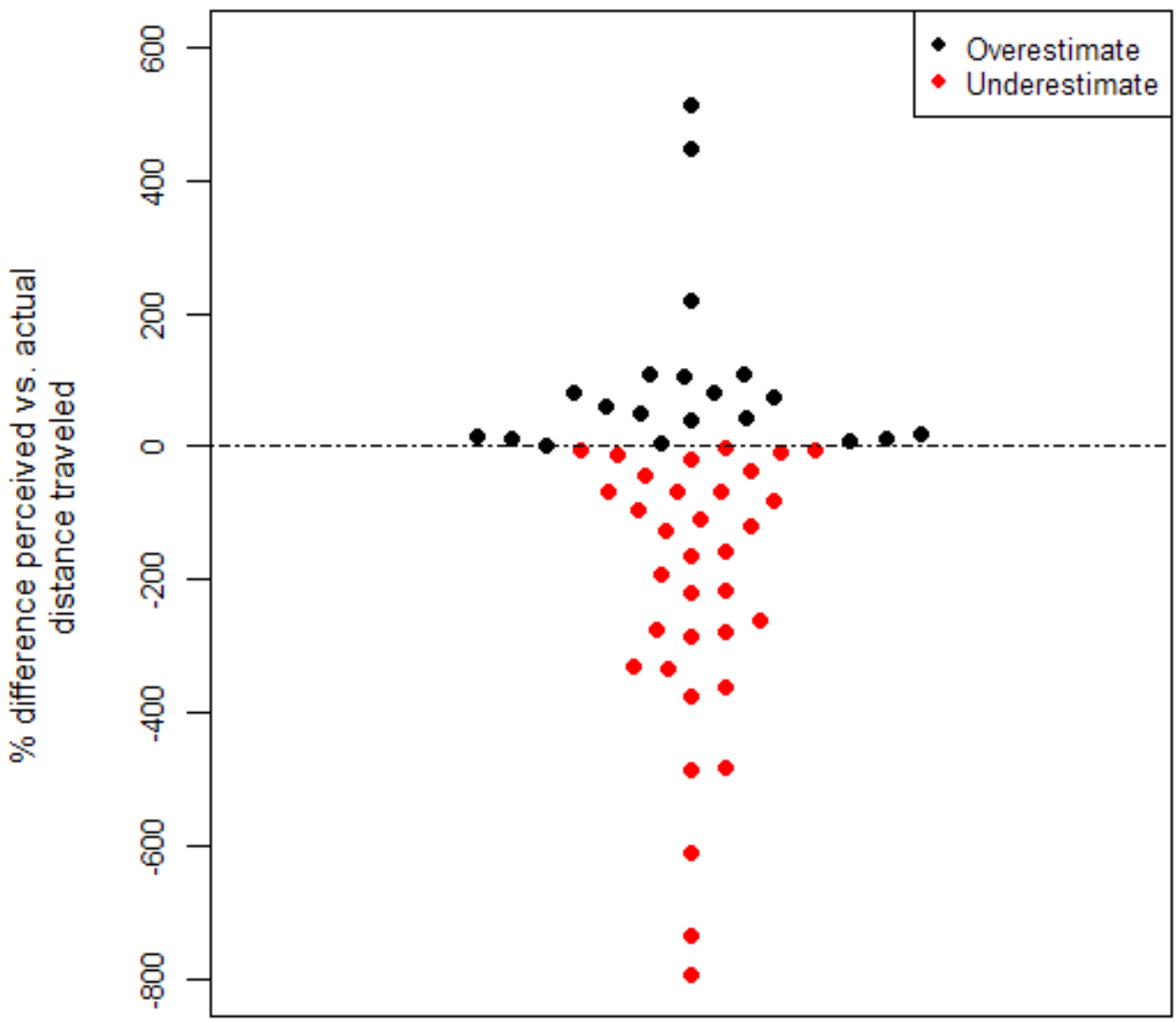

Figure 3.4. Percent difference between perceived distance and actual distance traveled for black bear hunters in Garrett County, Maryland, USA during the 2005-2006 Maryland bear hunting seasons. The largest observed overestimation has been excluded from the plot area to allow greater detail for the remaining data. 


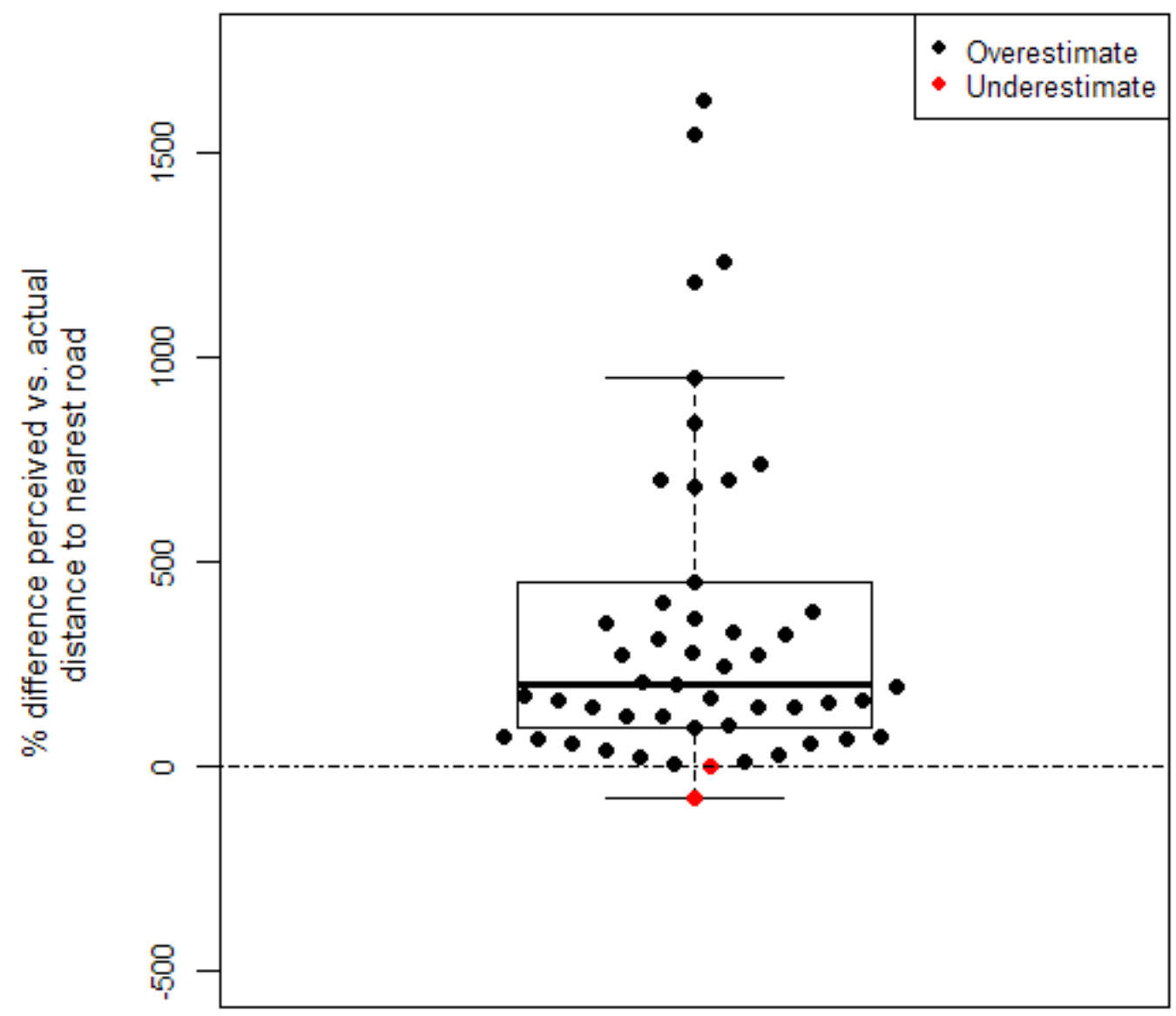

Figure 3.5. Percent difference between perceived distance and actual distance to the nearest road for Maryland black bear hunters during the 2005-2006 Maryland bear hunting seasons. Three data points representing the greatest observed overestimations have been excluded from the plot area to allow greater detail for the remaining data. 
CHAPTER 4

HARVEST VULNERABILITY OF FEMALE BLACK BEARS IN WESTERN

MARYLAND 
November 2012

Michael D. Jones

West Virginia University

322 Percival Hall

Morgantown, WV 26506

920/598-0311

mike.jones731@gmail.com

RH: Jones • Maryland Black Bear Harvest Vulnerability

\section{Harvest Vulnerability of Female Black Bears in Western Maryland}

MICHAEL D. JONES, Division of Forestry and Natural Resources, West Virginia University, Morgantown, WV 26506

ABSTRACT Recreational hunting is the most common tool used to manage black bear populations. Due to the low reproductive potential of the species, bear populations are sensitive to overharvest, especially of females. Therefore, it is important for managers to understand harvest vulnerability when using hunting as a management tool. Most research on this topic focuses on the game species, while neglecting the hunter aspect. We used Global Positioning System (GPS) and Geographic Information System (GIS) technology to model the predicted harvest vulnerability of female bears in western Maryland. We collected GPS locations for 10 bears and 108 bear hunters during fall of 2005-2007. We used those location data, along with 7 environmental variable data layers, to create predictive occurrence models for bears and bear hunters. We created the models using Maxent, a presence-only modeling approach. We then overlaid the 2 models to identify areas of high and low harvest vulnerability. Jackknife tests revealed that slope and land ownership (i.e., private/public) were the most important variables for determining female bear distribution, whereas land ownership and cover type were the most important for the hunter model. For both models, probability of occurrence was, on average, $\sim 60 \%$ higher on public land than on private land. Approximately $12 \%$ of the study area was 
classified as high relative probability of bear occurrence, whereas $\sim 16 \%$ was classified as high probability of hunter occurrence. However, only $2.6 \%$ of the county represented areas of high probability of occurrence for both (i.e., high harvest vulnerability). Eighty-one percent of those areas were located on public land. Our model performed poorly when predicting known bear harvest locations. Only $4.2 \%$ of all previous bear harvests (2004-2011 Maryland bear hunting seasons) were located within areas predicted as high harvest vulnerability. Areas with low hunter but high bear probability of occurrence (i.e., low harvest vulnerability) comprised $3.8 \%$ of the study area. These areas included 9 contiguous blocks of $>1 \mathrm{~km}^{2}$, representing possible natural refugia from hunting pressure. Those blocks were all at least partially located on public land. Median values in the blocks showed they were 2.3 times steeper, 2.0 times farther from roads, and 1.5 times farther from streams than the median values for the rest of the study area. Our study provided useful maps of the distributions of female bears and bear hunters. However, our model of harvest vulnerability was not useful for predicting harvest locations. This indicates that overlap in hunter and bear distributions does not necessarily translate to actual harvesting of bears.

KEYWORDS Black bear, Global Positioning System, harvest vulnerability, hunting, Maryland, maximum entropy, Maxent, presence-only modeling, Ursus americanus.

The Journal of Wildlife Management 00(0):000-000, 201X

\section{INTRODUCTION}

With virtually no natural predators, natural mortality of adult black bears (Ursus americanus; hereafter bears) has been documented as low as 1\% (Kasworm and Thier 1994). Human-induced mortality (e.g., vehicle collisions, recreational hunting, poaching) has a larger impact on bear populations than natural mortality in most areas (Cowan 1972, Bunnell and Tait 1985, Pelton 
2000). Recreational hunting is the most effective and commonly-used management technique where controlling population growth of black bears is an objective (Cowan 1972, Bunnell and Tait 1985). Black bears have one of the lowest reproductive potential of any land mammal in North America (Jonkel and Cowan 1971), making the species susceptible to overharvest (Kolenosky 1986). Bear populations that are overharvested, especially in the female segment of the population, can take years to recover (Miller 1989). Miller and Miller (1988) simulated the overharvest of a black bear population and found that, if the population was reduced to $50 \%$ of its original abundance and then hunting ceased, it would take 6 years for the population to recover to the original size. If the harvest rate remained at $75 \%$ of the original rate, it would take the same population 17 years to recover. Although research and harvest data show that males are more vulnerable to hunting, the harvest of females has the greatest potential of impacting the population (Fraser et al. 1982, Bunnell and Tait 1985). Given the potential impacts of overharvest, understanding harvest vulnerability is an essential, yet difficult, task for any bear manager. This information allows managers the option of adjusting aspects of their hunting seasons (e.g., harvest regulations, land access) to increase the effectiveness of recreational harvest for achieving population goals.

Of the research on harvest vulnerability, most has been focused on the game species, while few studies have examined hunter characteristics. Traditional hunter research has relied on hunter surveys to gain information, even though this information can be inaccurate (Stedman et al. 2004, Diefenbach et al. 2005). With Global Positioning System (GPS) and Geographic Information System (GIS) technology becoming increasingly affordable, researchers are able to use that technology to track hunter movement and habitat use, and develop expectations for the spatial patterns of harvest pressure. Lyon and Burcham (1998) issued GPS units to elk (Cervus 
elaphus) hunters in Montana and were able to record distances and speeds traveled, habitat use, and slope. They found that hunters spent most of their time in less steep areas, areas closer to roads, and open-forest habitat. Broseth and Pederson (2000) tracked willow ptarmigan (Lagopus lagopus) hunters in Norway and determined that willow ptarmigans were most vulnerable when near starting locations of hunters. Diefenbach et al. (2005) used GPS technology to aerially record the locations and calculate the density of black bear and white-tailed deer (Odocoileus virginianus) hunters in Pennsylvania. They found that hunters generally remained close to roads, although bear hunters were observed farther from roads than deer hunters. Keenan (2010) found that the density of Pennsylvania deer hunters on public land was about 2 times greater than on private land in one of his study areas. Most recently, Lebel et al. (2012) used GPS units and surveys to identify characteristics affecting deer hunter success, and recommended increasing accessibility and visibility near access roads to promote hunter success.

We modeled harvest vulnerability for female bears in western Maryland, an area where a bear hunting season was recently reestablished. During the 1950s, Maryland's bear population was in danger of extirpation, prompting the state to close bear hunting in 1953 (Spiker 2011). Following the closure of the season, the population recovered to levels that allowed Maryland to reopen the hunting season in 2004. Because the hunting season was closed for many years, little information is available regarding harvest pressure and vulnerability in the state. We used GPS technology to record locations for both female bears and bear hunters. We used these data to develop presence-only predictive occurrence models for both species, resulting in a map of female bear distribution and a map of hunter distribution. We overlaid these 2 models to identify areas of high harvest vulnerability and areas of low harvest vulnerability that may be acting as 
natural refugia for bears. To evaluate how well our model could predict bear harvests, we examined model values at locations of previous Maryland bear harvests.

\section{METHODS}

\section{Study Area}

We conducted this study in Garrett County, Maryland which is the westernmost county in the state (Fig. 3.1). Garrett County is bordered by Pennsylvania to the north and West Virginia to the south and west. The total area of this county is $1,722 \mathrm{~km}^{2}$. Maryland's black bear population occurs at its highest densities in Garrett County and the adjacent Allegany County to the east, which is the only area in the state where bear hunting is currently permitted (Spiker 2011).

Elevations on the study area range from $292-1,028 \mathrm{~m}$. The majority of the study area is forested, with approximately $68 \%$ of the total area covered in deciduous forests. The human population density in the area is relatively low at 18 persons $/ \mathrm{km}^{2}$ (U.S. Census Bureau 2010). Approximately $22 \%$ of the area is public land, including several large contiguous public areas. The 221-km² Savage River State Forest is the largest public area in the county and makes up almost $13 \%$ of the study area.

The study area contains 5 different forest-type groups (U.S. Department of Agriculture Forest Service 1999). Oak/hickory (oaks (Quercus spp.) and hickories (Carya spp.)) is the most common, making up 54\% of all forested land in Garrett County. Northern hardwood (red maple (Acer rubrum), sugar maple (A. saccharum), American beech (Fagus grandifolia), yellow birch (Betula alleghaniensis), and black cherry (Prunus serotina)) is also common in the study area, making up 33\% of forests. Elm/ash/red maple (elm (Ulmus spp.), ash (Fraxinus spp.), and red maple), white/red pine (white pine (Pinus strobus) and red pine (Pinus resinosa)), and spruce/fir (spruce (Picea spp.) and fir (Abies spp.)) all account for $\leq 7 \%$ of the total forested land. The understory vegetation in these forest-type groups includes mountain laurel (Kalmia latifolia), 
rhododendron (Rhododendron spp.), serviceberry (Amelanchier arborea), dogwood (Cornus spp.), and hazelnut (Corylus spp.), which are important sources of food and thick cover for bears.

\section{Black Bear GPS Data Collection}

Staff from the Maryland Department of Natural Resources (MDNR) captured bears in Garrett County from 2005-2007 using barrel traps, spring-activated foot snares, and running with hounds (H. A. Spiker, MDNR, personal communication). Bears were chemically immobilized and females with neck circumferences of $>48 \mathrm{~cm}$ were fitted with Lotek Model 3300S GPS collars (Lotek Wireless Inc., Newmarket, Ontario, Canada) weighing 285 g (Lotek 2005). Bears with neck circumferences $<48 \mathrm{~cm}$ do not allow for the proper positioning of the collar antenna, which reduces the accuracy of the GPS coordinates. GPS collars were programmed to record a waypoint every 4 hours and the battery life was approximately 1 year. Each waypoint recorded the latitude and longitude at the current position, along with date and time. Each collar also emitted a VHF signal that could be used to locate the bear in the event of a GPS failure. For bears remaining collared into the denning season, den sites were located using the VHF signal and collars were replaced during MDNR's annual den checks. At that time the GPS data were downloaded from the collars. If a collar remained stationary for an extended period of time, the collar would emit a unique VHF "mortality signal." These collars were located to determine the cause of the lack of movement. Any mortalities or slipped collars were recorded and data were recovered from the collar if possible.

\section{Bear Hunter GPS Data Collection}

During the first years of the reestablished bear hunting seasons in Maryland, each hunter that was awarded a tag was required to attend a pre-hunt meeting the day before the opening of the season. During the pre-hunt meetings from 2005-2007, MDNR asked hunters to voluntarily 
participate in a GPS study of their movements (H. A. Spiker, MDNR, personal communication). Each volunteer was assigned a uniquely numbered Garmin 12XL GPS unit (Garmin Corporation, Olathe, Kansas) attached to an elastic armband. In order to record detailed movement data, the GPS units were programmed to record a waypoint every 2 minutes. Positional accuracy for these GPS units was $15 \mathrm{~m}$ (Garmin 1997). Hunters were instructed to turn on the GPS when they entered the field during their hunt and turn it off when they left the field. Hunters were given a brief demonstration, written instructions, and additional batteries. They were asked to return the GPS units at an MDNR bear check station.

We downloaded all GPS data and removed extraneous points. Excluded points were locations where the hunter was in a building (e.g, home, business), within a city where hunting was prohibited, outside of Garrett County, or outside of the permitted hunting hours. Additionally, we excluded points where the speed of travel between locations indicating the use of a motorized vehicle. Excluding these locations ensured that we only used data representing times when a hunter was able to encounter and legally harvest a bear. However, additional locations were likely included where hunters were in the field but not actually hunting.

\section{Predictive Occurrence Modeling of Bears and Bear Hunters}

We used maximum entropy modeling in program Maxent (Phillips et al. 2004) for both the bear and bear hunter models. Maximum entropy distribution modeling is based on estimating the target distribution by finding the distribution with the maximum entropy (i.e., closest to uniform) given environmental constraints (Phillips et al. 2004). By finding the distribution with the maximum entropy, no prior assumptions are made regarding the distribution. Maxent requires 2 components: presence location data (i.e., coordinates of a known occurrence of the target species) and raster environmental layers that may help describe factors influencing the suitability 
of an area for the target species (Phillips et al. 2006). The program then generates up to 10,000 random locations across the study area, called pseudoabsences, which help describe the available values of the environmental layers within the study area. By comparing the values of the environmental layers at the presence locations to the available values at the pseudoabsence points, Maxent can define constraints for the range of values of each environmental layer at which the species will occur (Elith et al. 2011). Maxent then generates a distribution that is closest to uniform and still satisfies the constraints (Phillips et al. 2006). The resulting map output is a raster dataset of values that represent the relative probability of occurrence of the target species in each raster cell. Maxent has become an increasingly popular program for predictive occurrence modeling as it has consistently outperformed other presence-only modeling approaches (Elith et al. 2006, Peterson et al. 2007, Ortega-Huerta and Peterson 2008).

We created separate Maxent models for bears and bear hunters to quantify the probability of a black bear and hunter occupying the same area, thus predicting harvest vulnerability. Because the majority of bear and hunter GPS locations were within Garrett County, we only created these models for the extent of Garrett County. Maxent is generally insensitive to the effects of spatial autocorrelation (Kaliontzopoulou et al. 2008) and has been successfully used with GPS telemetry data (Monterroso et al. 2009). However we reduced those effects more by using 25 randomly-selected locations from each bear and 1 location from each bear hunting event. We only included bear GPS locations during fall to provide a more accurate picture of bear distribution during that time. Because the 2005-2007 hunting seasons only lasted 2-4 days, we did not have sufficient bear locations to only include locations recorded during the hunting seasons. For the environmental layer inputs, we followed the bear occurrence model created by Clark et al. (1993) and used the following variables: elevation, slope, aspect, distance to nearest 
road, distance to nearest stream, and cover type diversity (Table 4.1). We also used a binary public land layer as an additional categorical variable not used in the Clark et al. (1993) model. We used the National Elevation Dataset (NED) for the elevation and to derive the slope and aspect layers. We created the distance to roads and distance to streams layers using the Euclidean Distance tool in ArcGIS. The cover type layer was a reclassified version of the National Land Cover Dataset (NLCD) data layer. Cover type diversity is defined as the number of unique cover types within the radius of the mean distance traveled by a female black bear in a 4-hr time period. Since a new bear GPS location is recorded every 4 hours, we calculated the distance traveled between subsequent locations using Hawth's Analysis Tools and found the mean of those distances. We then used the Focal Statistics tool in ArcGIS, with the mean distance traveled as the neighborhood size, to calculate the number of different cover types surrounding each raster cell. For example, if a given cell was classified as deciduous forest but was surrounded by wetlands and agricultural land (within the specified neighborhood), that cell was assigned a diversity value of 3 . All data layers were set to a $30-\mathrm{m}$ raster cell size as that is the coarsest resolution of all the data layers.

We assumed that bear hunters chose hunting locations based on the likelihood of encountering a bear, so hunter distribution should be dictated by the same variables as bear distribution, although the importance of those variables may differ between the 2 groups. Therefore, the hunter model included the same environmental variables as the bear model except used cover type instead of cover type diversity. We calculated Pearson correlation coefficients for all variables in ENMTools 1.3 (Warren et al. 2010) to test for multicollinearity. If 2 variables were highly correlated $\left(R^{2}>|0.80|\right)$, the least biologically relevant of the 2 was removed (Lozier et al. 2009). 
We replicated the bear and hunter models 50 times each. We used bootstrapping to select $20 \%$ of the occurrence points to be used as a testing dataset for each replication. The Maxent output provided a probability of occurrence across the study area, as well as a quantification of the relative contribution (i.e., relative importance) of each environmental variable in the model. As an additional measure of variable importance, we selected the option in Maxent to run jackknife tests for each variable. This technique runs the model using only 1 variable at a time, thus showing how much unique information each variable contributes to the complete model. Each model output also includes curves that show how probability of occurrence changes with changes in values of each environmental variable. We used the mean Maxent output as the final model for each. We used the mean area under the receiver operating characteristic curve (AUC) to evaluate the predictive performance of each model. AUC values, which compare the model to null expectations, are the most commonly used measure of Maxent model performance (Elith et al. 2006). If $\mathrm{AUC}=0.5$, the model does not perform any better than a random model, and model performance gets better as AUC approaches 1.0. We also determined values of both models at each bear harvest location during the 2004-2010 Maryland bear hunting seasons, as recorded by MDNR, to assess how well our models explained previous bear harvest.

Once we created the bear and hunter occurrence models, we reclassified the rasters to only include high, medium, or low relative probability of occurrence. From this map we used raster calculator to identify areas with high probabilities of bear and hunter occurrence as well as areas of high probability of bear occurrence but low probability of hunter occurrence. Areas with high probabilities for both groups indicated a high probability of bears encountering hunters, and thus where harvest vulnerability is high for females. Clusters with high bear 
probabilities but low hunter probabilities indicated areas where harvest vulnerability is low that may serve as de facto sanctuaries for female bears.

\section{RESULTS}

We used 230 GPS locations from 108 bear hunters and 250 locations from 10 bears as the Maxent inputs. None of the environmental variables we proposed exhibited high collinearity, so all were included in our models. The 50 replications of our bear model (Fig. 4.1) had a mean $\mathrm{AUC}=0.794(\mathrm{SE}=0.002$; Fig. 4.2). All replicates had predictions that were significantly better than random predictions. Both the percent contribution calculation and jackknife test of variables show that slope was the most important environmental variable for predicting bear occurrence, with $35.3 \%$ contribution (Table 4.2). Land ownership (public/private) and distance to roads also were relatively important, whereas aspect and cover type diversity had little impact on the model performance. Our hunter model replications (Fig. 4.3) had a mean AUC $=0.764$ $(\mathrm{SE}=0.002$; Fig. 4.4). As with the bear model, all hunter model replicates produced significantly better predictions than random. Our measure of variable importance showed that land ownership and cover type were used most in the model (38.7\% and $25.7 \%$ contribution, respectively; Table 4.2). All other variables were much less important, with aspect again being the least important variable.

Both models showed that mean probability of occurrence on public land was $\sim 60 \%$ higher compared to private land (Appendix C). For most variables in the hunter model, probability of occurrence remained fairly constant at all values. Probability of occurrence declined slightly at slopes steeper than $\sim 18 \%$. The bear model showed that probability of occurrence was much higher at slopes of $\sim 15-22 \%$, on average, than at steeper or flatter locations. Probability of occurrence generally increased for bears with increasing distance to 
nearest stream, before leveling off at $\sim 1000 \mathrm{~m}$. For the bear model, $33.8 \%$ of the county was classified as low, $54.3 \%$ as medium, and $11.9 \%$ as high probability of occurrence. The hunter model had a similar makeup, with $23.3 \%$ low, $60.5 \%$ medium, and $16.2 \%$ high probability of occurrence. The locations considered high probability of occurrence for both female bears and hunters totaled just $93.5 \mathrm{~km}^{2}$, or $5.43 \%$ of the county (Fig. 4.5, Table 4.3). Eighty-one percent of that area fell within public land. The area representing high bear occurrence but low hunter occurrence also was small, at $0.9 \%$ of the study area $\left(15.2 \mathrm{~km}^{2}\right)$, with $50 \%$ falling within the boundaries of public land.

We used 356 harvest locations from the 2004-2011 Maryland bear hunting seasons to evaluate how well our models predict areas of known bear harvest (Fig. 4.6). Only 15 harvest locations $(4.2 \%)$ fell within the area we predicted to have the highest harvest vulnerability, whereas 16 points were located within our predicted low vulnerability areas. Sixty-three harvest points (17.7\%) were located in areas classified as high probability of female bear occurrence, and $88(22.8 \%)$ were in areas of high probability of hunter occurrence. However, $92(25.8 \%)$ harvest locations were located in low bear probability areas, and $65(18.3 \%)$ points were within low hunter probability areas. When examining locations of female bear harvests only, we found similar results. Of those points, $3.3 \%$ fell within our predicted high vulnerability areas, whereas 2 times that amount were located in predicted low vulnerability areas. Just over $17 \%$ were in high bear probability areas, and 19.2\% were in high hunter probability areas. To determine if year impacted our results, we also looked only at harvest locations from the 2005-2007 bear hunting seasons. For all harvests during those seasons, 5.9\% were located in the high vulnerability area, and $3.8 \%$ of female harvests during those seasons were in those areas. 
Of the predicted low vulnerability areas, 9 blocks existed that were $>1 \mathrm{~km}^{2}$, with the largest block being $6.2 \mathrm{~km}^{2}$ (Fig. 4.5). Five (1.4\%) of all harvest locations and $1.3 \%$ of female harvests occurred within these blocks. All blocks were at least partially located within public land layers. We compared median values of each environmental variable between the low vulnerability blocks and Garrett County overall. The median slope of these areas was 2.3 times steeper $(25.9 \%$ vs. $11.5 \%)$ than the median of the study area. These areas also were nearly 2 times farther from roads than the median of Garrett County $(357.1 \mathrm{~m}$ vs. $187.2 \mathrm{~m})$ and 1.5 times farther from streams (404.7 m vs. $271.1 \mathrm{~m})$.

\section{DISCUSSION}

The importance of slope for our bear model is consistent with the findings of Amstrup and Beecham (1976) and Powell and Mitchell (1998), who showed that bears tended to use relatively steep slopes compared to their availability. We expected predicted bear occurrence to be higher on private land, because private land is more prevalent in the county, and private lands presumably are more likely to restrict or prohibit hunting. However, public lands in the study area offer some of the largest contiguous blocks of forest in the county, providing bear habitat. Our bear hunter model also showed higher probability of occurrence on public land. This is consistent with the findings of Vieira et al. (2003) and Keenan (2010), who both reported higher ungulate hunter densities on public land compared to private land.

The mean AUC for our female bear model was above the recommended threshold of 0.7 , indicating a useful model (Baldwin 2009). However, several studies report AUC $>0.9$ when using a Maxent modeling approach (Kaliontzopoulou et al. 2008, Monterroso et al. 2009, Gormley et al. 2011). Lozier et al. (2009) used Maxent to model black bear distribution in the western United States, and achieved an $\mathrm{AUC}=0.983$. However, they used entirely climate- 
related variables, which likely have a much greater impact on bear distribution in the western United States compared to the eastern United States. We believe the main explanation for the relatively low AUC for our model is the adaptable and generalist nature of black bears. Black bears are a widespread species that occurs throughout much of the United States and Canada (Pelton 2000), illustrating their ability to live in a variety of habitats. Because of their adaptability, we would expect them to be less sensitive to differences in habitat and environmental variables, although the variables we used have been shown to influence bear distribution (Clark et al. 1993). Research has shown that Maxent and other species distribution modeling approaches often have less predictive power (i.e., lower AUC) when used for generalist species compared to species that are more specialized in their habitat requirements. Evangelista et al. (2008) compared predictive occurrence model performance for a habitat generalist and habitat specialist plant species. They found that AUC values were higher for the generalist species for all 3 modeling approaches they examined. For Maxent, the AUC for the specialist model was $38 \%$ higher than the AUC for the generalist (0.773 vs. 0.559$)$. Lobo et al. (2008) argued that AUC can be a misleading measure of model accuracy when used for generalist species, because the AUC will continue to increase as environmental variables are added.

For the hunter model, we found no similar research to compare AUC values. We are aware of only 1 study that modeled humans using Maxent. In that study, van Gils and Kayijamahe (2009) modeled human activity (e.g., camps, beehives, antelope snares) in Rwanda, but did not report AUC. Based on the useful threshold of AUC $=0.7$, the AUC of our hunter model can be considered relatively low. The reason for not producing a higher AUC may be explained best by the numerous factors that affect where hunters choose to hunt. Bear hunters 
likely do not choose their locations based solely on environmental conditions in those areas. Many bear hunters probably choose hunting locations on land they own, or their family or friends own, regardless of whether or not the location offers the best hunting opportunities. Hunters unfamiliar with the area (e.g., nonresidents) may not have the opportunity to scout the area prior to the hunt, and may simply choose an area that is easiest for them to find and access. In addition, "prime" bear habitat may be off-limits to hunters due to private ownership, or difficulty of access (e.g., no roads, steep slopes, dense vegetation). Garrett County is comprised of $78 \%$ private land, and much of that land probably restricts hunter access.

We were surprised at the small size area of overlap between high bear and high hunter occurrence. We also were surprised at the poor model performance when using harvest locations to assess predictive power. Although we built the model using only female bear locations, our model did not perform well predicting female harvest locations either, so that is not a reasonable explanation. There are a number of alternative explanations for this performance. One is that our low sample size and bear locations outside of the hunting area negatively impacted the model. Issues such as collar failures and slipped collars limited our sample size to just 10 bears. To increase the number of locations, we included all fall locations of bears so most did not actually occur during the 2-4 day hunting season. Maxent has been shown to be robust to small sample size (Pearson et al. 2007, Kumar and Stohlgren 2009), yielding models with high predictive power using as few as 5 occurrences (Pearson et al. 2007). Although our number of bear occurrences $(n=250)$ was likely sufficient, having only 10 individual bears increases the chance that our sample is not representative of all female bears in Garrett County.

Having locations outside of the hunting seasons may have negatively affected the predictive power of our model if bear behavior is different during the hunting season than before 
or after the season, which has been reported for other game species. Connor et al. (2001) documented elk movements from public land to private land once hunting began. Mule deer (Odocoileus hemionus) in Colorado were shown to move to areas with more escape cover during the hunting season only if located in an area open to hunting (Kufeld et al. 1988). Ordiz et al. (2012) found that brown bears (Ursus arctos) in Scandinavia became more active at night when the hunting season began. If Maryland bears exhibit similar changes during the hunting season, accurately modeling harvest vulnerability would be much more difficult. For areas predicted as high harvest vulnerability, if hunter and bear use of an area is temporally stratified, vulnerability could actually be quite low. However, because the hunting seasons are so short, the majority of bears may not encounter hunters at a level that affects their behavior. This is a potential reason for the poor fit of our model to the harvest locations. It also is possible that hunters using areas of low hunter occurrence have higher harvest success rates. Although those areas are predicted to not have hunters based on environmental conditions, hunters may use them for other reasons (e.g., land access). If hunter density is low enough to prevent bear behavioral changes, hunters in those areas could actually have a higher chance of harvest than hunters in areas where bears become more nocturnal or reduce movements. However, we do not have sufficient data to detect bear behavioral changes or spatial harvest success rates.

Another explanation for the poor predictive performance is that harvest vulnerability, as we define it, does not necessarily translate to bear harvest. We already mentioned how the timing of hunter and bear landscape use can influence the relationship between vulnerability predictions and actual harvest. Harvest success is, in part, affected by chance encounters between hunters and bears, so hunting an area with high bear density does not guarantee a chance to harvest a bear. Maryland does not allow organized man drives or the use of dogs for 
bear hunting, so hunters and bears could be in close proximity without an encounter. Harvest success also can be affected by visibility. Visibility is influenced by weather and vegetation, and a bear hunter can be close to a bear without having an opportunity to harvest it if visibility is low. Areas of high bear density likely correlate with thick cover, which could reduce visibility and, therefore, hunter encounters with bears.

Another factor that may have affected the predictive performance of the model is inaccuracy in harvest location records. Harvest locations were conveyed to MDNR staff by pointing to the general kill location on a map, and locations were later geo-referenced. This approach is useful for providing MDNR with a picture of the general distribution of bear harvest, but may influence how we evaluate the performance of our model. Due to the small area classified as high harvest vulnerability, even slight inaccuracies in harvest location reporting could impact our evaluation of the model.

The comparison of the low vulnerability blocks to the rest of the county provides insight into what may protect female bears from harvest. Bears have been shown to use steep or moderately steep slopes (Amstrup and Beecham 1976, Clark et al. 1993, Powell and Mitchell 1998). Bears may use those areas to exploit specific food sources, as they have been shown to adjust habitat use seasonally to focus on the most abundant or nutritious foods available (Jonkel and Cowan 1971, Garshelis and Pelton 1981, Raine and Kansas 1990). However, the steep slopes also may provide protection from human disturbance, including hunting pressure. Hunters may avoid very steep slopes as they would make travel and recovery of a harvested bear difficult. Our hunter model indicated that the probability of occurrence of hunters declined slightly beginning at approximately 18\% slope. Lyons and Burcham (1998) and Stedman et al. (2004) found that ungulate hunters generally used flatter slopes. Bears may adjust their 
landscape use in response to the presence of hunters, perhaps moving to steeper slopes, where hunter density is lower.

The largest low vulnerability blocks also were much farther from roads and streams, on average, compared to the county as a whole, indicating that these are relatively isolated areas. Although our hunter model did not show a large response of probability of occurrence to distance from roads or streams, probability of occurrence did decrease at locations farther from both. Lyon and Burcham (1998), Gratson and Whitman (2000), Stedman et al. (2004), all found that the presence of roads increases hunter use. These low vulnerability blocks may provide bears with some level of protection from hunters and other human disturbances, providing the potential to serve as de facto refugia. Keenan (2010) found that areas far from roads and on steep slopes received low harvest pressure and acted as refugia for white-tailed deer in Pennsylvania. Powell et al. (1996) observed significantly higher black bear density and survivorship in North Carolina inside an established bear sanctuary compared to outside. The sanctuary produced dispersing individuals that traveled into areas where bear harvest was permitted. Beringer et al. (1998) suggested that even small sanctuaries are important for supporting female bears in a heavily hunted population. They also found that sanctuaries produced surplus bears that were available for harvest outside of the sanctuaries. In addition to established bear sanctuaries, Ryan (2009) documented population growth for bears living near active mine sites in West Virginia, which provided protection from hunting, and population decline for bears living on areas more accessible to hunting pressure.

Overall, our study yielded useful predictions of the distribution of female bears and bear hunters, along with measures of the effects of environmental variables on the distributions. Our bear hunter model performed fairly well, given the complexities of modeling human spatial 
behavior, and provided a map of the distribution of harvest pressure. However, our approach was not valuable for predicting bear harvest locations, due to a number of factors that highlight the difficulty of modeling harvest vulnerability.

\section{MANAGEMENT IMPLICATIONS}

Our results provide MDNR with its first prediction of distributions of female bears and bear hunters during the hunting season. MDNR can use this information to, if necessary, adjust hunting season regulations or approaches to increase the efficacy of this management tool. Because the current goal is to slow bear population growth in the state, MDNR can decide to focus efforts on increasing access and hunting pressure in the low vulnerability blocks we identified, perhaps by increasing hunter awareness of hunting opportunities in those areas. However, because our bear data during the hunting season was sparse, additional research should be conducted to validate our model and determine if female bears are actually using those areas during the hunting season. As harvest regulations and population goals potentially change, MDNR may decide to protect these low vulnerability areas to provide females with access to unhunted habitat. This approach has been successfully used in North Carolina to promote sustainable bear harvest, but should not be implemented as long as the goal is to limit population growth.

\section{AKNOWLEDGMENTS}

Funding for this project was provided by Federal Aid in Wildlife Restoration Act Project W-61-R, Maryland Department of Natural Resources, and West Virginia University Division of Forestry. Thank you to MDNR personnel for issuing hunter GPS units and collecting bear data. We thank all of the Maryland bear hunters who volunteered for the study. 


\section{LITERATURE CITED}

Amstrup, S. C., and J. Beecham. 1976. Activity patterns of radio-collared black bears in Idaho. Journal of Wildlife Management 40:340-348.

Baldwin, R. A. 2009. Use of maximum entropy modeling in wildlife research. Entropy 11:854-866.

Beringer, J., S. G. Seibert, S. Reagan, A. J. Brody, M. R. Pelton, and L. D. Vangilder. 1998. The influence of small sanctuary on survival rates of black bears in North Carolina. Journal of Wildlife Management 62:727-734.

Broseth, H., and H. C. Pederson. 2000. Hunting effort and game vulnerability studies on a small scale: a new technique combining radio-telemetry, GPS, and GIS. Journal of Applied Ecology 37:182-190.

Bunnell, F. L., and D. E. N. Tait. 1985. Mortality rates of North American bears. Arctic $38: 316-323$

Clark, J. D., J. E. Dunn, and K. G. Smith. 1993. A multivariate model of female black bear habitat use for a Geographic Information System. Journal of Wildlife Management $57: 519-526$.

Connor, M. M., G. C. White, and D. J. Freddy. 2001. Elk movement in response to early-season hunting in northwest Colorado. Journal of Wildlife Management 65:926-940.

Cowan, I. McT. 1972. The status and conservation of bears (Ursidae) of the world- 1970 . International Conference on Bear Research and Management 2:343-367.

Diefenbach, D. R., J. C. Finley, A. E. Luloff, R. Stedman, C. B. Swope, H. C. Zinn, G. J. San Julian. 2005. Bear and deer hunter density and distribution on public land in Pennsylvania. Human Dimensions of Wildlife 10:201-212. 
Elith, J., C. H. Graham, R. P. Anderson, M. Dudik, S. Ferrier, A. Guisan, R. J. Hijmans, F. Huettman, J. R. Leathwick, A. Lehmann, J. Li, L. G. Lohmann, B. A. Loiselle, G. Manion, C. Moritz, M. Nakamura, Y. Nakazama, J. McC. Overton, A. T. Peterson, S. J. Phillips, K. S. Richardson, R. Scachetti-Pereira, R. E. Schapire, J. Sobero’n, S. Williams, M. S. Wisz, and N. E. Zimmermann. 2006. Novel methods improve prediction of species' distributions from occurrence data. Ecography 29:129-151.

Elith, J., S. J. Phillips, T. Hastie, M. Dudik, Y. E. Chee, and C. J. Yates. 2011. A statistical explanation of MaxEnt for ecologists. Diversity and Distributions 17:43-57.

Evangelista, P. H., S. Kumar, T. J. Stohlgren, C. S. Jarnevich, A. W. Crall, J. B. Norman III, and D. T. Barnett. 2008. Modelling invasion for a habitat generalist and a specialist plant species. Diversity and Distributions 14:808-817.

Fraser, D., J. F. Gardner, G. B. Kolenosky, and S. Strathearn. 1982. Estimation of harvest rate of black bears from age and sex data. Wildlife Society Bulletin 10:53-57.

Garmin Corporation. 1997. GPS XL personal navigator operator's manual.

Garshelis, D. L., and M. R. Pelton. 1981. Movements of black bears in the Great Smoky Mountains National Park. Journal of Wildlife Management 45:912-925.

Gormley, A. M., D. M. Forsyth, P. Griffioen, M. Lindeman, D. S. L. Ramsey, M. P. Scroggie, and L. Woodford. 2011. Using presence-only and presence-absence data to estimate the current and potential distributions of established invasive species. Journal of Applied Ecology 48:25-34.

Gratson, M. W., and C. L. Whitman. 2000. Road closures and density and success of elk hunters in Idaho. Wildlife Society Bulletin 28:302-310. 
Jonkel, C. J., and I. McT. Cowan. 1971. The black bear in the spruce-fir forest. Wildlife Monographs 27.

Kaliontzopoulou, A., J. C. Brito, M. A. Carretero, S. Larbes, and D. J. Harris. 2008. Modelling the partially unknown distribution of wall lizards (Podarcis) in North Africa: ecological affinities, potential areas of occurrence, and methodological constraints. Canadian Journal of Zoology 86:992-1001.

Kasworm, W. F., and T. J. Their. 1994. Adult black bear reproduction, survival, and mortality sources in northwest Montana. International Conference on Bear Research and Management 9:223-230.

Keenan, M. T. 2010. Hunter distribution and harvest of female white-tailed deer in Pennsylvania. Thesis, The Pennsylvania State University, State College, USA.

Kolenosky, G. B. 1986. The effects of hunting on an Ontario black bear population. International Conference on Bear Research and Management 6:45-55.

Kufeld, R. C., D. C. Bowden, and D. L. Schrupp. 1988. Influence of hunting on movements of female mule deer. Journal of Range Management 41:70-72.

Kumar, S., and T. J. Stohlgren. 2009. Maxent modeling for predicting suitable habitat for threatened and endangered tree Canacomyrica monticola in New Caledonia. Journal of Ecology and Natural Environment 1:94-98.

Lebel, F., C. Dussault, A. Massé, and S. D. Côté. 2012. Influence of habitat features and hunter behavior on white-tailed deer harvest. Journal of Wildlife Management 76:1431-1440.

Lobo, J. M., A. Jiménez-Valverde, and R. Real. 2007. AUC: a misleading measure of the performance of predictive distribution models. Global Ecology and Biogeography $17: 145-151$. 
Lotek Wireless Fish and Wildlife Monitoring. 2005. Small and midsize animals GPS location system user's manual GPS_3300.

Lozier, J. D., P. Aniello, and M. J. Hickerson. 2009. Predicting the distribution of Sasquatch in western North America: anything goes with ecological niche modeling. Journal of Biogeography 36:1623-1627.

Lyon, L. J., and M. G. Burcham. 1998. Tracking elk hunters with the global positioning system. U. S. Department of Agriculture, Forest Service, Rocky Mountain Research Station, Fort Collins, Colorado, USA.

Miller, S. D., and S. M. Miller. 1988. Interpretation of bear harvest data. Alaska Department of Fish and Game, Juneau, USA.

Miller, S. D. 1989. Population management of bears in North America. International Conference on Bear Research and Management 8:357-373.

Monterroso, P., J. C. Brito, P. Ferreras, and P. C. Alves. 2009. Spatial ecology of the European wildcat in a Mediterranean ecosystem: dealing with small radio-tracking datasets in species conservation. Journal of Zoology 279:27-35.

Ordiz, A., O. G. Støen, S. Sæbø, J. Kindberg, M. Delibes, and J. E. Swenson. 2012. Do bears know they are being hunted? Biological Conservation 152:21-28.

Ortega-Huerta, M. A., and A. T. Peterson. 2008. Modeling ecological niches and predicting geographic distributions: a test of six presence-only methods. Revista Mexicana de Biodiversidad 79:205-216.

Pearson, R. G., C. J. Raxworthy, M. Nakamura, and A. T. Peterson. 2007. Predicting species distributions from small numbers of occurrence records: a test case using cryptic geckos in Madagascar. Journal of Biogeography 34:102-117. 
Pelton, M. R. 2000. Black bear. Pages 547-555 in G. A. Feldhamer, B. C. Thompson, and J. A. Chapman, editors. Wild mammals of North America: biology, management, and conservation. Second edition. The John Hopkins University Press, Baltimore, Maryland, USA.

Peterson, A. T., M. Papes, and M. Eaton. 2007. Transferability and model evaluation in ecological niche modeling: a comparison of GARP and Maxent. Ecography 30:550-560

Phillips, S. J., M. Dudik, and R. E. Schapire. 2004. A maximum entropy approach to species distribution modeling. Proceedings of twenty-first International Conference on Machine Learning.

Phillips, S. J., R. P. Anderson, and R. E. Schapire. 2006. Maximum entropy modeling of species geographic distributions. Ecological Modelling 190:231-259.

Powell, R. A., J. W. Zimmerman, D. E. Seaman, and J. F. Gilliam. 1996. Demographic analysis of a hunted black bear population with access to a refuge. Conservation Biology $10: 224-234$.

Powell, R. A., M. S. Mitchell. 1998. Topographical constraints and home range quality. Ecography 21:337-341.

Raine, R. M., and J. L. Kansas. 1990. Black bear seasonal food habits and distribution by elevation in Banff National Park, Alberta. International Conference on Bear Research and Management 8:297-304.

Ryan, C. W. 2009. Population ecology, residents' attitudes, hunter success, economic impact, modeling management options and retention time of Telazol of West Virginia black bears. Dissertation, West Virginia University, Morgantown, USA. 
Seaman, D. E., and R. A. Powell. 1996. An evaluation of the accuracy of kernel density estimators for home range analysis. Ecology 77:2075-2085.

Spiker, H. 2011. Maryland black bear population status report. Maryland Department of Natural Resources, Wildlife and Heritage Service, Oakland, USA.

Stedman, R., D. R. Diefenbach, C. B. Swope, J. C. Finley, A. E. Luloff, H. C. Zinn, G. J. San Julian, and G. A. Wang. 2004. Integrating wildlife and human-dimensions research methods to study hunters. Journal of Wildlife Management 68:762-773.

U.S. Census Bureau. 2010. Census 2010 summary file 1, geographic header record G001. U.S. Census Bureau, Washington, D.C., USA.

U.S. Department of Agriculture Forest Service [USFS]. 1999. Northeastern forest and inventory analysis. Maryland statewide results. < <ttp://www.fs.fed.us/ne/fia/states/md/ index.html $>$ Accessed 11 Feb 2010.

van Gils, H., and E. Kayijamahe. 2009. Sharing natural resources: mountain gorillas and people in the Parc National des Volcans, Rwanda. African Journal of Ecology 48:621-627.

Warren, D. L., R. E. Glor, and M. Turelli. 2010. ENMTools: a toolbox for comparative studies of environmental niche models. Ecography 33:607-611.

Associate Editor: 
Table 4.1. Environmental variables used to create predictive occurrence models for black bears and bear hunters in western Maryland.

\begin{tabular}{|c|c|c|c|}
\hline Variable & Code & Ranges and classes & Source \\
\hline Aspect & aspect & $\begin{array}{l}1=\text { flat } \\
2=\text { North } \\
3=\text { East } \\
4=\text { South } \\
5=\text { West }\end{array}$ & Derived from NED \\
\hline Cover type & lulc & $\begin{array}{l}1=\text { developed } \\
2=\text { agriculture } \\
3=\text { open water } \\
5=\text { deciduous forest } \\
6=\text { mixed forest } \\
7=\text { wetland } \\
8=\text { grassland } \\
9=\text { agriculture } \\
10=\text { evergreen forest }\end{array}$ & National Land Cover Dataset (NLCD) \\
\hline $\begin{array}{l}\text { Cover type diversity } \\
\text { (\# of cover types) }\end{array}$ & diversity & $1-9$ & Derived from NLCD \\
\hline $\begin{array}{l}\text { Distance to nearest } \\
\operatorname{road}(\mathrm{m})\end{array}$ & droad & $0-2282$ & $\begin{array}{l}\text { Derived from USGS National Hydrography } \\
\text { Dataset }\end{array}$ \\
\hline $\begin{array}{l}\text { Distance to nearest } \\
\text { stream }(\mathrm{m})\end{array}$ & dstream & $0-1652$ & $\begin{array}{l}\text { Derived from U.S. Census Bureau TIGER/Line } \\
\text { shapefiles }\end{array}$ \\
\hline Elevation (m) & elev & $292-1027$ & USGS National Elevation Dataset (NED) \\
\hline Land ownership & public & $\begin{array}{l}0=\text { private land } \\
1=\text { public land }\end{array}$ & Maryland Department of Natural Resources \\
\hline Slope (\%) & slope & $0-113$ & Derived from NED \\
\hline
\end{tabular}


Table 4.2. Percent contribution of environmental variables to predictive occurrence models for female black bears and bear hunters in Garrett County, Maryland.

\begin{tabular}{lcc}
\hline & \multicolumn{2}{c}{ \% contribution } \\
\cline { 2 - 3 } Variable & Bear & Hunter \\
\hline Aspect & 5.2 & 2.6 \\
Cover type & --- & 25.7 \\
Cover type diversity & 2.3 & --- \\
Distance to nearest road & 10.0 & 4.8 \\
Distance to nearest & & \\
stream & 15.7 & 9.7 \\
Elevation & 12.6 & 9.6 \\
Land ownership & 19.0 & 38.7 \\
Slope & 35.3 & 9.0 \\
\hline
\end{tabular}


Table 4.3. Percent overlap (as percent of study area) of probability of occurrence classes for female black bear and bear hunter Maxent models in western Maryland.

\begin{tabular}{crcc}
\hline $\begin{array}{c}\text { Probability of } \\
\text { hunter occurrence }\end{array}$ & \multicolumn{3}{c}{$\begin{array}{c}\text { Probability of bear } \\
\text { occurrence }\end{array}$} \\
\hline & Low & Medium & High \\
Low & 9.14 & 12.79 & 0.88 \\
Medium & 23.23 & 32.32 & 5.35 \\
High & 1.07 & 9.43 & 5.43 \\
\hline
\end{tabular}




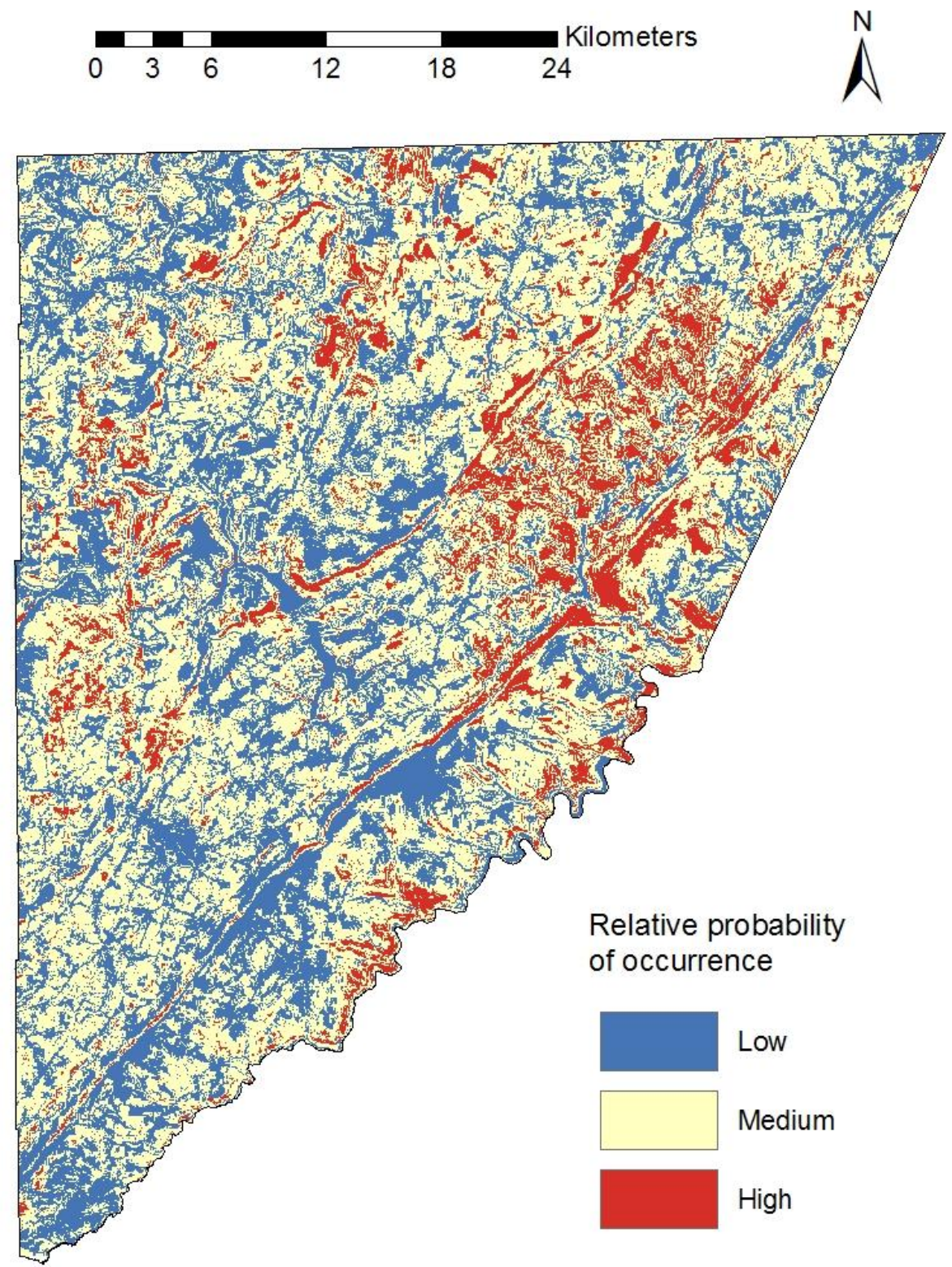

Figure 4.1. Mean output of 50 replications of a Maxent model of female black bear distribution in Garrett County, Maryland. Output has been reclassified as high, medium or low relative probability of bear occurrence. 


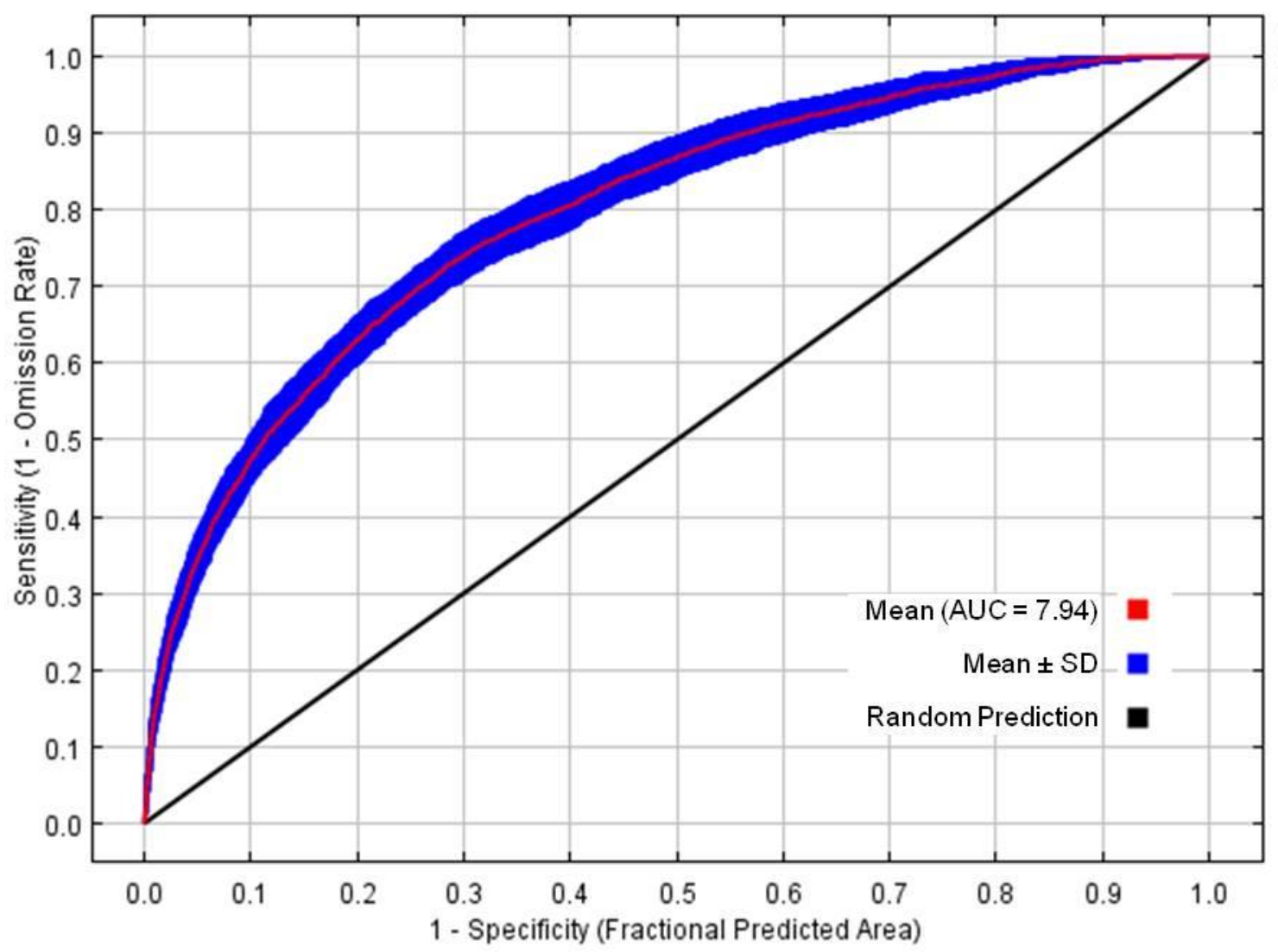

Figure 4.2. Maxent output of area under the receiver operating characteristic curve (AUC) for 50 replications of a model of female black bear distribution in Garrett County, Maryland. 

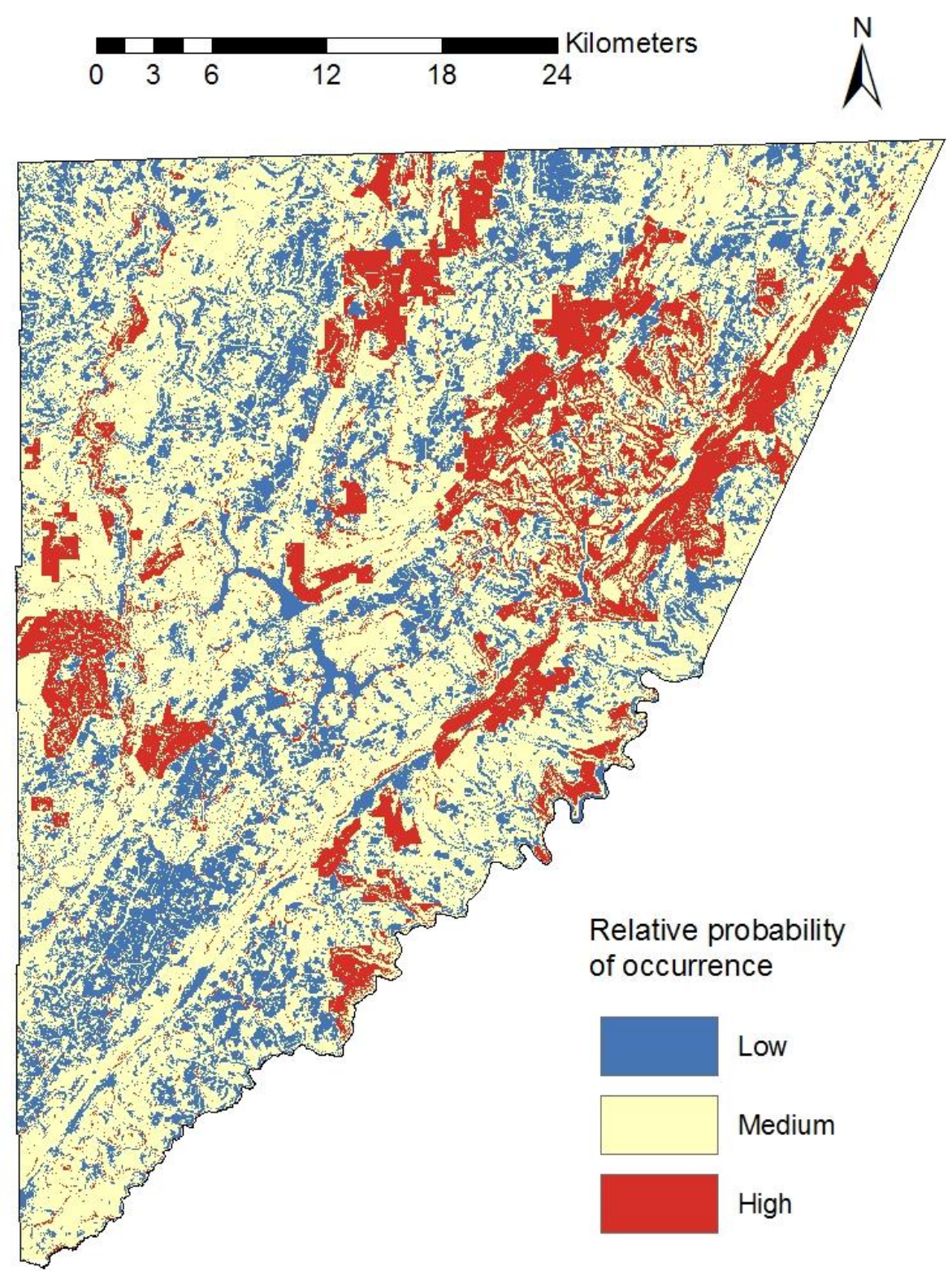

Figure 4.3. Mean output of 50 replications of a Maxent model of black bear hunter distribution in Garrett County, Maryland. Output has been reclassified as high, medium or low relative probability of hunter occurrence. 


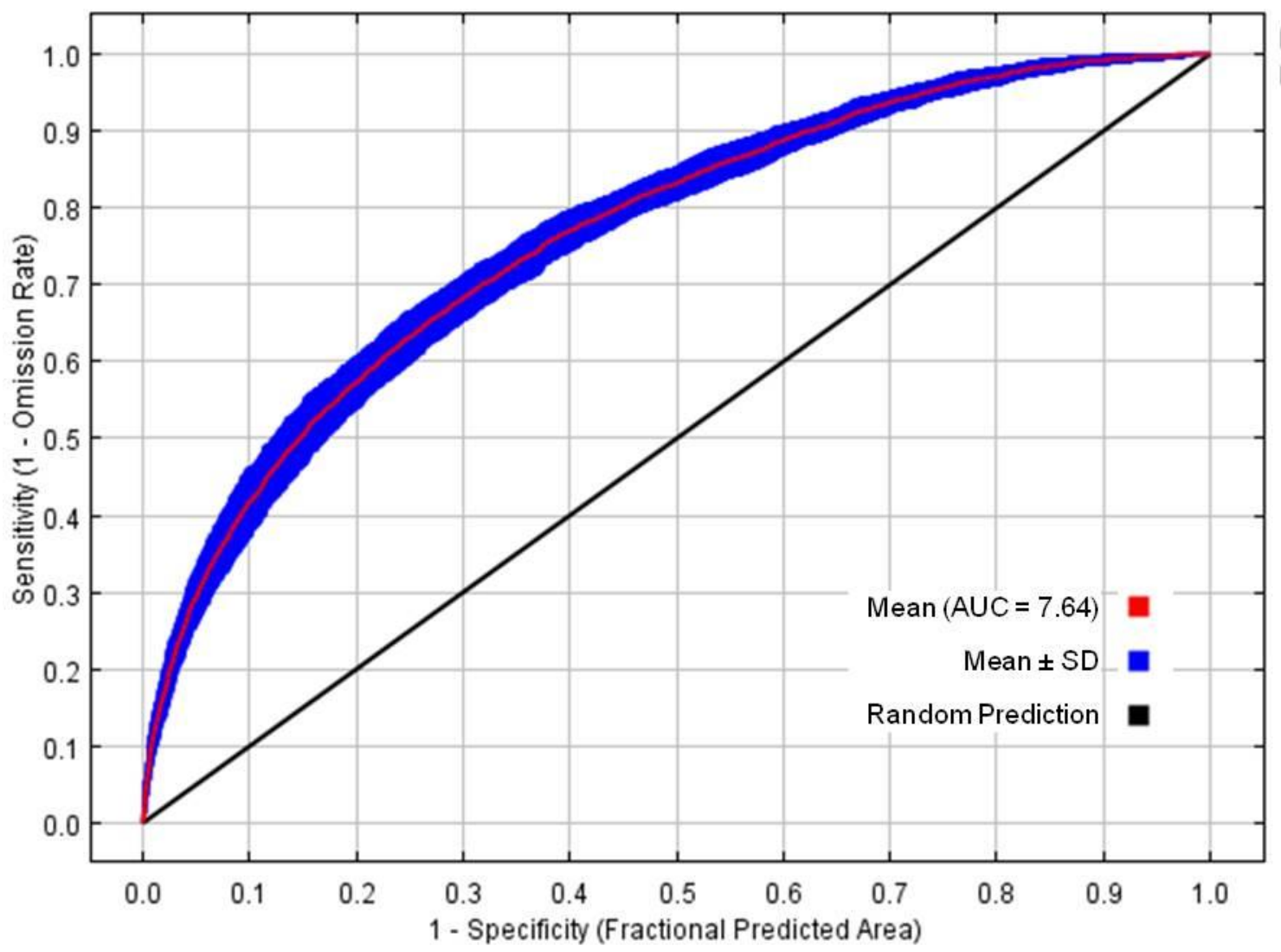

Figure 4.4. Maxent output of area under the receiver operating characteristic curve (AUC) for 50 replications of a model of black bear hunter distribution in Garrett County, Maryland. 


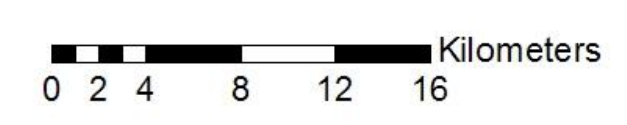

$\stackrel{N}{N}$

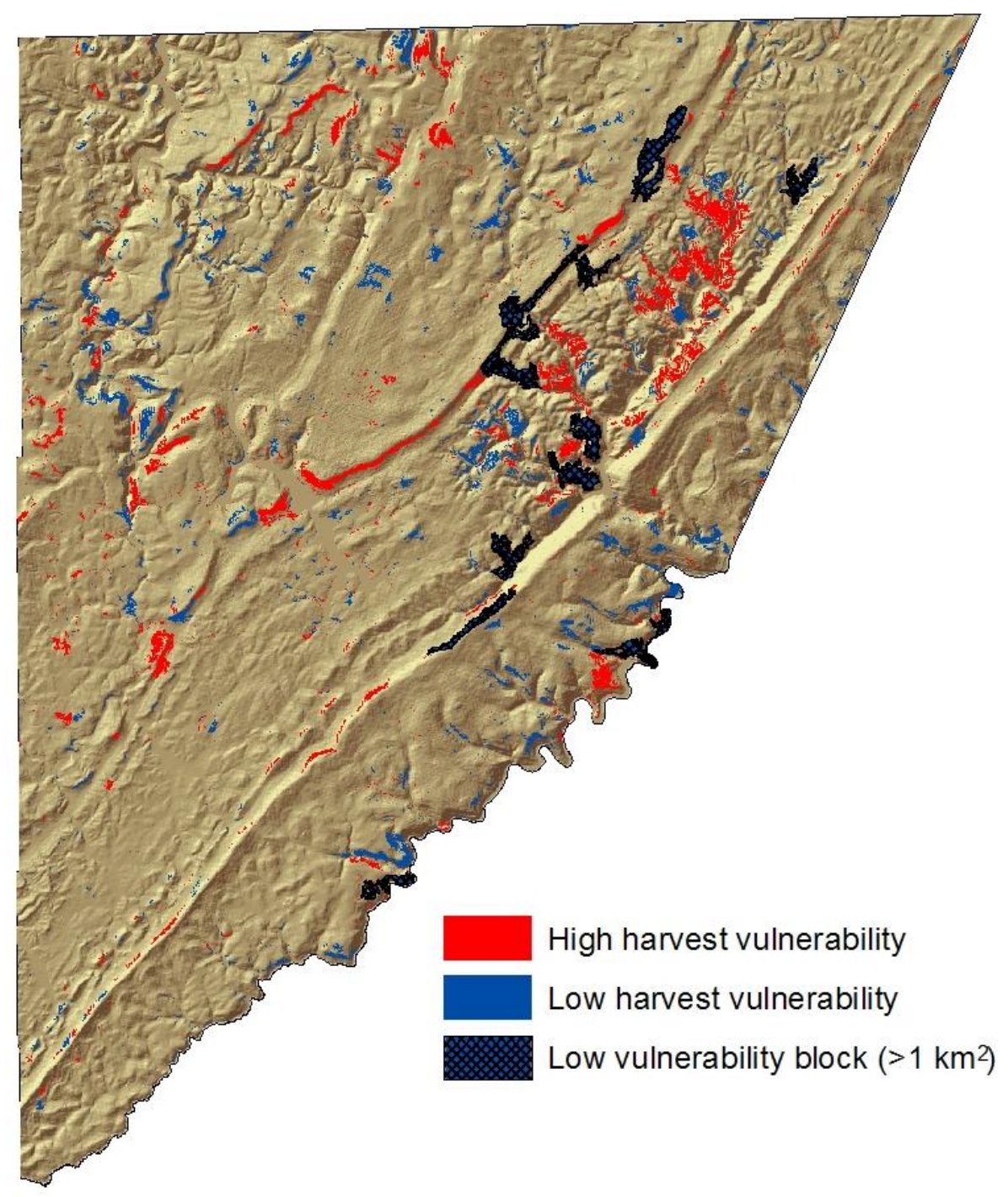

Figure 4.5. Areas identified as having high or low harvest vulnerability of female black bears based on Maxent distribution models for female bears and bear hunters in Garrett County, Maryland. High vulnerability locations represent areas where the probability of occurrence of bears and hunters are both high. Low vulnerability locations represent areas where the probability of occurrence is high for bears, but low for hunters. 
CHAPTER 5

HOME RANGE DYNAMICS OF FEMALE BLACK BEARS IN WESTERN

MARYLAND 


\section{Home Range Dynamics of Female Black Bears in Western Maryland}

Michael D. Jones ${ }^{1 *}$

${ }^{1}$ Division of Forestry and Natural Resources, West Virginia University, Morgantown, WV 26506

*Corresponding author 


\begin{abstract}
We examined the home range dynamics of 15 female Black Bears in western Maryland from 2005-2007 using GPS collars. Fixed kernel estimates for annual, spring, summer, and fall home ranges were $10.40 \mathrm{~km}^{2}, 8.93 \mathrm{~km}^{2}, 16.08 \mathrm{~km}^{2}$, and $19.35 \mathrm{~km}^{2}$, respectively. At $\alpha=0.10$, fall and summer home ranges were larger than spring home ranges, but summer and fall ranges were similar. Solitary females had mean spring home ranges 6.9 times larger than females with cubs-of-the-year, but ranges did not differ during other seasons. Home range centroids changed little among seasons for individuals, with a mean shift of $0.91 \mathrm{~km}$. Between years, home range boundaries shifted little but the size of some home ranges changed considerably. Intraspecific overlap of home ranges occurred in all 3 seasons and percent overlap varied greatly among bears. Our home range size estimates were smaller than earlier estimates in Maryland, but were comparable to estimates from other Appalachian states. The discrepancy in estimates from our study and previous Maryland Black Bear studies was likely due to a combination of expansion of the bear population, habitat improvements, and increased access to anthropogenic food sources. Other Black Bear studies have documented smaller spring home ranges compared to other seasons, and this is believed to be caused by lower activity levels following hibernation and, for females with cubs-of-the-year, limitations on movement imposed by the cubs. Overlap of female home ranges also has been documented in Black Bear research and suggests that habitat productivity and food sources are sufficient to reduce agonistic interactions among females.
\end{abstract}

\title{
Introduction
}

The home range of an animal is most simply described as "the area, usually around a home site, over which the animal normally travels in search of food" (Burt 1943). Estimating the size and 
spatial distribution of Ursus americanus Pallas (Black Bear) home ranges can be of interest to researchers and wildlife managers. Female bears are generally territorial and their home ranges are affected mostly by the distribution of food sources (Garshelis and Pelton 1981, Jonkel and Cowan 1971, Lindzey and Meslow 1977, Rudis and Tansey 1995). Therefore, female bear home ranges are often indicative of the overall habitat quality of an area (Beecham 1983, Ford 1983, Koehler and Pierce 2003). The size and spatial distribution of home ranges also can change seasonally as bears shift to the most abundant and nutritous food sources available (Garshelis and Pelton 1981, Rogers 1987). Additionally, home range sizes of female bears are affected by female bear density. Because females are territorial, higher bear density may force a reduction in average home range size (Young and Ruff 1982). There is evidence that 2 factors reduce the territoriality of female Black Bears: family groups and abundant food sources (Elowe 1984, Reynolds and Beecham 1980, Rogers 1987). Whereas most young males disperse relatively long distances, female offspring generally exhibit some degree of natal philopatry, often establishing a territory on the periphery of their mother's territory (Reynolds and Beecham 1980, Waser and Jones 1983). Female bears also have been shown to be less territorial around highly abundant food sources (e.g., garbage dumps) where resource competition is lower (Rogers 1987, Young and Ruff 1982).

Black Bear home range size varies widely across North America, with reported mean female home range sizes as small as $0.86 \mathrm{~km}^{2}$ in Louisiana (Leigh 2007) and as large as $294.8 \mathrm{~km}^{2}$ in Manitoba (Pacas and Paquet 1994). In the Appalachian region, mean female home ranges are usually within the range of 5-49 $\mathrm{km}^{2}$ (Table 5.1). In Maryland, only 2 studies have analyzed Black Bear home range dynamics (Dateo 1997, Webster 1994). Since those studies, the bear population in western Maryland has increased dramatically while the habitat has been altered by 
human development. Due to these changes, we expect that bear movements and home range dynamics have changed as well. Our objective was to use GPS telemetry to examine annual and seasonal home ranges sizes, shifts, and overlap of female bears in western Maryland.

\section{Field-Site Description}

We conducted this study in Garrett County, Maryland which is the westernmost county in the state (Fig. 1). Garrett County encompasses $1,722 \mathrm{~km}^{2}$ and is bordered by Pennsylvania to the north and West Virginia to the south and west. Maryland's Black Bear population occurs at its highest densities in Garrett County and the adjacent Allegany County to the east, which is the only area in the state where bear hunting is currently permitted (Spiker 2011). Elevations on the study area range from $292-1,028 \mathrm{~m}$. The majority of the study area is forested, with approximately $68 \%$ of the total area covered in deciduous forests. The human population density in the area is relatively low at 18 persons $/ \mathrm{km}^{2}$ (U.S. Census Bureau 2010). Approximately 22\% of the area is public land, including several large contiguous public areas. The 221- $\mathrm{km}^{2}$ Savage River State Forest is the largest public area in the county and makes up almost 13\% of the study area.

The study area contains 5 different forest-type groups (U.S. Department of Agriculture Forest Service 1999). Oak/Hickory (Oaks [Quercus spp.] and Hickories [Carya spp.]) is the most common, making up 54\% of all forested land in Garrett County. Northern hardwood (Acer rubrum Linnaeus [Red Maple], A. saccharum Marsh. [Sugar Maple], Fagus grandifolia Ehrh. [American Beech], Betula alleghaniensis Britton [Yellow Birch], and Prunus serotina Ehrh. [Black Cherry]) is also common, making up 33\% of forests. Elm/Ash/Red Maple (Ulmus spp. (Elm), Fraxinus spp. (Ash), and Red Maple), White/Red Pine (Pinus strobus Linnaeus [White 
Pine] and P. resinosa Aiton [Red Pine]), and Spruce/Fir (Picea spp. (Spruce) and Abies spp. (Fir)) all account for $\leq 7 \%$ of the total forested land. The understory vegetation in these foresttype groups includes Kalmia latifolia (Mountain Laurel), Rhododendron spp. (Rhododendron), Amelanchier arborea (Serviceberry), Cornus spp. (Dogwood), and Corylus spp. (Hazelnut), which are important sources of food and thick cover for bears.

\section{Methods}

\section{Black Bear GPS Data Collection}

MDNR captured bears in Garrett County from 2005-2007 using barrel traps, springactivated foot snares, and running with hounds (H.A. Spiker, MDNR, Oakland, MD, pers. comm.). Bears were chemically immobilized and females with neck circumferences of $>48 \mathrm{~cm}$ were fitted with Lotek Model 3300S GPS collars weighing $285 \mathrm{~g}$ (Lotek 2005). Bears with neck circumferences $<48 \mathrm{~cm}$ do not allow for the proper positioning of the collar antenna, which reduces the accuracy of the GPS coordinates. Morphometric measurements as well as sex and reproductive status were recorded for each captured bear. A premolar was extracted from each bear and used to age the individual using cementum annuli count techniques. GPS collars were programmed to record a waypoint every 4 hours and the battery life was approximately 1 year. Each waypoint recorded the latitude and longitude at the current position, along with the date and time. Each collar also emitted a VHF signal that could be used to locate the bear in the event of a GPS failure. If a collar remained stationary for an extended period of time, the collar would emit a unique VHF "mortality signal." These collars were located to determine the cause of the lack of movement. Any mortalities or slipped collars were recorded and data were recovered from the collar if possible. 
For bears remaining collared into the denning season, den sites were located using the VHF signal and collars were replaced during MDNR's annual den checks. At that time GPS data were downloaded from the collars.

\section{Home Range Analysis}

We estimated both annual and seasonal home ranges using GPS data. We estimated seasonal home ranges based on 3 seasons: spring (den emergence-2 June), summer ( 3 June-11 September), and fall (12 September-den entry). The 2 June division is based on the mean separation date between adult females and their yearlings (Schwartz and Franzmann 1992) and the shift in diet to soft mast. This also is prior to the peak breeding season for the midAppalachian region (Echols 2000, Ryan 1997). We chose the 11 September division to approximate the date of the shift from soft mast to hard mast as the primary food source. We identified den emergence using the first sustained movement from the den site and we defined the time of den entry as the date when fall movement ceased or became drastically reduced.

We used 95\% minimum convex polygon (MCP) and 95\% fixed kernel density estimates for both the seasonal and annual home range estimates. We only used the MCP method to facilitate comparison with earlier Black Bear home range studies, specifically the 2 studies conducted in western Maryland (Dateo 1997, Webster 1994). We chose the 95\% fixed kernel density method to create a more informative and reliable home range estimate. We used Geospatial Modeling Environment (Beyer 2011) in ArcGIS 10 for the fixed kernel and MCP estimates. For seasonal home ranges, we only included bears that had at least 30 locations for a given season (Girard et al. 2002). For annual home ranges, we only included bears that had data in all 3 seasons and had a minimum of 100 locations (Girard et al. 2002). We calculated the appropriate fixed kernel smoothing parameter $(h)$ using least-squares cross-validation (LSCV), 
likelihood cross-validation (CVh) reference smoothing parameter $\left(h_{r e f}\right)$, and proportions of $h_{r e f}$ $(0.4,0.6,0.8)$. We used a Kruskal-Wallis test to compare annual and seasonal home ranges. If the Kruskal-Wallis statistic was significant $(\mathrm{P}<0.05)$, we used a pairwise Wilcoxon rank sum test to compare medians of the groups. We used a Wilcoxon rank sum test to examine home range differences between females with cubs-of-the-year and solitary females (i.e., bears without cubs-of-the-year). To quantify seasonal shifts in home range, we used ArcGIS to create centroids for each seasonal home range polygon and measured the distances between centroids. We also measured percent overlap of seasonal home ranges of individuals and overlap of 2 or more individuals.

\section{Results}

We included 8,281 GPS locations from 15 female Black Bears in our home range analysis (Appendix D). We removed all locations recorded during the denning period of each bear. Three bears were tracked during 2005, 9 during 2006, and 9 during 2007. Five of the 15 bears were tracked for multiple years, although not always continuously. Additional captured bears were excluded from analysis when collar failure, slipped collars, or mortality prevented adequate data collection. Three bears were monitored for all 3 seasons, allowing us to estimate annual home range size. We estimated 10 spring, 17 summer, and 10 fall home ranges (Fig. 2-5). The number of locations recorded for an individual bear during a year was 31-1325 ( $x=394$; Table 5.2).

For the fixed kernel estimates, LSCV failed to select a smoothing factor for most bears due to the large number of locations associated with the GPS data. CVh led to obvious undersmoothing of most home ranges, causing highly fragmented polygons. The reference bandwidth resulted in oversmoothing, with the polygons extending far beyond the extent of the 
bear locations. After visually comparing different proportions of $h_{\text {ref }}(0.4,0.6,0.8)$, we determined that $0.8 h_{\text {ref }}$ produced the most biologically relevant home range polygons with minimal undersmoothing or oversmoothing, consistent with the results of Worton (1995). We used this bandwidth selection method for all reported fixed kernel estimates.

\section{Annual and seasonal home range size}

Mean annual, spring, summer, and fall home range sizes were $10.40 \mathrm{~km}^{2}, 8.93 \mathrm{~km}^{2}$, $16.08 \mathrm{~km}^{2}$, and $19.35 \mathrm{~km}^{2}$, respectively (Table 5.2). Seasonal home ranges approached statistical significance at the 0.05 level and were different at the 0.10 level $\left(\chi^{2}=5.97, P=0.05\right)$. At the 0.10 significance level, fall home ranges were larger than spring home ranges $(P=0.10)$, but not different than summer home ranges $(P=0.75)$. Summer home ranges also were significantly larger than spring home ranges $(P=0.07)$. We monitored 8 bears during spring and summer and/or fall. For $6(75 \%)$ of those bears, spring home ranges were the smallest seasonal home range.

Of the seasonal home ranges, only summer home ranges were different among years $\left(\chi^{2}=8.42, P=0.01\right)$. Summer home ranges were larger in 2005 than $2006(P=0.05)$, but the other pairwise comparisons were not significant. Mean summer home range size in 2005 was 3.5 times larger than the mean summer home range size in $2006\left(32.41 \mathrm{~km}^{2}\right.$ vs. $\left.9.28 \mathrm{~km}^{2}\right)$. We did not compare annual home range size among years due to low sample size $(n=3)$.

\section{Reproductive status}

Of the 37 seasonal home range estimates, $23(62.2 \%)$ were for bears with cubs-of-the-year (COY). Two (66.7\%) of the bears tracked in 2005, 7 (77.8\%) of the bears tracked in 2006, and 
3 (33.3\%) of the bears tracked in 2007 had COY. Solitary females had larger mean spring and summer home ranges than females with COY, but only the spring home ranges were significantly larger ( $W=21, P=0.02$; Table 5.3$)$. Mean spring home ranges of solitary females were 6.9 times larger than those of females with COY.

\section{Home range fidelity and overlap}

Thirteen bears were monitored for consecutive seasons, allowing us to measure home range fidelity. Home range centroids shifted $0.22-2.40 \mathrm{~km}(x=0.91 \mathrm{~km})$ between any 2 seasons. Mean home range shift was slightly higher from summer to fall $(1.00 \mathrm{~km})$ than from spring to summer $(0.83 \mathrm{~km})$, but the difference was not significant $(W=30, P=0.87)$. Reproductive status of bears did not affect seasonal home range shifts $(W=30.5, P=0.78)$. Individual summer home ranges overlapped $55.17-100.00 \%(x=79.26 \%)$ of spring home ranges. Similar overlap occurred with summer and fall home ranges, where individual fall ranges contained 30.87$98.32 \%(x=73.78 \%)$ of the summer home ranges.

We tracked 5 bears for multiple years during the same season, allowing us to examine interannual differences in seasonal home ranges. One bear had a spring home range 9.9 times larger in 2006 than 2007, even though that bear had COY in 2006. The 2006 spring home range completely enclosed the perimeter of the 2007 spring home range. Three bears had multiple summer home range estimates. Summer home ranges differed between years by $32.68-292.38 \%$. The bear with the smallest difference between home ranges $(32.68 \%)$ was tracked during summers of 2005 and 2007, and had COY during both years. The larger summer home range for each bear overlapped the smaller summer home range by $71.51-97.91 \%$. For the 
bear tracked during 2 fall seasons, the home range from 2007, when the female was solitary, overlapped the 2006 fall home range, when the bear had COY, by $89.89 \%$.

Twelve bears exhibited seasonal home ranges that overlapped with other radiocollared bears during the same season (Fig. 3-5; Table 5.4); 4 of 10 (40.0\%) bears in spring, 6 of 17 $(35.3 \%)$ in summer, and 2 of $10(20.0 \%)$ in fall. Of those, 8 bears had home ranges that overlapped the home range of 1 other bear. The other 4 bears had home ranges that overlapped 2 other bears. Overlapping of 3 bear home ranges only occurred during summer. The percentage of the home range overlapped by at least 1 other bear varied widely (4.47-100.00\%), but averaged $39.36 \%$ (Table 5.4). Mean percent overlap was highest in spring, but overlap also was most variable during that season.

\section{Discussion}

Our mean annual, spring, summer, and fall MCP home range estimates were all smaller than those reported by Webster (1994) and Dateo (1997) for the same study area (Table 5.1). Our mean annual fixed kernel home range estimate, which we assume more accurately reflects the true home range size, was comparable to some estimates from other Appalachian states, such as Virginia and Tennessee (Table 5.1). However, our estimate was lower than those from Pennsylvania and West Virginia, which are adjacent states to our study area.

There are a number of explanations for the difference between our MCP estimates and those from the 2 previous Maryland bear studies. First, the difference in number of locations used to estimate home ranges may account for some of the discrepancy. While Webster (1994) and Dateo (1997) located each bear approximately 3 times per week, our GPS collars collected locations at a much higher rate. MCP estimates are heavily influenced by sample size (Anderson 
1982), so our estimates would be expected to differ somewhat from previous studies. However, given the magnitude of difference among our estimates and those of Webster (1994) and Dateo (1997), the disparity in home range estimates likely extends beyond sample size differences, and is more a result of biological, behavioral, and landscape changes occurring since those studies. The increasing bear population in western Maryland, coupled with landscape changes, most likely explain the difference in our home range estimates compared to previous estimates. Maryland's bear population has been increasing rapidly in recent decades (see Chapter 5). Female bears are generally territorial (Young and Ruff 1982), so higher bear density could be expected to force females to reduce their home range sizes. Higher bear density likely would increase intraspecific interactions for resources, causing female bears to more aggressively defend resources within their home ranges. Limitations on the size of an area that a female bear could successfully defend may have an indirect negative effect on overall home range size. It is likely that habitat and land use changes also have affected the home range size of female bears. Like most of the eastern United States, Garrett County has seen an increase in human population and development. The county is a popular vacation destination, and the construction of businesses and vacation homes has increased rapidly in certain parts of the county. From 1990 to 2005, the human population in Garrett County increased only 6\%, whereas the number of housing units rose 33\% (Garrett County Planning Commission 2008). Development can affect bear home range size in 2 ways; by reducing the amount and connectivity of forest cover, and by providing anthropogenic food sources. Urbanization generally reduces the area of forested bear habitat, and fragments existing habitat. As more people visit Garrett County, traveling longer distances becomes more hazardous for bears, especially due to higher risk of bear-vehicle collisions (Brody and Pelton 1989). Bears may limit the size of their home ranges to avoid 
traveling long distances and reduce unnecessary risk. A potentially positive result of increased human presence is the availability of anthropogenic food sources. The presence of anthropogenic food sources may supplement a bear's diet enough to reduce the need for that bear to cover a large area to secure food resources. The interspersion of forests and developed areas, common in some parts of the county, could be considered high quality bear habitat in terms of cover and food availability. Previous studies have shown that bear home ranges are generally smaller in higher quality habitat (Ford 1983, Garshelis and Pelton 1981, Lindzey and Meslow 1977). The smaller spring home ranges compared to summer and fall home ranges is consistent with previous Maryland bear studies (Dateo 1997, Webster 1994), as well as studies from Pennsylvania (Alt et al. 1980) and Virginia (Kasbohm et al. 1998). One explanation for the size difference is the relatively low activity levels of bears immediately following den emergence. Tøien et al. (2011) found that Black Bears maintained reduced metabolic rates for up to 3 weeks after den emergence, even though body temperature returned to normal rather quickly. Garshelis and Pelton (1980) reported low spring activity levels in bears in the Great Smoky Mountains National Park. They suggested that, because bears largely relied on herbaceous material in spring, the low nutritional value of spring diets limited the energy bears could expend traveling. Another explanation for smaller spring home ranges is the reproductive status of the bears. We found that bears with COY had smaller spring home ranges than solitary females, supporting the findings of previous bear studies in the region (Alt et al. 1980, Dateo 1997, Kasbohm et al. 1998, Webster 1994) and in other parts of the United States (Moyer et al. 2007, Smith and Pelton 1990). Because 7 of 10 (70\%) bears tracked during spring had COY, the . Cubs are quite small in spring and require a great deal of attention from their mothers, so the size of spring home ranges of females with COY may be limited by the low mobility of the cubs. Cubs 
become much more mobile and independent during the summer, which explains why we found no difference between summer or fall home ranges of solitary bears and bears with COY.

Our 2 measures of intra-year home range fidelity (centroid shifts and home range overlap) both indicate that the general location of a home range changes minimally between seasons. The mean seasonal home range shift from our study was similar to shifts observed by Alt et al. (1980) in Pennsylvania (0.91 km vs. $0.93 \mathrm{~km})$. Olfenbuttel (2005) also found that most bears in Virginia did not shift home ranges seasonally, or exhibited small shifts. Although the general locations of seasonal home ranges seem to stay relatively constant, our analysis of overlap shows that the size and/or shape of the seasonal home ranges did change for some bears. We found similar results with our inter-year home range analysis, as seasonal home range size changed substantially between years, but home ranges showed extensive overlap. This may be explained by variation in the quality, quantity, and spatial distribution of food resources on the landscape. Bears can adjust their home ranges to take advantage of the most abundant and nutritious foods available in a given season (Garshelis and Pelton 1981). In the Great Smoky Mountains National Park, $83 \%$ of bears had large shifts in seasonal home ranges, especially from summer to fall (Garshelis and Pelton 1981). The bears in that study shifted to areas with more oak mast during the fall. However, most bears in our study exhibited high overlap of seasonal home ranges, which supports the results of our home range shift analysis and suggests that home range shifts are smaller than those reported by Garshelis and Pelton (1981). Female bears in our study usually remained in the same general area between seasons and years, but some adjusted their movements, possibly to exploit available resources. MDNR fall hard-mast surveys for Garrett County classified 2005 and 2007 as mast failures, while the 2006 crop was rated as average (MDNR, unpublished data). We might expect home range shifts during those mast 
failures as bears would be forced to travel to different areas to secure enough food. However, the availability of anthropogenic food sources may have helped buffer the effects of variation in natural food availability. The presence of refuse, bird feeders, and other supplemental food supplies may provide enough energy to reduce the need for bears to substantially shift home ranges among seasons or years.

Individual home ranges overlapped with other radio-collared bears in all 3 seasons. Our mean percent overlap was higher than, but similar to, mean yearly values reported by Higgins (1997) for female bears in Virginia $(x=31.2 \%, 28.2 \%)$. Powell (1987) and Horner and Powell (1990) both reported extensive overlap of female bear home ranges in North Carolina, but their quantification of overlap did not allow for comparison to our results. We did not have sufficient sample size to test for differences in overlap among seasons, but summer was the only season that had instances of 3 bears with overlapping home ranges. Horner and Powell (1990) reported larger area overlap during late summer than during the breeding season (early summer) or fall. Although female bears are generally territorial, kinship and abundant food sources have been shown to reduce territoriality (Elowe 1984, Reynolds and Beecham 1980, Rogers 1987). Young females often remain on the periphery of their mother's territory (Reynolds and Beecham 1980, Waser and Jones 1983) and half-siblings or full-siblings may share a portion of their home ranges. Female bears also have been shown to be less territorial around highly abundant food sources (Rogers 1987, Young and Ruff 1982). Females in relatively unproductive boreal forest habitat usually exhibit higher territoriality than females in highly productive Appalachian forests (Jonkel and Cowan 1971, Powell 1987). In both instances, bears may tolerate various degrees of female home range overlap, even to the extent that they can no longer be considered territorial (Elowe 1984, Horner and Powell 1990, Powell 1987). We suspect that both of these factors help 
explain the overlap observed in our study. It is likely that some level of kinship is present in our monitored bears as the population has been established long enough for several litters to form family group home ranges. Because litter size is highly dependent on female nutrition, the relatively high mean reproductive output of Maryland bears (3.0 cubs/yr; Spiker 2011) indicates high quality habitat in the study area. This productive habitat may reduce competition for resources and allow for greater overlap among females.

Managers and researchers often focus on female bears because their survival and reproductive output have a large effect on the population dynamics. To best manage the female segment of a bear population, it is essential to identify the spatial scale at individual bear operate. The results of this study will help managers better understand how management decisions (e.g., habitat management, recreational hunting) will impact the bear population and at which spatial scale bear management and research should be conducted. Our home range estimates and observations of home range overlap provide insight into female bear movements and intraspecific interaction that can help MDNR develop expectations for female movements based on season and reproductive status.

\section{Acknowledgments}

Funding for this project was provided by Federal Aid in Wildlife Restoration Act Project W-61-R, Maryland Department of Natural Resources, West Virginia University Division of Forestry. Thank you to MDNR personnel at Mt. Nebo for bear trapping and data collection. 


\section{Literature Cited}

Alt, G.L., G.J. Matula, Jr., F.W. Alt, and J.S. Lindzey. 1980. Dynamics of home range and movements of adult black bears in northeastern Pennsylvania. International Conference on Bear Research and Management 4:131-136.

Anderson, D. J. 1982. The home range: a new nonparametric estimation technique. Ecology 63:103-112.

Beyer. H.L. 2011. Geospatial modeling environment 0.7.1. Available online at http://www.spatialecology.com. Accessed May 10, 2012.

Brody, A.J. 1984. Habitat use by black bears in relation to forest management in Pisgah National Forest, North Carolina. M.S. Thesis, University of Tennessee, Knoxville, TN.

Brody, A.J., and M.R. Pelton. 1989. Effects of roads on black bear movements in western North Carolina. Wildlife Society Bulletin 17:5-10.

Brown, W.S. 1980. Black bear movements and activities in Pocahontas and Randolph counties, West Virginia. M.S. Thesis. West Virginia University, Morgantown, WV.

Burt, W.H. 1943. Territoriality and home range concepts as applied to mammals. Journal of Mammalogy 24:346-352.

Dateo, D.M. 1997. Use of home range and influences of habitat selection on crop depredation by black bears (Ursus americanus) in western Maryland. M.S. Thesis. Frostburg State University, Frostburg, MD.

Echols, K.N. 2000. Aspects of reproduction and cub survival in a hunted population of Virginia black bears. M.S. Thesis. Virginia Polytechnic Institute and State University, Blacksburg, VA. 
Elowe, K.D. 1984. Home range, movements, and habitat preferences of black bear (Ursus americanus) in western Massachusetts. M.S. Thesis. University of Massachusetts, Amherst, MA.

Ford, R.G. 1983. Home range in a patchy environment: Optimal foraging predictions. American Zoologist 23:315-326.

Garner, N.P. 1986. Seasonal movements, habitat selection, and food habits of black bears (Ursus americanus) in Shenandoah National Park, Virginia. M.S. Thesis. Virginia Polytechnic Institute and State University. Blacksburg, VA.

Garrett County Planning Commission. 2008. 2008 Garrett County comprehensive plan. Available online at http://www.garrettcounty.org/planning-land-development/comprehensive-planning. Accessed October 18, 2012.

Garshelis, D.L., and M.R. Pelton. 1980. Activity of black bears in the Great Smoky Mountains National Park. Journal of Mammalogy 61:8-19.

Garshelis, D.L., and M.R. Pelton. 1981. Movements of black bears in the Great Smoky Mountains National Park. Journal of Wildlife Management 45:912-925.

Girard, I., J. Oullet, R. Courtois, C. Dussault, and L. Breton. 2002. Effects of sampling effort based on GPS telemetry on home-range size estimations. Journal of Wildlife Management 66:1290-1300.

Hansen, M.C., and R.A. Riggs. 2008. Accuracy, precision, and observation rates of global positioning system telemetry collars. Journal of Wildlife Management 72:518-526. 
Higgens, J.C. 1997. Survival, home range and spatial relationships of Virginia's exploited black bear population. M.S. Thesis. Virginia Polytechnic Institute and State University, Blacksburg, VA.

Horner, M.A., and R.A. Powell. 1990. Internal structure of home ranges of black bears and analyses of home-range overlap. Journal of Mammalogy 71:402-410.

Jones, M.D., and M.R. Pelton. 2003. Female American black bear use of managed forest and agricultural lands in coastal North Carolina. Ursus 14:188-197.

Jonkel, C.J., and I.M. Cowan. 1971. The black bear in the spruce-fir forest. Wildlife Monographs 27.

Kasbohm, J.W., M.R. Vaughan, and J.G. Kraus. 1998. Black bear home range dynamics and movement patterns during a gypsy moth infestation. Ursus 10:259-267.

Kraus, J.G. 1990. Home ranges and den site characteristics of female black bears and aspects of bear population structure in West Virginia. M.S. Thesis. West Virginia University, Morgantown, WV.

Leigh, J. 2007. Effects of aversive conditioning on behavior of nuisance Louisiana black bears. M.S. Thesis. Louisiana State University, Baton Rouge, LA.

Lindzey, F.G., and E.C. Meslow. 1977. Home range and habitat use by black bears in southwestern Washington. Journal of Wildlife Management 41:413-425.

Lotek Wireless Fish and Wildlife Monitoring. 2005. Small and midsize animals GPS location

Moyer, M.A., J.W. McCown, and M.K. Oli. 2007. Factors influencing home-range size of female Florida black bears. Journal of Mammalogy 88:468-476. 
Olfenbuttel, C. 2005. Home range dynamics of black bears in the Alleghany Mountains of western Virginia. M.S. Thesis. Virginia Polytechnic Institute and State University, Blacksburg, VA.

Pacas, C.J., and P.C. Paquet. 1994. Analysis of black bear home range using a geographic information system. International Conference on Bear Research and Management 9:419-425.

Powell, R.A. 1987. Black bear home range overlap in North Carolina and the concept of home range applied to black bears. International Conference on Bear Research and Management 7:235-242.

Quigley, H.B. 1982. Activity patterns, movement ecology, and habitat utilization of black bears in the Great Smoky Mountains National Park, Tennessee. M.S. Thesis. University of Tennessee, Knoxville, TN.

Reynolds, D.G., and J.J. Beecham. 1980. Home range activities and reproduction of black bears in west-central Idaho. Bears: Their Biology and Management 4:181-190.

Rogers, L.L. 1987. Effects of food supply and kinship on social behavior, movements, and population growth of black bears in northeastern Minnesota. Wildlife Monographs 97:1-72.

Ryan, C.W. 1997. Reproduction, survival, and denning ecology of black bears in southwestern Virginia, M.S. Thesis. Virginia Polytechnic Institute and State University, Blacksburg, VA.

Seaman, D.E., J.J. Millspaugh, B.J. Kernohan, G.C. Brundige, K.J. Raedeke, and R.A. Gitzen. 1999. Effects of sample size on kernel home range estimates. Journal of Wildlife Management 63:739-747. 
Schwartz, C.C., and A.W. Franzmann. 1992. Dispersal and survival of subadult black bears from the Kenai Peninsula, Alaska. Journal of Wildlife Management 56:426-431.

Smith, T.R., and M.R. Pelton. 1990. Home ranges and movements of black bears in a bottomland hardwood forest in Arkansas. International Conference on Bear Research and Management 8:213-218.

Spiker, H. 2011. Maryland black bear population status report. Maryland Department of Natural Resources, Wildlife and Heritage Service, Oakland, MD.

Tøien, Ø., J. Blake, D.M. Edgar, D.A. Grahn, H.C. Heller, and B.M. Barnes. 2011. Hibernation in black bears: Independence of metabolic suppression from body temperature. Science 331:906-909.

U.S. Census Bureau. 2010. Census 2010 summary file 1, geographic header record G001. U.S. Census Bureau, Washington, D.C..

U.S. Department of Agriculture Forest Service [USFS]. 1999. Northeastern forest and inventory analysis. Maryland statewide results. Available online at http://www.fs.fed.us/ne/fia/states/md/index.html. Accessed February, 112010.

Waser, P.M., and W.T. Jones. 1983. Natal philopatry among solitary mammals. Quarterly Review of Biology 58:355-390.

Webster, T.W. 1994. Movements and use of habitat of female black bears in western Maryland. M.S. Thesis. Frostburg State University, Frostburg, MD.

Worton, B.J. 1995. Using Monte Carlo simulation to evaluate kernel-based home range estimators. Journal of Wildlife Management 59:794-800.

Young, B.F., and R.L. Ruff. 1982. Population dynamics and movements of black bears in east central Alberta. Journal of Wildlife Management 46:845-86. 
Table 5.1. Previously reported mean home range estimates for Ursus americanus (Black Bear) in the Appalachian Region. MCP = minimum convex polygon.

\begin{tabular}{llcrl}
\hline State & Author & $\begin{array}{c}\text { Mean home } \\
\text { range size }\left(\mathrm{km}^{2}\right)\end{array}$ & $N$ & Estimator \\
\hline Maryland & Webster 1994 & 41 & 3 & MCP \\
Maryland & Dateo 1994 & 36 & 5 & MCP \\
North Carolina & Brody 1984 & 17 & 11 & MCP \\
North Carolina & Jones and Pelton 2003 & 8 & 13 & MCP \\
Pennsylvania & Alt et al. 1980 & 41 & 12 & Bivariate normal \\
Tennessee & Quigley 1982 & 5 & 10 & MCP \\
Virginia & Garner 1986 & 22 & 25 & MCP \\
Virginia & Higgens 1997 & 7 & 27 & Fixed kernel \\
Virginia & Olfenbuttel 2005 & 30 & 76 & Fixed kernel \\
West Virginia & Brown 1980 & 49 & 8 & Bivariate normal \\
West Virginia & Kraus 1990 & 26 & 15 & MCP \\
\hline
\end{tabular}


Table 5.2. Home range estimates for female Ursus americanus (Black Bear) in Garrett County, Maryland, USA from $2005-2007$.

\begin{tabular}{|c|c|c|c|c|c|c|c|c|}
\hline & \multirow[b]{2}{*}{$N$} & \multirow[b]{2}{*}{ No. locations } & \multicolumn{3}{|c|}{ 95\% Fixed kernel home range $\left(\mathrm{km}^{2}\right)$} & \multicolumn{3}{|c|}{$95 \% \mathrm{MCP}$ home range $\left(\mathrm{km}^{2}\right)$} \\
\hline & & & Mean & $\mathrm{SE}$ & Range & Mean & SE & Range \\
\hline Annual & 3 & $758-1325$ & 10.40 & 1.42 & $7.65-12.42$ & 9.83 & 2.28 & $7.20-14.37$ \\
\hline Spring & 10 & $78-375$ & 8.93 & 3.63 & $0.07-35.54$ & 6.73 & 1.31 & $0.05-34.79$ \\
\hline Summer & 17 & $31-433$ & 16.08 & 2.62 & $3.72-48.01$ & 10.57 & 1.53 & $4.14-27.75$ \\
\hline Fall & 10 & $56-517$ & 19.35 & 7.16 & $5.18-80.95$ & 13.18 & 3.86 & $3.03-39.35$ \\
\hline
\end{tabular}


Table 5.3. Seasonal $95 \%$ fixed kernel home range estimates by reproductive status for female Ursus americanus (Black Bear) in Garrett County, Maryland, USA from 2005-2007. * = statistically different. COY $=$ female with cubs-of-the-year. Solitary $=$ females without cubs-of-the-year.

\begin{tabular}{llcccc}
\hline & & \multicolumn{3}{c}{$95 \%$ Fixed kernel home range $\left(\mathrm{km}^{2}\right)$} \\
\cline { 4 - 6 } & Reproductive & & & & \\
& Status & $N$ & Mean & SE & Range \\
\hline \multirow{4}{*}{ Spring } & Solitary & 3 & $22.20^{*}$ & 8.09 & $7.60-35.54$ \\
& COY & 7 & $2.60^{*}$ & 0.69 & $0.05-5.30$ \\
\multirow{4}{*}{ Fall } & Solitary & 6 & 19.40 & 3.00 & $8.57-28.06$ \\
& COY & 11 & 14.28 & 3.81 & $3.72-48.01$ \\
& Solitary & 5 & 12.91 & 3.72 & $5.18-25.75$ \\
& COY & 5 & 25.79 & 14.01 & $6.23-80.95$ \\
\hline
\end{tabular}


Table 5.4. Overlap of seasonal home ranges among female Ursus americanus (Black Bear) in Garrett County, Maryland, USA from 2005-2007.

\begin{tabular}{lrrccccc}
\hline & & \multicolumn{3}{c}{ Area of overlap $\left(\mathrm{km}^{2}\right)$} & \multicolumn{3}{c}{$\%$ Overlap } \\
\cline { 3 - 8 } & $N$ & Mean & SE & Range & Mean & SE & Range \\
\hline Spring & 4 & 1.70 & 0.11 & $1.59-1.82$ & 50.11 & 21.87 & $4.47-100.00$ \\
Summer & 6 & 10.27 & 3.01 & $1.31-22.18$ & 41.24 & 12.00 & $15.29-96.52$ \\
Fall & 2 & 4.77 & 0.00 & $4.77-4.77$ & 12.21 & 6.32 & $5.89-18.52$ \\
\hline
\end{tabular}




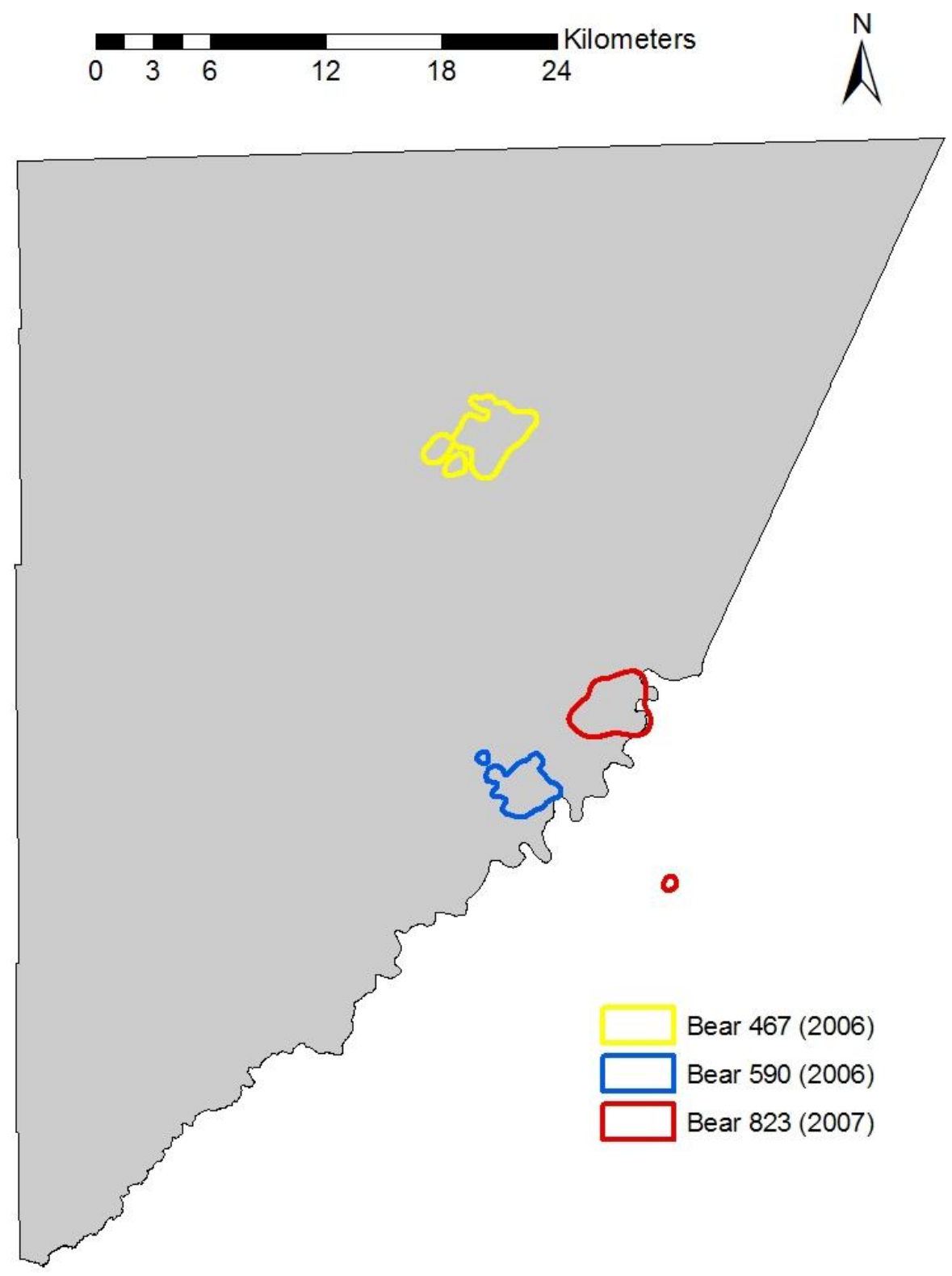

Figure 5.1. Annual 95\% fixed kernel home ranges of female Ursus americanus (Black Bear) in Garrett County, Maryland, USA from 2006-2007. Each color polygon represents an individual female Black Bear. The year the data was collected is in parentheses following the bear ID. 


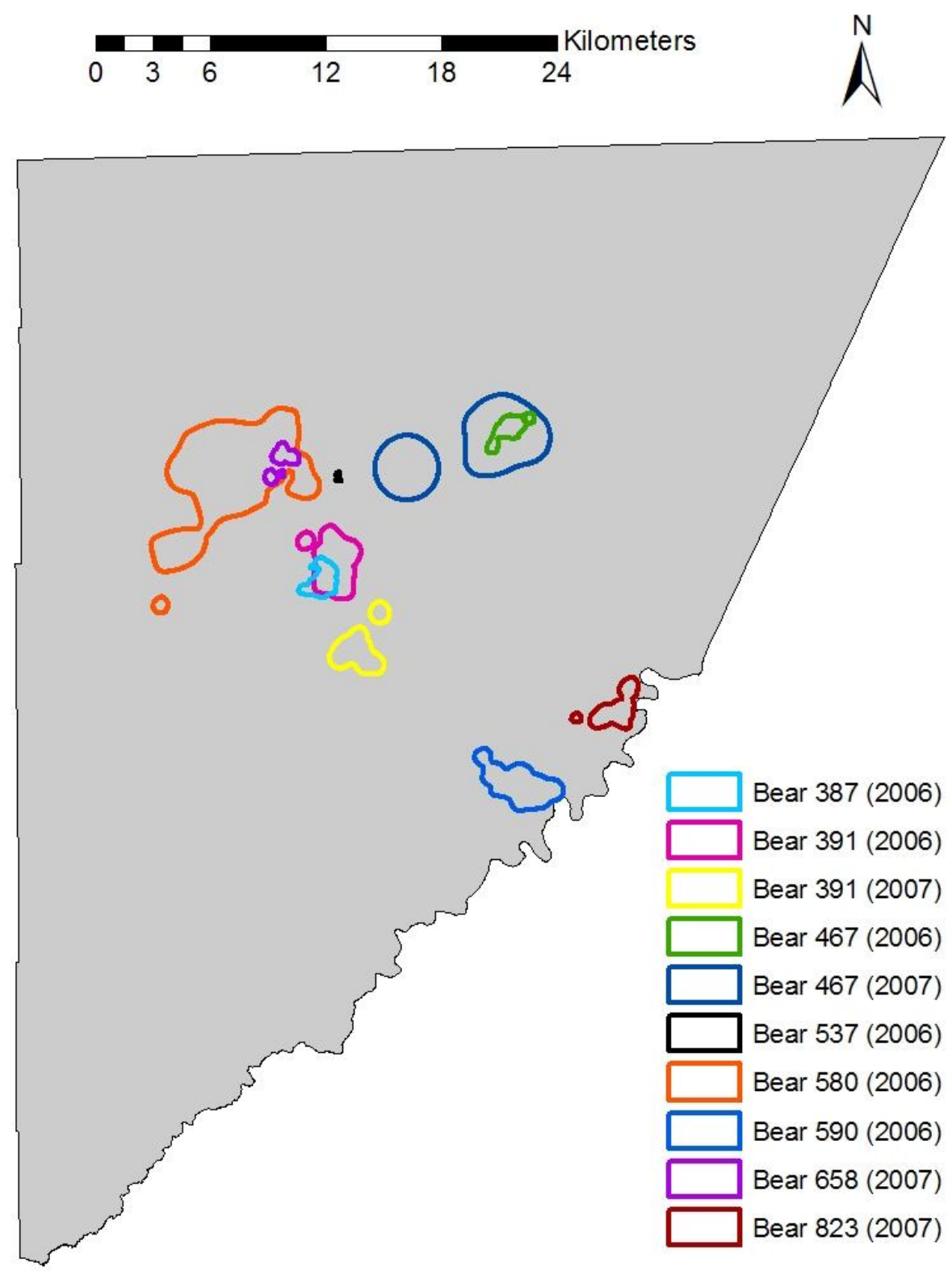

Figure 5.2. Spring 95\% fixed kernel home ranges of female Ursus americanus (Black Bear) in Garrett County, Maryland, USA from 2006-2007. Each color polygon represents an individual female Black Bear. The year the data was collected is in parentheses following the bear ID. 


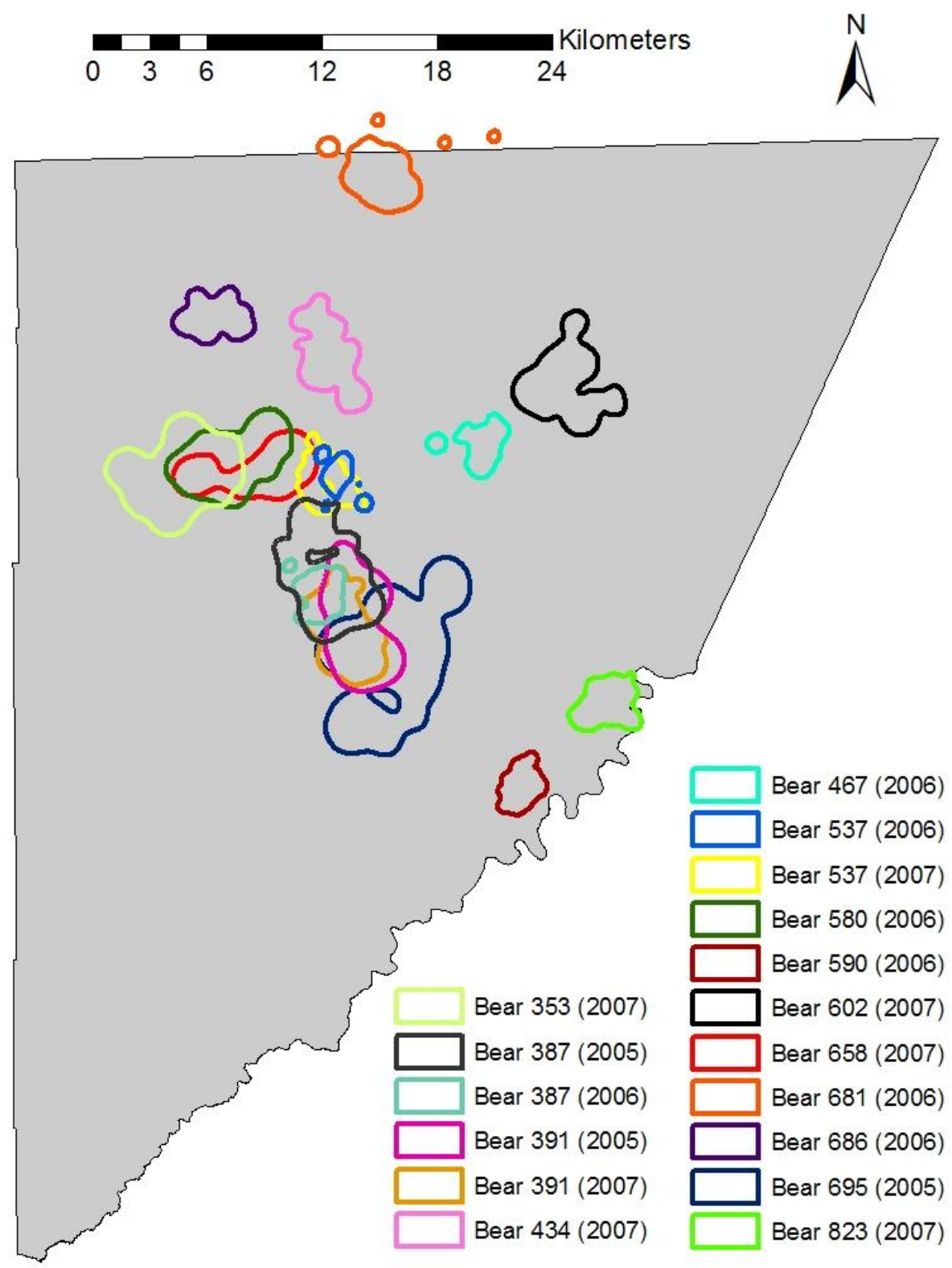

Figure 5.3. Summer 95\% fixed kernel home ranges of female Ursus americanus (Black Bear) in Garrett County, Maryland, USA from 2005-2007. Each color polygon represents an individual female Black Bear. The year the data was collected is in parentheses following the bear ID. 


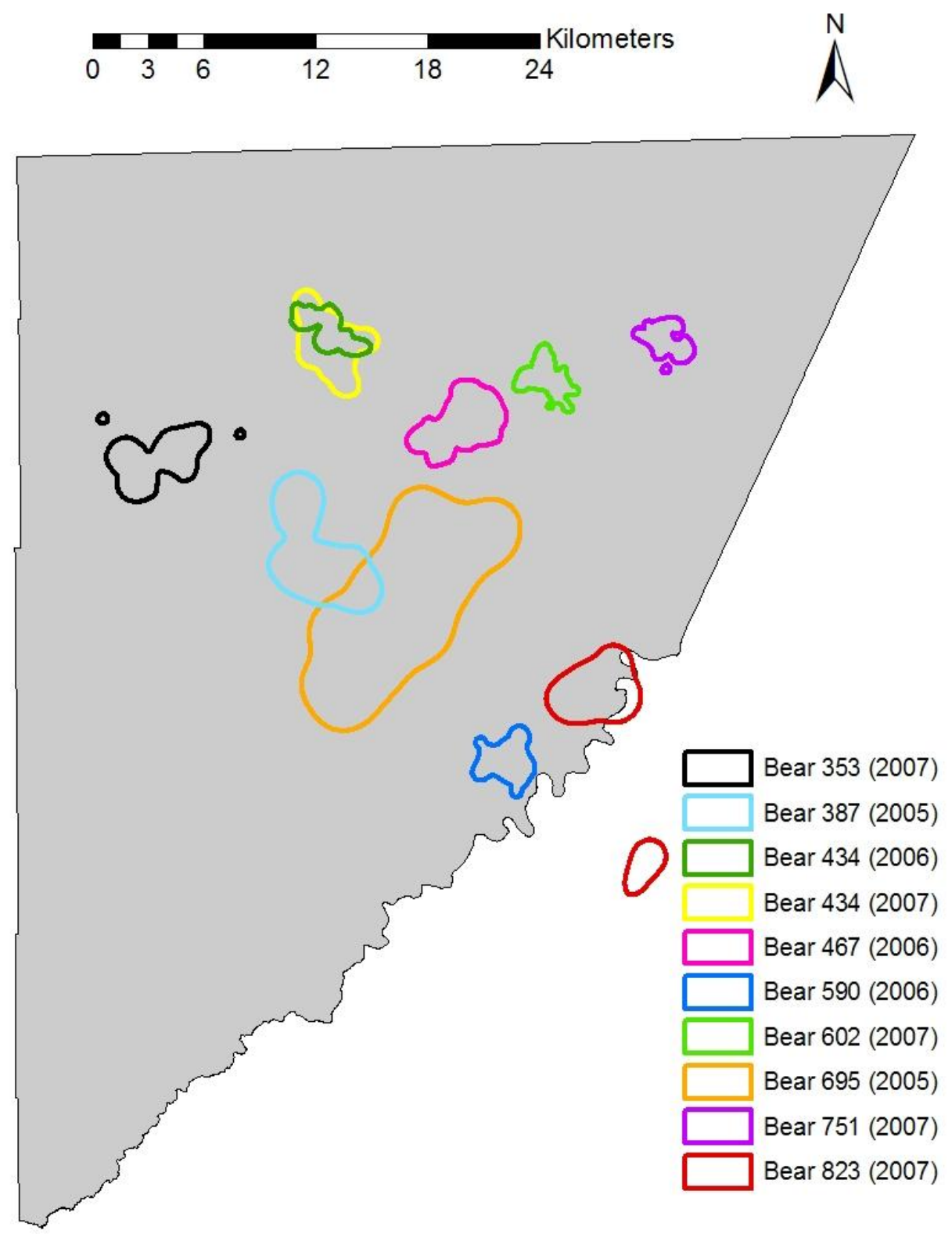

Figure 5.4. Fall 95\% fixed kernel home ranges of female Ursus americanus (Black Bear) in Garrett County, Maryland, USA from 2005-2007. Each color polygon represents an individual female Black Bear. The year the data was collected is in parentheses following the bear ID. 
APPENDICES 
Appendix A. Gender and capture results for each individual black bear indentified from hair samples collected in western Maryland during summer 2011.

\begin{tabular}{|c|c|c|c|c|c|}
\hline Bear ID & $\begin{array}{c}\text { Capture } \\
\text { county }\end{array}$ & Sex & $\begin{array}{c}\text { No. } \\
\text { samples } \\
\text { collected }\end{array}$ & Recapture & $\begin{array}{l}\text { Structure } \\
\text { group }\end{array}$ \\
\hline BRMD-001 & Garrett & $\mathrm{F}$ & 1 & No & 2 \\
\hline BRMD-002 & Garrett & $\mathrm{F}$ & 1 & No & 1 \\
\hline BRMD-003 & Garrett & $\mathrm{F}$ & 1 & No & 1 \\
\hline BRMD-004 & Garrett & $\mathrm{F}$ & 1 & No & 3 \\
\hline BRMD-005 & Allegany & $\mathrm{F}$ & 1 & No & 1 \\
\hline BRMD-006 & Garrett & $\mathrm{F}$ & 1 & No & 1 \\
\hline BRMD-007 & Garrett & $\mathrm{F}$ & 1 & No & 1 \\
\hline BRMD-008 & Garrett & $\mathrm{F}$ & 1 & No & 1 \\
\hline BRMD-009 & Garrett & $\mathrm{M}$ & 1 & No & 1 \\
\hline BRMD-010 & Garrett & $\mathrm{F}$ & 1 & No & 1 \\
\hline BRMD-011 & Garrett & M & 1 & No & 1 \\
\hline BRMD-012 & Allegany & M & 1 & No & 3 \\
\hline BRMD-013 & Allegany & M & 1 & No & 3 \\
\hline BRMD-014 & Allegany & M & 1 & No & 1 \\
\hline BRMD-015 & Allegany & M & 1 & No & 3 \\
\hline BRMD-016 & Garrett & M & 1 & No & 1 \\
\hline BRMD-017 & Garrett & M & 1 & No & 1 \\
\hline BRMD-018 & Garrett & M & 1 & No & 1 \\
\hline BRMD-019 & Garrett & $\mathrm{F}$ & 1 & No & 1 \\
\hline BRMD-020 & Garrett & $\mathrm{F}$ & 1 & No & 2 \\
\hline BRMD-021 & Garrett & M & 1 & No & 1 \\
\hline BRMD-022 & Allegany & $\mathrm{F}$ & 1 & No & 3 \\
\hline BRMD-023 & Allegany & $\mathrm{F}$ & 1 & No & 3 \\
\hline BRMD-024 & Allegany & $\mathrm{F}$ & 1 & No & 3 \\
\hline BRMD-025 & Allegany & M & 1 & No & 2 \\
\hline BRMD-026 & Garrett & M & 1 & No & 1 \\
\hline
\end{tabular}


Appendix A. Continued

\begin{tabular}{|c|c|c|c|c|c|}
\hline Bear ID & $\begin{array}{l}\text { Capture } \\
\text { county }\end{array}$ & Sex & $\begin{array}{c}\text { No. } \\
\text { samples } \\
\text { collected }\end{array}$ & Recapture & $\begin{array}{l}\text { Structure } \\
\text { group }\end{array}$ \\
\hline BRMD-028 & Garrett & $\mathrm{F}$ & 1 & No & 1 \\
\hline BRMD-029 & Garrett & $\mathrm{F}$ & 1 & No & 1 \\
\hline BRMD-030 & Garrett & M & 1 & No & 1 \\
\hline BRMD-031 & Garrett & M & 1 & No & 1 \\
\hline BRMD-032 & Garrett & $\mathrm{F}$ & 1 & No & 3 \\
\hline BRMD-033 & Frederick & M & 1 & No & 2 \\
\hline BRMD-034 & Washington & $\mathrm{F}$ & 1 & No & 3 \\
\hline BRMD-035 & Allegany & $\mathrm{F}$ & 1 & No & 1 \\
\hline BRMD-036 & Allegany & $\mathrm{F}$ & 1 & No & 1 \\
\hline BRMD-037 & Allegany & $\mathrm{F}$ & 1 & No & 1 \\
\hline BRMD-038 & Garrett & M & 1 & No & 1 \\
\hline BRMD-039 & Frederick & $\mathrm{F}$ & 1 & No & 2 \\
\hline BRMD-040 & Allegany & F & 1 & No & 2 \\
\hline BRMD-041 & Allegany & $\mathrm{F}$ & 1 & No & 1 \\
\hline BRMD-042 & Garrett & $\mathrm{F}$ & 1 & No & 1 \\
\hline BRMD-043 & Garrett & $\mathrm{F}$ & 1 & No & 2 \\
\hline BRMD-044 & Garrett & $\mathrm{F}$ & 1 & No & 1 \\
\hline BRMD-045 & Garrett & $\mathrm{F}$ & 1 & No & 1 \\
\hline BRMD-046 & Garrett & F & 1 & No & 1 \\
\hline BRMD-047 & Garrett & $\mathrm{F}$ & 1 & No & 1 \\
\hline BRMD-048 & Garrett & $\mathrm{F}$ & 1 & No & 1 \\
\hline BRMD-049 & Garrett & M & 1 & No & 1 \\
\hline BRMD-050 & Garrett & M & 1 & No & 2 \\
\hline BRMD-051 & Allegany & M & 1 & No & 1 \\
\hline BRMD-052 & Garrett & M & 1 & No & 1 \\
\hline BRMD-053 & Garrett & $\mathrm{F}$ & 1 & No & 1 \\
\hline BRMD-054 & Garrett & F & 1 & No & 1 \\
\hline BRMD-055 & Garrett & $\mathrm{F}$ & 1 & No & 1 \\
\hline
\end{tabular}


Appendix A. Continued

\begin{tabular}{|c|c|c|c|c|c|}
\hline Bear ID & $\begin{array}{l}\text { Capture } \\
\text { county }\end{array}$ & Sex & $\begin{array}{c}\text { No. } \\
\text { samples } \\
\text { collected }\end{array}$ & Recapture & $\begin{array}{l}\text { Structure } \\
\text { group }\end{array}$ \\
\hline BRMD-056 & Garrett & $F$ & 1 & No & 1 \\
\hline BRMD-057 & Allegany & M & 1 & No & 1 \\
\hline BRMD-058 & Garrett & M & 1 & No & 1 \\
\hline BRMD-059 & Garrett & $\mathrm{F}$ & 1 & No & 1 \\
\hline BRMD-060 & Garrett & $\mathrm{F}$ & 1 & No & 1 \\
\hline BRMD-061 & Allegany & $\mathrm{F}$ & 1 & No & 3 \\
\hline BRMD-062 & Allegany & $\mathrm{F}$ & 1 & No & 3 \\
\hline BRMD-063 & Washington & M & 1 & No & 2 \\
\hline BRMD-064 & Garrett & $\mathrm{M}$ & 5 & Yes & 1 \\
\hline BRMD-065 & Garrett & $\mathrm{F}$ & 4 & No & 1 \\
\hline BRMD-066 & Garrett & $\mathrm{F}$ & 3 & No & 1 \\
\hline BRMD-067 & Allegany & $\mathrm{F}$ & 3 & No & 1 \\
\hline BRMD-068 & Frederick & M & 2 & No & 2 \\
\hline BRMD-069 & Frederick & M & 2 & No & 2 \\
\hline BRMD-070 & Garrett & $\mathrm{F}$ & 3 & No & 1 \\
\hline BRMD-071 & Garrett & M & 4 & No & 1 \\
\hline BRMD-072 & Garrett & M & 7 & Yes & 1 \\
\hline BRMD-073 & Garrett & $\mathrm{F}$ & 3 & Yes & 1 \\
\hline BRMD-074 & Garrett & $\mathrm{F}$ & 2 & Yes & 1 \\
\hline BRMD-075 & Garrett & $\mathrm{F}$ & 3 & No & 1 \\
\hline BRMD-076 & Garrett & $\mathrm{F}$ & 2 & No & 1 \\
\hline BRMD-077 & Garrett & $\mathrm{F}$ & 2 & Yes & 1 \\
\hline BRMD-078 & Garrett & M & 3 & No & 1 \\
\hline BRMD-079 & Allegany & $\mathrm{F}$ & 2 & No & 1 \\
\hline BRMD-080 & Garrett & $\mathrm{M}$ & 3 & No & 1 \\
\hline BRMD-081 & Garrett & M & 5 & Yes & 1 \\
\hline BRMD-082 & Allegany & $\mathrm{F}$ & 4 & Yes & 1 \\
\hline BRMD-083 & Allegany & M & 7 & Yes & 1 \\
\hline
\end{tabular}


Appendix A. Continued

\begin{tabular}{|c|c|c|c|c|c|}
\hline Bear ID & $\begin{array}{l}\text { Capture } \\
\text { county }\end{array}$ & Sex & $\begin{array}{c}\text { No. } \\
\text { samples } \\
\text { collected }\end{array}$ & Recapture & $\begin{array}{l}\text { Structure } \\
\text { group }\end{array}$ \\
\hline BRMD-084 & Allegany & $\mathrm{F}$ & 2 & Yes & 1 \\
\hline BRMD-085 & Frederick & M & 2 & No & 1 \\
\hline BRMD-086 & Garrett & M & 2 & No & 1 \\
\hline BRMD-087 & Garrett & $\mathrm{F}$ & 2 & No & 3 \\
\hline BRMD-088 & Garrett & M & 4 & Yes & 1 \\
\hline BRMD-089 & Garrett & M & 3 & No & 1 \\
\hline BRMD-090 & Garrett & $\mathrm{F}$ & 3 & Yes & 3 \\
\hline BRMD-091 & Garrett & $\mathrm{F}$ & 4 & No & 3 \\
\hline BRMD-092 & Garrett & $\mathrm{F}$ & 5 & No & 3 \\
\hline BRMD-093 & Garrett & M & 3 & Yes & 1 \\
\hline BRMD-094 & Allegany & $\mathrm{F}$ & 6 & Yes & 1 \\
\hline BRMD-095 & Allegany & M & 2 & No & 1 \\
\hline BRMD-096 & Garrett & M & 2 & No & 1 \\
\hline BRMD-097 & Garrett & $\mathrm{F}$ & 2 & No & 2 \\
\hline BRMD-098 & Garrett & $\mathrm{F}$ & 2 & No & 1 \\
\hline BRMD-099 & Garrett & M & 4 & Yes & 2 \\
\hline BRMD-100 & Garrett & M & 3 & No & 2 \\
\hline BRMD-101 & Garrett & $\mathrm{F}$ & 4 & No & 1 \\
\hline BRMD-102 & Garrett & $\mathrm{F}$ & 3 & No & 2 \\
\hline BRMD-103 & Allegany & $\mathrm{F}$ & 6 & Yes & 2 \\
\hline BRMD-104 & Washington & M & 4 & No & 2 \\
\hline BRMD-105 & Allegany & M & 2 & No & 1 \\
\hline BRMD-106 & Allegany & $\mathrm{F}$ & 2 & No & 3 \\
\hline BRMD-107 & Allegany & $\mathrm{F}$ & 2 & No & 1 \\
\hline BRMD-108 & Garrett & $\mathrm{F}$ & 2 & No & 3 \\
\hline
\end{tabular}


Appendix B. Alleles and allele frequencies at 8 loci used to idensitfy black bear hair samples collected in western Maryland during summer 2011.

\begin{tabular}{|c|c|c|c|}
\hline Locus & $N$ & Allele & Frequency \\
\hline \multirow[t]{5}{*}{ G1A } & 106 & 185 & 0.085 \\
\hline & & 187 & 0.406 \\
\hline & & 189 & 0.212 \\
\hline & & 191 & 0.203 \\
\hline & & 193 & 0.094 \\
\hline \multirow[t]{6}{*}{ G10B } & 105 & 155 & 0.019 \\
\hline & & 157 & 0.357 \\
\hline & & 159 & 0.052 \\
\hline & & 161 & 0.314 \\
\hline & & 163 & 0.038 \\
\hline & & 165 & 0.219 \\
\hline \multirow[t]{8}{*}{ G10C } & 107 & 104 & 0.065 \\
\hline & & 106 & 0.005 \\
\hline & & 108 & 0.019 \\
\hline & & 110 & 0.458 \\
\hline & & 112 & 0.103 \\
\hline & & 114 & 0.271 \\
\hline & & 116 & 0.075 \\
\hline & & 118 & 0.005 \\
\hline
\end{tabular}


Appendix B. Continued

\begin{tabular}{|c|c|c|c|}
\hline Locus & $N$ & Allele & Frequency \\
\hline \multirow[t]{7}{*}{ G1D } & 106 & 172 & 0.019 \\
\hline & & 176 & 0.481 \\
\hline & & 178 & 0.08 \\
\hline & & 180 & 0.057 \\
\hline & & 182 & 0.038 \\
\hline & & 184 & 0.193 \\
\hline & & 186 & 0.132 \\
\hline \multirow[t]{12}{*}{ G10L } & 107 & 135 & 0.145 \\
\hline & & 137 & 0.168 \\
\hline & & 139 & 0.056 \\
\hline & & 143 & 0.047 \\
\hline & & 145 & 0.028 \\
\hline & & 147 & 0.093 \\
\hline & & 149 & 0.084 \\
\hline & & 151 & 0.023 \\
\hline & & 153 & 0.182 \\
\hline & & 155 & 0.047 \\
\hline & & 157 & 0.122 \\
\hline & & 159 & 0.005 \\
\hline \multirow[t]{8}{*}{ G10M } & 97 & 209 & 0.082 \\
\hline & & 211 & 0.077 \\
\hline & & 213 & 0.062 \\
\hline & & 215 & 0.479 \\
\hline & & 217 & 0.139 \\
\hline & & 219 & 0.129 \\
\hline & & 221 & 0.026 \\
\hline & & 223 & 0.005 \\
\hline
\end{tabular}


Appendix B. Continued

\begin{tabular}{|c|c|c|c|}
\hline Locus & $N$ & Allele & Frequency \\
\hline \multirow[t]{9}{*}{ G10P } & 96 & 150 & 0.078 \\
\hline & & 154 & 0.047 \\
\hline & & 156 & 0.005 \\
\hline & & 158 & 0.208 \\
\hline & & 160 & 0.042 \\
\hline & & 162 & 0.328 \\
\hline & & 164 & 0.146 \\
\hline & & 166 & 0.141 \\
\hline & & 170 & 0.005 \\
\hline \multirow[t]{11}{*}{ G10X } & 98 & 140 & 0.031 \\
\hline & & 142 & 0.077 \\
\hline & & 144 & 0.332 \\
\hline & & 146 & 0.102 \\
\hline & & 148 & 0.102 \\
\hline & & 150 & 0.168 \\
\hline & & 152 & 0.015 \\
\hline & & 154 & 0.071 \\
\hline & & 156 & 0.005 \\
\hline & & 158 & 0.061 \\
\hline & & 160 & 0.036 \\
\hline
\end{tabular}


Appendix C. Maxent output of response curves for models of black bear and bear hunter occurrence in western Maryland. Red lines/bars represent means over 50 replications. Blue lines/bars represent range of values. Turquoise bars represent expected values for a random model.
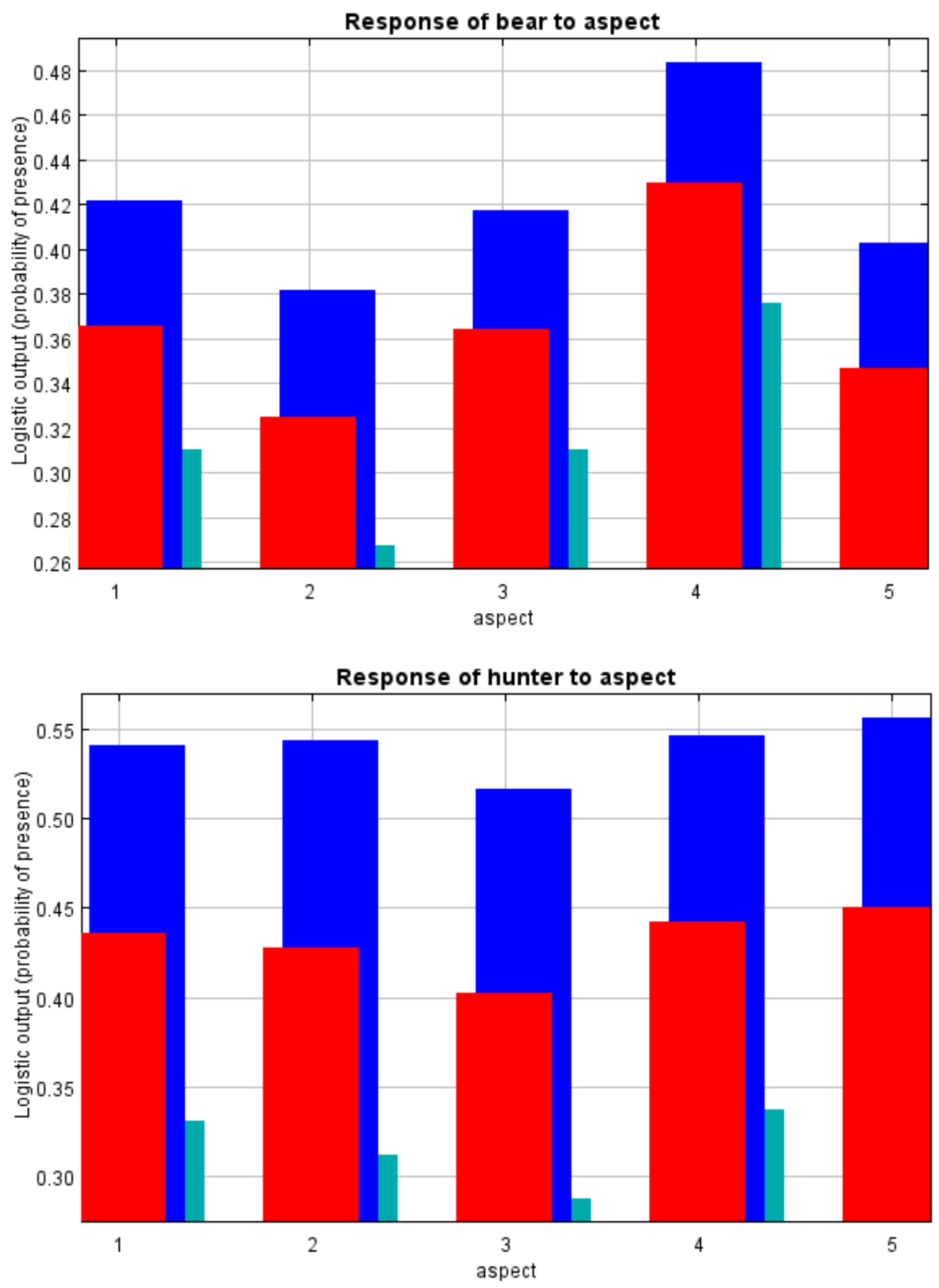
Appendix C. Continued
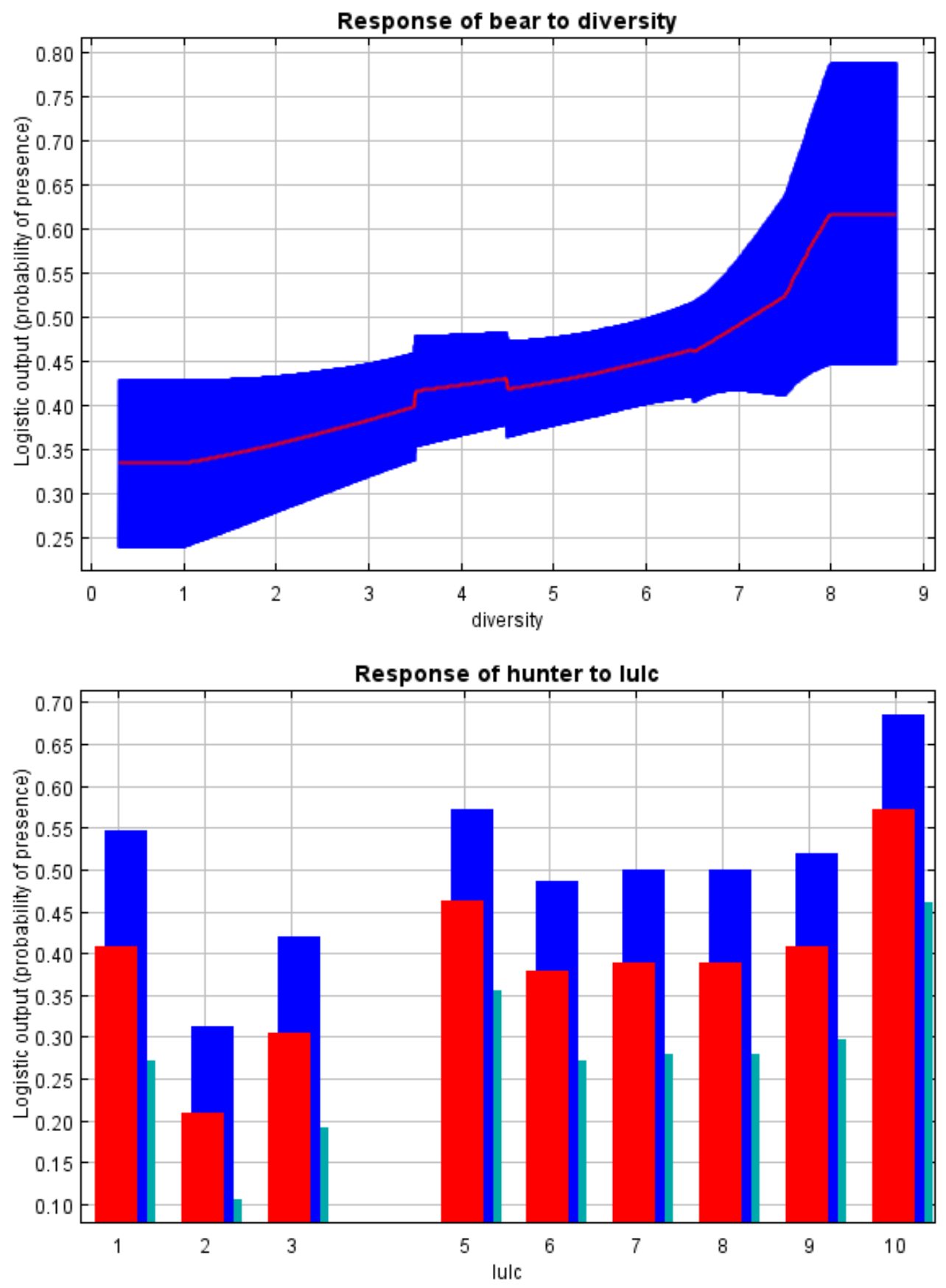
Appendix C. Continued
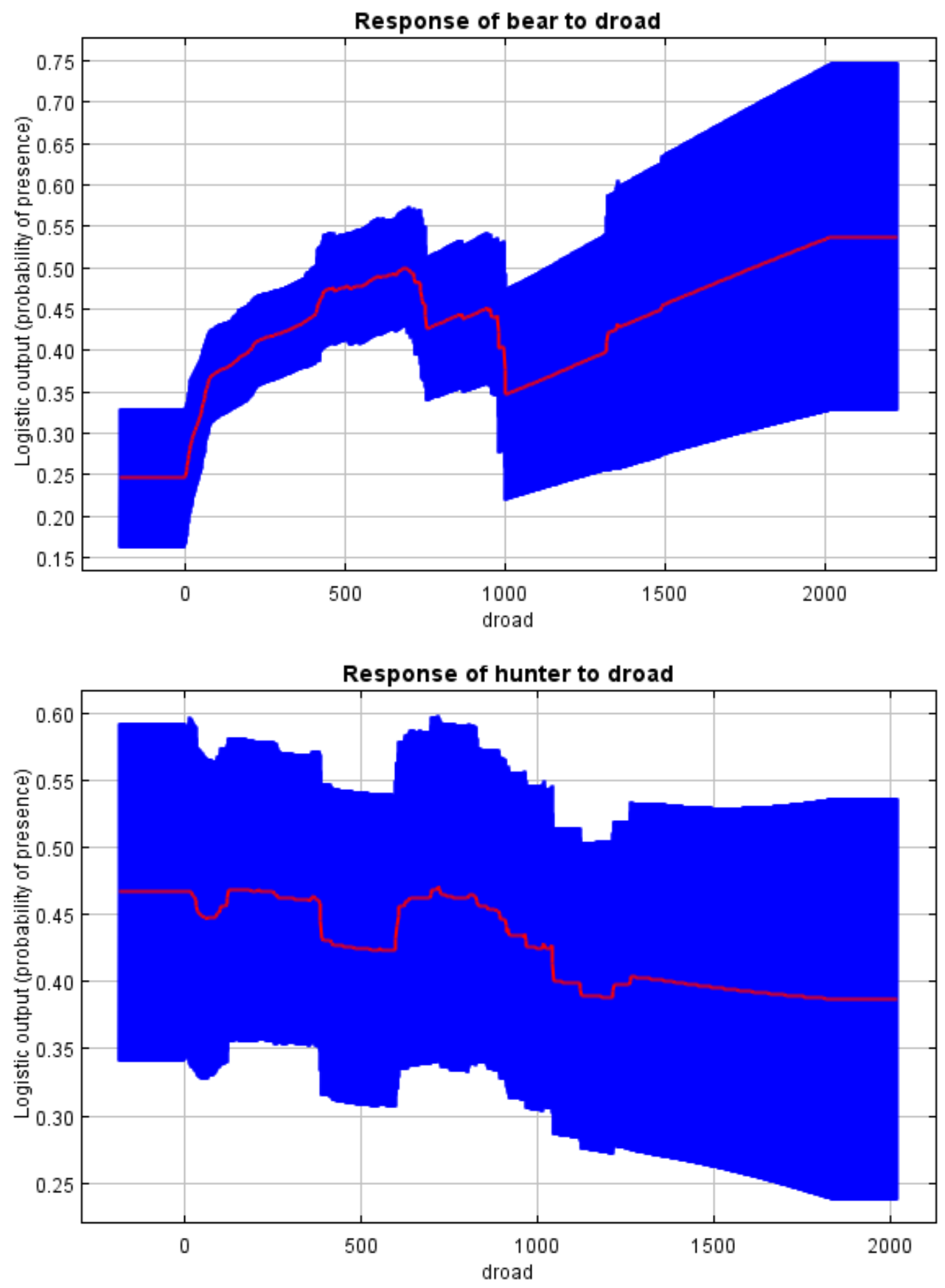
Appendix C. Continued
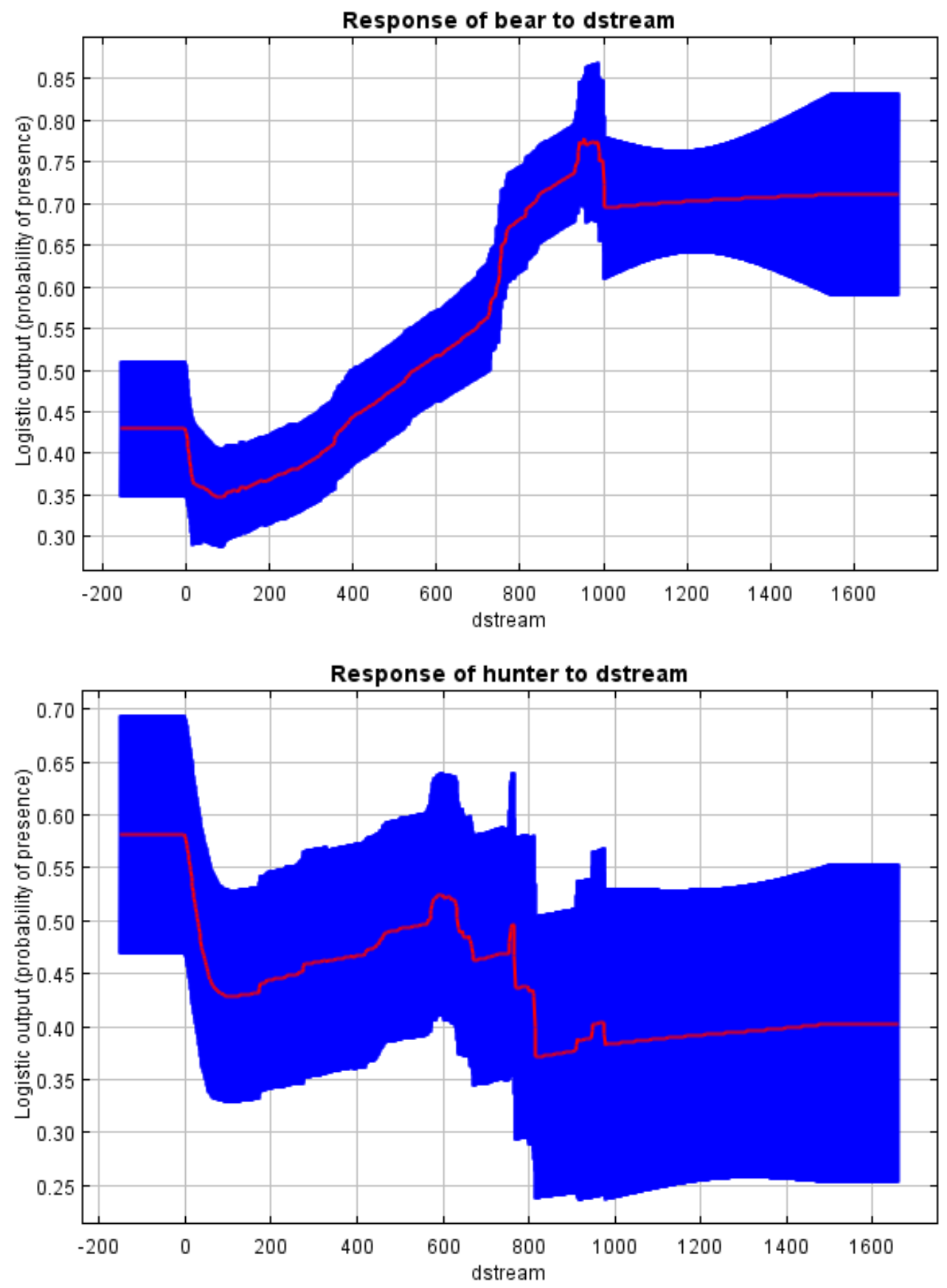
Appendix C. Continued
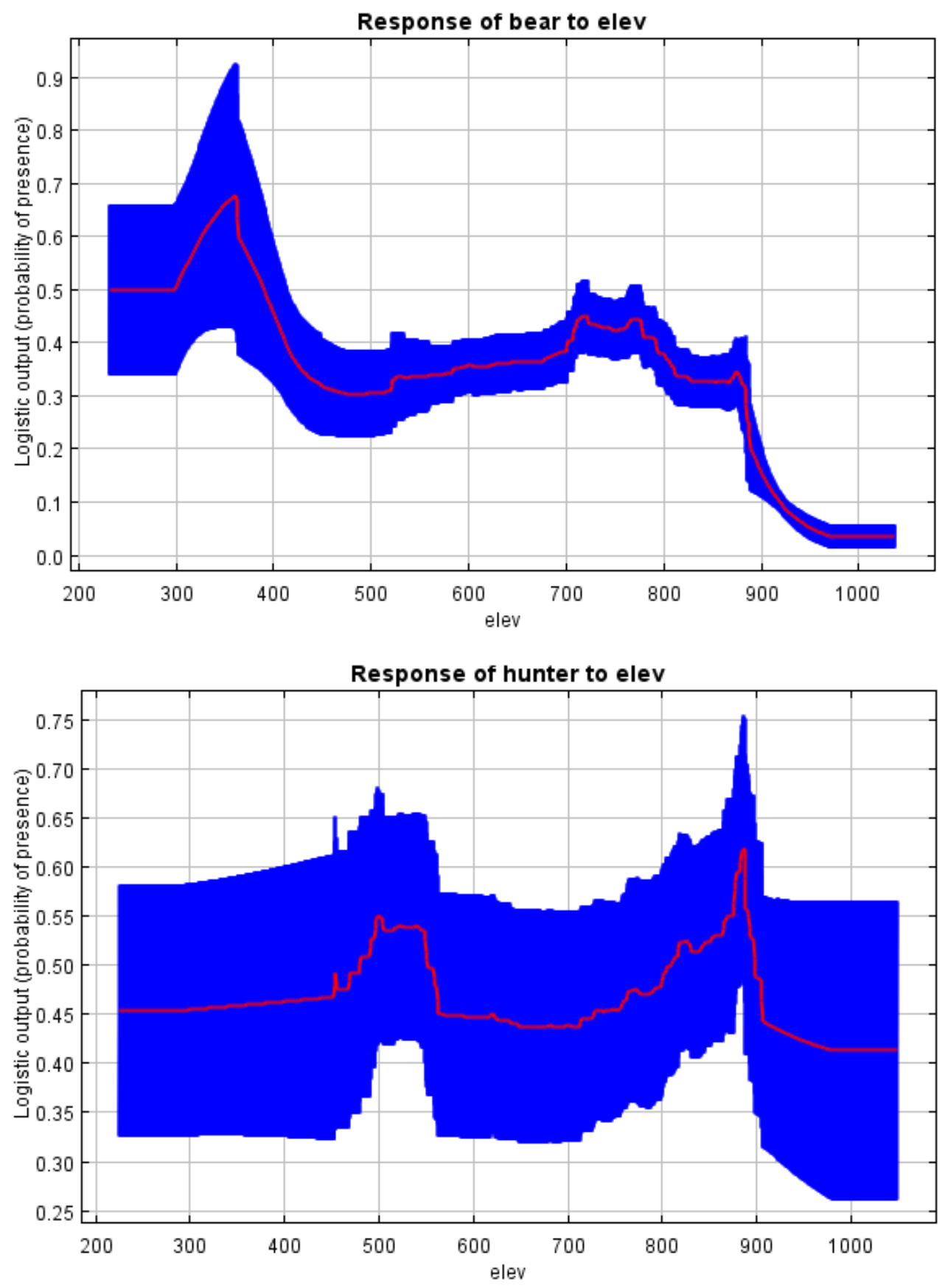
Appendix C. Continued
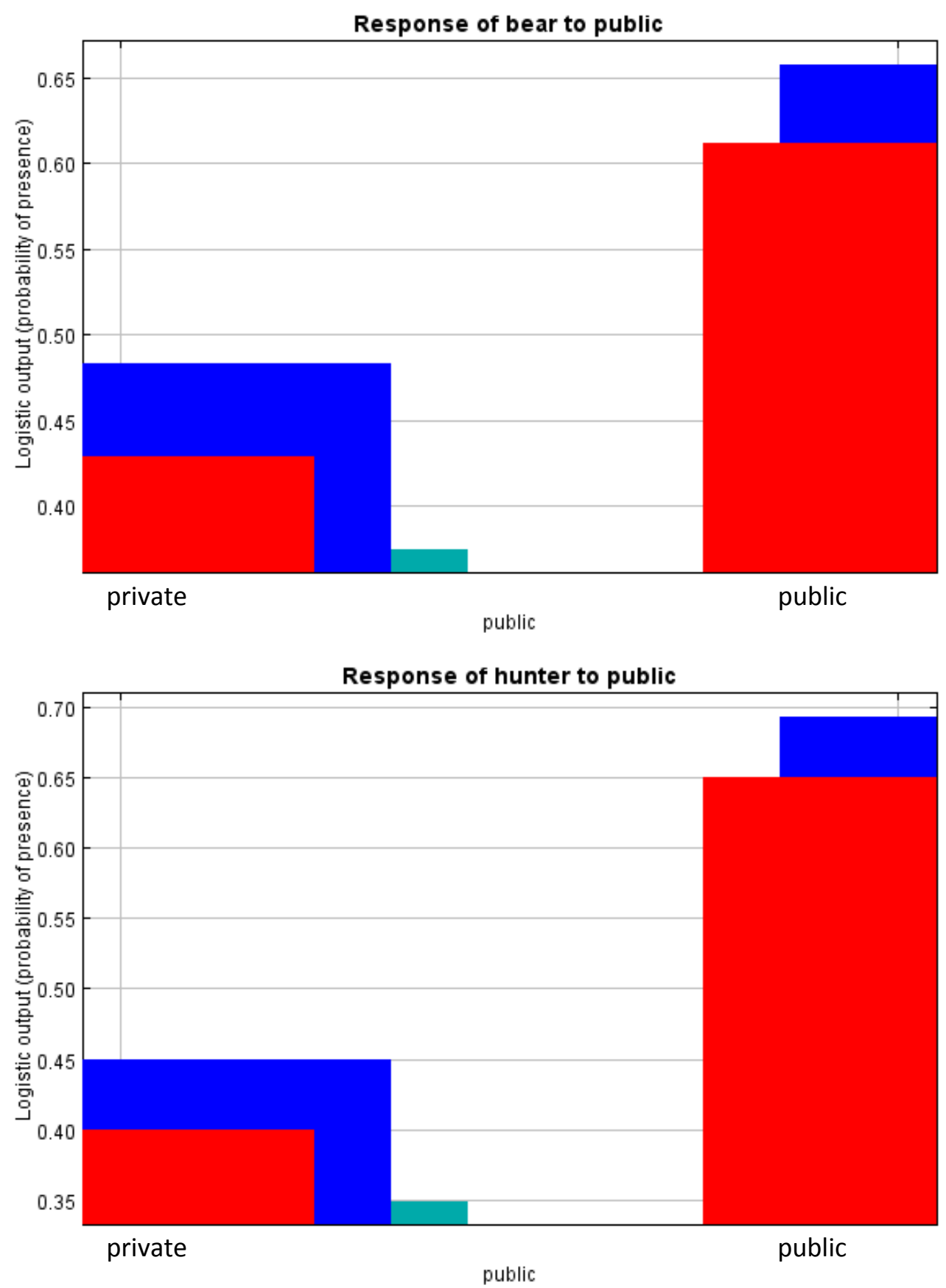
Appendix C. Continued
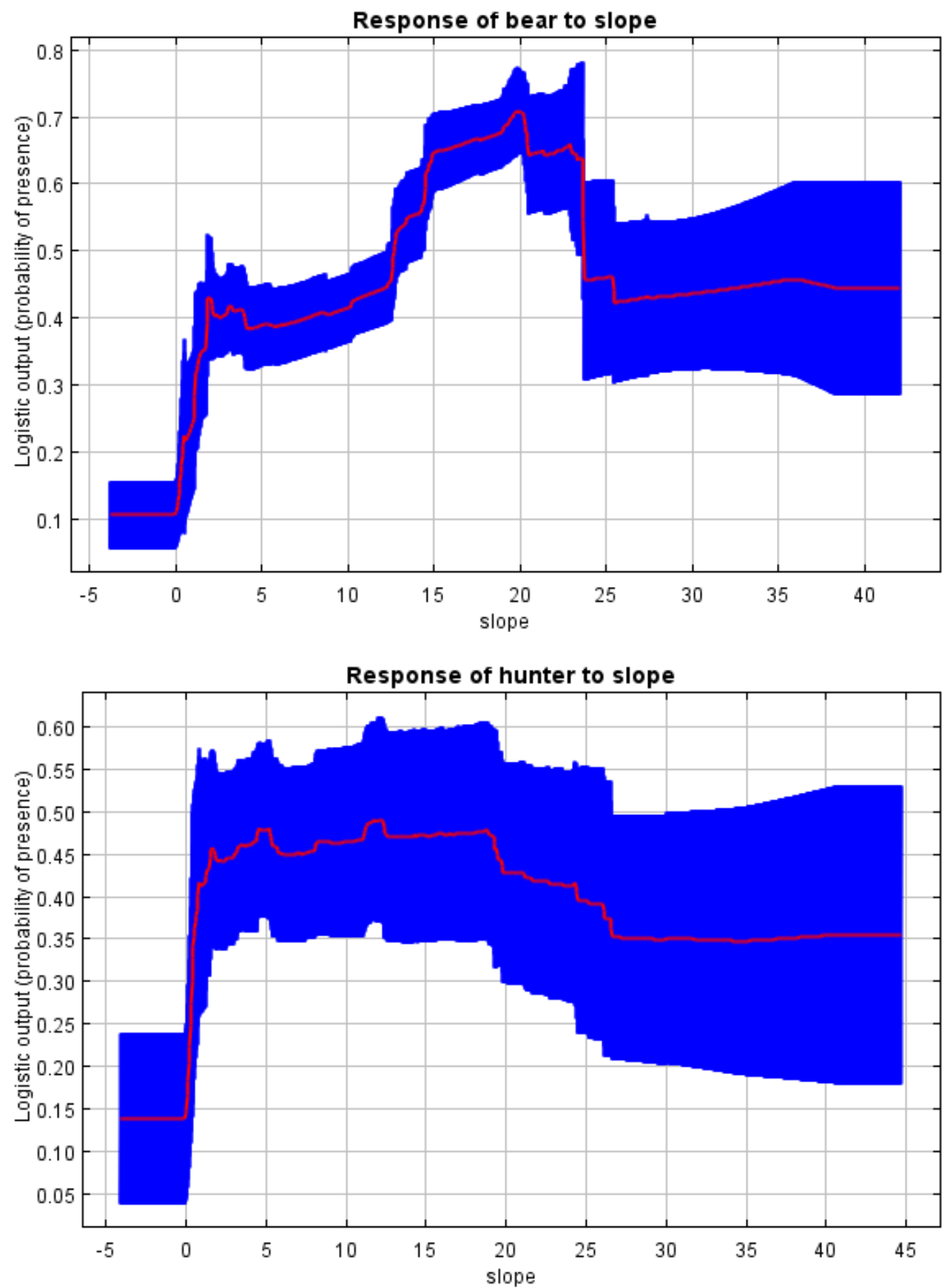
Appendix D. Annual and seasonal 95\% fixed kernel and 95\% minimum convex polygon (MCP) home range estimates and reproductive statuses of adult female Black Bears monitored in Garrett County, Maryland, USA from 2005-2007. COY = females with cubs-of-the-year.

Solitary $=$ females without cubs-of-the-year. $N=$ number of GPS locations used to estimate home range size.

\begin{tabular}{|c|c|c|c|c|c|c|}
\hline \multirow[b]{2}{*}{ Bear ID } & \multirow[b]{2}{*}{ Season } & \multirow[b]{2}{*}{ Year } & \multirow[b]{2}{*}{$\begin{array}{c}\text { Reproductive } \\
\text { status }\end{array}$} & \multirow[b]{2}{*}{$N$} & \multicolumn{2}{|c|}{ Home range estimator } \\
\hline & & & & & $\begin{array}{c}\text { 95\% Fixed } \\
\text { kernel }\left(\mathrm{km}^{2}\right)\end{array}$ & $\begin{array}{c}95 \% \mathrm{MCP} \\
\left(\mathrm{km}^{2}\right)\end{array}$ \\
\hline 353 & Summer & 2007 & Solitary & 141 & 28.06 & 17.65 \\
\hline 353 & Fall & 2007 & Solitary & 188 & 13.99 & 8.66 \\
\hline 387 & Spring & 2006 & $\mathrm{COY}$ & 78 & 2.52 & 1.64 \\
\hline 387 & Summer & 2005 & Solitary & 108 & 26.25 & 17.63 \\
\hline 387 & Summer & 2006 & $\mathrm{COY}$ & 120 & 6.69 & 4.14 \\
\hline 387 & Fall & 2005 & Solitary & 172 & 25.75 & 16.11 \\
\hline 391 & Spring & 2006 & Solitary & 124 & 7.60 & 4.46 \\
\hline 391 & Spring & 2007 & $\mathrm{COY}$ & 194 & 5.17 & 3.77 \\
\hline 391 & Summer & 2005 & COY & 31 & 22.98 & 7.54 \\
\hline 391 & Summer & 2007 & COY & 139 & 17.32 & 10.84 \\
\hline 434 & Summer & 2007 & Solitary & 231 & 13.98 & 10.97 \\
\hline 434 & Fall & 2006 & $\mathrm{COY}$ & 62 & 6.23 & 3.03 \\
\hline 434 & Fall & 2007 & Solitary & 250 & 13.74 & 11.40 \\
\hline 467 & Annual & 2006 & $\mathrm{COY}$ & 1137 & 12.42 & 14.37 \\
\hline 467 & Spring & 2006 & $\mathrm{COY}$ & 330 & 2.15 & 2.18 \\
\hline 467 & Spring & 2007 & Solitary & 193 & 23.46 & 9.79 \\
\hline 467 & Summer & 2006 & $\mathrm{COY}$ & 309 & 6.30 & 7.79 \\
\hline 467 & Fall & 2006 & COY & 498 & 14.46 & 11.78 \\
\hline 537 & Spring & 2006 & $\mathrm{COY}$ & 210 & .07 & .05 \\
\hline 537 & Summer & 2006 & $\mathrm{COY}$ & 139 & 3.72 & 4.69 \\
\hline 537 & Summer & 2007 & Solitary & 307 & 8.57 & 6.58 \\
\hline 580 & Spring & 2006 & Solitary & 259 & 35.54 & 34.79 \\
\hline
\end{tabular}


Appendix D. Continued

\begin{tabular}{|c|c|c|c|c|c|c|}
\hline \multirow[b]{2}{*}{ Bear ID } & \multirow[b]{2}{*}{ Season } & \multirow[b]{2}{*}{ Year } & \multirow[b]{2}{*}{$\begin{array}{c}\text { Reproductive } \\
\text { status }\end{array}$} & \multirow[b]{2}{*}{$N$} & \multicolumn{2}{|c|}{ Home range estimator } \\
\hline & & & & & $\begin{array}{c}95 \% \text { Fixed } \\
\text { kernel }\left(\mathrm{km}^{2}\right)\end{array}$ & $\begin{array}{c}95 \% \mathrm{MCP} \\
\left(\mathrm{km}^{2}\right)\end{array}$ \\
\hline 580 & Summer & 2006 & Solitary & 335 & 20.72 & 19.03 \\
\hline 590 & Annual & 2006 & $\mathrm{COY}$ & 758 & 7.65 & 7.20 \\
\hline 590 & Spring & 2006 & $\mathrm{COY}$ & 333 & 7.45 & 5.30 \\
\hline 590 & Summer & 2006 & $\mathrm{COY}$ & 369 & 5.63 & 4.42 \\
\hline 590 & Fall & 2006 & $\mathrm{COY}$ & 56 & 7.51 & 4.18 \\
\hline 602 & Summer & 2007 & Solitary & 168 & 18.79 & 12.17 \\
\hline 602 & Fall & 2007 & Solitary & 450 & 5.87 & 5.58 \\
\hline 658 & Spring & 2007 & $\mathrm{COY}$ & 275 & 1.59 & 1.32 \\
\hline 658 & Summer & 2007 & $\mathrm{COY}$ & 227 & 16.18 & 9.32 \\
\hline 681 & Summer & 2006 & COY & 104 & 12.98 & 6.37 \\
\hline 686 & Summer & 2006 & COY & 81 & 8.93 & 5.93 \\
\hline 695 & Summer & 2005 & $\mathrm{COY}$ & 55 & 48.01 & 27.75 \\
\hline 695 & Fall & 2005 & $\mathrm{COY}$ & 68 & 80.95 & 39.35 \\
\hline 751 & Fall & 2007 & Solitary & 321 & 5.18 & 3.51 \\
\hline 823 & Annual & 2007 & COY & 1325 & 11.12 & 7.92 \\
\hline 823 & Spring & 2007 & COY & 375 & 3.73 & 3.97 \\
\hline 823 & Summer & 2007 & $\mathrm{COY}$ & 433 & 8.32 & 6.90 \\
\hline 823 & Fall & 2007 & $\mathrm{COY}$ & 517 & 19.79 & 28.18 \\
\hline
\end{tabular}

